\title{
O Uso da Modelagem Matemática no Ensino de Funções: Uma Abordagem Dinâmica e Variacional
}

\author{
Ronaldo Ramunno
}

Dissertação apresentada ao Instituto de Matemática e Estatística da Universidade de São Paulo como requisito parcial para a obtenção do título de mestre em Ciências no Programa de Mestrado Profissional em Ensino de Matemática

Orientador: Prof. Dr. Ricardo Bianconi 



\title{
O Uso da Modelagem Matemática no Ensino de Funções: Uma Abordagem Dinâmica e Variacional
}

\author{
Ronaldo Ramunno
}

Comissão Julgadora:

- Prof. ํㅡㅁ. Ricardo Bianconi (orientador) - IME-USP

- Prof. ${ }^{\text {a }}$ Dra . Vanessa Aparecida Trevizan de Lima - IFSP

- Prof. ${ }^{a}$ Dra ${ }^{\text {a }}$. Raquel Milani - FE-USP 

À minha querida esposa Carmem Paiva Ramunno, que sem seu apoio, incentivo e paciêncía, eu não tería conseguido realizar esse trabalho. 



\section{AGRADECIMENTOS}

Ao meu orientador prof. Dro Ricardo Bianconi, pela colaboração e orientação no desenvolvimento de nossa proposta.

À Universidade de São Paulo, especificamente ao IME pela oportunidade de Mestrado oferecida.

Ronaldo 



\section{RESUMO}

RAMUNNO, R. O Uso da Modelagem Matemática no Ensino de Funções: Uma Abordagem Dinâmica e Variacional. 2019. 212 f. Dissertação (Mestrado Profissional no Ensino de Matemática) - Instituto de Matemática e Estatística, Universidade de São Paulo, São Paulo, 2019.

Este trabalho teve como tema de estudo o uso da Modelagem Matemática para o ensino e aprendizagem de funções na Educação Básica. O objetivo foi realizar uma alternativa pedagógica de ensino usando a Modelagem Matemática para abordar o conceito de função em uma perspectiva dinâmica e variacional e desenvolver nos alunos a capacidade de matematização de uma situação-problema usando funções. A proposta foi desenvolver, planejar, realizar e analisar uma alternativa pedagógica de ensino com alunos da $3^{a}$ série do Ensino Médio de uma escola pública da cidade de São Paulo/SP.

Nesse estudo pretendemos em um primeiro momento, investigar o papel da Modelagem Matemática na resolução de problemas que envolvam funções elementares. Em nossa investigação, enfatizamos a relação dinâmica entre as variáveis. Foi posteriormente desenvolvido o conceito de taxa de variação instantânea.

A estratégia metodológica usada foi um estudo experimental que se deu por meio de uma alternativa pedagógica de ensino elaborada de modo que a aprendizagem ocorresse em estágios gradativos de abstração e complexidade.

A análise de dados coletados foi de natureza qualitativa baseadas nas pesquisas na área de Modelagem Matemática, Aprendizagem Significativa de Ausubel e Registros de Representação Semiótica de Raymond Duval.

Palavras-chave: Ensino Médio, Modelagem Matemática, Educação Matemática, Ensino de Funções. 



\begin{abstract}
RAMUNNO, R. The Use of Mathematical Modeling in Teaching Functions: A Dynamic and Variational Approach. 2019. 212 f. Dissertation (Professional Master in Teaching Mathematics) - Institute of Mathematics and Statistics, University of São Paulo, São Paulo, 2019.
\end{abstract}

This study had as its theme the use of Mathematical Modeling for teaching and learning functions in Basic Education. The objective was to carry out a pedagogical alternative of teaching using Mathematical Modeling to approach the concept of function in a dynamic and variational perspective and to develop in students the ability to mathematize a problem situation using functions.

The proposal was to develop, plan, carry out and analyse a pedagogical alternative of teaching with the students of third year secondary school in the city of São Paulo / SP. In this study, we intended to investigate the role of Mathematical Modeling in solving problems involving elementary functions. In our investigation, we emphasize the dynamic relationship between variables. The concept of instantaneous rate of change was later developed.

The methodological strategy used was an experimental study that was carried out through a pedagogical alternative of elaborated teaching so that the learning took place in gradual stages of abstraction and complexity.

The data analysis was qualitative based on the researches in Mathematical Modeling, Significant Learning of Ausubel and Semiotic Representation Registers of Raymond Duval.

Key words: Secondary School, Mathematical Modeling, Mathematics Education, Functions Teaching. 



\section{SUMÁRIO}

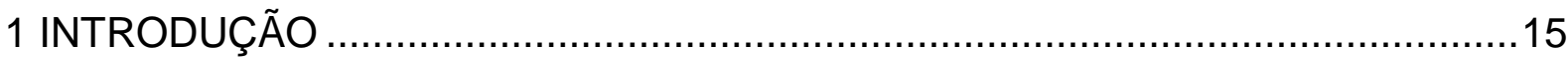

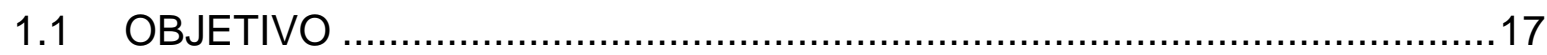

2 REFERENCIAL TEÓRICO E METODOLÓGICO ….............................................19

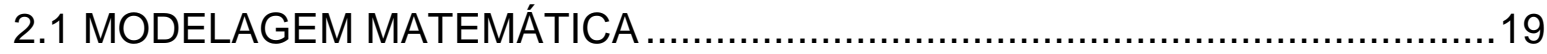

2.2 MODELAGEM MATEMÁTICA NA EDUCAÇÃO MATEMÁTICA .....................21

2.3 A OCORRÊNCIA DE APRENDIZAGEM SIGNIFICATIVA............................22

2.4 O USO DE DIFERENTES REGISTROS DE REPRESENTAÇÃO...................23

3 ESTRATÉGIAS DE INVESTIGAÇÃO E DESENVOLVIMENTO ….......................25

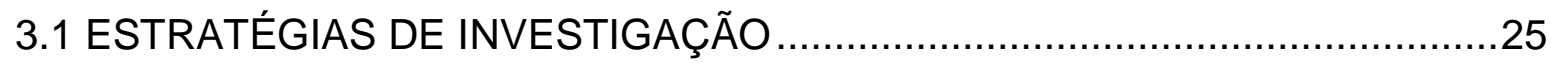

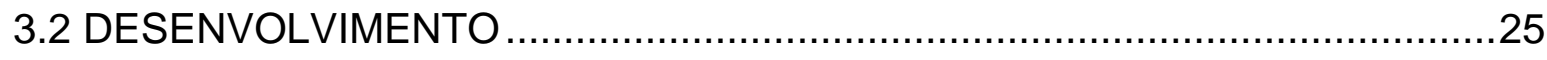

4 FUNDAMENTAÇÃO TEÓRICA ENVOLVIDA NO PROCESSO DE ENSINO-

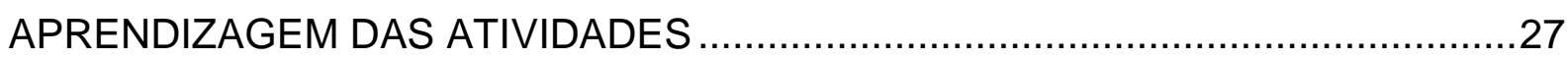

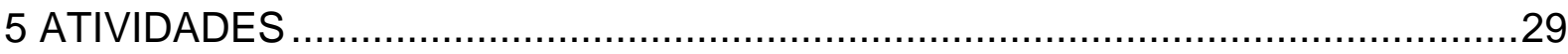

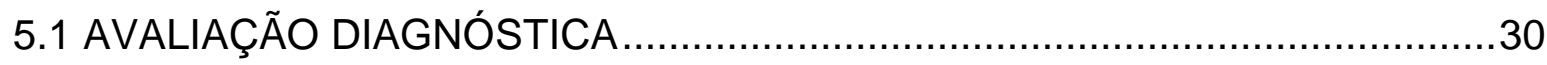

5.1.1 Análise a priori das respostas da avaliação diagnóstica ............................31

5.1.2 Análise a posteriori das respostas da avaliação diagnóstica .....................38

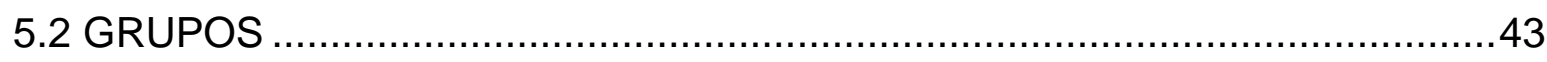

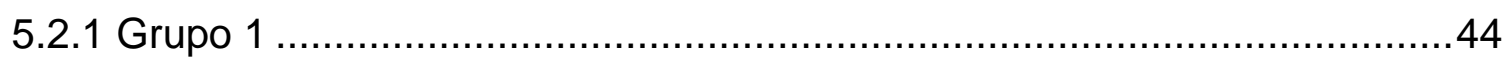

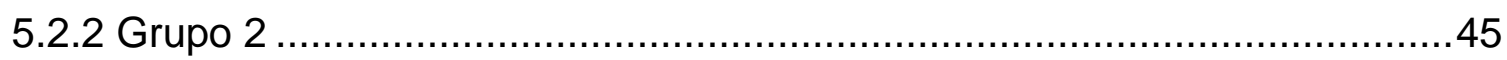

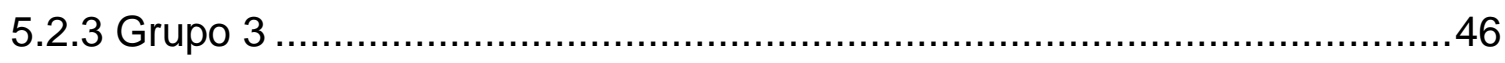

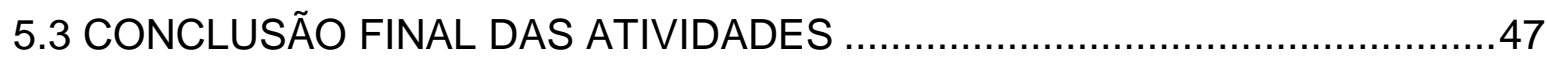

5.3.1 Dificuldades no processo de Modelagem Matemática ..............................50

5.3.2 Efeito sinérgico das atividades de Modelagem Matemática......................51

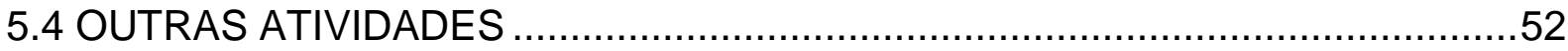

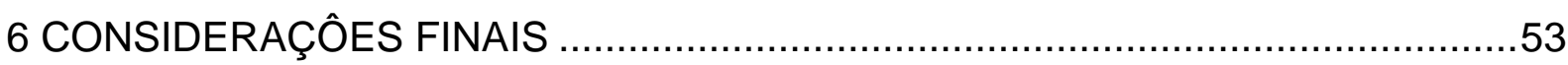

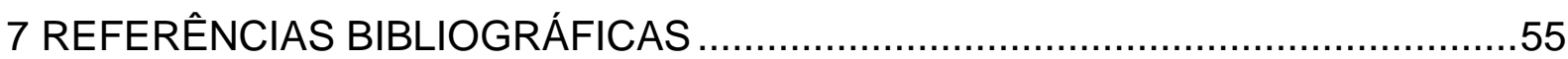


Apêndice A - Fundamentação teórica envolvida no processo de ensino-

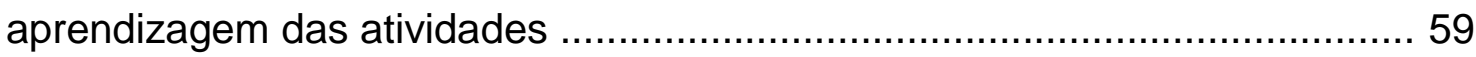

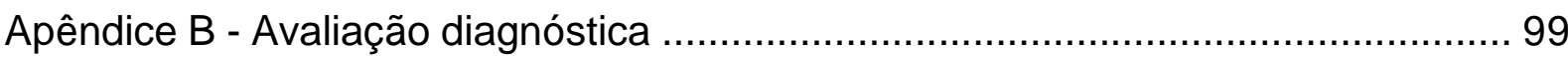

Apêndice C - Análise a posteriori do conhecimento sobre funções elementares .... 109

Apêndice D - Grupo 1: Material desenvolvido para a Modelagem ........................... 115

Apêndice E - Grupo 2: Material desenvolvido para a Modelagem ......................... 141

Apêndice F - Grupo 3: Material desenvolvido para a Modelagem ......................... 169

Apêndice G - Sugestão de atividade de Modelagem Matemática para professores ............................................................... 189

Apêndice H - Outras Atividades ..................................................................... 195 


\title{
1 INTRODUÇÃO
}

Uma problemática que pretendemos estudar se refere à ausência da abordagem dinâmica/variacional no ensino de função, em que a abordagem algébrica/estática é mais enfatizada no currículo do Ensino Básico em detrimento da abordagem dinâmica/variacional.

Por meio do viés algébrico, o conceito de função é estabelecido em termos de uma correspondência estática entre os valores das variáveis $\mathrm{x}$ e $\mathrm{y}$, onde o gráfico da função é, em geral, plotado por meio de uma tabela em que os valores mais "fáceis" são escolhidos. A curvatura das curvas que compõem o gráfico da função é, em geral, induzida pelo acréscimo de mais pontos.

Estuda-se injetividade, sobrejetividade da função, discutem-se (caso existam) os zeros da função, mas não se fala nos pontos críticos que são os elementos de articulação do esboço do gráfico de uma função real de uma variável real. A função (expressão analítica) é construída por meio de um procedimento estático e induzido por propriedades algébricas da função.

Segundo a pesquisadora Zuffi (2002), o conceito de função, ensinado no currículo das escolas do Ensino Médio, teve um longo e delicado processo de desenvolvimento histórico que culminou com as definições de Dirichlet (1837) e Bourbaki (1939), as quais possibilitaram um alto nível de abstração desse conceito.

Segundo Zuffi,

\begin{abstract}
a linguagem formal do professor tenta aproximar o conceito de função das suas definições mais atuais, como as de Bourbaki e Dirichlet. Entretanto, em seu uso prático, este tema fica restrito a concepções mais clássicas, como a de Euler. Em ambos os casos, parece haver uma dicotomia entre a linguagem matemática utilizada para lidar com o teórico e aquela para expressar as questões práticas. (Zuffi, p. 307, 2000)
\end{abstract}

Vasco (2003) acentua o fato de que as definições usuais de função restringem o aspecto variacional da noção de função ligada aos contextos em que são utilizadas. Além do conceito de função, segundo Cabral (1998) e Sierpinska (1992), o viés algébrico funciona como obstáculo de aprendizagem quando os alunos se defrontarem no Ensino Superior com problemas de taxas relacionadas e otimização no Cálculo Diferencial e Integral.

Diversos pesquisadores têm usado a Modelagem Matemática para o ensino de funções. Brito (2004) e outros autores, usaram a Modelagem Matemática para ensinar 
funções elementares (linear, quadrática, exponencial, logarítmica), mas a ênfase desses pesquisadores foi investigar como as situações de Modelagem Matemática em sala de aula podem favorecer a atribuição de sentido e construção de significado Matemático na escola.

O presente trabalho pretendeu alcançar objetivo semelhante ao ampliar o estudo para abordar o conceito de função em uma perspectiva variacional. Tivemos o intuito de atingir o conteúdo de taxas relacionadas e otimização, fazendo uma "ponte" conceitual no ensino de função entre o Ensino Médio e o Ensino Superior no sentido de minimizar futuros obstáculos epistemológicos no Cálculo Integral e Diferencial. Acreditamos que mesmo para os alunos que não optem pela área de exatas, o conceito de derivada é importante para o desenvolvimento do raciocínio.

Uma hipótese subjacente à proposta do uso da Modelagem Matemática no Ensino Médio é que a abordagem permite que questões advindas do âmbito de interesse dos alunos podem motivar e apoiar a compreensão de conteúdos e conceitos da matemática escolar. Para Lachini (2001), a maneira mais eficaz de lidar com tradições arraigadas, como é, por exemplo, o insucesso de muitos alunos em matemática, é levar em consideração as relações cotidianas e contextualizadas com a vida dos alunos.

Segundo Charlot (2000), uma motivação, agente externo, pode causar uma mobilização interna e essa desencadear o desejo de aprender. A motivação é uma condição necessária para mobilizar a aprendizagem.

A Modelagem Matemática favorece a realização de trabalhos em grupos e a cooperação em sala de aula que contribui para se atingir a zona de desenvolvimento proximal (Vygotsky). Aprender um conceito é atribuir-lhe sentido e construir o seu significado.

A Modelagem Matemática permite o uso de diferentes registros de representação dos objetos matemáticos. A teoria das Representações Semióticas de Raymond Duval usa a pluralidade de representações em matemática para expressar um objeto matemático e segundo essa teoria quanto maior a coordenação entre diferentes registros de representação maior será a capacidade do aluno em compreender o objeto matemático.

No âmbito da Educação Matemática, a teoria de David Ausubel tem como uma de suas principais argumentações que para ocorrer à aprendizagem é necessário partir daquilo que o aluno já sabe. Aquilo que o aluno já sabe ou deveria saber em 
cada nova situação de aprendizagem é caracterizado pelo autor como "subsunçores" e a literatura, em geral, refere-se a eles como conhecimentos prévios.

Diversos estudos e trabalhos de pesquisa na área da Educação Matemática sinalizam que características de atividades de Modelagem Matemática podem contribuir para que ocorra a aprendizagem significativa (Barbosa J. C, 2001).

Sendo assim, acreditamos que o presente trabalho pode colaborar efetivamente para a aprendizagem de Matemática e mais precisamente de Modelagem Matemática com ênfase no conceito de função.

O propósito desse estudo teve como foco uma alternativa pedagógica de ensino baseado na metodologia da Modelagem Matemática. Assim, desenvolvemos, planejamos e realizamos uma alternativa pedagógica de ensino com alunos da $3^{a}$ série do Ensino Médio de uma escola pública da cidade de São Paulo/SP.

A intenção foi levar essa metodologia de ensino para o ambiente escolar, seja em aulas regulares ou em aulas extraclasse, como apresentado nesse trabalho. Sugerimos que para inserir a modelagem matemática nas aulas regulares, o tempo para a atividade apresentada seja reduzido e integrado no conteúdo a ser ensinado.

No caso, as atividades foram realizadas com um número pequeno de alunos que se interessaram na proposta e que queriam expandir suas habilidades na Matemática. Nessa metodologia é utilizada a Modelagem Matemática para resolução de problemas envolvendo funções elementares, a abordagem do conceito de função será focada no aspecto dinâmico/variacional e por fim introduzir e desenvolver o conceito de taxa de variação instantânea e otimização.

\subsection{OBJETIVO}

O trabalho teve como foco um experimento de ensino baseado na Modelagem Matemática. Assim, desenvolvemos, planejamos e realizamos uma experiência de Modelagem Matemática com alunos da 3ª série do Ensino Médio da Escola Estadual Anhanguera.

A intenção foi levar a metodologia da Modelagem Matemática para as aulas de Matemática e dentro desse contexto ensinar o conceito de função em uma abordagem dinâmica/variacional e posteriormente introduzir o conceito de taxa de variação. 
A escolha da Modelagem Matemática foi devido ao seu potencial motivador e contextualizado.

Pretendeu-se então, responder à seguinte pergunta: o uso da Modelagem Matemática pode ajudar a ensinar e aprender o conceito de função numa abordagem dinâmica/variacional?

Para responde-la analisamos os dados coletados a partir da realização da experiência composta pelos seguintes aspectos:

- Orientar os alunos no processo de Modelagem Matemática;

- Provocar a ocorrência de aprendizagem significativa no estudo de modelagem e mais especificamente no conceito de função (relação entre quantidades variáveis);

- Desenvolver a aprendizagem do conceito de taxa de variação instantânea aplicada à resolução de problemas e em seguida ensinar o conceito intuitivo de derivada. 


\section{REFERENCIAL TEÓRICO E METODOLÓGICO}

\subsection{MODELAGEM MATEMÁTICA}

Segundo Bassanezi (2001), um Modelo Matemático é um sistema conceitual, descritivo ou explicativo, expresso por meio de uma linguagem ou uma estrutura matemática e tem por finalidade descrever ou explicar o comportamento de outro sistema, podendo permitir a realização de previsões sobre este outro sistema.

O uso da Modelagem Matemática como metodologia para ensinar Matemática, vem sendo desenvolvida e aprimorada nos últimos anos por muitos pesquisadores (Blum e Niss, 1991; Carreira, 2001; Bassanezi, 2001; Barbosa, 2001).

Kaiser e Sriraman (2006) sistematizaram o que denominaram de perspectivas para Modelagem Matemática nas quais evidenciam diversos aspectos quanto ao objetivo central com que a atividade de modelagem é desenvolvida em contextos educativos. Os autores se referem a essas perspectivas como: realística, contextual, sócio crítica, epistemológica, cognitiva e educacional.

O estudo desse trabalho foi focado nas perspectivas epistemológicas, cognitiva e educacional da Modelagem Matemática pela sua potencialidade na Educação Matemática. Especificamente no que se refere ao ensino de função, diversos estudos têm mostrado que professores e alunos apresentam obstáculos epistemológicos ao lidarem com funções (Zuffi, 2001; Machado, 1997; Sierpinska, 1992). Esses obstáculos são evidenciados, em parte desses estudos, pela diversidade de conceituações que alunos e professores manifestam e a falta de integração e unidade de significação.

A atividade de Modelagem Matemática pode ser descrita em termos de uma situação inicial (problemática), de uma situação final desejada (solução) e de um conjunto de procedimentos e conceitos necessários para passar da situação inicial para a situação final (Figura 1). 


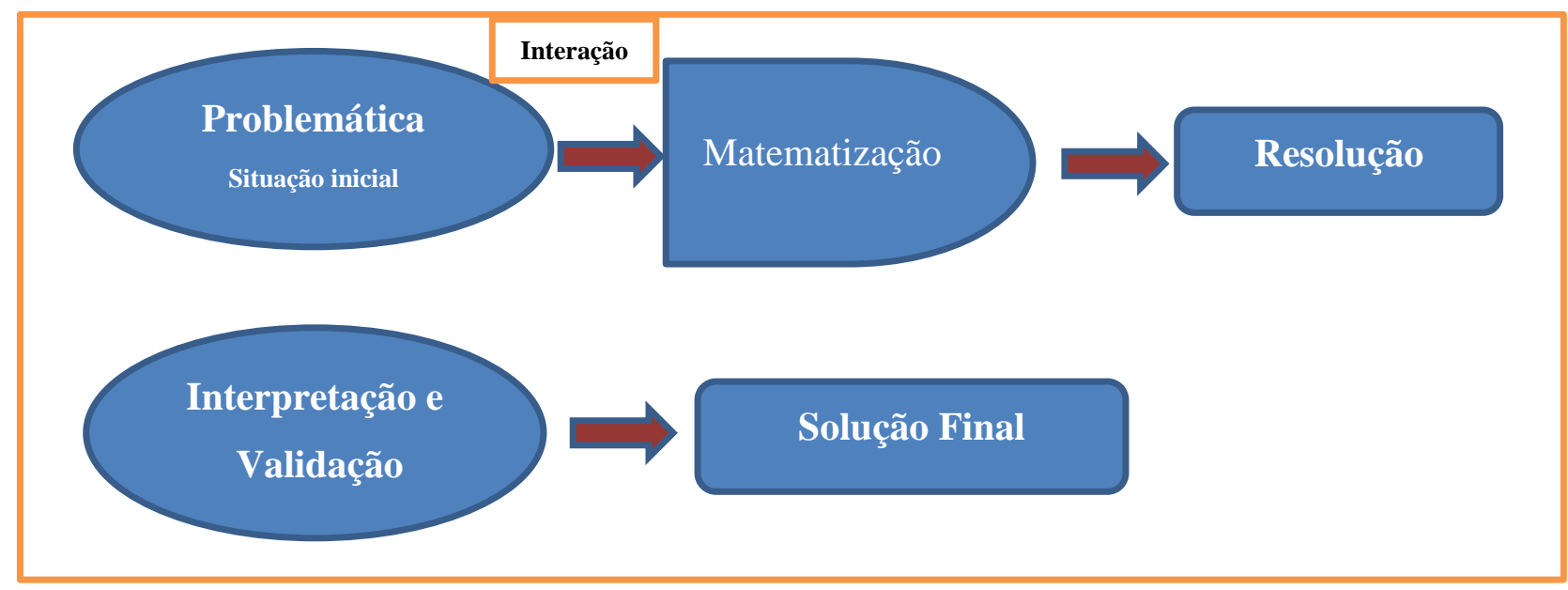

Figura 1 - Fases de modelagem matemática.

Esquema elaborado com base em BASSANEZI, R. C. Ensino-Aprendizagem com Modelagem Matemática. Editora Contexto, São Paulo, 2002.

As fases de modelagem são definidas como:

- Problemática: Situação na qual o aluno não possui esquemas a priori para a sua solução. Pretende-se responder a uma ou várias perguntas sobre uma situação-problema.

- Fase de interação: É a fase de modelagem matemática onde os alunos se informam sobre os conceitos extramatemáticos e a coleta de dados para a posterior formulação do problema. Ela permite buscar informações e conceitos para definir o problema.

- Fase de Matematização: Depois de identificado a situação-problema e terminado a fase de interação, temos o problema na linguagem verbal, mas precisamos transpô-la para a linguagem simbólica e abstrata da matemática. Precisa-se formular hipóteses, selecionar as variáveis e identificar padrões e regularidades que remetam a conceitos matemáticos.

- Fase de Resolução: Consiste na construção de um modelo matemático com a finalidade de representar a situação, responder a situação-problema e se possível realizar previsões para o problema. 
- Fase de Interpretação e Validação: Analisar a resposta do problema e validar a representação matemática confrontando o modelo matemático com os dados experimentais obtidos.

Ações cognitivas dos alunos nas atividades de Modelagem Matemática:

1. Compreensão da situação inicial;

2. Matematização;

3. Síntese;

4. Interpretação e validação;

5. Comunicação e argumentação.

A caracterização da Modelagem Matemática em relação a outras atividades investigativas reside justamente na presença desse conjunto de ações, ou seja, os alunos nas atividades de modelagem se envolvem com essas ações e estas desencadeiam processos cognitivos que estimulam a aprendizagem de um modo contextual e relacional.

\subsection{MODELAGEM MATEMÁTICA NA EDUCAÇÃO MATEMÁTICA}

Modelos Matemáticos constituem formas de representação da realidade. Tabelas, relações funcionais, gráficos, figuras geométricas são alguns exemplos de modelos matemáticos. O trabalho parte da ideia de que muitos exemplos de modelos matemáticos incluem usualmente o uso de variáveis e relações entre essas variáveis que podem ser expressas por meio de funções. É nesse ambiente que se dará o processo de conceituação, pois pretende-se apresentar o conhecimento não somente de forma encadeada, como na visão cartesiana, mas como relações em rede de significações.

No âmbito da Educação Matemática, tem grande importância a obtenção e validação dos modelos matemáticos, pois usada como alternativa pedagógica, esta deve servir de pano de fundo e motivação para o aprendizado de conteúdos da própria Matemática.

Não endosso a visão utilitarista da Matemática, mesmo sabendo do potencial de aplicabilidade da Modelagem Matemática, esse não será o foco do trabalho, mas o potencial dessa metodologia para ensinar conceitos matemáticos. 
Nesse projeto segui a proposta defendida por Almeida e Dias (2004), de que o envolvimento e familiarização dos alunos nas atividades de modelagem deve se dar de forma gradativa.

Os autores argumentam que em um primeiro momento o professor deve colocar os alunos em contato com uma situação-problema, expondo os dados e informações necessárias. A investigação do problema, a análise, seleção de variáveis e modelagem é acompanhada pelo professor, principalmente a fase de matematização. Foi esse tipo de proposta que seguimos nas atividades propostas no projeto.

\subsection{A OCORRÊNCIA DE APRENDIZAGEM SIGNIFICATIVA}

No âmbito da Educação Matemática, a teoria de David Ausubel, tem como fundamento teórico que para ocorrer a aprendizagem, é necessário partir daquilo que o aluno já sabe.

Aquilo que o aluno já sabe ou deveria saber em cada nova situação de aprendizagem é caracterizado pelo autor como "subsunçores" e a literatura, em geral, refere-se a eles como conhecimentos prévios. A teoria de Ausubel indica as condições básicas para que o ensino conduza a uma aprendizagem significativa:

1. O material organizado para o ensino deve ser potencialmente significativo;

2. A estrutura cognitiva do aluno deve dispor de conhecimentos prévios que permitam relacionar o que o aluno já sabe com os novos conhecimentos;

3. O aluno deve apresentar uma predisposição positiva para aprender de maneira significativa, ou seja, para relacionar o conhecimento que já tem com o que deve aprender.

Logo, é importante estruturar situações didáticas que sejam capazes de considerar esses fatores. Diversos projetos de ensino e trabalhos de pesquisa na área da Educação Matemática já sinalizam que características de Modelagem Matemática podem contribuir para que os fatores elencados por Ausubel sejam ativados durante seu desenvolvimento. 


\subsection{O USO DE DIFERENTES REGISTROS DE REPRESENTAÇÃO}

Compreender um objeto matemático consiste em reconhecer suas propriedades e representações características, relacioná-los com outros objetos para uma compreensão abrangente e integral.

Representações matemáticas são ferramentas que viabilizam o contato com os conceitos matemáticos e, por meio destes, o sujeito interage com o conhecimento matemático. Nesse contexto, a representação torna o objeto matemático "presente".

A teoria de Representação Semiótica de Raymond Duval, tem como foco a pluralidade de representações semióticas em Matemática, e trata de um conjunto de argumentos que defendem a diversificação de representações de um mesmo objeto que é essencial para a compreensão dos conceitos.

Para designar os diferentes tipos de representação semiótica (língua natural, gráficos, figuras, equações algébricas, e outras), Duval introduz o termo "registros de representação semiótica”. Assim podemos falar em registro algébrico, registro gráfico, registro figural, etc.

Três condições são essenciais para que um sistema de signos constitua um registro de representação semiótica:

1. A representação precisa ser identificável, isto é, é preciso reconhecer na representação o que ela representa;

2. O tratamento, que consiste em transformações internas ao registro, transformações em que se tem como registro de partida e registro de chegada um mesmo registro; simplificar uma fração é um exemplo de tratamento de registro de representação;

3. A conversão que implica transformar um registro de representação de um objeto matemático em outro; a conversão, é uma transformação externa ao registro de partida, ou seja, são transformações em que o registro de partida difere do registro de chegada; associar à função: $y=x^{2}+2 x+3$ o gráfico de uma parábola é um exemplo de conversão. Nesse exemplo, percebe-se que, embora ambos os registros se refiram ao mesmo objeto matemático (função polinomial do segundo grau), eles não representam o objeto matemático em sua totalidade, mas parcialmente.

Essa atividade de transformação representacional é fundamental, pois é ela que conduz mecanismos subjacentes à compreensão, levando o aluno a refletir sobre 
diferentes características de um objeto matemático associado às diferentes representações.

É nesse contexto, que se percebe o potencial das atividades de Modelagem Matemática no que diz respeito à investigação sobre a compreensão de matemáticos que se fazem presentes nas situações de modelagem a $p$ coordenação entre os diferentes registros de representação associados aos Gujeıus. 


\section{ESTRATÉGIAS DE INVESTIGAÇÃO E DESENVOLVIMENTO}

\subsection{ESTRATÉGIAS DE INVESTIGAÇÃO}

A pesquisa compreendeu um estudo experimental, cuja análise foi de natureza qualitativa consistindo de dois questionários: um a priori realizado antes das atividades de modelagem e outro a posteriori realizado depois das modelagens. As respostas dos grupos foram fichadas. Todo esse procedimento ocorreu na sala de aula disponível pela diretoria do colégio estadual Anhanguera para as atividades de modelagem. Os termos de consentimento foram assinados pela diretora, professora, pais e alunos.

\subsection{DESENVOLVIMENTO}

A proposta do trabalho foi desenvolver as atividades de Modelagem Matemática em horários e espaços extraclasse em vez de incluir as atividades de modelagem nas aulas regulares de Matemática, não obstante pretende-se trabalhar em conjunto com o professor dos alunos no sentido de harmonizar e integrar subsídios para otimizar as atividades. Foram atividades extracurriculares, especialmente realizadas para essa finalidade.

Nesse trabalho realizou-se atividades de modelagem matemática em espaço extraclasse, pois a complexidade das modelagens e o tempo de dedicação dos grupos assim exigia, mas professores podem e devem trabalhar com modelagem matemática inserida no próprio conteúdo a ser ministrado, tomando o cuidado para verificar se o tempo e a complexidade das atividades não superem a viabilidade do projeto. Para realizar as modelagens com toda a classe, basta escolher um problema que exija a utilização de conceitos matemáticos que queira trabalhar e formar grupos maiores dependendo do número de alunos.

A intenção foi avançar em termos de conceitos e abstração em relação à estrutura curricular estabelecida. Nas atividades realizadas, os alunos foram expostos a situações-problema que requerem o uso da Modelagem Matemática, que nesse experimento foi focado no uso de funções elementares numa abordagem variacional.

No final das atividades de modelagem pretendeu-se criar uma "ponte conceitual" entre função para modelar variações e o conceito de taxa de variação 
instantânea e um início intuitivo do conceito de derivada. O experimento foi realizado em estágios de forma gradativa.

No primeiro estágio, o professor/orientador colocou os alunos numa situaçãoproblema, incluindo os dados e as informações necessárias. O professor acompanhou a investigação do problema, a análise e a utilização de um modelo matemático, de modo que a definição das variáveis e hipóteses, a transição para a linguagem matemática, as validações do modelo fossem orientadas e avalizadas pelo professor. Nesse primeiro estágio, pretendeu-se ambientar os alunos e ensinar o processo de modelagem para que os mesmos adquirissem confiança e entusiasmo pela atividade. Ou seja, o papel do professor/orientador foi acompanhar todas as fases de modelagem dando apenas as informações necessárias e orientando todo o processo sem dar a resposta pronta.

Desde o primeiro estágio, e em todos eles, foi inserido, principalmente na fase de matematização, o ensino de função numa perspectiva dinâmica/variacional. No segundo estágio, uma situação-problema foi sugerida pelo professor aos alunos, e estes, divididos em grupos completaram a coleta de informações para a investigação da situação e realizaram a definição de variáveis e a formulação das hipóteses simplificadoras para posterior validação do modelo matemático. Nesse estágio, mudase a independência do aluno, pois este teve que mobilizar vários recursos cognitivos para completar a atividade, sempre mediadas pelo professor que forneceu informações suficientes para o processo se desenvolver.

No terceiro estágio, onde os alunos já conseguiam desenvolver atividade de modelagem matemática, o professor/pesquisador voltou a ser protagonista e desenvolveu seu último objetivo que foi ensinar o conceito de taxa de variação instantânea e posteriormente numa abordagem intuitiva e usando o computador levar os alunos até o conceito de derivada. 
4 FUNDAMENTAÇÃO TEÓRICA ENVOLVIDA NO PROCESSO DE ENSINOAPRENDIZAGEM DAS ATIVIDADES

Todo o conteúdo de suporte teórico foi utilizado conforme a necessidade durante as atividades de modelagem matemática estão disponíveis no Apêndice $A$.

O material apresentado foi usado de acordo com a necessidade dos estudantes envolvidos. Não foi usado todo o material, mas boa parte dele, pois as modelagens não usaram alguns conceitos que estão nesse material, entretanto, esse material foi fornecido para os estudantes como estudo extra.

O material teórico usado nesse trabalho foi baseado no livro: Cálculo - Vol.1. autor: Howard Anton. $8^{\mathrm{a}}$ edição. Bookman 


\section{ATIVIDADES}

Nesta seção, apresentaremos as atividades e os resultados encontrados na aplicação da Modelagem Matemática realizada com os grupos. As atividades foram realizadas em 4 fases com cada grupo. Os grupos eram formados por:

- Grupo 1: Isabelle e Elisa

- Grupo 2: Giovanna e Victor

- Grupo 3: Ingrid e Lucas

As atividades de modelagem foram realizadas em oito encontros semanais em duas salas de aula, uma para atividades de computação e vídeo e outra para aulas de orientação teórica. A duração das atividades de modelagem matemática foi de 2,5 horas antes das aulas regulares de matemática dos alunos. Eles chegavam às 16:30 e saíam as 19:00 para entrar nas suas salas de aula com a professora de matemática. Também foi utilizado 4 sábados para orientação via Skype ou e-mail com duração de 1,5 horas. Assim tivemos um total de 26 horas distribuídos entre atividades de orientação das fases de modelagem, atividades com o programa Geogebra e aulas para consolidar conhecimentos prévios necessários para cada grupo.

As atividades no Geogebra já tinham a estrutura prontas feitas pelo professor, pois não haveria tempo para ensinar ferramentas mais avançadas do programa. $O$ foco foi nas atividades conceituais e manipulação das funções elementares.

O grupo 2 e também os outros grupos assistiram ao vídeo: Universo Mecânico, pois os conceitos contidos nesse vídeo foram usados posteriormente com todos os três grupos para a introdução do conceito de derivada. O grupo 2 que fez a modelagem da queda livre com o programa Tracker assistiu em casa novamente 0 vídeo.

Para as modelagens foram definidos cinco temas: Solução salina/densidade, otimização da melhor idade para engravidar, queda livre/derivada, afastamento das galáxias/idade do universo e pêndulo. Os grupos escolheram o que gostaram mais e as atividades sobre a idade do universo e pêndulo ficaram como sugestão para professores. Fiz desse modo para que eles ao menos escolhessem uma atividade que gostassem para promover motivação.

A modelagem sobre queda livre foi inspirada no vídeo Universo Mecânico e todas os passos desenvolvidos até chegar ao conceito de derivada foi criado pelo autor. A atividade sobre densidade da solução de água/sal foi inspirada numa modelagem feita pelo Bassanezi, onde ele usou equações diferenciais para deduzir a 
função exponencial a partir do conhecimento de que uma função exponencial tem taxa de variação relativa constante, e como eu não poderia fazer isso pois os alunos não tem esse conceito, desenvolvi um modelo partindo de dados obtidos via experiência de laboratório.

A modelagem sobre a idade ideal para engravidar foi baseada num artigo: $A$ vida por trás dos olhos amendoados: Um livro reportagem sobre os portadores da Síndrome de Down. Londrina; Eduel,2002. Afastamento das Galáxias inspirado no livro: A Student's Guide to Mathematics of Astronomy. Modelagem do pêndulo, baseada no programa PHET.

\subsection{AVALIAÇÃO DIAGNÓSTICA}

Os objetivos da análise a priori das questões feitas aos alunos antes da Modelagem Matemática era verificar os conhecimentos prévios dos alunos sobre funções elementares. Essa avaliação está disponível no Apêndice B.

Com as questões 1 e 2 pretendeu se verificar como o aluno faz a distinção entre linguagem matemática formal e termos informais para expressar o entendimento do conceito de função. Pretendeu se avaliar também se o conceito de função dos alunos tem o viés algébrico.

A questão 3 objetivou saber quais imagens de funções elementares vinham a mente dos alunos, notadamente as funções lineares, quadráticas, exponenciais e trigonométricas, pois essas funções seriam necessárias para as atividades de Modelagem Matemática.

Nas questões 4, 5, 6 e 7 pretendeu se verificar a compreensão de notações e símbolos abstratos para representar o conceito de função. Capacidade de reconhecer a variável independente e dependente bem como os coeficientes das funções. $\mathrm{Na}$ Física aparece a fórmula horária do espaço em função do tempo que troca as variáveis e coeficientes, mas a estrutura funcional é a mesma de uma função polinomial de $2^{\circ}$ grau.

As questões 8 e 9 pretendeu se verificar como os alunos fazem a distinção entre uma expressão algébrica, uma equação e uma função.

A questão 10 serviu para verificar se os alunos eram capazes de reconhecer se um gráfico representa uma função ou não. 
A questão 11 era para avaliar o conhecimento da variável dependente e independente e sobre domínio e imagem de uma função.

A questão 12 pretendemos avaliar se os alunos eram capazes de mudar de registro de representação gráfica para algébrica e interpretar os dois juntos. A questão 13 a mesma coisa só que para função polinomial de $2^{\circ}$ grau.

A questão 14 uma avaliação se os alunos compreendiam taxa de variação constante e sua relação com a inclinação da reta. Conceito fundamental para a introdução ao conceito de derivada.

As questões de 15 a 18 também pretendemos avaliar se aos alunos eram capazes de mudar de registro de representação gráfica para algébrica e interpretar os dois juntos e também determinar a imagem e domínio dessas funções, bem como avaliar quais seriam os conhecimentos prévios dos alunos para poder intervir em cada caso para preparar para a Modelagem Matemática.

\subsubsection{Análise a priori das respostas da avaliação diagnóstica}

Apresentaremos a análise a priori das respostas dos grupos às questões propostas antes das atividades de Modelagem Matemática

Com relação às questões 1 e 2 que visavam se os alunos tinham a correta compreensão sobre o conceito de função, verificou se que os grupos 1 e $3 \mathrm{com}$ exceção do grupo 2, colocaram em suas definições que a cada elemento do domínio $x$ está associado um único elemento y do contradomínio. Nenhum dos três grupos mencionou em suas definições que $x$ é a variável independente e y a variável dependente, o que era esperado devido ao viés algébrico que é mais enfatizada no currículo da educação básica em detrimento da abordagem dinâmica e variacional. Nas atividades de Modelagem Matemática será dado prioridade a abordagem variacional. 


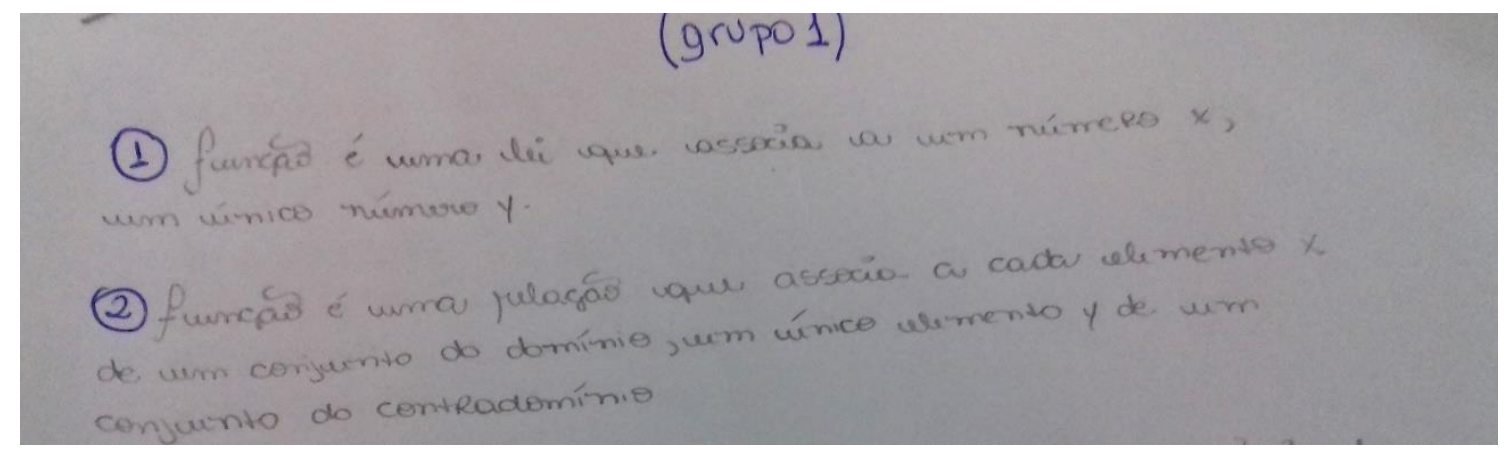

Figura 2

Questionário a priori disponível no Apêndice B.

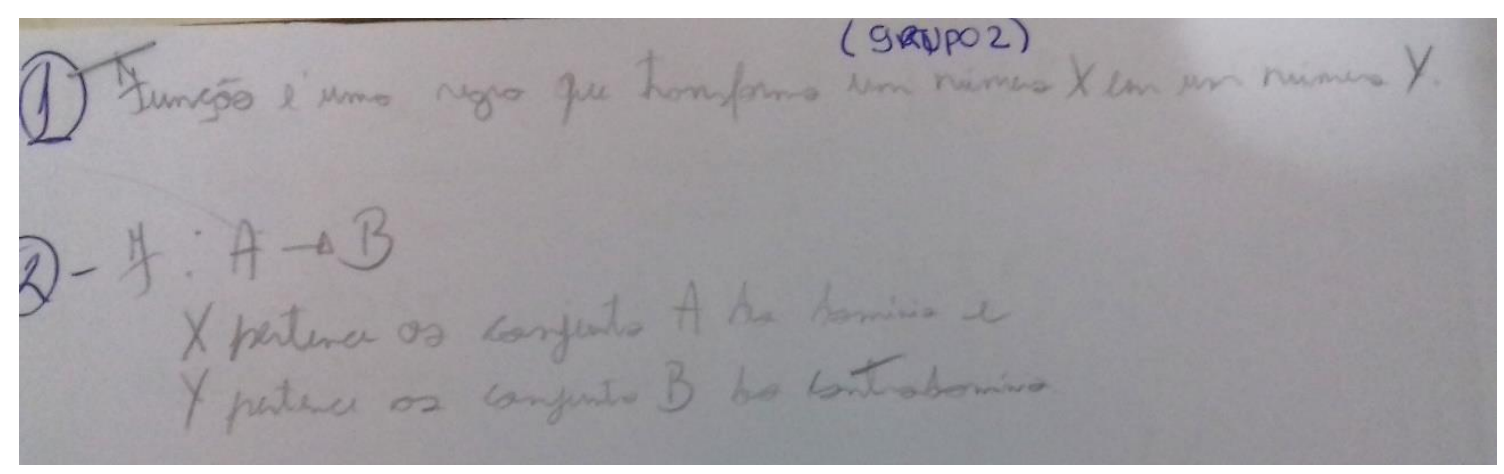

Figura 3

Questionário a priori disponível no Apêndice B.

Com relação à questão 3 que visava quais imagens de funções elementares vinham à mente dos alunos, verificou se os três grupos deram exemplos simples, mas satisfatórios de funções elementares.

Na questão 4, não houve problema na identificação do símbolo abstrato com a definição e interpretação do signo no conceito de função. Na questão 5 todos os três grupos perceberam que se tratava de uma equação de $1^{\circ}$ grau e não uma função. $\mathrm{Na}$ questão 6 com exceção do grupo 2, houve uma confusão dos grupos 1 e 3 que identificaram uma função do $1^{\circ}$ grau ao invés de uma expressão algébrica. Com relação à questão 7 , todos os grupos não reconheceram que se tratava de uma função de $1^{\circ}$ grau, o que também era esperado, pois como não reconheciam quem eram as variáveis independentes e dependentes e além disso o parâmetro b da função foi colocado ao quadrado, levou aos dois grupos pensarem que se tratava de uma equação de $2^{\circ}$ grau. 
O exagero dos livros didáticos em colocar $\mathrm{x}$ e y como variáveis e as letras $\mathrm{a}, \mathrm{b}$ e c como coeficientes das funções elementares provoca uma padronização simbólica deletéria para a identificação do tipo de função.

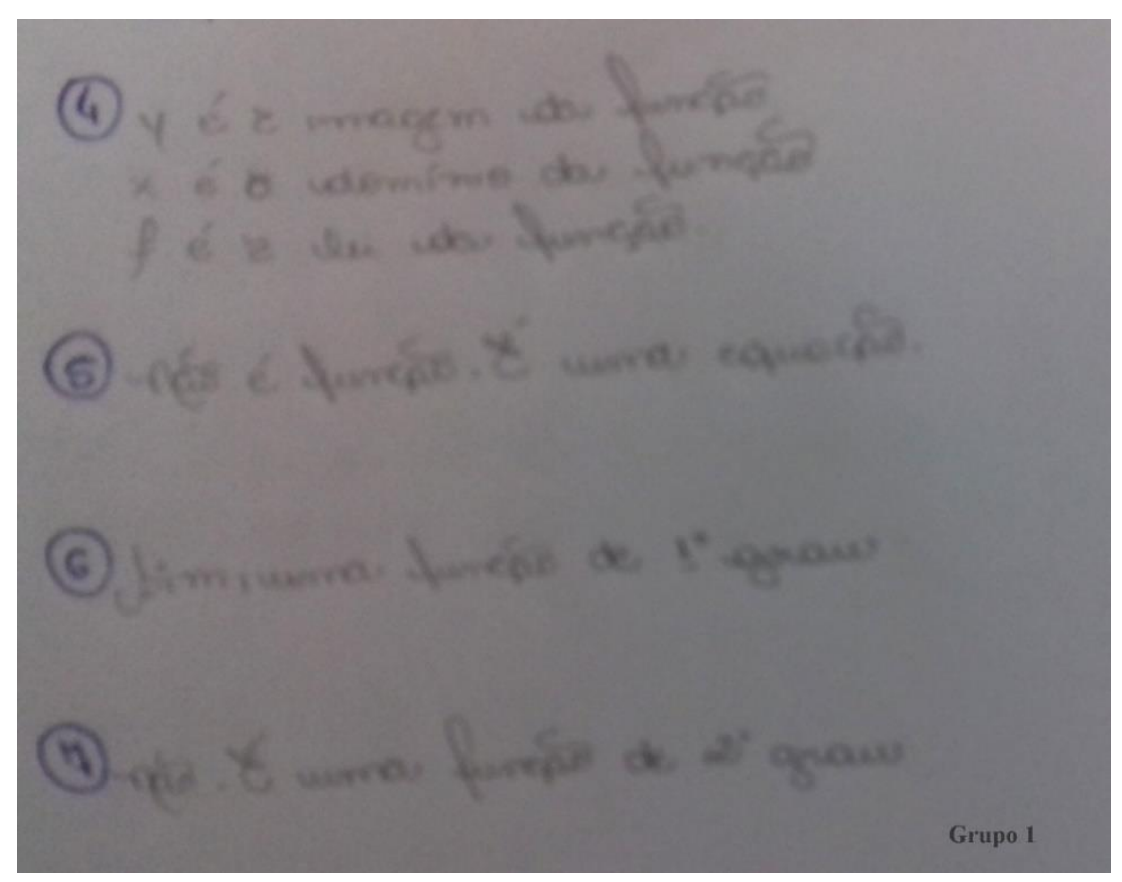

Figura 4

Questionário a priori disponível no Apêndice B.

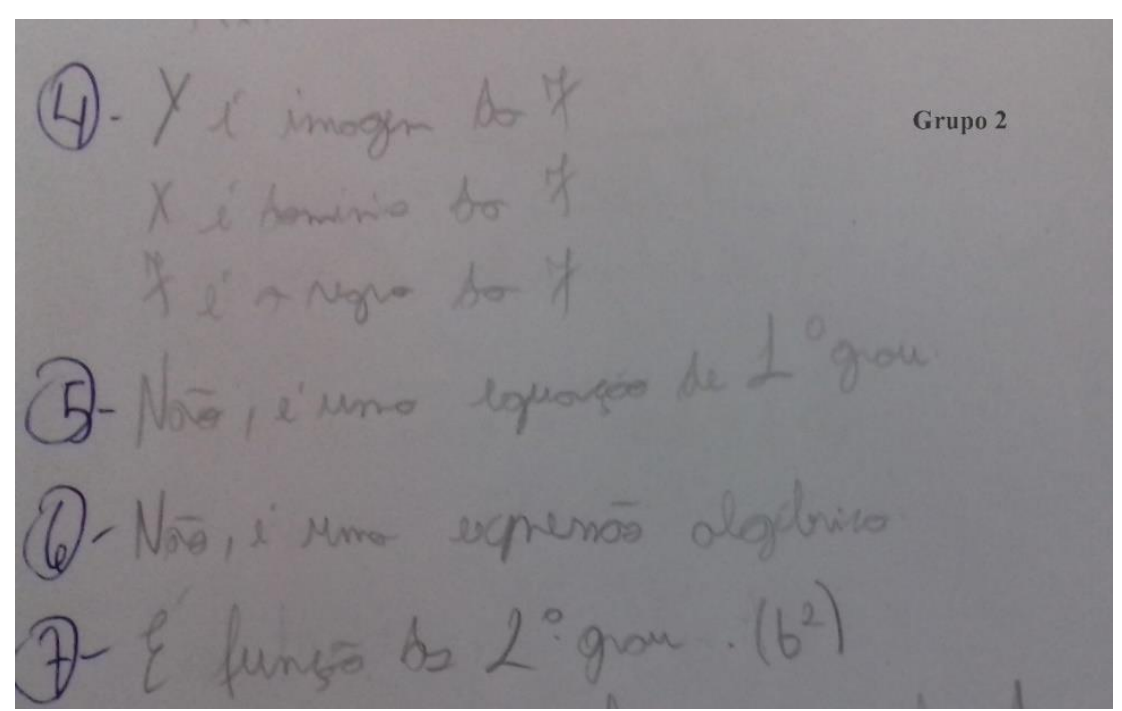

Figura 5

Questionário a priori disponível no Apêndice B. 


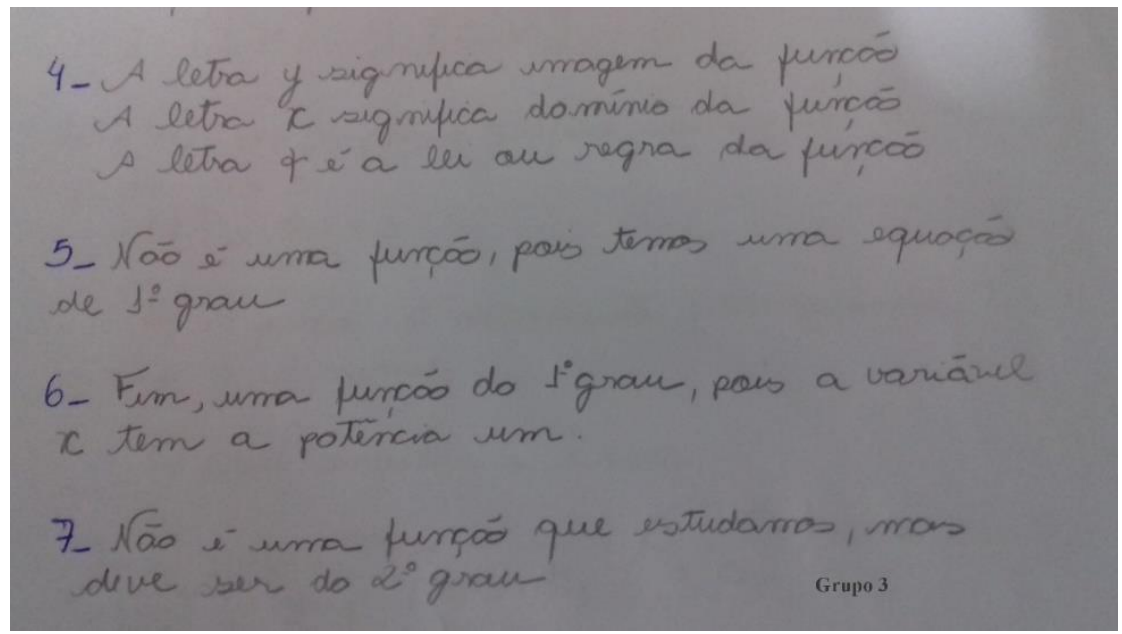

Figura 6

Questionário a priori disponível no Apêndice B.

Na questão 8, todos os grupos não conseguiram identificar com precisão quem era a variável independente e dependente, o grupo 1 confundiu a variável independente com o $\mathbf{x}$, ao invés de a. 0 grupo 3 afirmou que era uma função que nunca tinham estudado, não percebendo que se tratava de uma função polinomial de $2^{\circ}$ grau, onde trocou se o símbolo a pelo símbolo $\mathbf{x}$, sendo que a é a variável independente e $\mathbf{x}$ uma constante.

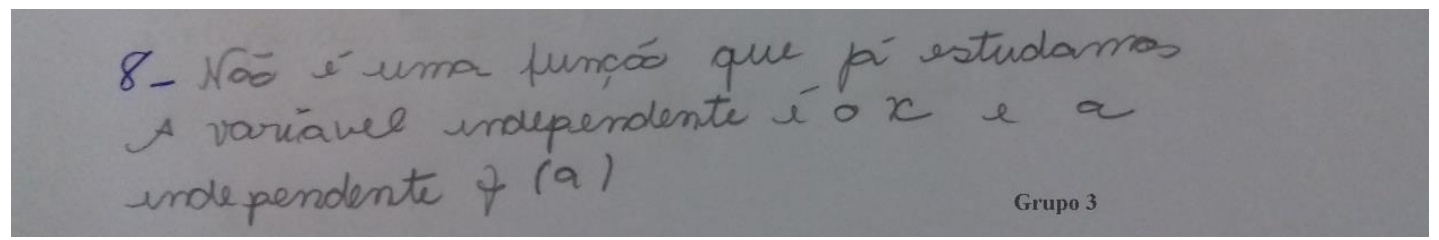

Figura 7

Questionário a priori disponível no Apêndice B.

Na questão 9, todos os três grupos afirmaram que se tratava de uma função que representava uma circunferência. Apesar de que os grupos 1 e 3 terem colocado corretamente nas questões 1 e 2 , que a cada valor de $\mathbf{x}$ deve haver um único elemento de $\mathbf{y}$, esse conhecimento no registro de representação verbal não foi transferido para o registro simbólico da equação. 
Figura 8

Questionário a priori disponível no Apêndice B.

$\mathrm{Na}$ questão 10, os três grupos reconheceram o gráfico 1 como função e 0 gráfico 3 disseram que era função, pois para eles a equação da circunferência representa uma função, erro semelhante a questão 9, que nesse caso também o conhecimento no registro de representação verbal não foi transferido para o registro gráfico. Estranhamente todos os grupos afirmaram corretamente que o gráfico 2 não era função, mas o acerto provavelmente foi devido ao fato de ser um gráfico estranho ao conhecimento deles.

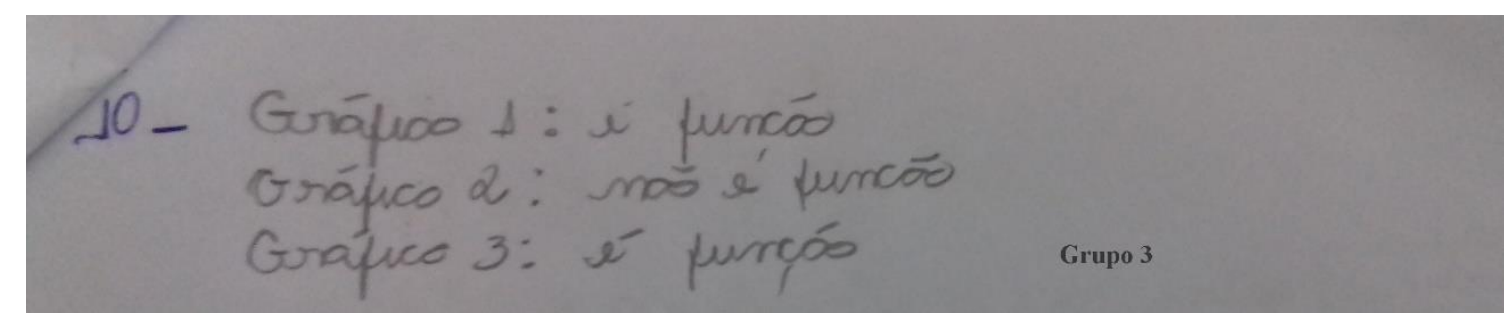

Figura 9

Questionário a priori disponível no Apêndice B.

Com relação a questão $\mathbf{1 1}$, todos os grupos acertaram que era a variável dependente e independente, isso indica que através do registro gráfico eles ligaram a abcissa à variável independente e a ordenada a variável dependente, mas no registro algébrico houve erros de identificação.

Na questão 12 pretendíamos avaliar se os alunos eram capazes de mudar de registro de representação gráfica para algébrica e interpretar os dois juntos. $\mathrm{O}$ grupo 1 e 3 conseguiram identificar o coeficiente linear e que a função é crescente, mas não souberam calcular o coeficiente angular. $\mathrm{O}$ grupo 2 conseguiu completar todas as perguntas e expressar a forma algébrica do gráfico. Percebe se uma falha na compreensão da função polinomial de $1^{\circ}$ grau que foi trazida até o $3^{\circ}$ ano. 


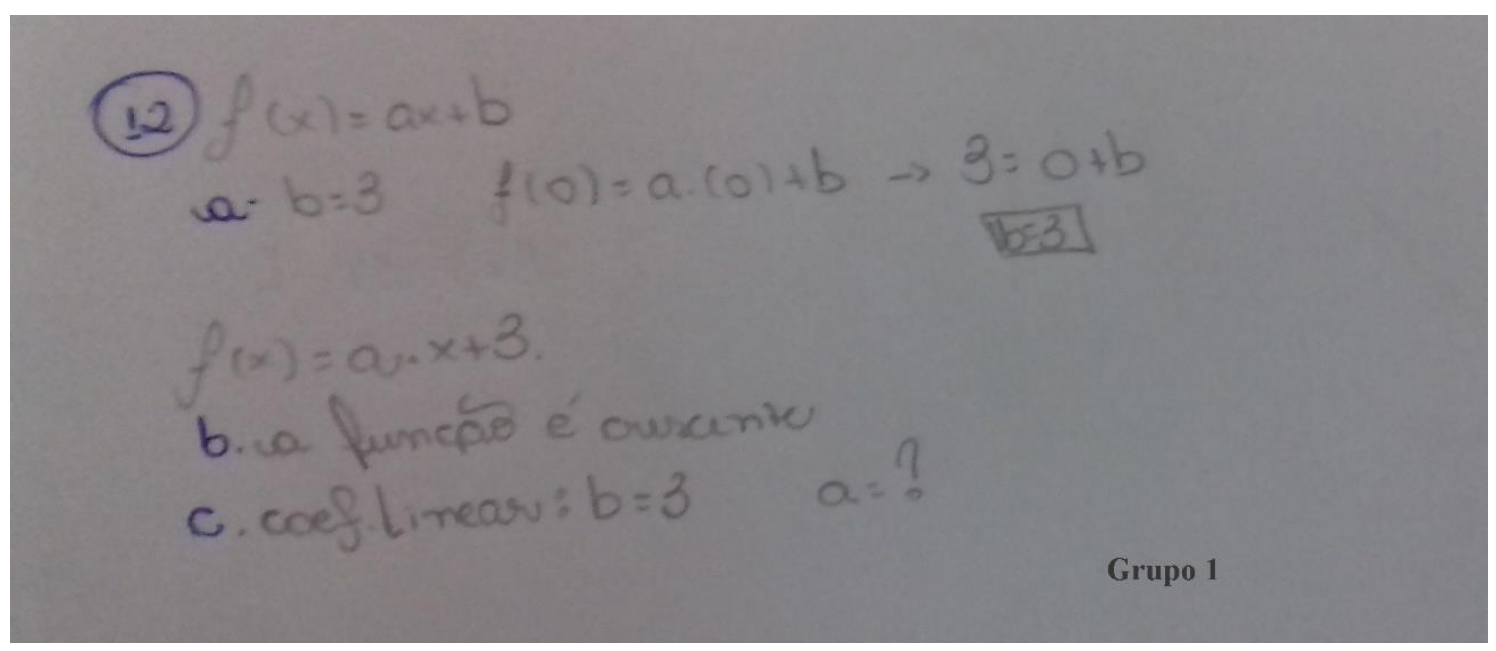

Figura 10

Questionário a priori disponível no Apêndice B.

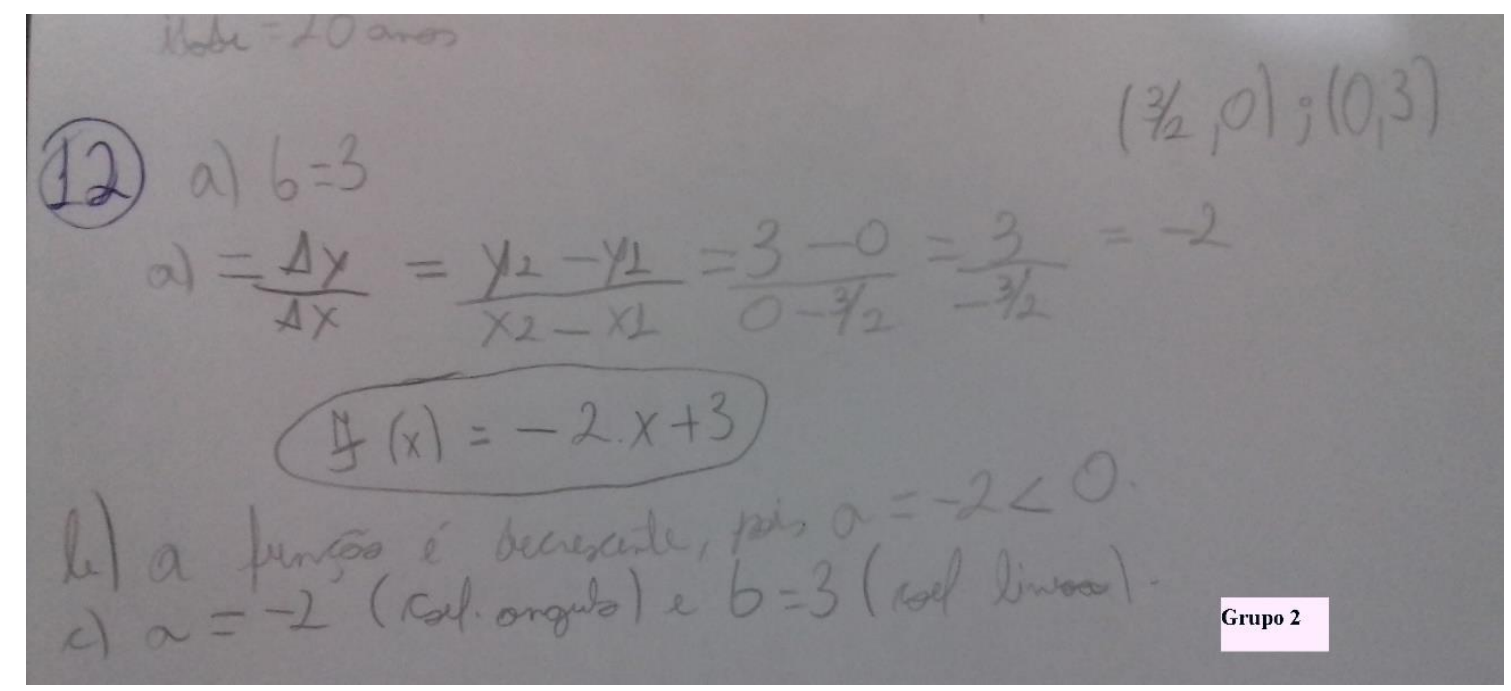

Figura 11

Questionário a priori disponível no Apêndice B.

A questão 13, nenhum grupo conseguiu fazer a passagem de registro gráfico para o algébrico de uma função polinomial de $2^{\circ}$ grau, apenas identificaram as raízes e através delas calcular o ponto médio achar a coordenada $\mathbf{x}$ do vértice.

A questão 14 referente a compreensão de taxa de variação, apenas o grupo 2 conseguiu resolver, o que confirma a falta de compreensão do conceito de coeficiente angular dos grupos 1 e 3 se refletiu nessa questão. 
$\mathrm{Na}$ questão 15, todos os grupos conseguiram expressar o gráfico da função exponencial na expressão algébrica, com um erro de todos os grupos na questão b referente à imagem da função onde colocaram o número 1 como pertencendo a imagem da função. Os estudantes tiveram uma revisão sobre funções exponenciais no início das aulas, acreditamos que esse fato consolida a boa performance nessa questão.

$\mathrm{Na}$ questão 16, os gráficos ficaram bons, mas transmitiram o erro na questão 15 referente à imagem da função exponencial, pois percebe se que não identificaram a assíntota e o gráfico dá a impressão que toca a assíntota y=1.

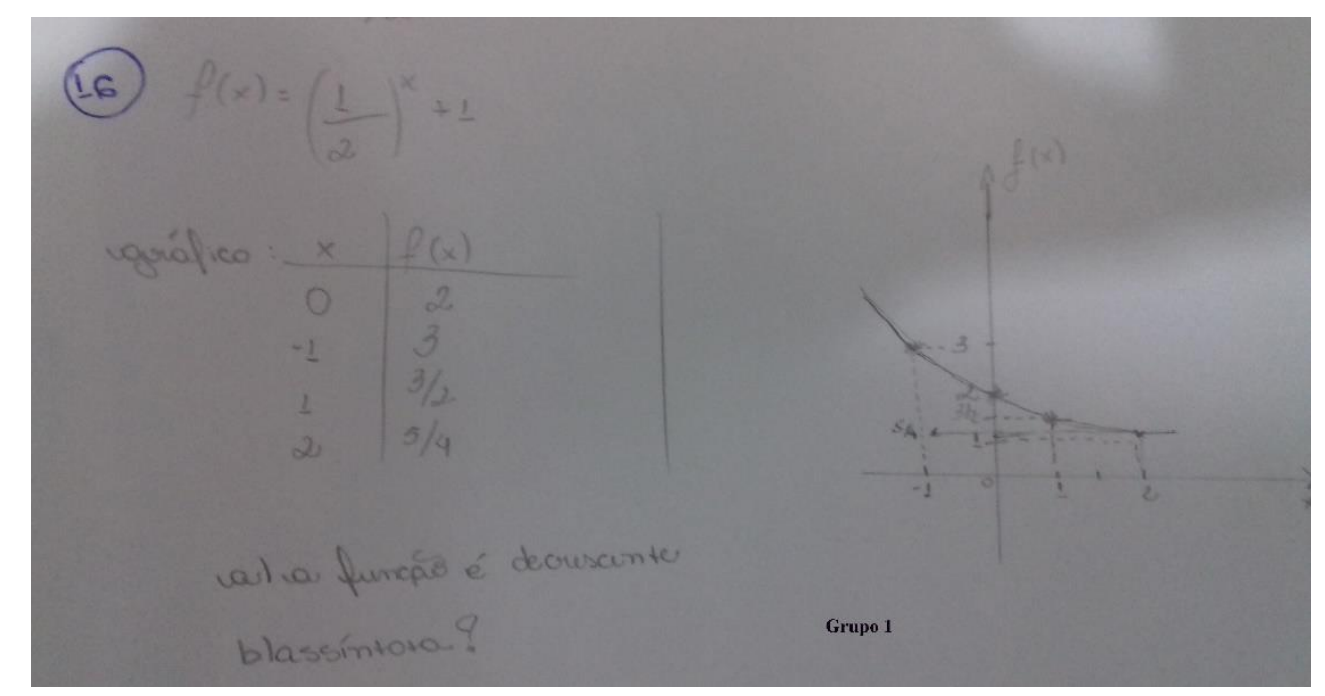

Figura 12

Questionário a priori disponível no Apêndice B.

A questão 17 foi pedido a imagem e período de uma função trigonométrica senoidal, pois iríamos fazer uma Modelagem Matemática envolvendo movimento de um pêndulo e conceitos como período, imagem e frequência são essenciais. Essa questão serviu como preparação para a questão 18. Para facilitar a identificação da imagem dessa função, colocamos de forma abstrata o intervalo da imagem usando os parâmetros $\mathbf{a}$ e $\mathbf{b}$ e demos a expressão para determinar o período $\mathbf{p}$. Desse modo não houve dificuldades nos três grupos.

$\mathrm{Na}$ questão 18, conseguiram achar o período e a imagem a partir do gráfico, pois o conhecimento foi transferido da questão 17 , isso mostra que se o aluno tem conhecimento prévio ele é capaz de transferir parcialmente esse conhecimento mesmo quando o objeto matemático estiver em outro registro de representação, que 
na questão 17 estava no registro algébrico e na questão 18 estava no registro gráfico. Repare que com relação ao conceito de amplitude somente o grupo 2 acertou e com relação ao conceito de período, não tendo o valor do coeficiente $\mathbf{c}$ não souberam identificar no gráfico o período $\mathbf{p}$ que possibilitaria calcular o valor do coeficiente $\mathbf{c}$ da função. Sinal que não entenderam o conceito de período apenas aplicaram a fórmula.

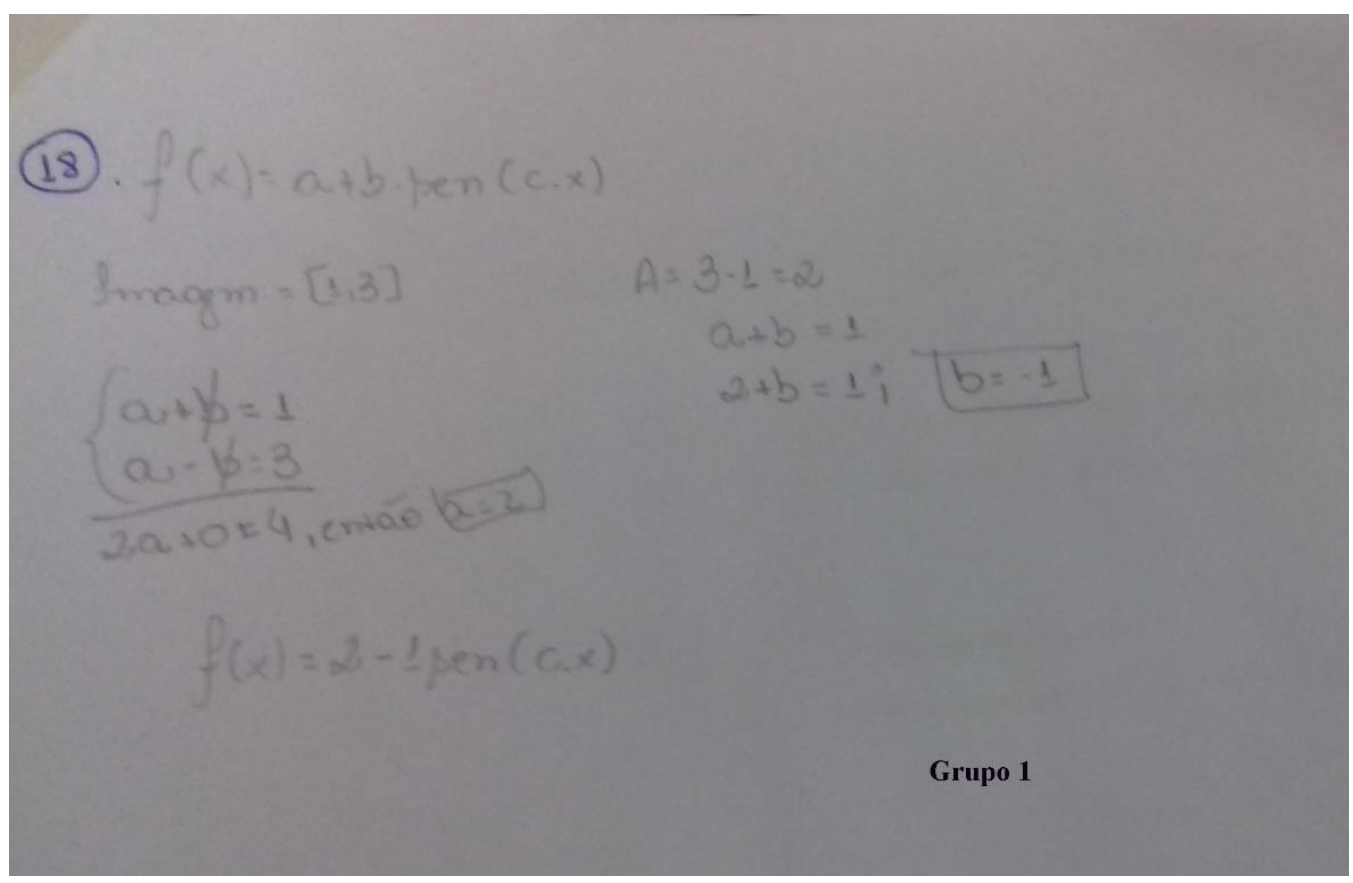

Figura 13

Questionário a priori disponível no Apêndice B.

\subsubsection{Análise a posteriori das respostas da avaliação diagnóstica}

Após as atividades de modelagem concluídas, foi apresentada aos grupos as questões da análise a posteriori. Isso foi feito no nosso último encontro após o término da exposição sobre o conceito de derivada. Eles não sabiam que haveria questões a posteriori.

A seguir, apresentaremos uma análise a posteriori das respostas dos grupos às questões propostas após as atividades de Modelagem Matemática.

As questões propostas foram diferentes para cada grupo, pois após a análise a priori percebi que cada grupo tinha dificuldades e conceitos diferentes sobre funções 
elementares, assim a análise a posteriori foi preparada para extrair o máximo de conhecimentos de cada grupo.

Com relação às questões 1 e 2 , apenas o grupo 1 acrescentou que $\mathbf{x}$ é a variável independente e y a variável dependente. A correta identificação das variáveis do problema é fundamental para a fase de matematização da Modelagem Matemática e para a compreensão dinâmica do conceito de função, sendo que se o aluno consegue identificar melhor o que varia e em função de que varia ele estará a caminho de formular uma função para a Modelagem. Durante a fase de matematização foi bastante trabalhado esse tipo de identificação, inicialmente com problemas de taxas relacionadas (ver aplicação do conceito de função).

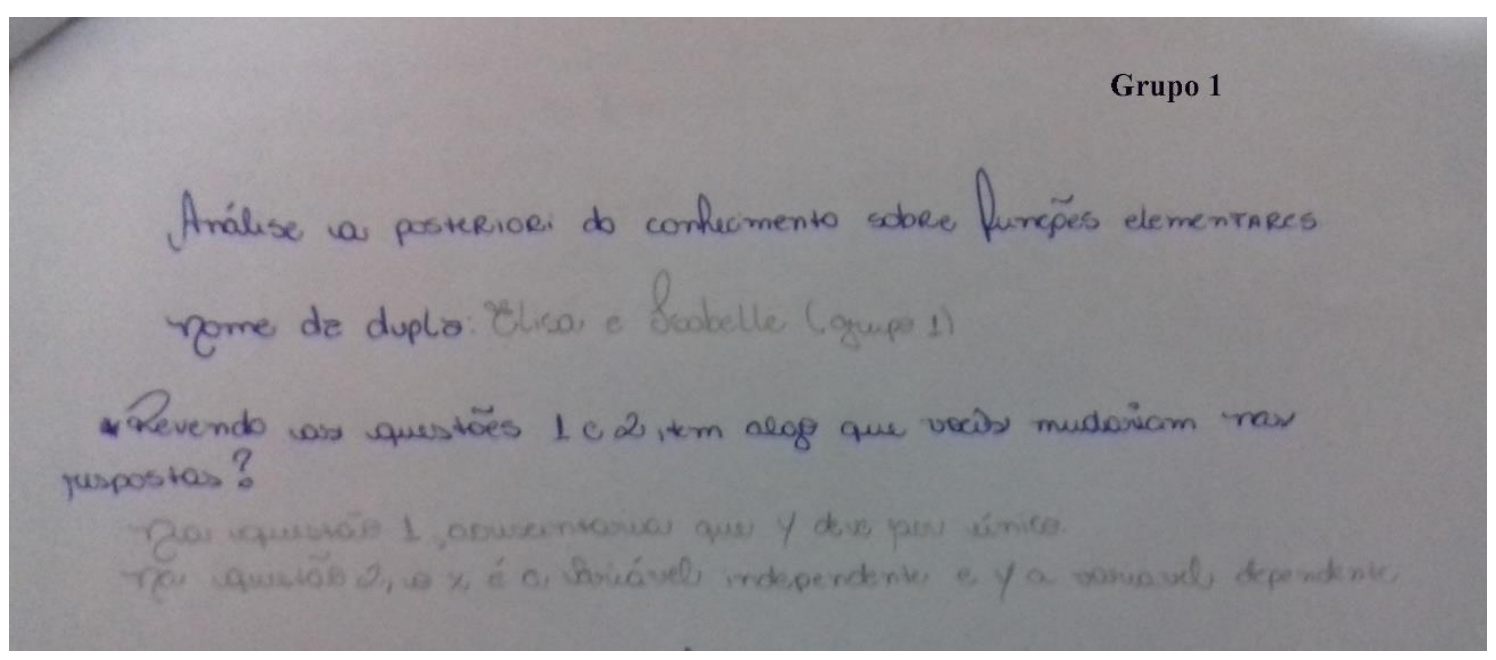

Figura 14

Questionário a priori disponível no Apêndice C.

$\mathrm{Na}$ questão 6, os grupos 1 e 3 corrigiram a questão. É uma expressão matemática e não uma função. Revendo a questão 7 , os grupos corretamente identificaram como função de $1^{\circ} \mathrm{grau}$, provavelmente a localização das variáveis dependente $\mathrm{e}$ independente e que $\mathbf{x}$ e $\mathbf{y}$ não precisam ser variáveis, mas podem aparecer como constantes, facilitou a percepção de que se tratava de uma função de $1^{\circ}$ grau. Na questão 8, o mesmo ocorreu com os três grupos conseguiram perceber que se tratava de uma função de $2^{\circ}$ grau. 


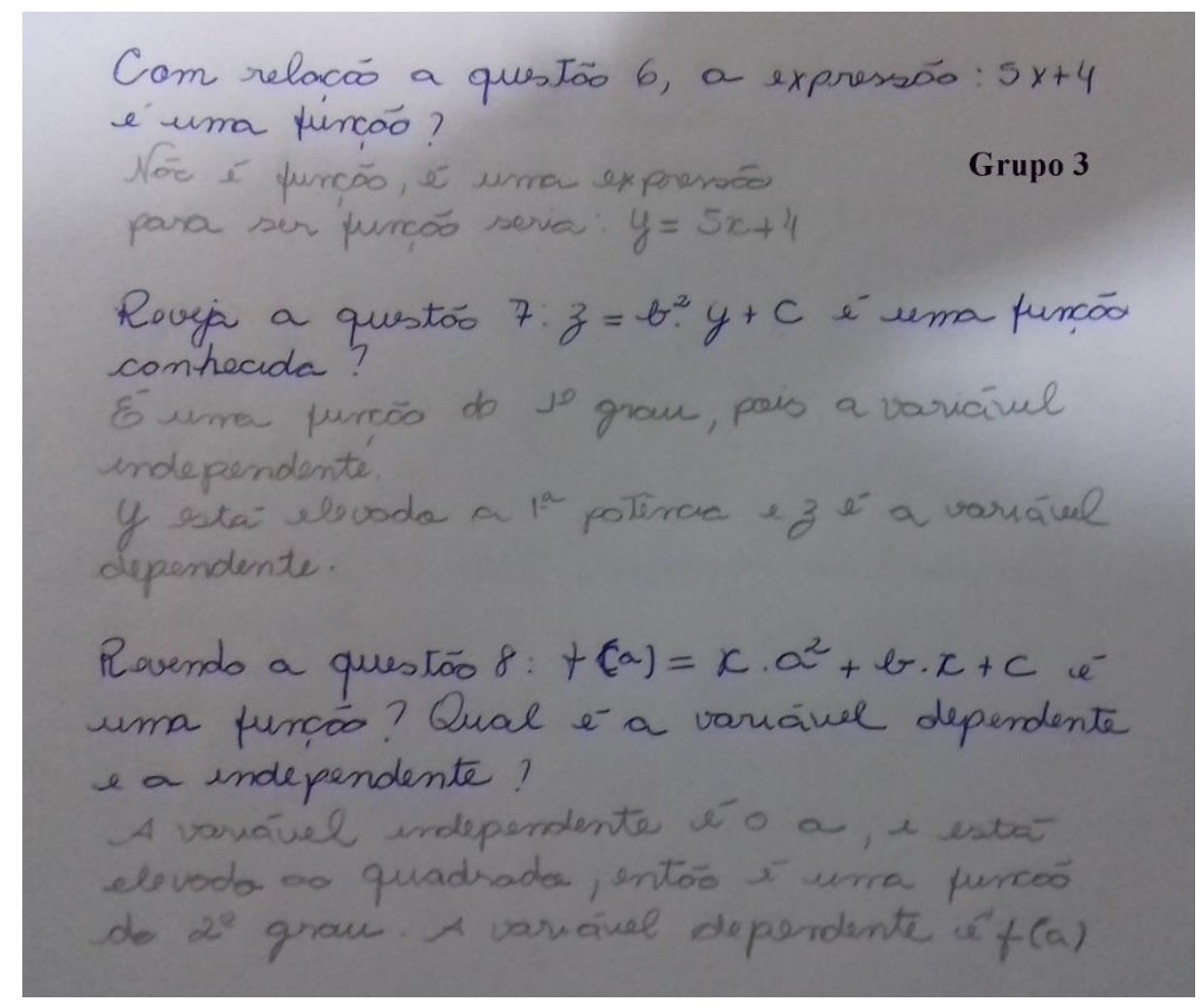

Figura 15

Questionário a priori disponível no Apêndice C.

Nas questões 9 e 10, os grupos corrigiram as mesmas dizendo que na questão 9 não se tratava de uma função e na questão 10, somente o gráfico 1 era função. Foi trabalhado via gráficos com geogebra, o teste da reta vertical, onde uma curva no plano xy é o gráfico de uma função se nenhuma reta vertical cortar a curva mais de uma vez. Também através da representação algébrica, mostramos que para um mesmo valor de $\mathbf{x}$ do domínio teremos dois valores de $\mathbf{y}$ na imagem na equação da circunferência.

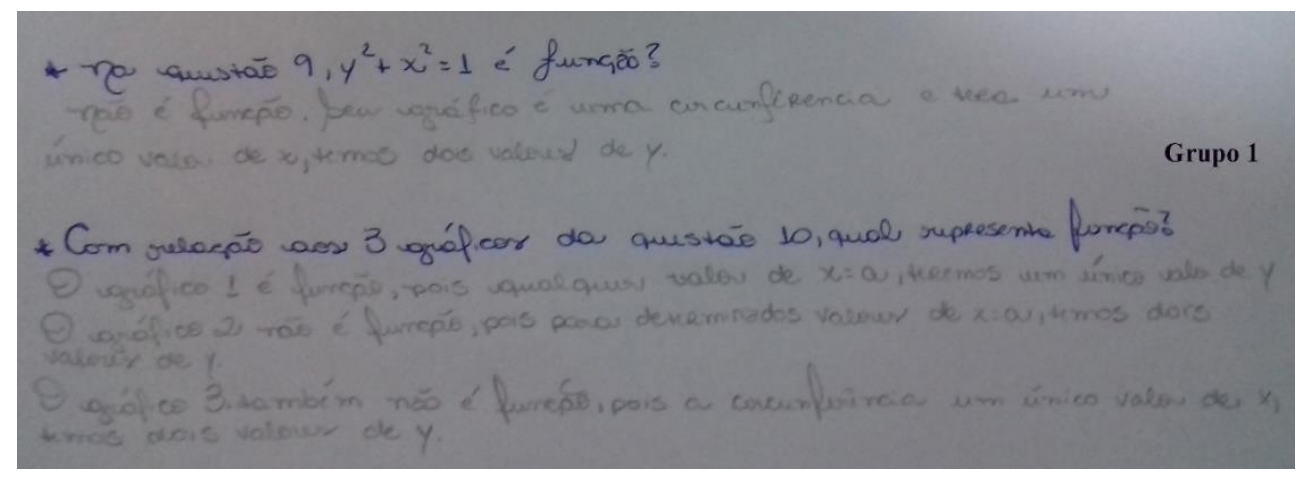

Figura 16

Questionário a priori disponível no Apêndice C. 
$\mathrm{Na}$ questão 12, somente o grupo 2 soube responder adequadamente qual era o coeficiente angular na fase a priori, mas os grupos 1 e 3 corrigiram corretamente essa questão na fase a posteriori. Trabalhamos o conceito de inclinação da reta e taxa de variação usando o GeoGebra e exercícios de aplicação de funções.

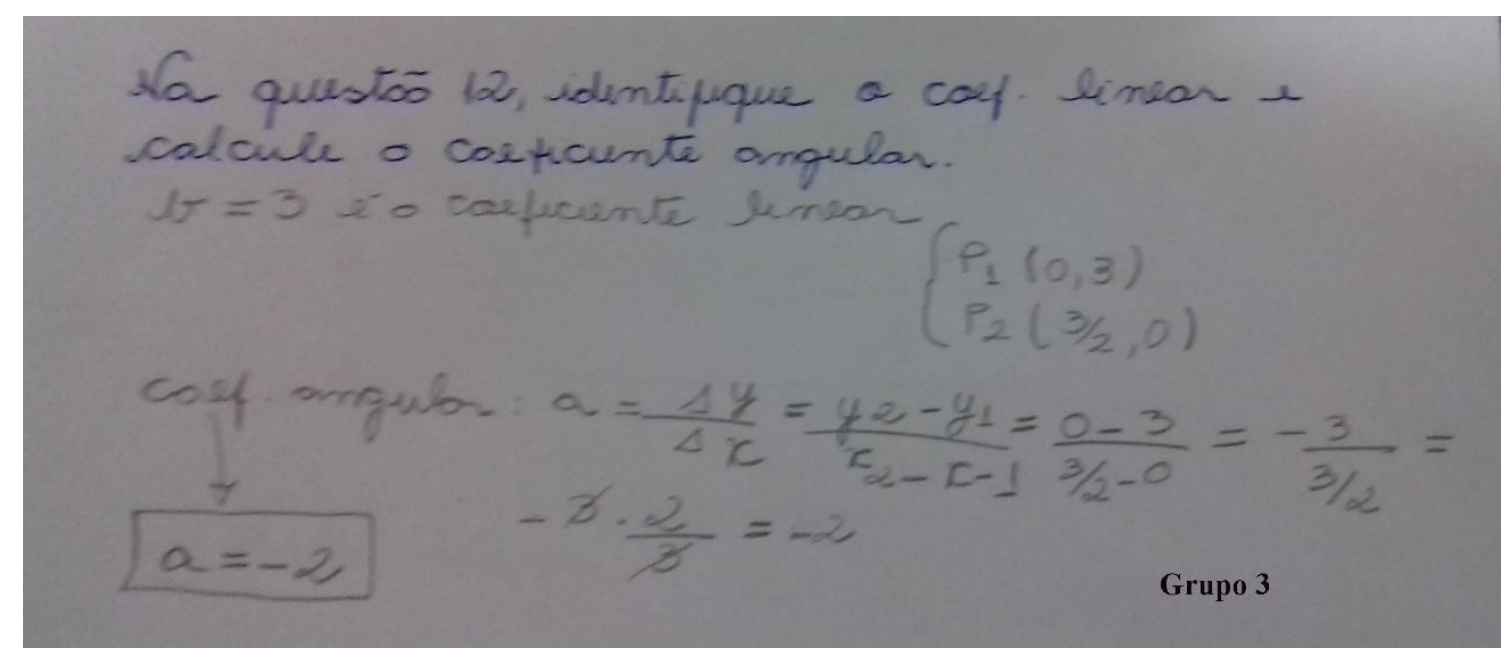

Figura 17

Questionário a priori disponível no Apêndice C.

Na questão 13, apenas houve um erro de cálculo do grupo 2 na coordenada $\mathbf{x}$ do vértice, mas todos os grupos desenvolveram bem a questão.

Foi trabalhado as operações algébricas extraídas das informações dos gráficos de parábolas. Nenhum dos componentes dos grupos sabiam como partir de uma representação gráfica de uma parábola, determinar a lei de formação e posteriormente o vértice. Aqui houve a necessidade de aula expositiva antes das modelagens. 


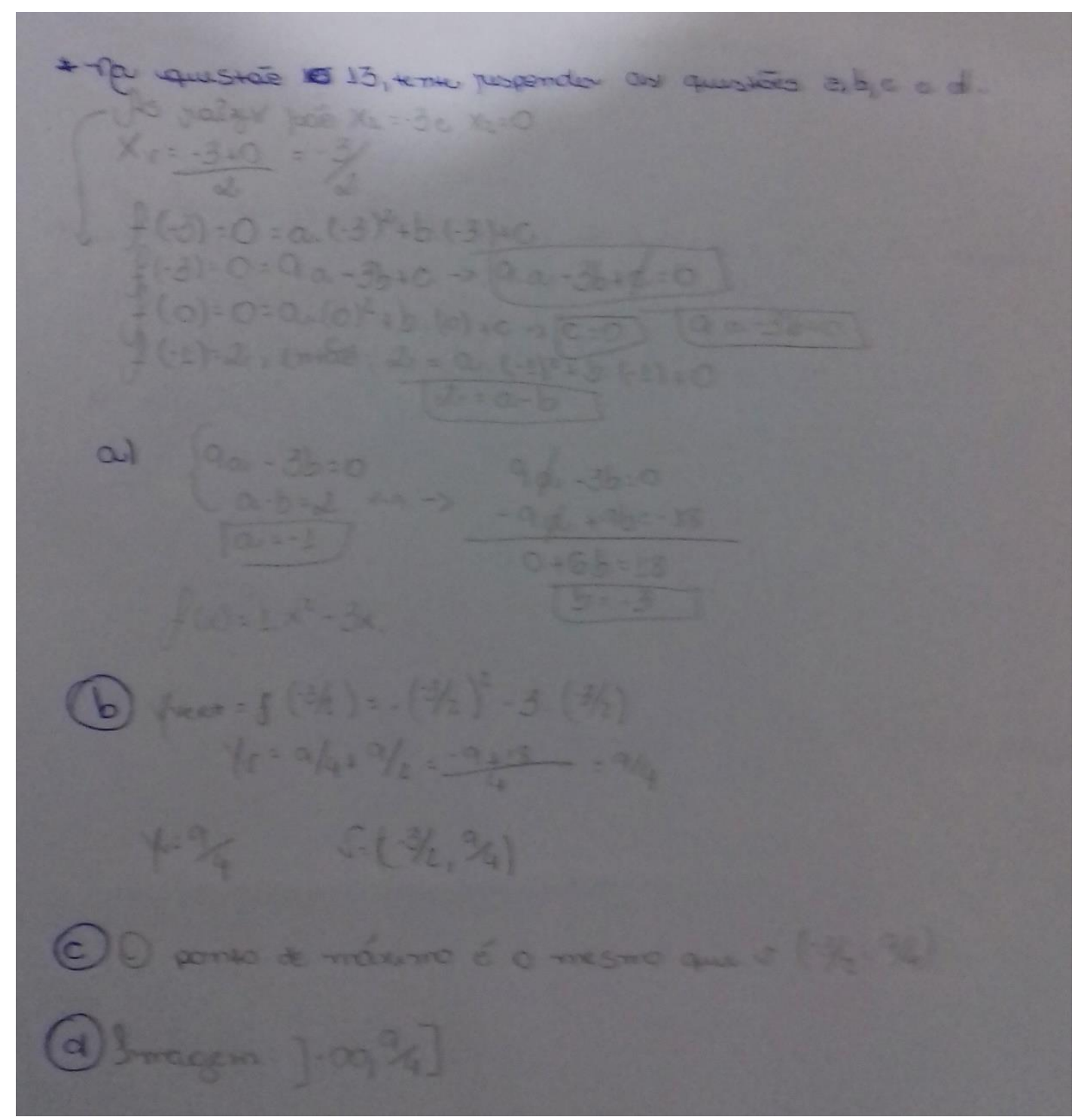

Figura 18

Questionário a priori disponível no Apêndice C.

A questão 14, sobre taxas de variação todos os grupos conseguiram resolver a questão, pois foi trabalhado minunciosamente o conceito de taxa de variação, haja vista que seria usado esse conceito como conhecimento prévio para a introdução do conceito de derivada.

Na questão 16-b, somente o grupo 3 conseguiu achar o valor da assíntota, mas não explicou por quê. Foi trabalhado no geogebra a localização da assíntota, mas acredito que houve falha de uma melhor explicação conceitual, o que resultou na incompreensão dos alunos desse conceito.

Na questão 18, somente o grupo 1 consegui perceber através do gráfico que 0 período da função trigonométrica era $\mathbf{p}=\boldsymbol{л}$ sendo que o grupo 3 tinha acertado a 
questão e o grupo 2 errou nas análises a priori e posteriori. Foi trabalhado bastante nas atividades de modelagem de um pêndulo o conceito de período, amplitude e frequência tanto via representação gráfica como algébrica, mas os conceitos de período e amplitude não foram adequadamente assimilados pelo grupo 2.

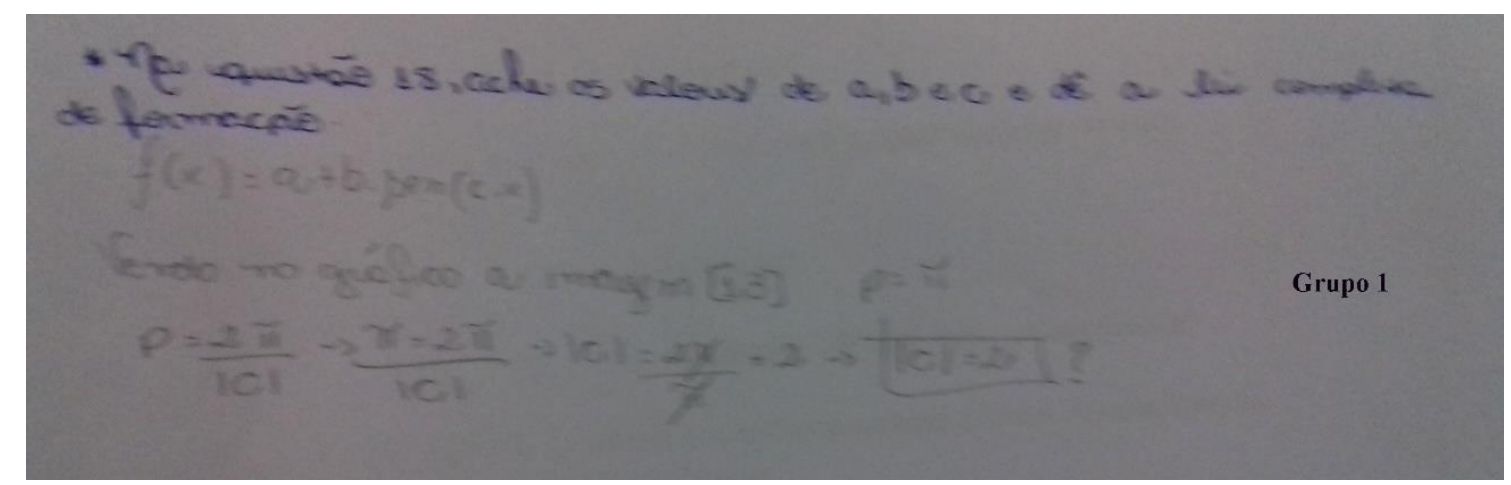

Figura 19

Questionário a priori disponível no Apêndice C.

Para cada grupo foi apresentada uma análise a posteriori do conhecimento sobre funções elementares. Essas análises estão disponíveis no Apêndice C.

\subsection{GRUPOS}

Os três grupos formados são da mesma sala do $3^{\circ}$ ano do ensino médio. Os estudantes vieram de escolas públicas, sendo que dois deles estão fazendo cursinho. O grupo1 teve um ótimo engajamento, a Elisa que está fazendo cursinho se empenhou bastante no experimento de laboratório e nas orientações semanais, facilitando bastante a realização da modelagem principalmente na fase de interação e matematização.

A Elisa já era aluna do colégio Anhanguera desde o 1ํano do ensino médio e está fazendo cursinho. A Giovanna era de outro colégio, gosta de teatro e física. O Victor também era de outro colégio e se interessa muito por ciência. O Lucas tem muito talento para Matemática. A Ingrid começou a trabalhar no início das atividades de modelagem, mas teve muito apoio do Lucas. A Isabelle gosta de Química e também já estudava no colégio Anhanguera. 
O grupo 2 teve um pouco de dificuldade para manipular o programa Tracker onde tive que explicar com mais detalhes a funcionalidade. A Giovanna era a mais engajada e conseguiu motivar o Victor e manter o ritmo da modelagem.

O grupo 3 apesar de deficiências na parte teórica, teve um comportamento excelente para aprender e finalizar cada fase da modelagem.

As atividades foram realizadas extraclasse, antes das aulas (17:00/19:30) todas as quintas feiras (8 semanas) e atividades para trabalhar no sábado com orientação via Skype e e-mail.

\subsubsection{Grupo 1}

O grupo 1 era composto por Isabelle e Elisa e a situação-problema foi relacionada a relação entre a variação da densidade da solução (água e cloreto de sódio) com a variação da quantidade de cloreto de sódio ( $\mathrm{Nacl}$ ) acrescentada a solução.

Na Modelagem Matemática do grupo 1 onde os alunos tiveram que fazer uma experiência e dela extrair dados para modelar uma função matemática, pretendíamos abordar novamente a noção de função exponencial dando ênfase à relação entre variáveis dependentes e independentes, usar tabelas e depois gerar gráficos, permitindo assim a conversão da função exponencial em diferentes registros de representação semiótica. Comparar o crescimento de uma função linear com a exponencial e as diferentes características de cada função. Introduzir o conceito de assíntota e velocidade de crescimento de uma função exponencial.

A produção, na íntegra desse grupo, está disponível no Apêndice D. Em relação as fases de modelagem do grupo 1, podemos destacar:

A fase 1 de interação não foi muito difícil, pois a Elisa já tinha conhecimento bem formado sobre densidade e empuxo, talvez por estar fazendo cursinho. $\mathrm{Na}$ fase de experimentação e extração de dados houve um erro na experiência do grupo, pois o cálculo do volume do ovo não foi bem feito e tiveram que refazer o experimento.

$\mathrm{Na}$ fase 3 de revisão de conceitos para matematização, houve dificuldade para encontrar a constante $k$ e na mudança de base de logaritmos, o que me levou a desenvolver os exercícios de comparação entre função linear e exponencial e aplicação de crescimento exponencial. 
$\mathrm{Na}$ fase 4 de validação, o grupo depois de fazer o gráfico da função pensou em se tratar de função linear, mas aplicando a ferramenta zoom do GeoGebra ficou claro que se tratava se de uma função exponencial de crescimento muito lento.

Já nas atividades no GeoGebra, foram focalizadas a manipulação de funções exponenciais, com a variação dos parâmetros das funções. Nenhuma das duas alunas conheciam bem o GeoGebra, mas como cada atividade já tinha os botões e barras deslizantes instaladas, facilitou muito a manipulação dos coeficientes da função e as subsequentes mudanças no gráfico. A maior dificuldade foi na compreensão da assíntota, pois graficamente não fica claro que o gráfico da função não toca a assíntota.

\subsubsection{Grupo 2}

O grupo 2 era composto por Victor e Giovana e a situação-problema foi relacionada a relação entre a distância percorrida pela bola e o tempo de queda da mesma e a relação entre a velocidade de um corpo em queda livre e o tempo de queda.

Na Modelagem Matemática do grupo 2 onde os alunos fizeram a análise do movimento do objeto em queda livre teve como objetivos: abordar novamente a noção de função, dando ênfase à relação entre as variáveis dependentes e independentes; identificar diferentes maneiras de representar uma relação funcional, através de gráficos e tabelas, mostrando a possibilidade de transitar entre elas, ou seja, fazer a conversão entre diferentes registros de representação semiótica; a partir das mudanças dos coeficientes da função, fazer o aluno perceber as mudanças no gráfico; levar o aluno a conjecturar a representação gráfica de determinados movimentos; através da análise gráfica, introduzir os conceitos de ponto máximo e ponto mínimo, intervalo de crescimento e decrescimento, simetria da parábola.

A produção, na íntegra desse grupo, está disponível no Apêndice E.

Em relação as fases de modelagem do grupo 1, podemos destacar:

A fase 1 de interação não teve problema pois o grupo conhecia bem os conceitos de cinemática e queda livre. Na fase 2 onde foi necessário usar o programa Tracker e transpor os dados para o GeoGebra e Excel, houve dificuldades, pois era tudo muito novo para eles, mas com orientação e atividades no computador, eles se saíram bem. Na fase 3 de matematização, houve bastante dificuldade em relação a 
taxa de variação linear, o que me levou a aplicar o exercício proposto de projeto de uma estrada.

$\mathrm{Na}$ fase 4 na parte de introdução ao conceito de taxa de variação instantânea o grupo compreendeu que a velocidade estava tendendo a um valor específico, pois os cálculos via fórmula da velocidade média levavam a esse valor, pois a medida que o tempo se aproximava de 1 segundo a velocidade se aproximava de $9,8 \mathrm{~m} / \mathrm{s}$. A parte da generalização da velocidade instantânea causou bastante dúvidas, o que era esperado pois envolve o conceito de limite que é muito abstrato. A intenção dessa atividade foi apenas introduzir o conceito de taxa de variação instantânea sem o rigor matemático e usando conhecimentos prévios da Física como queda livre, aceleração e velocidade média.

Já nas atividades no GeoGebra, notou-se que a Giovanna sabia interagir bem com o software, pelo menos nas funções básicas.

A atividade no GeoGebra referente a taxa de variação e coeficiente angular da reta foi fundamental para a compreensão desse conceito. As atividades sobre ponto de máximo e mínimo da parábola ajudou muito na compreensão de altura máxima de um projétil.

\subsubsection{Grupo 3}

O grupo 3 era composto por Lucas e Ingrid e a situação-problema foi relacionada a relação entre a idade da gestante e Síndrome de Down.

$\mathrm{Na}$ Modelagem Matemática do grupo 3 os alunos já partiram de dados reais de gráficos e tiveram que extrair informações relevantes para montar tabelas que depois seriam usadas para gerar a função por partes. Essa atividade exigiu várias operações de tratamento e manipulação matemática e posteriormente a conversão dos dados tratados em gráficos e fórmulas algébricas para depois fazer a Modelagem Matemática.

A produção, na íntegra desse grupo, está disponível no Apêndice $F$.

Em relação as fases de modelagem do grupo 1, podemos destacar:

$\mathrm{Na}$ fase 1 de interação foi necessário dedicar aula expositiva para o conceito de probabilidade condicional, o Lucas conhecia o conceito, mas a Ingrid nunca tinha visto. Na fase 2 na parte de matematização: definição de variáveis, houve bastante dificuldade, a montagem da tabela não é fácil e tive que ajudar bastante nessa fase. 
Na fase 3 de revisão teórica, revisamos a Regra de Cramer. Na fase 4 de resolução e validação houve muita dificuldade em partindo dos pontos plotados no gráfico, definir uma função por partes (quadrática). Essa superação foi feita usando o Geogebra com o posterior cálculo dos parâmetros das funções via Regra de Cramer

As atividades no GeoGebra, foram fundamentais para separar os dados em duas funções quadráticas, pois através da manipulação dos coeficientes fizemos a primeira "interpolação" dos pontos A B, C e posteriormente D, E e F. Após os cálculos dos parâmetros, o grupo verificou via gráfico que a função dava uma boa modelagem para os dados. As outras atividades no Geogebra desse grupo foram similares ao do grupo 2.

\subsection{CONCLUSÃO FINAL DAS ATIVIDADES}

Análise baseada na proposta pedagógica usando Modelagem Matemática e as teorias de Registros de Representação Semiótica de Raymound Duval e Aprendizagem Significativa de David Ausubel.

Baseado na teoria de Duval, as intervenções didáticas foram planejadas para que os alunos tivessem a maior quantidade possível de representações semióticas do objeto matemático em estudo, como língua natural, gráficos e equações algébricas. Procuramos satisfazer as três condições que a teoria propõe: a representação precisa ser identificável, ou seja, reconhecer na representação o que ela representa. $O$ tratamento que consiste em transformações internas ao registro, como resolver equações e manipular gráficos. A conversão que implica em transformar um registro de representação de um objeto matemático em outro, como exemplo: associar uma equação ao seu respectivo gráfico.

Essas atividades de transformações representacionais dos objetos matemáticos são fundamentais, pois é ela, segundo o autor, que conduz a mecanismos subjacentes à compreensão levando os alunos à refletirem sobre diferentes características de um objeto matemático associado às diferentes representações semióticas.

A coordenação de registros de representação mobiliza simultaneamente dois ou mais registros associados a um mesmo objeto matemático que em nosso estudo focou no conceito de função. $O$ objetivo também é de que os alunos percebessem que esses registros se complementam no sentido de que um tipo de registro pode 
expressar características ou propriedades do objeto matemático que não se manifestam claramente em outro. Por exemplo, na identificação de um ponto de máximo ou mínimo de uma função quadrática. A visualização da existência desse ponto fica bem mais evidente no registro gráfico do que na expressão algébrica associada à função, mas para determinar o valor exato desse ponto requer o uso de representação algébrica.

A Modelagem Matemática favorece a coordenação dos registros de representação, pois para modelar o aluno necessariamente terá que realizar diversas conversões e tratamentos sobre o mesmo objeto matemático.

Nas atividades de modelagem que realizamos, os alunos tiveram que expressar padrões e ideias na linguagem verbal na fase de interação e definição da situaçãoproblema para a linguagem matemática simbólica e gráfica nas fases de matematização e validação. Essas conversões de registros semióticos revelaram para os alunos as várias características do objeto matemático que estudavam. Um exemplo é a identificação de um ponto de máximo ou de mínimo em uma função quadrática a fim de responder um problema de otimização. A visualização da existência de pontos de máximo ou mínimo fica evidente no registro gráfico, mas para determinar o valor exato desses pontos precisamos da representação algébrica. O mesmo ocorre com as funções trigonométricas e exponenciais onde características específicas de cada objeto matemático era mais explicita ou útil para responder determinadas questões da situação problema.

Usando a teoria de Aprendizagem Significativa de Ausubel, procuramos partir daquilo que o aluno já sabe, ou seja, os conhecimentos prévios do aluno como base para a aprendizagem. Procuramos estabelecer as condições básicas para que a aprendizagem ocorra: o material organizado para o ensino deve ser significativo, a estrutura cognitiva do aluno deve dispor de conhecimentos prévios que permitam relacionar o que o aluno já sabe com os novos conhecimentos e o aluno deve apresentar predisposição para aprender. Quando faltou conhecimento prévio, foi usado aulas expositivas. O material organizado nas modelagens foi significativo para os alunos, pois o material de ensino era estimulante e motivador: vídeos, programas dinâmicos no Geogebra, Tracker e experimentos de laboratório.

A Modelagem Matemática estimula essa prática pois as atividades implicam a resolução de situações problema que não são resolvidas por meio de procedimentos 
predefinidos e cujas soluções não são previamente conhecidas, assim a resolução correta de um problema é indício de que ocorreu a aprendizagem significativa.

Para que o aluno consiga resolver cada fase da modelagem matemática, ele tem que entender os padrões e regularidades da situação-problema para poder expressá-los em linguagem matemática. Isso implica que a aprendizagem não foi mecânica onde usa se a memória e conceitos já definidos para aplicar em questões simples.

Nas atividades fizemos uso intensivo do programa Geogebra, pois a Modelagem Matemática requer o uso desse tipo de ferramenta, pois muitas vezes, os cálculos são difíceis, os gráficos e as manipulações dos parâmetros da função são facilmente realizados com a ajuda desse software. A possibilidade de experimentar, visualizar e coordenar de forma dinâmica as representações algébricas, gráficas e tabulares são vantagens no sentido que o tempo para realizar essas tarefas fica muito reduzido permitindo que os alunos concentrem as suas atenções nas características de cada representação semiótica facilitando a compreensão do objeto matemático.

As 18 questões (referentes ao conceito de função e conhecimentos das funções elementares) foram apresentadas aos três grupos logo após uma breve explanação sobre o que é Modelagem Matemática e como iríamos trabalhar. Somente após as atividades de Modelagem Matemática e exercícios sobre funções, apresentamos novamente aos grupos, as questões onde haviam problemas conceituais ou apresentaram conceitos não completos para serem revisitadas por eles.

De um modo geral houve melhora na capacidade dos grupos em transitar entre os registros de representação gráfica e algébrica e vice-versa, aprenderam a identificar as variáveis dependentes e independentes dentro do contexto de uma situação problema. Trabalharam bastante as variações dos coeficientes das funções elementares e suas respectivas mudanças no registro gráfico, ganhando assim uma visão mais ampla e dinâmica do que acontece com os gráficos variando cada coeficiente da função.

Quando faltavam conhecimentos prévios, eram dadas aulas expositivas tanto de Física como de Matemática. Dois alunos estão fazendo cursinho, o que facilitou a fase de interação dos grupos 1 e 2 pois exigiam conceitos da Física de Empuxo e Movimento Uniformemente Variado. Para o grupo 3 foi necessário revisão sobre probabilidade condicional e regra de Cramer. 
A Modelagem Matemática favoreceu a coordenação de vários registros de representação semiótica, pois para modelar os alunos tiveram que realizar diversas conversões e tratamentos sobre o mesmo objeto matemático.

Como o material organizado nas modelagens foi significativo para os alunos, pois o material de ensino era estimulante e motivador: vídeos, programas dinâmicos no Geogebra, Tracker e experimentos de laboratório. A existência de conhecimentos prévios dos alunos foi importante, apesar de que alguns conceitos tiveram que ser revisitados para a total compreensão das fases de interação e matematização.

A cooperação dos alunos nos seus respectivos grupos permitiu uma sinergia e troca de conhecimentos entre eles que favoreceu a aprendizagem de todos.

\subsubsection{Dificuldades no processo de Modelagem Matemática}

A fase de matematização foi a mais difícil para os três grupos, pois definir o problema e encontrar as variáveis mais adequadas para a formalização da situação problema era uma tarefa que nenhum deles havia executado. Nessa fase a orientação do professor foi crucial para não barrar a motivação dos alunos, fazendo sugestões sem dar respostas prontas, os grupos aos poucos encontraram uma boa solução.

O grupo 1 teve que refazer o experimento da densidade, pois no primeiro experimento erraram muito na medida do volume do ovo, que foi corrigido com a correta manipulação da proveta e Becker. Houve erros de cálculo ao fazer a tabela de densidade e concentração, mas corrigida na próxima aula. Ao plotar o gráfico no GeoGebra da densidade x massa de Nacl, o grupo pensou em se tratar de uma função linear, mas ao sugerir que usassem a ferramenta zoom, logo perceberam que era uma função exponencial. A fase de matematização foi a mais difícil para eles, pois não estavam acostumados a identificar com precisão as variáveis relevantes na situação problema.

O grupo 2 teve dificuldade esperada na introdução ao conceito de derivada, pois era um conceito que nunca tinham visto. O mesmo ocorreu com os outros dois grupos quando ao final das atividades apresentei a eles esse conceito de derivada, mas foi dado um passo relevante como introdução ao conceito, pois o modo de apresentação iniciou com o movimento de queda livre, conceito prévio bem sedimentado para todos os alunos. Partindo do conceito de velocidade média e 
usando o conceito de taxa de variação foi desenvolvida aos poucos a ideia de taxa de variação instantânea.

Como o grupo 3 partiu de dados extraídos de uma fonte, a dificuldade maior foi na estruturação das ferramentas matemáticas que seriam usadas para responder o problema. Como seria necessário saber matrizes, regra de Cramer e probabilidade condicional, foi feita uma revisão com o grupo. Eles já tinham aprendido esses conceitos, mas através de um breve diagnóstico de conhecimentos prévios, percebi que seria necessário um pouco mais de exercícios para seguir na fase de matematização.

\subsubsection{Efeito sinérgico das atividades de Modelagem Matemática}

A vantagem do uso de Modelagem Matemática reside no fato de que ela mobiliza quase que simultaneamente várias competências cognitivas, como reconhecer padrões e relações entre as variáveis, trabalhar em grupo, requer dois ou mais registros de representação de um mesmo objeto matemático, estimula a interdisciplinaridade e desenvolve a independência de pensamento que é tão crucial nos tempos atuais.

Usar Modelagem Matemática não é substituto de aulas expositivas que são imprescindíveis, mas pode ser usado como alternativa pedagógica e em paralelo com as aulas convencionais para agregar mais competências cognitivas e consolidação de conceitos matemáticos. As atividades de modelagem foram feitas em período extraclasse, mas nada impede que o professor reserve algumas aulas para inserir Modelagem Matemática. Um dos objetivos desse trabalho foi incorporar ao conceito de função a abordagem dinâmica e variacional que é subutilizada no ensino básico e para essa tarefa a Modelagem Matemática gerou as condições necessárias para esse fim.

Como professor aprendi muito com essa experiência, pois cada fase da modelagem com suas dificuldades trazidas pelos alunos e o modo de superá-las sem dar a resposta pronta a eles exigiu bastante estratégia para criar situações de aprendizagem onde o protagonista era o aluno. Com cada passo vencido, os alunos ganharam confiança e autonomia, outro fator fundamental na educação.

Citando uma frase de Freudenthal "é preciso dar significado matemático para a organização da realidade", as atividades de Modelagem Matemática, principalmente 
a fase de matematização favorece a aquisição desse processo ordenador da realidade.

Aproveitando deixo uma contribuição para futuras atividades. No Apêndice G segue uma sugestão de atividade de Modelagem Matemática para professores. A atividade que será descrita não foi realizada nesse trabalho, pois não havia tempo hábil, principalmente devido à complexidade da fase de interação onde vários conceitos de astronomia seriam necessários.

\subsection{OUTRAS ATIVIDADES}

Além das atividades apresentadas até aqui. Desenvolvemos atividades que envolvem: Modelagem Trigonométrica, uso do GeoGebra referente a Introdução do conceito de derivada e estudo do Pêndulo. Elas estão disponíveis no Apêndice $\mathrm{H}$. 


\section{CONSIDERAÇÔES FINAIS}

Esse projeto além da sua finalidade principal que foi dar uma perspectiva mais dinâmica e variacional ao conceito de função, visou estimular nos alunos a capacidade de matematização, que como esperado foi a fase mais difícil para todos os grupos, haja vista, que não é comum no ensino médio esse tipo de trabalho didático. Outro objetivo subjacente a esse projeto, foi desenvolver nos alunos a capacidade de fazer a conversão de um registro de representação de um objeto matemático em outro que segundo Duval é fator essencial para a efetiva compreensão do objeto matemático em estudo. A modelagem matemática requer esse tipo de atividade, pois foi necessário que os alunos fizessem várias conversões da função algébrica para a representação gráfica, e além disso visualizavam as mudanças nos coeficientes das funções e sua respectiva consequência no gráfico dessa função. Nesse trabalho tive o cuidado de verificar quais eram os conhecimentos prévios dos alunos e quando não o possuíam era ministrado aula expositiva para depois dar sequência nas fases de modelagem matemática.

Independentemente da análise a posterior do questionário aplicado após as atividades de modelagem matemática, que revela uma boa melhora no conceito de função e conhecimento e aplicação de funções elementares, a própria dinâmica das atividades mobilizou vários recursos cognitivos dos alunos. Penso que houve um efeito sinérgico das atividades de Modelagem Matemática. A vantagem do uso de Modelagem Matemática reside no fato de que ela mobiliza quase que simultaneamente várias competências cognitivas, como reconhecer padrões e relações entre as variáveis, trabalhar em grupo, requer dois ou mais registros de representação de um mesmo objeto matemático, estimula a interdisciplinaridade e desenvolve a independência de pensamento que é tão essencial na educação atual.

Usar Modelagem Matemática não é substituto de aulas expositivas que são imprescindíveis, mas pode ser usado como alternativa pedagógica e em paralelo com as aulas convencionais para agregar mais competências cognitivas e consolidação de conceitos matemáticos.

Como professor aprendi muito com essa experiência, pois cada fase da modelagem com suas dificuldades trazidas pelos alunos e o modo de superá-las sem dar a resposta pronta a eles exigiu bastante estratégia para criar situações de aprendizagem onde o protagonista era o aluno. Com cada passo vencido, os alunos ganharam confiança e autonomia, outro fator fundamental na educação. 


\section{REFERÊNCIAS BIBLIOGRÁFICAS}

ALMEIDA, L. M.; BRITO, D.S. Atividades de Modelagem Matemática: que sentido os alunos podem Ihe atribuir? Ciência e Educação (Unesp), v. 11, 2005, p. 1-16.

ALMEIDA, L. M.; BRITO, D.S. O conceito de função em situações de modelagem matemática. Revista Zetetikê, v.12, n.23, p.42-41, 2004.

ANTON, Howard. Cálculo. 8 ed. Porto Alegre: Bookman, 2007. p. 452-494.

AUSUBEL, D. P.; NOVAK, J. D.; HANESIAN, H. Psicologia educacional. Tradução Eva Nick. Rio de Janeiro: Interamericana, 1980.

BARBOSA, J. C. Modelagem matemática: Concepção e experiências de futuros professores. 253.f. Tese doutorado. Educação matemática. USP-SP, 2001.

BARBOSA, J. C. Modelagem na Educação Matemática: contribuições para o debate teórico. In: Anais da 24를 Reunião Anual da ANPED. Rio de Janeiro: ANPED, 2001. 1 CD.

BASSANEZI, R. C. Ensino-Aprendizagem com Modelagem Matemática. Editora Contexto, São Paulo, 2002.

BLUM, W.; NISS, M. Applied mathematical problem solving, modeling, applications, and links to other subjects - State, trends and issues. Educational Studies in Mathematics, v. 22, 1991, p. 37-68.

CABRAL, T.C.B. A lógica da intervenção nos processos de aprendizagem. Tese de Doutorado. USP- SP, 1998.

CARAÇA, B.DE J. Conceitos fundamentais da matemática. 9, ed. Lisboa: libraria Sá da Costa, 1948. 
CHARLOT, B. Da relação com o saber: elementos para uma teoria. Porto Alegre: Artmed, 2000.

CONNALLLY, E.; HUGHES-HALLETT, D.; et al. Funções para modelar variações: uma preparação para o cálculo. 3ª Edição, Editora LTC, Rio de Janeiro, 2009.

DAVIS, P. J. \& HERSH, R. A Experiência Matemática. 2 ed. Rio de Janeiro: Livraria Francisco Alves S.A, 1985.

DUVAL, R. Registros de representação semiótica e funcionamento cognitivo da compreensão em matemática. In: MACHADO, S. D.A. (Org.). Aprendizagem em matemática: registros de representação semiótica. Campinas: Papirus, 2003, p.11-33.

FLEISCH, D. \& KREGENOW J. A Student's Guide to the Mathematics of Astronomy. Cambridge UK: Cambridge University Press, 2013.

FREUDENTHAL, H. Mathematics as an Education task. Dordrecht: Kluwer,1973

GUIDORIZZI, H.L. Um Curso de Cálculo. 2 ed. Rio de Janeiro: LTC - Livros Técnicos e Científicos Editora S.A, 1985.

KAISER, G.; SRIRAMAN, B. A global survey of international perspectives on modelling in mathematics education. In: Zentralblatt fur Didaktik der Mathematik, v. 38, n. 3, 2006, p. 302-10.

RANDALL, DK. Física: Uma abordagem estratégica. São Paulo: Companhia Editora LTDA, 2009.

LACHINI, J. Subsídios para explicar o fracasso de alunos em Cálculo. In: LAUDARES, J. B.; LACHINI, J. (Orgs.); Educação Matemática: a prática educativa sob o olhar de professores de Cálculo. Belo Horizonte: FUMARC, 2001. Cap.6, p.146-190.

MACHADO, S. D.A (Org.). Educação Matemática - Uma (nova) Introdução. São Paulo: EDUC, 2012. 
MORETTO, V. P. Construtivismo: a produção do conhecimento em aula - RJ, 2003.

SIERPINSKA, A. Humanities Students and Epistemological Obstacles Related to Limits. Educational Studies in Mathematics, 1987.

VYGOSTSKY, L.S. A formação Social da mente. 6 ed. São Paulo: Livraria Martins Fontes, 1998.

ZUFFI, E. M. Alguns Aspectos do desenvolvimento histórico do conceito de função. Inc: Revista Educação Matemática. Ano 8, n 9-10, Abril, 2001. 

Apêndice A

Fundamentação teórica envolvida no processo de ensino-aprendizagem das atividades 



\subsection{O CONCEITO DE FUNÇÃO}

A definição de função como correspondência entre variáveis, independente de uma expressão analítica, foi dada por Peter Dirichlet em que, afirmou: "y é uma função de uma variável $\mathbf{x}$, definida no intervalo $\mathbf{a}<\mathbf{x}<\mathbf{b}$, se para cada valor da variável $\mathbf{x}$, nesse intervalo, corresponde um valor definido da variável $\mathbf{y}$, sendo irrelevante o modo como esta correspondência é estabelecida". (KLEINER, 1989, p. 291, apud RÊGO, 2000, p. 54)

Essa definição apresentada por Dirichlet foi, explicitamente, a primeira a limitar o domínio de uma função a um intervalo, o que antes era compreendido por todo o conjunto dos reais, além disso, esse matemático foi o primeiro a trabalhar a noção de função como uma correspondência arbitrária.

Em meados do século $X X$, essa definição começou a ser questionada, particularmente no que se refere à frase "... sendo irrelevante o modo como esta correspondência é estabelecida".

Os textos e publicações matemáticos do século $X X$ sofreram a influência da filosofia formalista. Para exemplificar esse formalismo, em 1939, encontra-se em um dos textos publicados pelo grupo Bourbaki, Théorie des Ensembles, a seguinte definição de função, apresentada por meio da linguagem da Teoria dos Conjuntos:

\footnotetext{
Sejam $\mathbf{E}$ e $\mathbf{F}$ dois conjuntos, podendo ser distintos ou não. Uma relação entre uma variável $\mathbf{x}$ de $\mathbf{E}$ e uma variável $\mathbf{y}$ de $\mathbf{F}$, é designada uma relação funcional em $\mathbf{x}$ se para cada $\mathbf{x} \in \mathbf{E}$, existe um único $\mathbf{y} \in \mathbf{F}$ que está na relação dada associado a $\mathbf{x}$. Denomina-se função à operação que, de alguma forma, associa a cada elemento $\mathbf{x} \in \mathbf{E}$ o elemento $\mathbf{y} \in \mathbf{F}$, o qual encontra-se ligado a $\mathbf{x}$ na relação considerada; diz-se que $\mathbf{y}$ é o valor da função relativo ao elemento $\mathbf{x}$, e que a função está determinada pela relação funcional dada. Duas relações funcionais equivalentes determinam a mesma função. (KLEINER, 1989, p. 299, grifo nosso)
}

Para concluir, de acordo com Fossa (1998, apud REGO, 2000), ao se fazer um levantamento histórico pode-se perceber três diferentes momentos no que se refere à evolução do conceito de função:

1. como dependência entre variáveis;

2. como expressão analítica;

3. como uma relação entre conjuntos. 
Em seu livro, Guidorizzi (1998) inicia o capítulo mencionando que entende função como sendo uma terna $(\mathbf{A}, \mathbf{B}, \mathbf{a} \rightarrow \mathbf{b})$ em que $\mathbf{A}$ e $\mathbf{B}$ são dois conjuntos e $\mathbf{a} \rightarrow \mathbf{b}$, uma regra que permite associar a cada elemento $\mathbf{a}$ de $\mathbf{A} \underline{\text { um único }} \mathbf{b}$ de $\mathbf{B}$. Em seguida, o autor define que o conjunto $A$ é o domínio de $f$ e o conjunto $B$ o contradomínio de $\mathbf{f}$, assim, aponta que uma função de uma variável real a valores reais representa uma função $\mathbf{f}: \mathbf{A} \rightarrow \mathbf{B}$, na qual $\mathrm{A}$ e B são subconjuntos de $\mathfrak{R}$, destacando ainda que $\mathbf{x}$ é a variável independente, e $\mathbf{y}$, a variável dependente.

Portanto, adotamos como definição de função: Uma função f é uma relação que associa a cada elemento $\mathbf{x}$ de um conjunto $\mathbf{D}$, chamado domínio, um único elemento $f(x)$ de um conjunto $\mathbf{C}$, denominado contradomínio.

E, as características de uma função, considerando $\mathbf{D}$ o domínio e C o contradomínio de uma função $\mathbf{f}$, que associa a $\mathbf{x} \in \mathbf{D}$ um valor $\mathbf{y} \in \mathbf{C}$.

1. Todo elemento de $\mathbf{D}$ deve estar associado a um elemento de $\mathbf{C}$ (ou seja, $f$ deve estar definida para todo elemento $\mathbf{x}$ do domínio $\mathbf{D}$ ).

2. Nem todo elemento de $\mathbf{C}$ precisa estar associado a um elemento de $\mathbf{D}$

3. Um elemento de $\mathbf{D}$ não pode estar associado a dois elementos de $\mathbf{C}$ (ou seja, a função não pode fornecer dois valores de y para um único $\mathbf{x}$ ).

4. Um elemento de $\mathbf{C}$ pode estar associado a mais de um elemento de $\mathbf{D}$ (ou seja, dois valores de $\mathbf{x}$ podem estar associados a um mesmo $\mathbf{y}$ ).

\subsection{VARIÁVEIS DEPENDENTES E INDEPENDENTES}

Para uma dada entrada $\mathbf{x}$, a saída de uma função $\mathbf{f}$ é denominada valor de $\mathbf{f}$ em $\mathbf{x}$, ou imagem de $\mathbf{x}$ em $\mathbf{f}$. Muitas vezes denotamos a saída de uma função por uma letra, digamos $y$, e escrevemos: $y=f(x)$

Essa equação expressa $\mathbf{y}$ como uma função de $\mathbf{x}$; a variável $\mathbf{x}$ é denominada variável independente de $\mathbf{f}$ ou argumento de $\mathbf{f}$, e a variável $\mathbf{y}$ é denominada variável dependente de $\mathbf{f}$.

Consideraremos apenas funções em que as variáveis independente e dependente são números reais, onde dizemos que fé uma função real de uma variável real. 


\subsubsection{O teste da reta vertical}

Nem toda curva no plano xy é o gráfico de uma função. Por exemplo, considere as curvas abaixo:
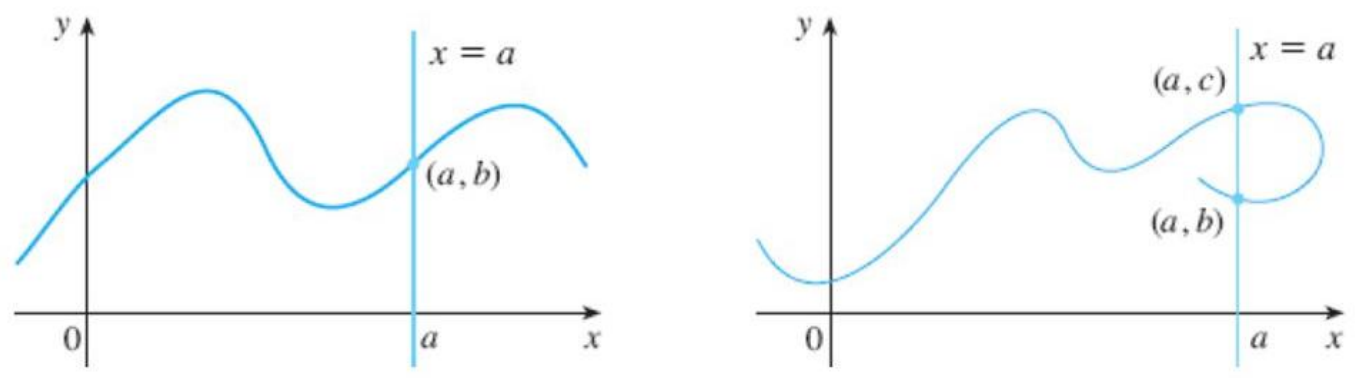

Figura 20 - Teste da reta vertical. O primeiro gráfico representa função e o segundo gráfico não representa função.

Fonte: Elaboradas pelo autor com o auxílio dos programas Geogebra, Excel e Graph. Foram salvas em jpeg.

O teste da reta vertical é uma curva no plano xy é o gráfico de uma função f se e somente se nenhuma reta vertical intersecta a curva mais de uma vez. Observe que a Figura 3 não passa pelo teste da reta vertical, logo a equação: $\mathbf{x}^{2}+\mathbf{y}^{2}=\mathbf{2 5}$ não define y como função de $\mathbf{x}$. Entretanto, se considerarmos a circunferência como a união das duas semicircunferências: $y=\sqrt{25-x^{2}}$ e $y=-\sqrt{25-x^{2}}$. Cada uma definirá y como uma função de $\mathbf{x}$, veja a Figura 4.

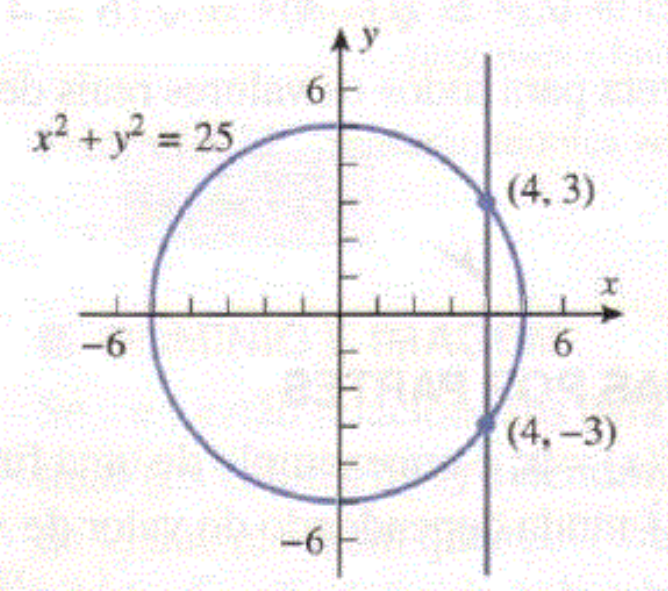

Figura 21 - Teste da reta vertical - não define função.

Fonte: Elaboradas pelo autor com o auxílio dos programas Geogebra, Excel e Graph. Foram salvas em jpeg. 

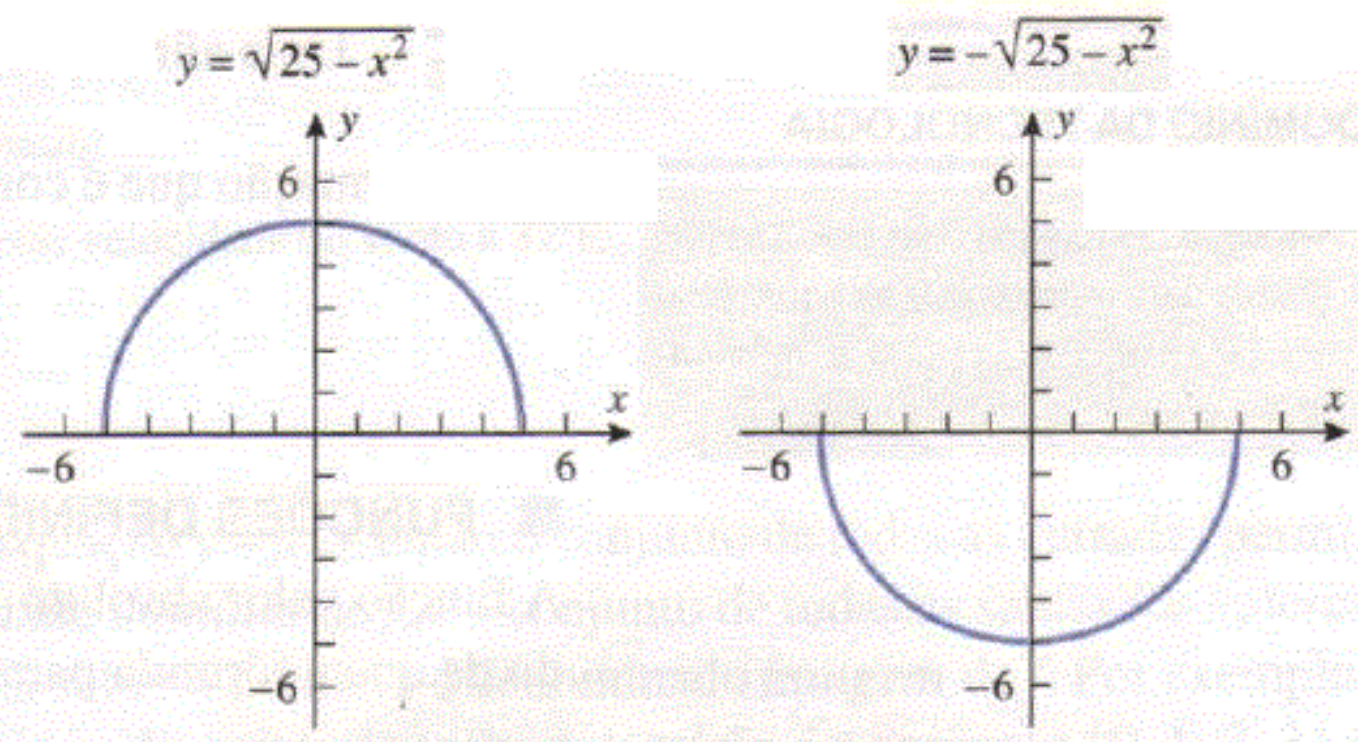

Figura 22 - Teste da reta vertical - define função.

Fonte: Elaboradas pelo autor com o auxílio dos programas Geogebra, Excel e Graph. Foram salvas em jpeg.

\subsection{DOMÍNIO E IMAGEM}

Se $\mathbf{x}$ e $\mathbf{y}$ estão relacionados pela equação $\mathbf{y}=\mathbf{f}(\mathbf{x})$, então o conjunto de dados de todas as entradas permitidas (valores de $\mathrm{x}$ ) é denominado domínio de $\mathbf{f}$, e o conjunto de todas as saídas (os valores de $y$ ) que resultam quando $\mathbf{x}$ varia sobre 0 domínio é denominado imagem de $\mathbf{f}$.

Às vezes considerações físicas ou geométricas impõem restrições sobre as entradas permissíveis de uma função. Por exemplo se $\mathbf{y}$ denota a área de um quadrado de lado $\mathbf{x}$, então essas variáveis estão relacionadas pela equação $\mathbf{y}=\mathbf{x}^{2}$ $O$ fato de que os comprimentos devem ser números não-negativos impõe a exigência que $x \geq 0$

Por exemplo, se $y=\frac{1}{x}$, então $\mathrm{x}=0$ não é uma entrada válida, pois divisão por zero não está definida, e se $y=\sqrt{x}$ então os valores negativos de $\mathbf{x}$ não são entradas válidas, pois produzem valores imaginários de $\mathbf{y}$, e vamos apenas trabalhar com funções reais de variável real. 


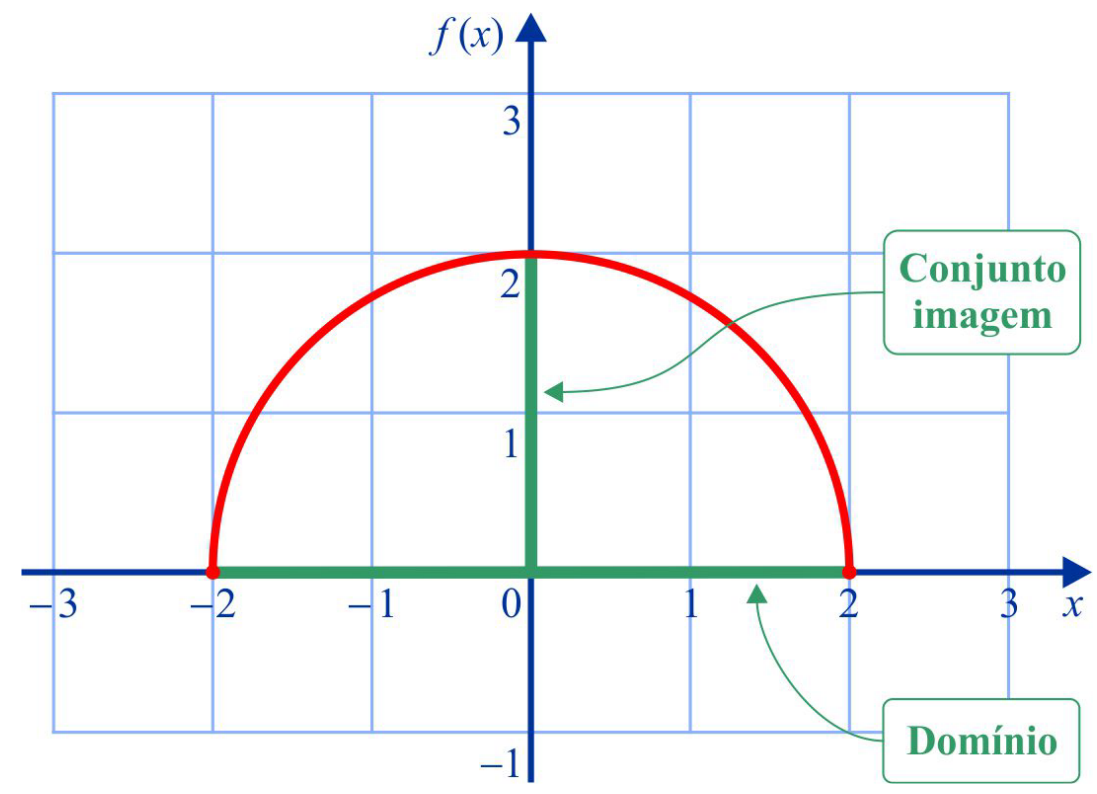

Figura 23 - Destaque conjunto imagem e domínio da função $F(x)=\sqrt{4}-x^{2}$.

Fonte: Elaboradas com o auxílio dos programas Geogebra, Graph, Adobe Photoshop e Corel Draw

O gráfico da função é a curva vermelha mostrada na Figura 5. Observe que f não está definida para $\mathrm{x}<-2$ e $\mathrm{x}>2$ pois, nesses casos, o termo dentro da raiz é negativo. Logo o domínio de $\mathbf{f}$ é o intervalo verde_indicado no eixo- $x$, ou seja, $\mathbf{D}=\{\mathbf{x}$ $\in \mathfrak{R} l-2 \leq \mathrm{x} \leq 2\}$.

O conjunto imagem de f é o conjunto de valores sobre o eixo-y relacionados a pontos da curva. Esse conjunto também está indicado em verde, e corresponde a Im $=\{y \in \Re / 0 \leq y \leq 2\}$.

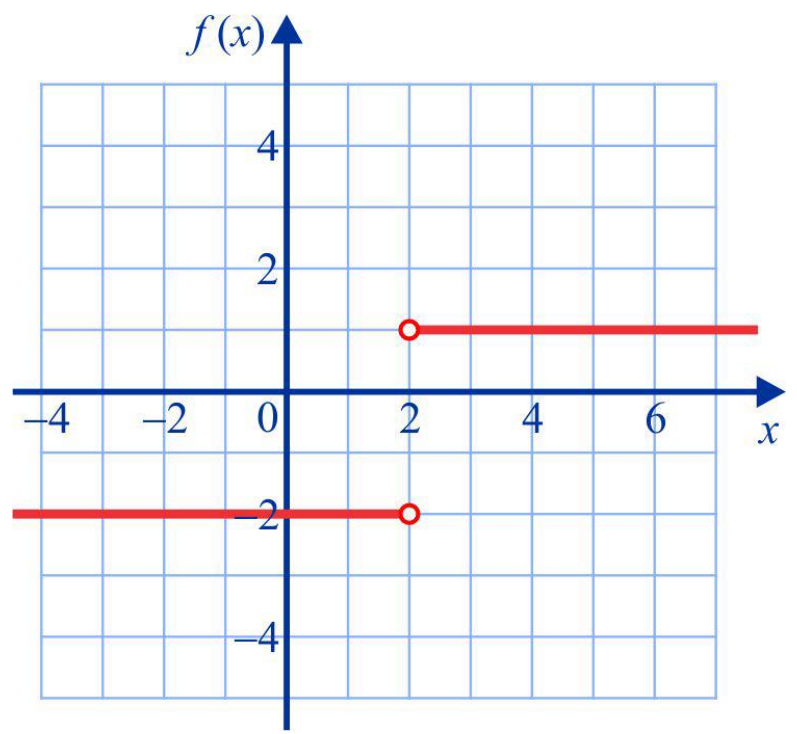

Figura $24-D=\{x \in \Re / x \neq 2\}$ e $\operatorname{Im}=\{-2,1\}$. 
Fonte: Elaboradas pelo autor com o auxílio dos programas Geogebra, Excel e Graph. Foram salvas em jpeg.

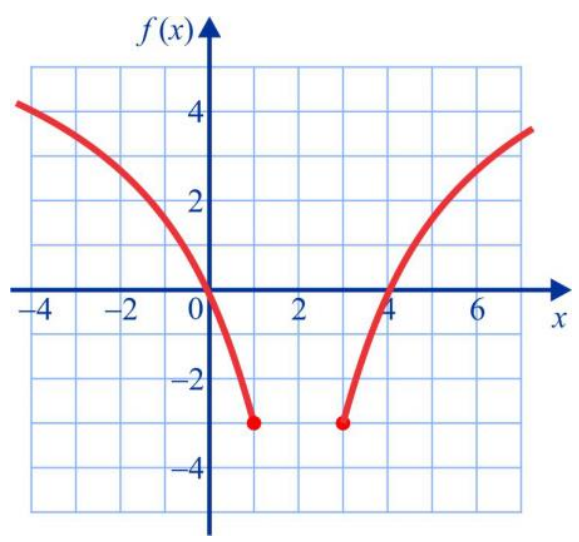

Figura $25-D=\{x \in \Re / x \leq 1$ ou $x \geq 3\}$ e $\operatorname{Im}=\{y \in \Re / y \geq-3\}$.

Fonte: Elaboradas com o auxílio dos programas Geogebra, Graph, Adobe Photoshop e Corel Draw

\subsubsection{O efeito de operações algébricas sobre o Domínio}

Expressões algébricas são, frequentemente, simplificadas cancelando fatores comuns no numerador e denominador. Entretanto, devemos tomar cuidado com tais simplificações pois elas podem alterar o domínio. O domínio natural da função abaixo consiste em todos os números reais, exceto $x=2$, pois $\mathrm{f}(2)$ não está definida.

$$
f(x)=\frac{x^{2}-4}{x-2} \rightarrow f(x)=\frac{(x-2)(x+2)}{x-2} \rightarrow f(x)=(x+2), \operatorname{com} x \neq 2
$$




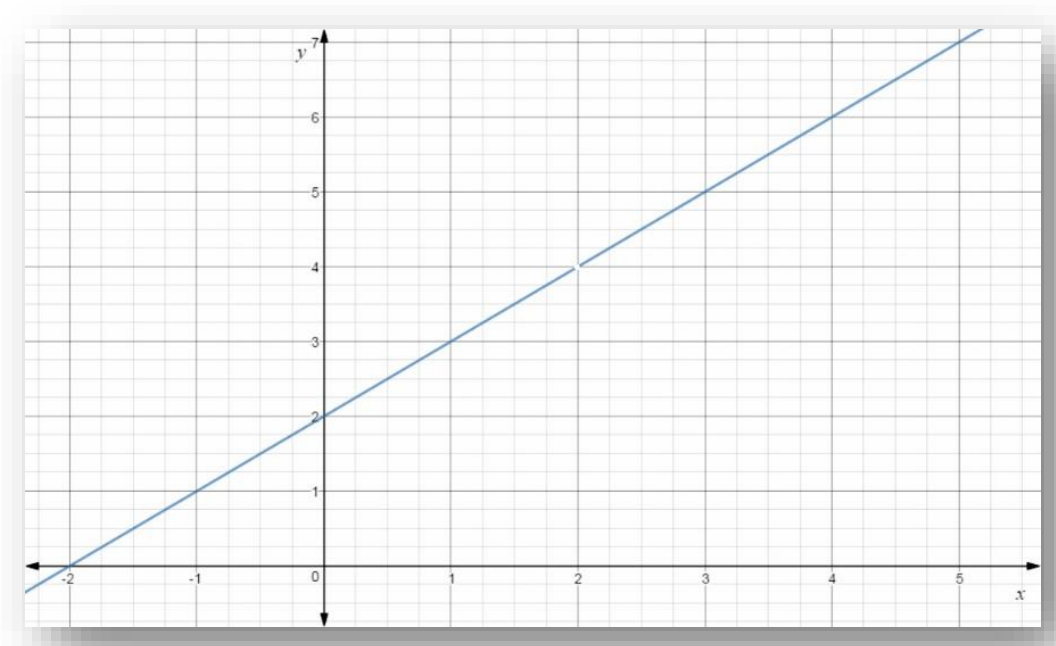

Figura 26 - Esboço de $f(x)=x+2(\operatorname{com} x \neq 2)$.

Fonte: Elaboradas com o auxílio dos programas Geogebra, Graph, Adobe Photoshop e Corel Draw

\subsection{CRESCIMENTO E DECRESCIMENTO}

\subsubsection{Intervalos de crescimento e decrescimento}

Seja $\mathbf{f}$ uma função definida em um intervalo $D$. Dizemos que:

1. $f$ é crescente em $D$ se, dados quaisquer $x 1$ e $x 2$ em $D$, tais que $x 1<x 2$, tivermos $f(x 1)<f(x 2)$;

2. $f$ é decrescente em $D$ se, dados quaisquer $x 1$ e $x 2$ em $D$, tais que $x 1<x 2$ tivermos $f(x 1)>f(x 2)$;

3. fé constante em $D$ se, dados quaisquer $x 1$ e $x 2$ em $D$, tivermos $f(x 1)=f(x 2)$;

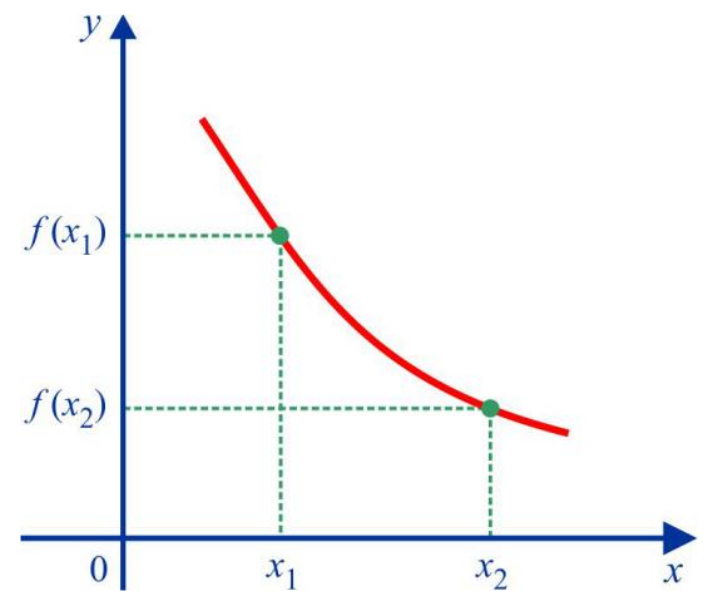

Figura 27 - Função decrescente.

Fonte: Elaboradas com o auxílio dos programas Geogebra, Graph, Adobe Photoshop e Corel Draw 


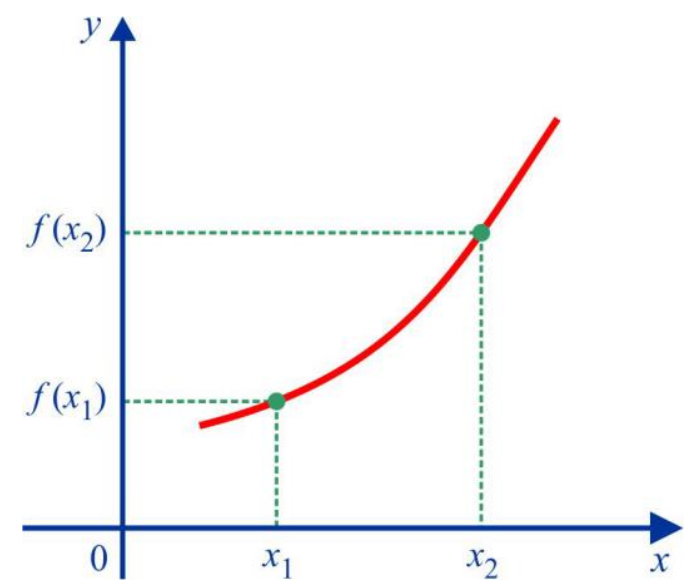

Figura 28 - Função crescente.

Fonte: Elaboradas com o auxílio dos programas Geogebra, Graph, Adobe Photoshop e Corel Draw

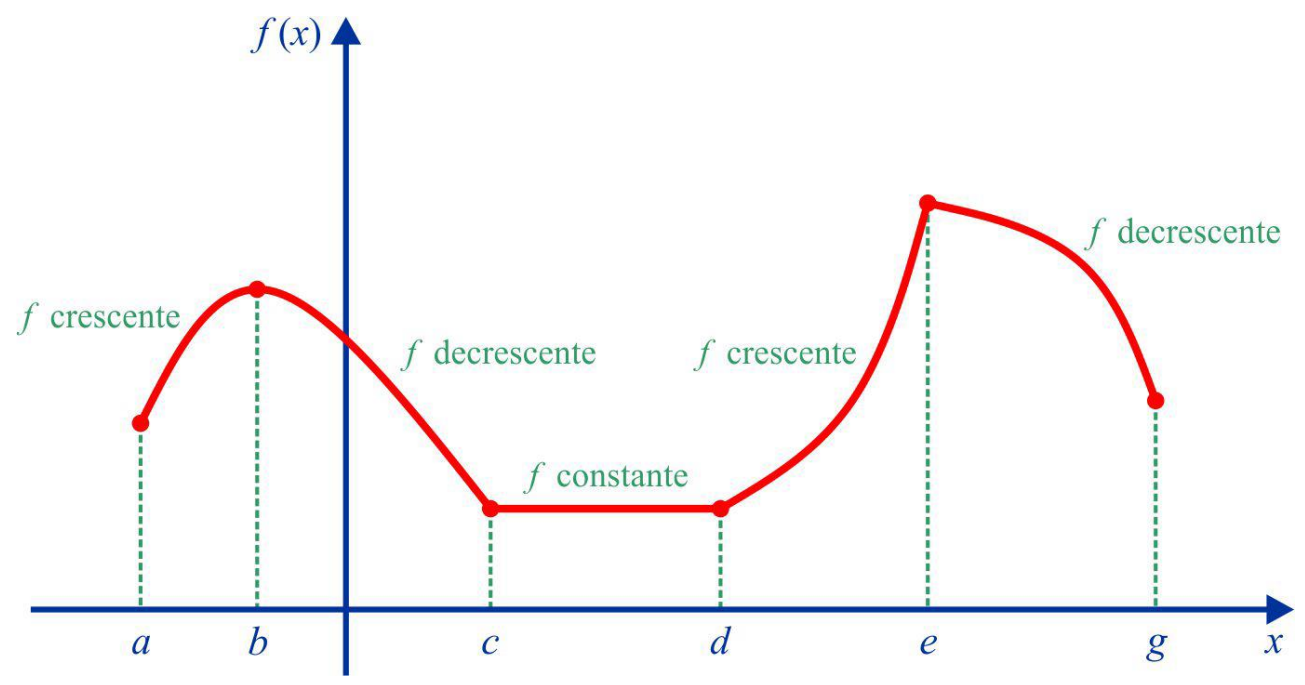

Figura 29 - Função com trechos crescentes, decrescentes e constante.

Fonte: Elaboradas com o auxílio dos programas Geogebra, Graph, Adobe Photoshop e Corel Draw

\subsubsection{Máximos e mínimos}

Assim como é importante saber em que intervalos uma função aumenta ou diminui, também é relevante conhecer seu valor máximo ou mínimo.

Vejamos como caracterizar esses pontos extremos. 
1. O valor é um máximo local - ou máximo relativo - de f se existe um intervalo $(a, b)$, contendo $\overline{\boldsymbol{x}}$, tal que $f(\overline{\boldsymbol{x}}) \geq f(x)$ para todo $\mathbf{x} \in(a, b)$. O valor é chamado ponto de máximo local.

2. O valor é um mínimo local - ou mínimo relativo - de f se existe um intervalo $(a, b)$, contendo $\overline{\boldsymbol{x}}$, tal que $f(\overline{\boldsymbol{x}}) \leq f(x)$ para todo $\mathbf{x} \in(a, b)$. O valor é chamado ponto de mínimo local.

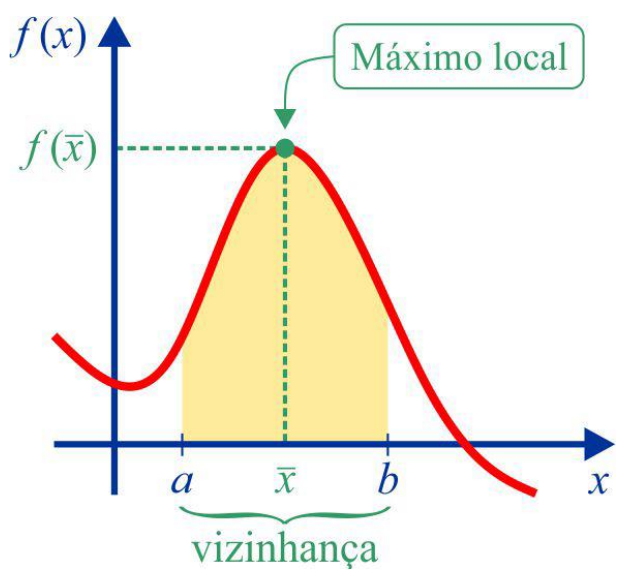

Figura 30 - Função com máximo local.

Fonte: Elaboradas com o auxílio dos programas Geogebra, Graph, Adobe Photoshop e Corel Draw

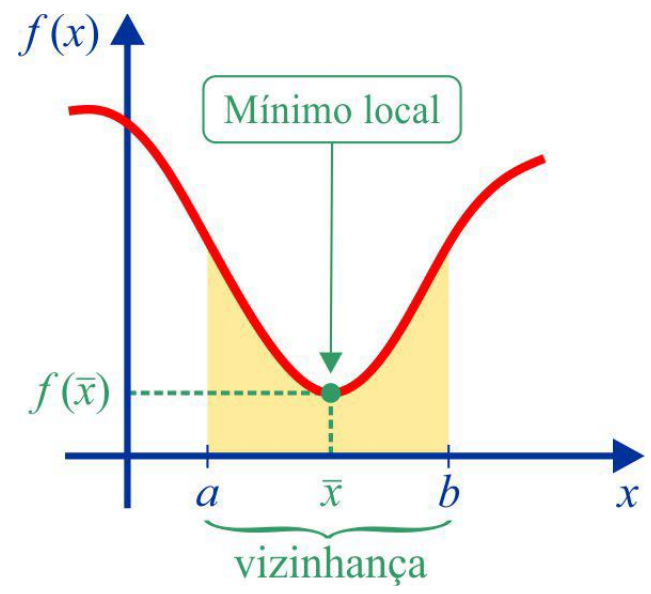

Figura 31 - Função com mínimo local.

Fonte: Elaboradas com o auxílio dos programas Geogebra, Graph, Adobe Photoshop e Corel Draw 


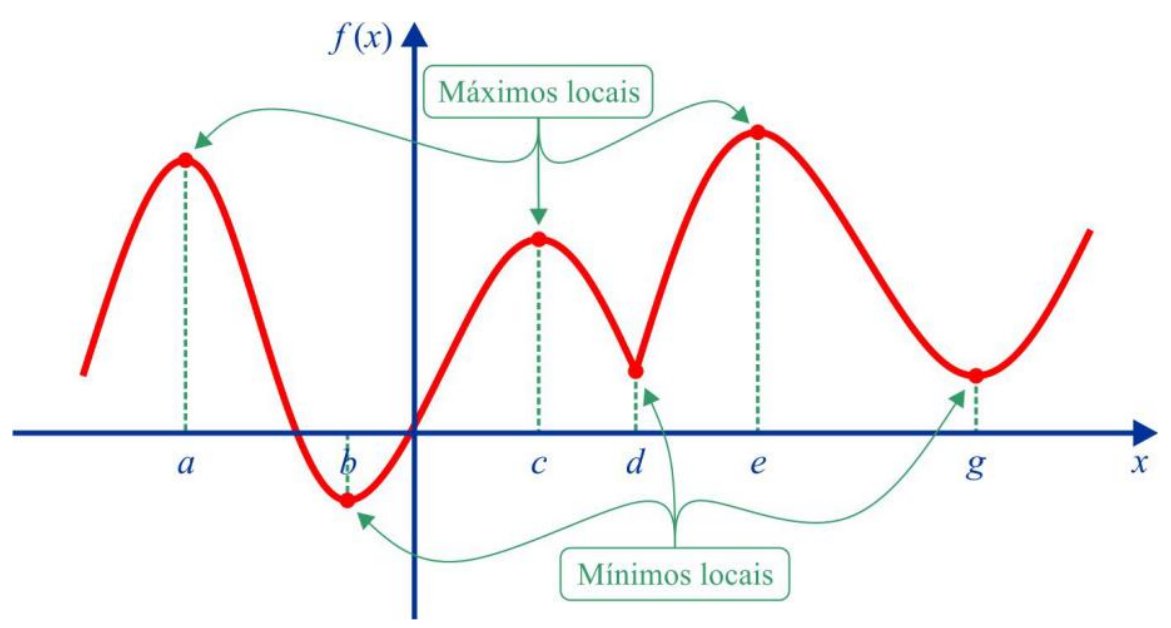

Figura 32 - Função com máximos e mínimos locais.

Fonte: Elaboradas com o auxílio dos programas Geogebra, Graph, Adobe Photoshop e Corel Draw

\subsubsection{Pontos extremos}

Pontos de máximo e de mínimo local têm grande aplicação prática. Se uma função está associada, por exemplo, a um gasto (de dinheiro, energia, matériasprimas, trabalho etc.), o ponto de mínimo será aquele que proporciona a maior economia possível. Por outro lado, para funções que envolvem o aproveitamento de recursos disponíveis, é comum calcular o ponto de máximo.

\subsection{OPERAÇÕES ARITMÉTICAS SOBRE FUNÇÕES}

Duas funções, $\mathbf{f}$ e $\mathbf{g}$, podem ser adicionadas, subtraídas, multiplicadas e divididas para formar novas funções: $f+g, f-g, f \cdot g$ e $\frac{f}{g}$.

Dadas as funções $\mathbf{f}$ e $\mathbf{g}$, definimos

1. $(f+g)(x)=f(x)+g(x)$

2. $(f-g)(x)=f(x)-g(x)$

3. $(f \cdot g)(x)=f(x) \cdot g(x)$

4. $\left(\frac{f}{g}\right)(x)=\frac{f(x)}{g(x)}$

Para as funções $f+g, f-g$ e $f \cdot g$, definimos o domínio como sendo a intersecção dos domínios de $\mathbf{f}$ e $\mathbf{g}$; para a função $\frac{f}{g}$, definimos o domínio como sendo a intersecção dos domínios de $\mathbf{f}$ e $\mathbf{g}$, excluídos os pontos onde $\mathrm{g}(\mathrm{x})=0$. 


\subsection{APLICAÇÃO NA ECONOMIA}

A função custo $C(x)$ fornece o custo total da produção de uma quantidade $\mathbf{x}$ de um produto, que a função receita $R(x)$ fornece a renda total de uma empresa ao vender uma quantidade $x$ de um produto e que a função lucro é definida por: $L(x)=R(x)-$ $C(x)$.

Posto isso, considere os dados de uma empresa que produz rádios. A fábrica e a maquinaria necessária para o início da produção constituem os custos fixos, os quais incorrem mesmo que não se produza rádio algum. A mão de obra, as matérias primas, os impostos são o custo variável, pois estas dependem de quantos rádios são fabricados.

Suponha que os custos fixos da empresa seja de: $R \$ 24.000,00$ e os custos variáveis por unidade produzida seja de $R \$ 7,00$. Então o $C(x)=7 x+24.000$ e que cada rádio seja vendida por $R \$ 15,00$. Então, a função receita será: $R(x)=15 x$.

Quando $C(x)=R(x)$ temos o ponto de equilíbrio, pois $L(x)=R(x)-C(x) \cdot L(x)=$ 0 implica em $R(x)=C(x)$. Assim, $L(x)=15 x-(24.000+7 x)=8 x-24.000$.

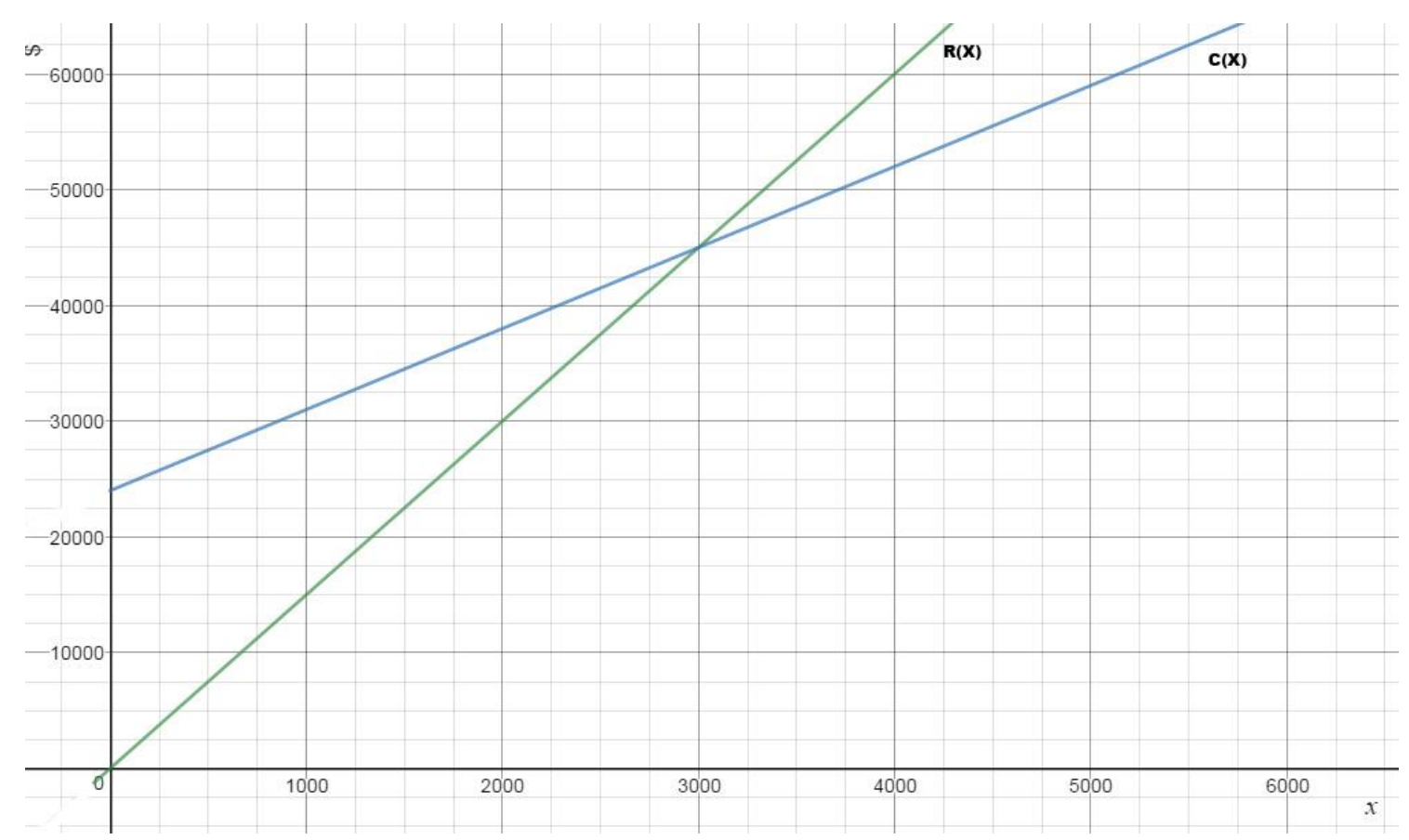

Figura 33 - Esboço da função custo e receita.

Fonte: Elaboradas com o auxílio dos programas Geogebra, Graph, Adobe Photoshop e Corel Draw 


\subsection{COMPOSIÇÃO DE FUNÇÕES}

Agora vamos considerar uma operação sobre funções, denominada composição, que não tem análogo direto em aritmética usual. Assim, dadas as funções $\mathbf{f}$ e $\mathbf{g}$, a composição delas, denotada por $\mathbf{f} \mathbf{o} \mathbf{g}$, é a função definida por:

$$
(f \circ g)(x)=f(g(x))
$$

O domínio de $\mathbf{f} \mathbf{o} \mathbf{g}$ consiste em todo $\mathbf{x}$ no domínio de $\mathbf{g}$ para o qual $\mathbf{g}(\mathbf{x})$ está no domínio de $\mathbf{f}$. Acompanhe um exemplo a seguir.

$$
\begin{gathered}
f(x)=x^{2}+3 \text { e } g(x)=\sqrt{x} \\
f(g(x))=[g(x)]^{2}+3=[\sqrt{x}]^{2}+3=x+3 \\
g(f(x))=\sqrt{f(x)}=\sqrt{x^{2}+3}
\end{gathered}
$$

\subsubsection{Função Composta}

Segundo o quadro abaixo, para que sejamos capazes de calcular $f(g(x))$ é preciso que:

1. $\mathbf{x}$ pertença ao domínio de $\mathbf{g}$;

2. $\mathbf{g}(\mathbf{x})$ (o valor de $\mathbf{g}$ em $\mathrm{x}$ ) pertença ao domínio de $\mathbf{f}$.

$\mathrm{Na}$ figura 16, os conjuntos em vermelho indicam o domínio e o conjunto imagem de $\mathbf{g}$, que são denominados $\mathbf{D}(\mathbf{g})$ e $\operatorname{Im}(\mathbf{g})$, respectivamente. Já os conjuntos azuis representam $\mathbf{D}(\mathbf{f})$ e $\mathbf{I m}(\mathbf{f})$ - o domínio e o conjunto imagem de f. O conjunto roxo no centro da imagem é a interseção de $\mathbf{I m}(\mathbf{g})$ e de $\mathbf{D}(\mathbf{f})$ ou seja, é o conjunto dos valores de $\mathbf{g}(\mathbf{x})$ que pertencem ao domínio de $\mathbf{f}$, como exigido na segunda condição apresentada acima. $\mathbf{O}$ domínio de $\mathbf{f} \mathbf{o} \mathbf{g}$, indicado em verde, contém os valores de $\mathbf{x}$ que satisfazem, ao mesmo tempo, as duas condições. 


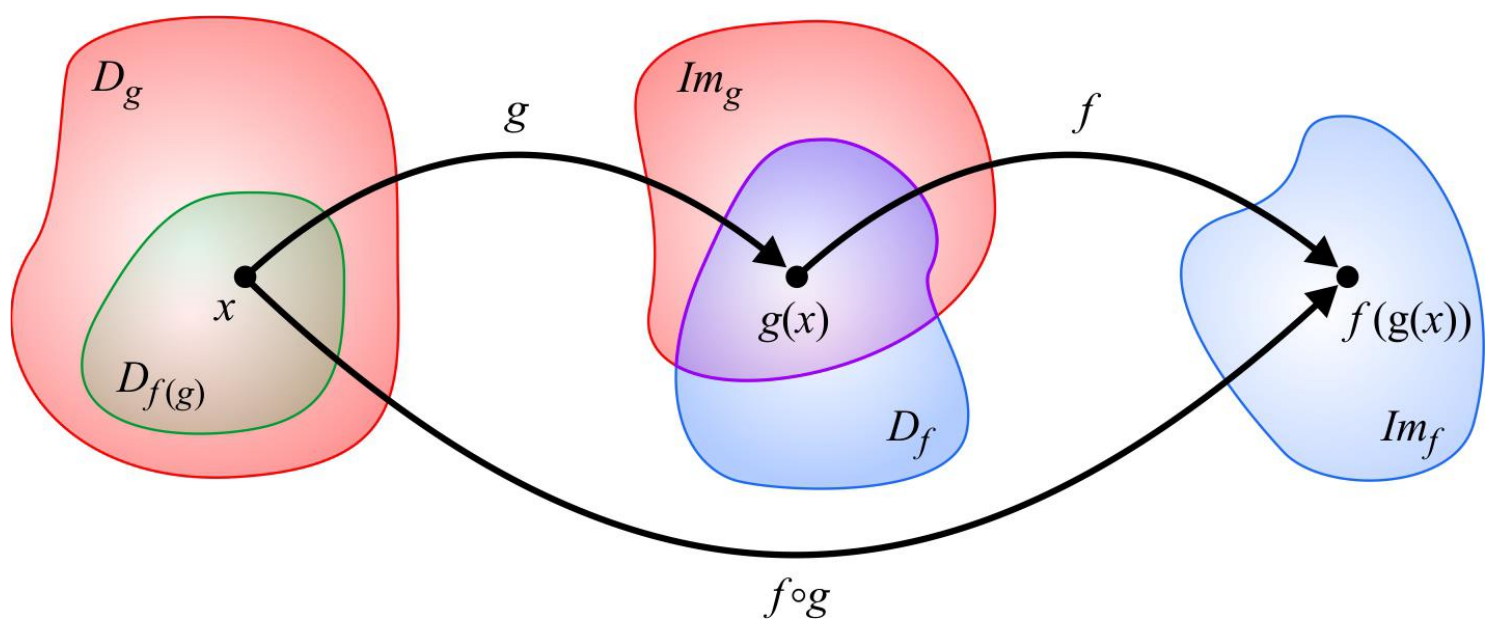

Figura 34 - Esquema função composta.

Fonte: Elaboradas com o auxílio dos programas Geogebra, Graph, Adobe Photoshop e Corel Draw

$\mathrm{Na}$ apresentação desse tema, sugerimos também a demonstração de uma aplicação na física:

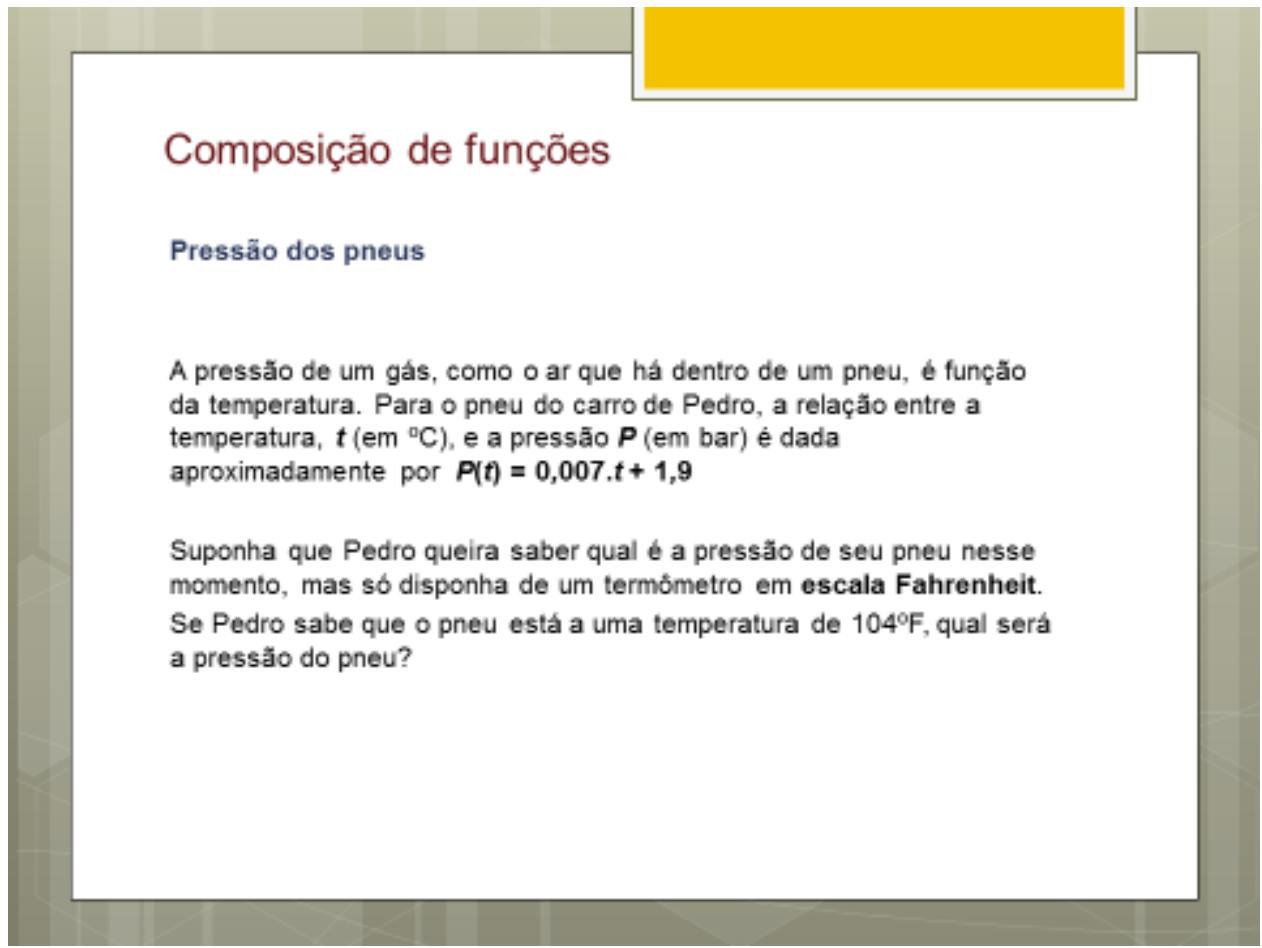

Fonte: Física: Uma Abordagem Estratégica 2ª̣ed. Randall D. Knight - Editora: Bookman 

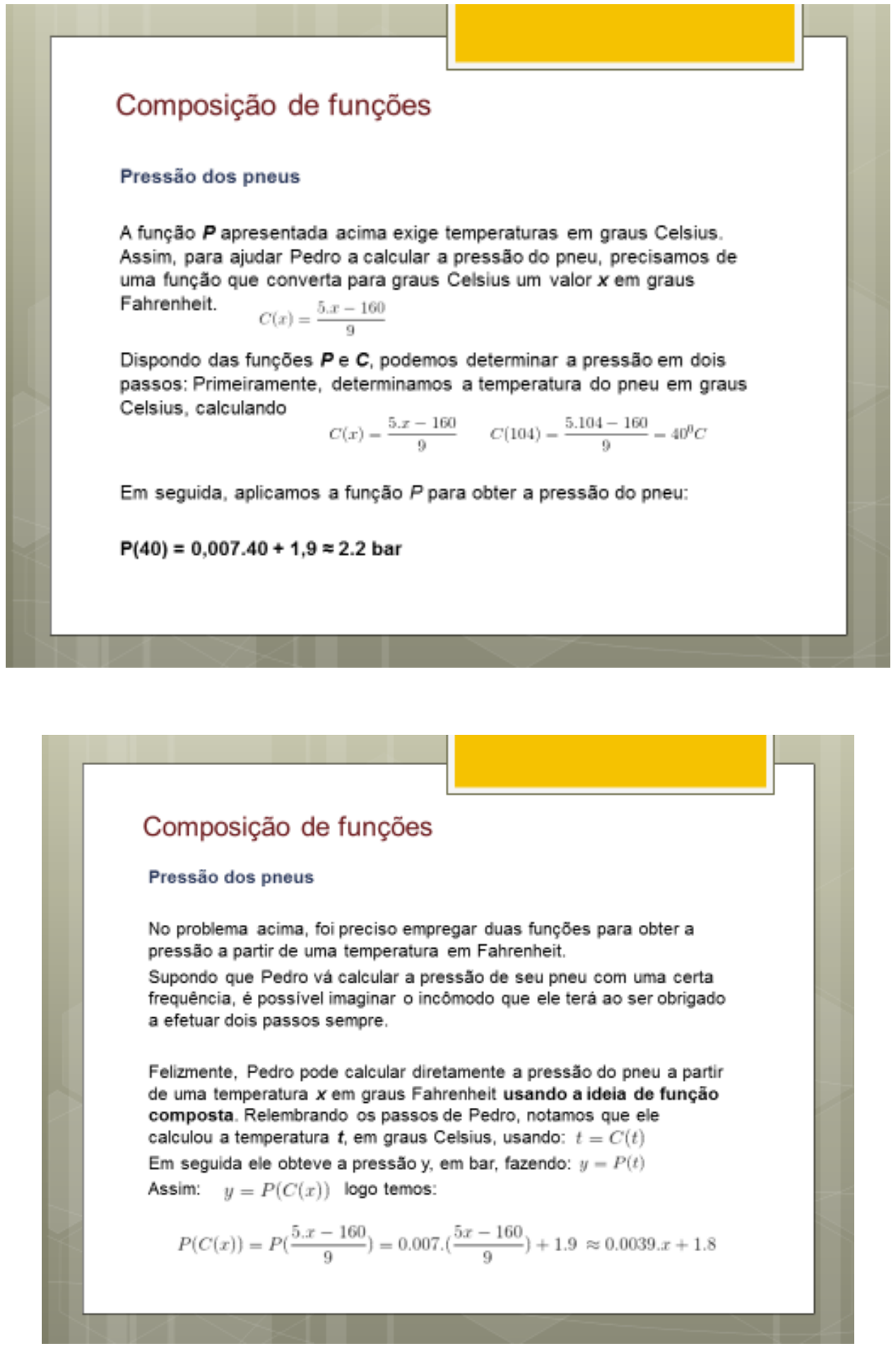


\subsection{TRANSLAÇÕES, REFLEXÕES, ALONGAMENTOS E COMPRESSÕES}

Na translação do tipo $y=f(x)+c$, o gráfico $y=f(x)$ é transladado verticalmente para cima $\mathrm{c}$ unidades se $\mathrm{c}>0$ e transladado verticalmente para baixo $\mathrm{c}$ unidades se $c<0$. Portanto, y se torna $g(x)$, ou seja uma translação vertical.
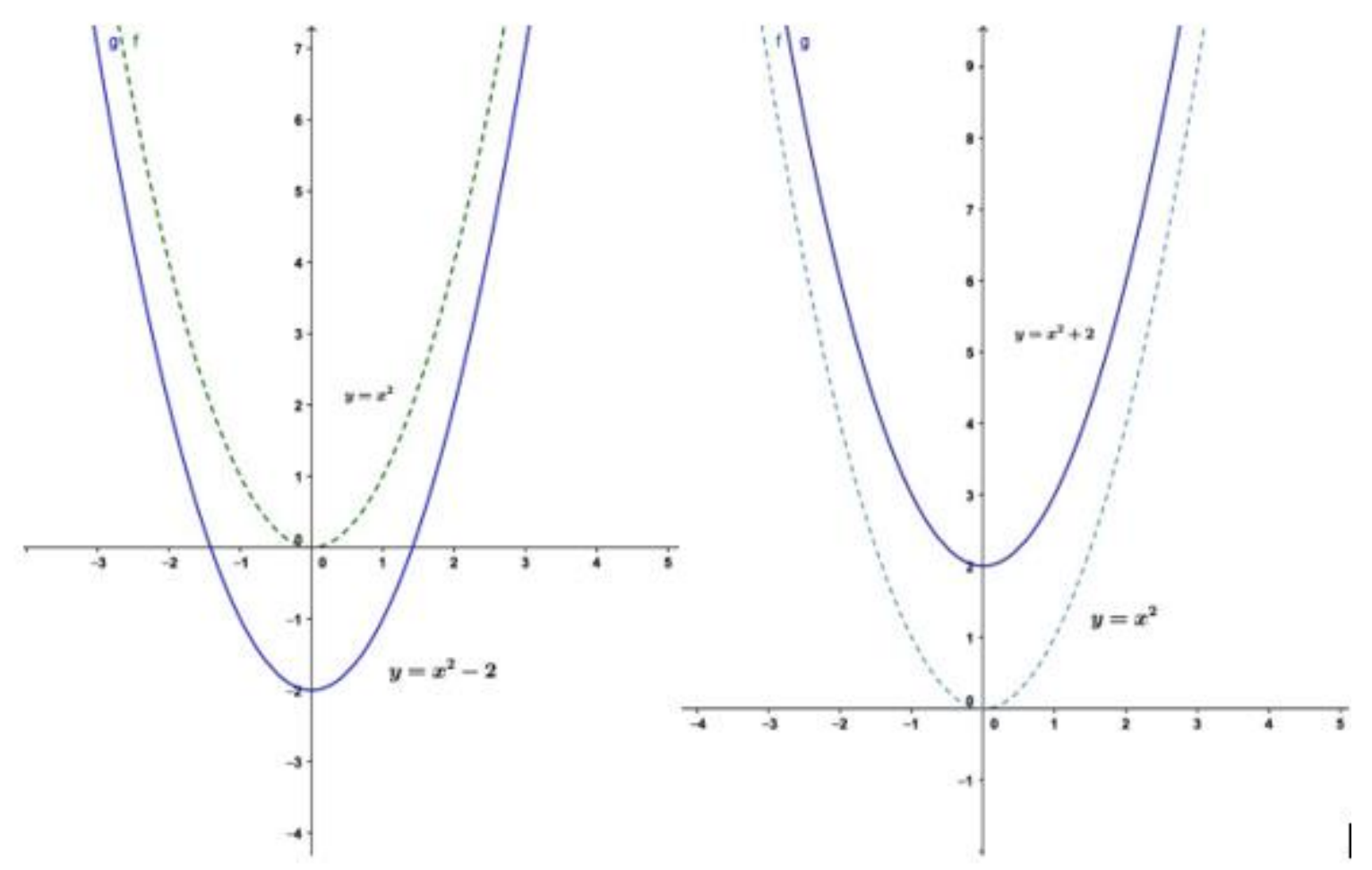

Figura 35 - Translações: $y=f(x)+c$ (translada o gráfico $y=f(x), c$ unidades).

Fonte: Elaboradas pelo autor com o auxílio dos programas Geogebra, Excel e Graph. Foram salvas em jpeg.

Na translação do tipo $y=f(x+c)$, o gráfico $y=f(x)$ é transladado horizontalmente para a esquerda se $\mathrm{c}>0$ e transladado horizontalmente para a direita se $\mathrm{c}<0$. Portanto, y se torna $\mathrm{g}(\mathrm{x})$, ou seja, translação horizontal. 

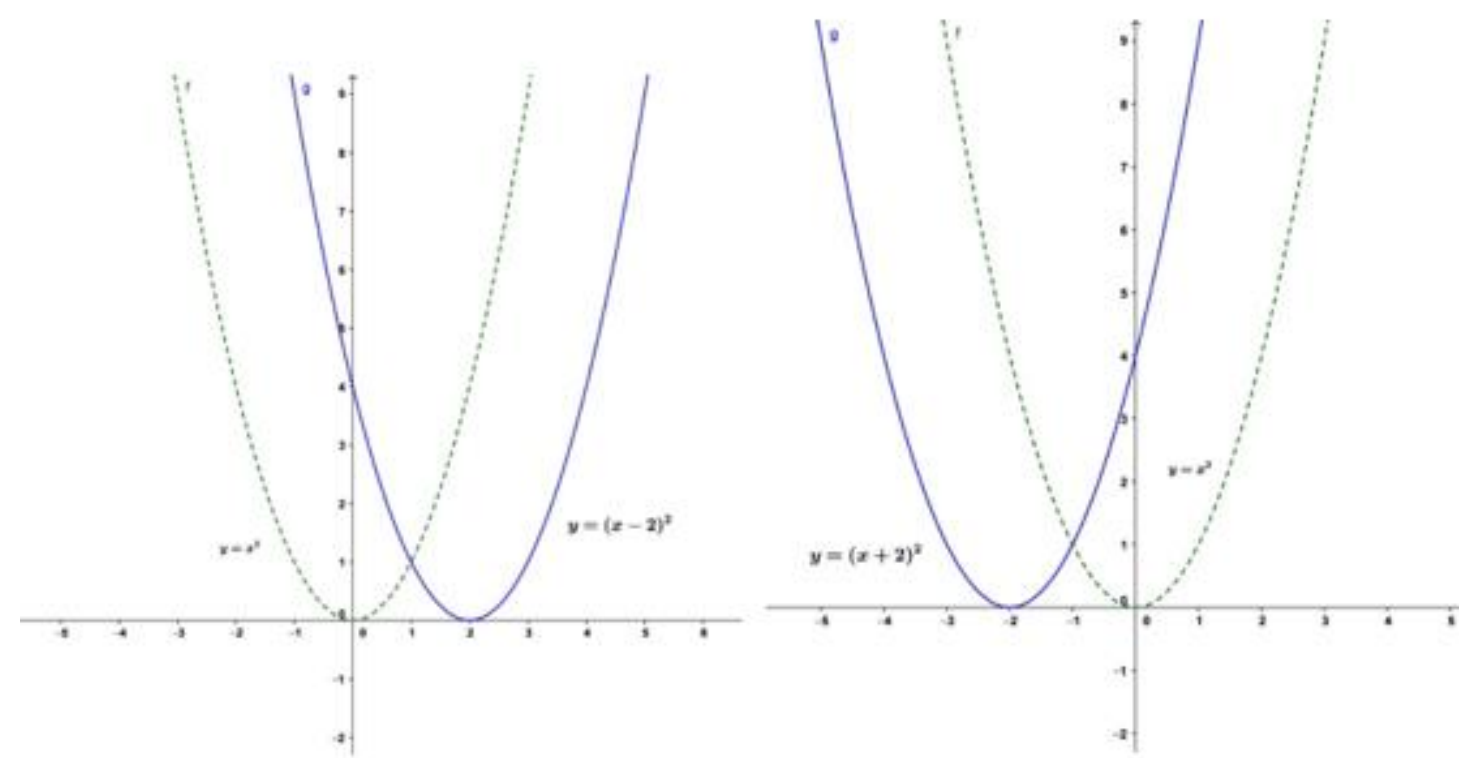

Figura 36 - Translações: $y=f(x+c)$ (translada o gráfico $y=f(x), c$ unidades).

Fonte: Elaboradas pelo autor com o auxílio dos programas Geogebra, Excel e Graph. Foram salvas em jpeg.

Na reflexão do tipo $y=f(-x)$, o gráfico $y=f(x)$ é refletido em relação ao eixo $y$. Já, Na reflexão do tipo $y=-f(x)$, o gráfico $y=f(x)$ é refletido pelo eixo $x$.
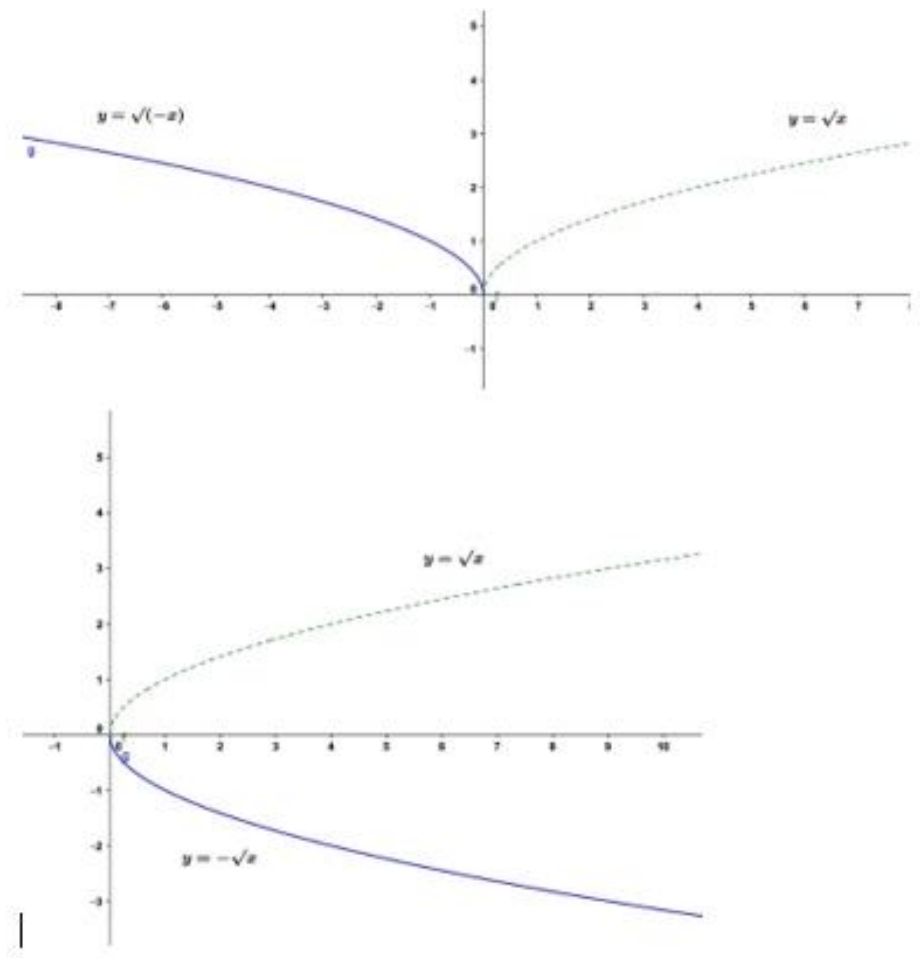

Figura 37 - Reflexões: $y=f(-x)$ (reflete o gráfico $y=f(x)$, pelo eixo $y$ ) e $y=-f(x)$ (reflete o gráfico $y=f(x)$, pelo eixo $x$ ). Fonte: Elaboradas pelo autor com o auxílio dos programas Geogebra, Excel e Graph. Foram salvas em jpeg. 
No alongamento do tipo $y=c \cdot f(x)$, o gráfico $y=f(x)$ é alongado verticalmente por um fator $c$ se $c>1$. Ou seja, o gráfico $y=f(x)$, é comprimido verticalmente por um fator $1 / \mathrm{c}$ se $0<\mathrm{c}<1$.

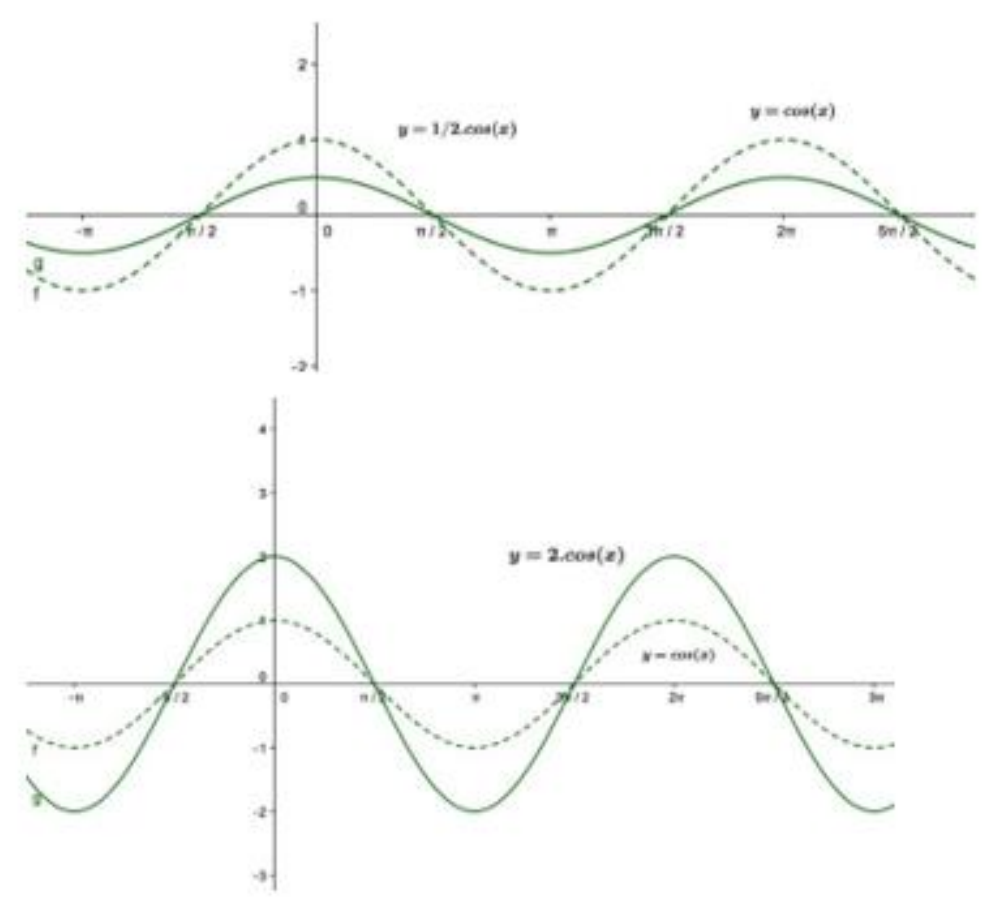

Figura $38-y=c \cdot f(x)$ (Alonga o gráfico $y=f(x)$, verticalmente por um fator c se $c>1$ (Comprime o gráfico $y=f(x)$, verticalmente por um fator $1 / \mathrm{c}$ se $0<\mathrm{c}<1$.

Fonte: Elaboradas pelo autor com o auxílio dos programas Geogebra, Excel e Graph. Foram salvas em jpeg.

Na reflexão do tipo $y=f(c \cdot x)$, o gráfico $y=f(x)$ é comprimido horizontalmente por um fator $\mathrm{c}$ se $\mathrm{c}>1$. Ou seja, o gráfico $\mathrm{y}=\mathrm{f}(\mathrm{x})$, é alongado horizontalmente por um fator $1 / \mathrm{c}$ se $0<\mathrm{c}<1$. 

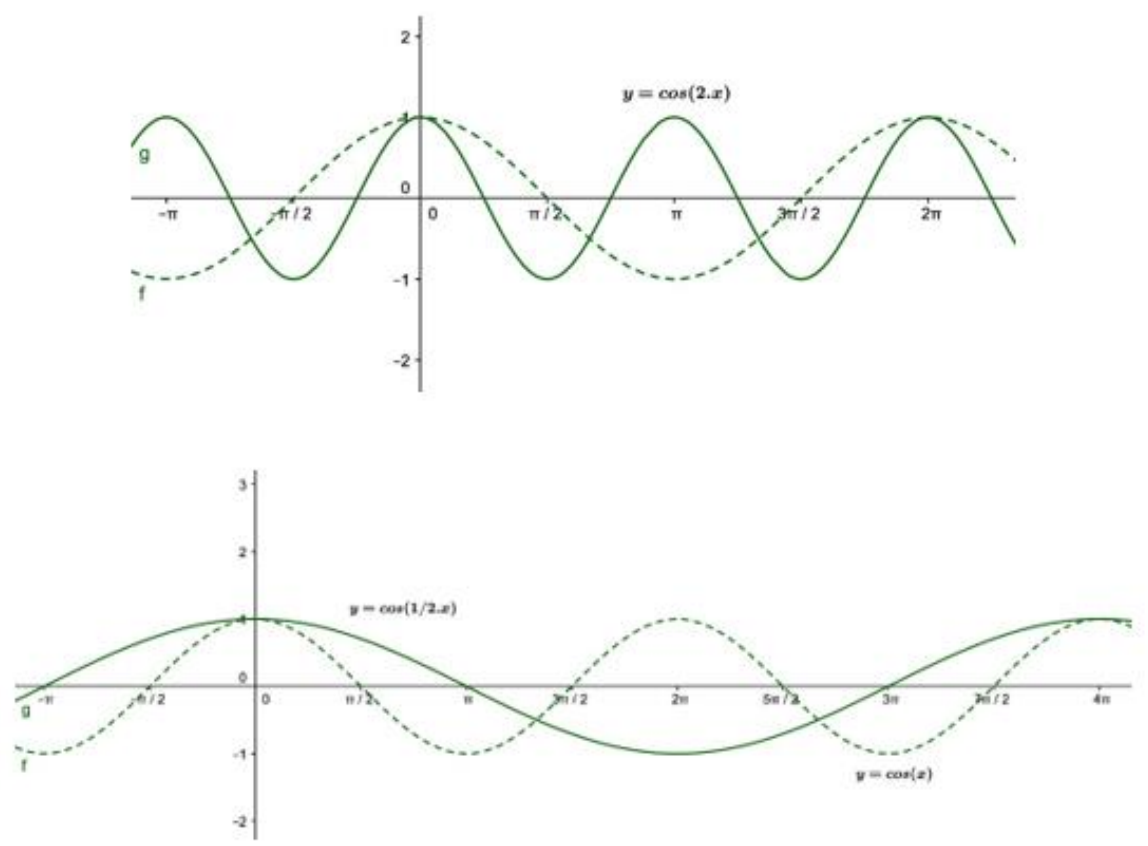

Figura $39-y=f(c \cdot x)$ (Comprime o gráfico $y=f(x)$, horizontalmente por um fator $c$ se $c>1$ (Alonga o gráfico $y=$ $f(x)$, horizontalmente por um fator $1 / c$ se $0<c<1$.

Fonte: Elaboradas pelo autor com o auxílio dos programas Geogebra, Excel e Graph. Foram salvas em jpeg.

\subsection{FUNÇÕES PARES E ÍMPARES}

Dizemos que uma função $f$ é uma função par se $f(-x)=f(x)$ e uma função ímpar se $f(-x)=-f(x)$. Geometricamente, os gráficos de funções pares são simétricos em relação ao eixo $y$, pois substituindo $x$ por $-x$ na equação $y=f(x)$ dá $y=f(-x)$, que é equivalente a equação original.

As funções $x^{3}, x^{5}, x^{7}$ e sen $(x)$ são exemplos de funções ímpares pois os gráficos são simétricos em relação à origem. Já, as funções $x^{4}, x^{6}, x^{8} e \cos (x)$ são exemplos de funções pares pois os gráficos são simétricos em relação ao eixo $y$. 


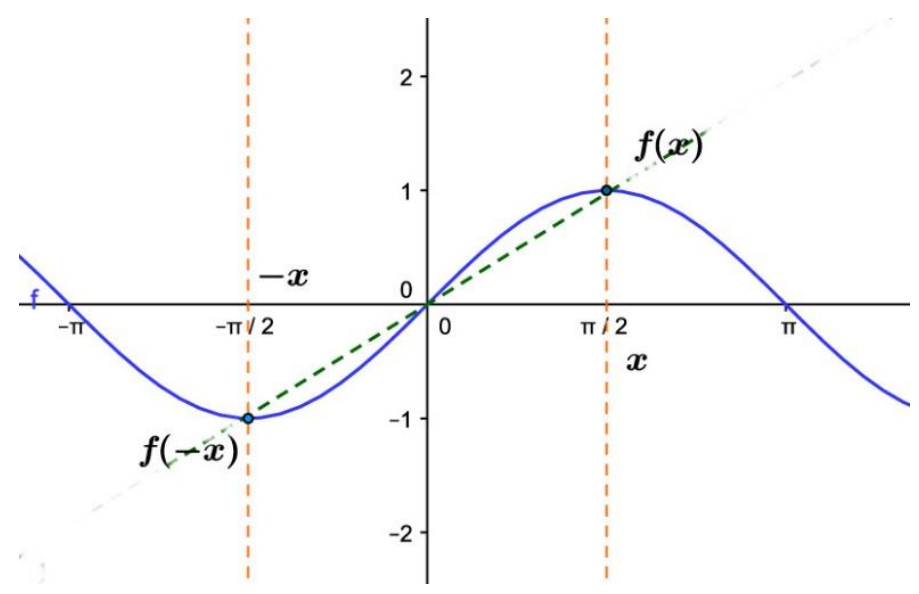

Figura 40 - Exemplo de função ímpar . $f(x)=\operatorname{sex}(x)$.

Fonte: Elaboradas pelo autor com o auxílio dos programas Geogebra, Excel e Graph. Foram salvas em jpeg.

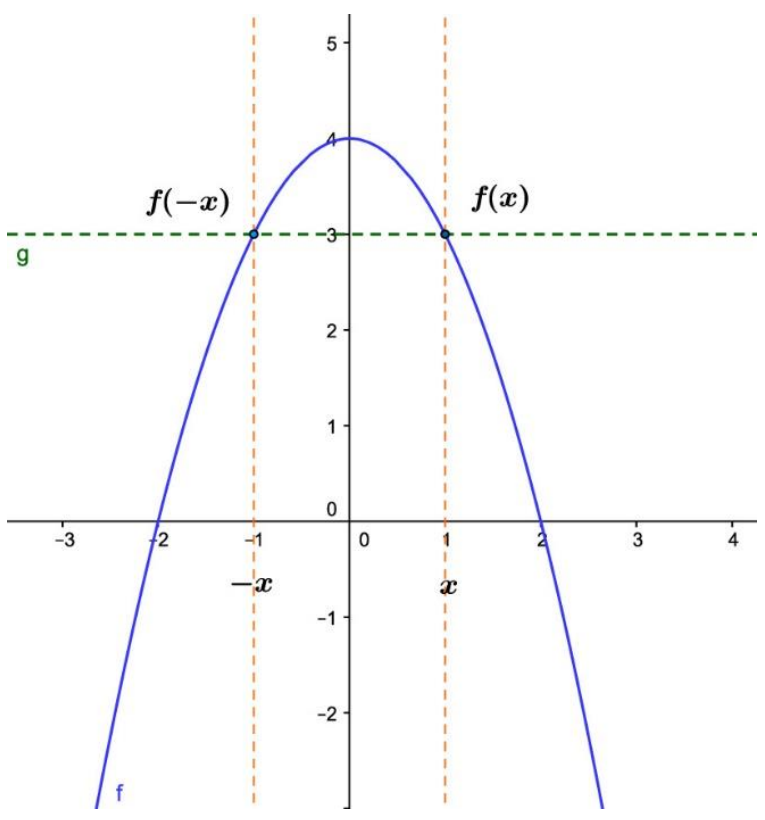

Figura 41 - Exemplo de função par.

Fonte: Elaboradas pelo autor com o auxílio dos programas Geogebra, Excel e Graph. Foram salvas em jpeg. 


\subsection{FAMÍLIA DE CURVAS}

O gráfico de uma função constante $\mathbf{f}(\mathbf{x})=\mathbf{c}$, que é uma reta horizontal. Se variarmos c obteremos um conjunto ou uma família de retas horizontais.

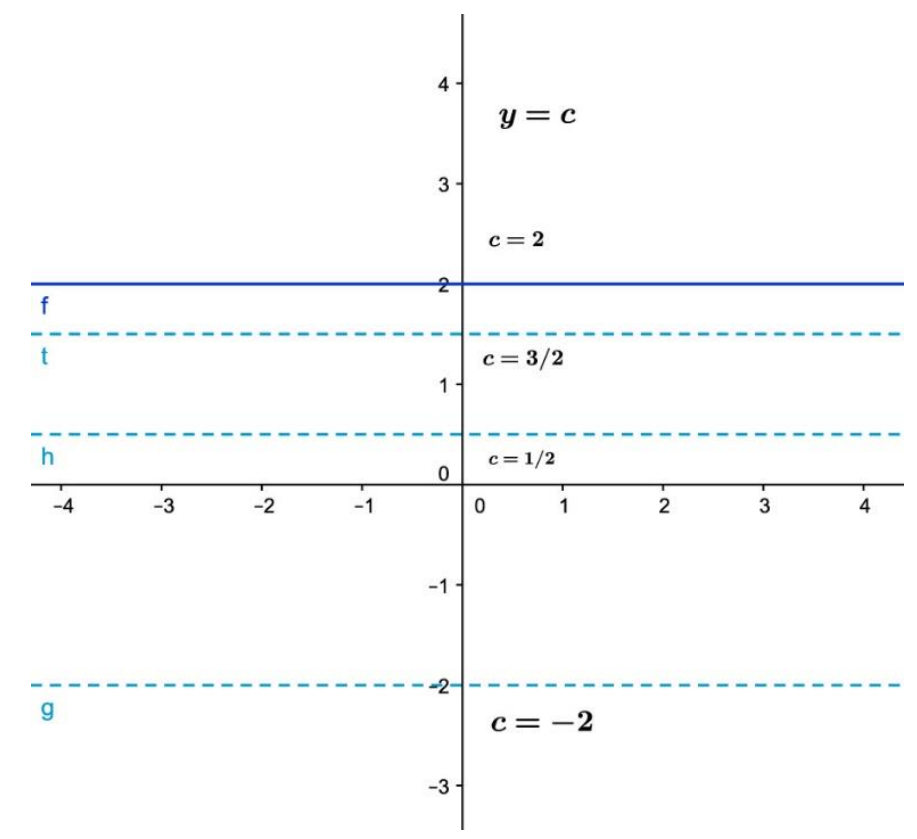

Figura 42 -

Fonte: Elaboradas pelo autor com o auxílio dos programas Geogebra, Excel e Graph. Foram salvas em jpeg.

\subsubsection{Família de curvas (linear)}

As constantes que variamos para produzir uma família de curvas são denominados parâmetros. A equação da forma $\mathbf{y}=\mathbf{m} \mathbf{x}+\mathbf{b}$ representa uma reta de inclinação $\mathbf{m}$ e corte com o eixo y em b. Se mantivermos b fixo e tratarmos $m$ como parâmetro, obteremos uma família de retas cujos membros têm, todos, o mesmo corte b com o eixo y. E se mantivermos $\mathbf{m}$ fixo e tratarmos b como parâmetro, obteremos uma família de retas paralelas, cujos membros têm a mesma declividade $\mathbf{m}$. 


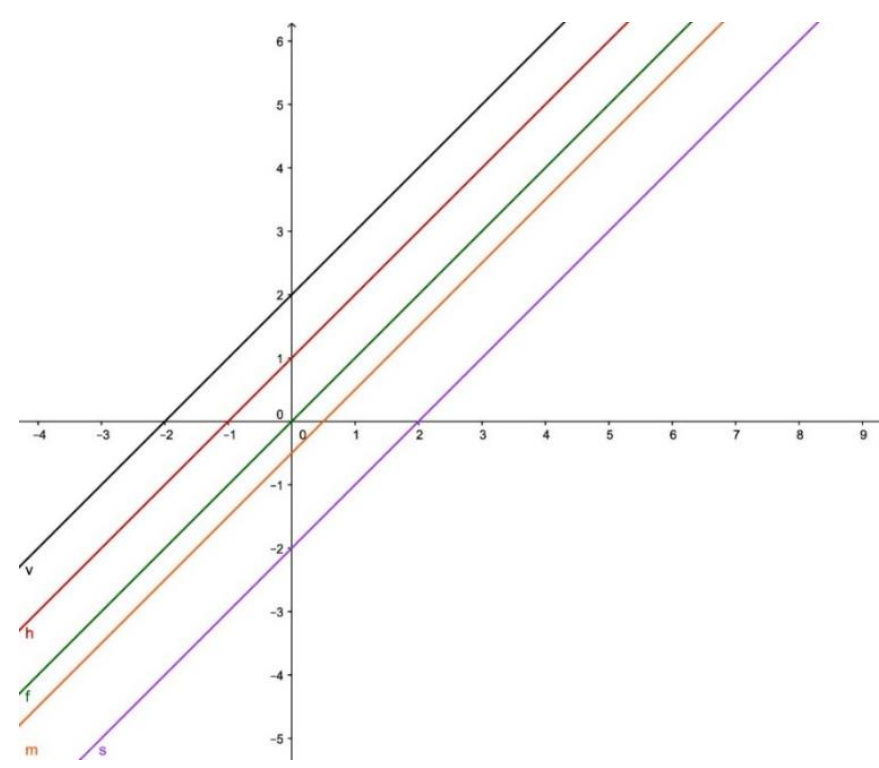

Figura $43-A$ família $y=m x+b$ ( $m$ fixo e $b$ variando).

Fonte: Elaboradas pelo autor com o auxílio dos programas Geogebra, Excel e Graph. Foram salvas em jpeg.

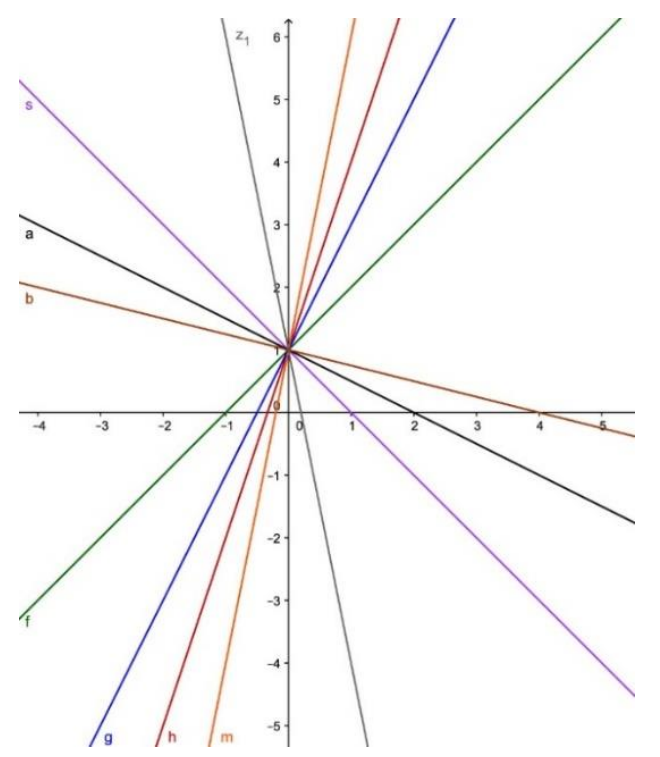

Figura $44-A$ família $y=m x+b$ (b fixo e $m$ variando).

Fonte: Elaboradas pelo autor com o auxílio dos programas Geogebra, Excel e Graph. Foram salvas em jpeg.

\subsubsection{Família de curvas $\left(y=x^{n}\right)$}

Uma função da forma $y=x^{n}$ onde $\mathbf{n}$ é constante ( $\mathbf{n}$ inteiro positivo), é denominada função potência. 


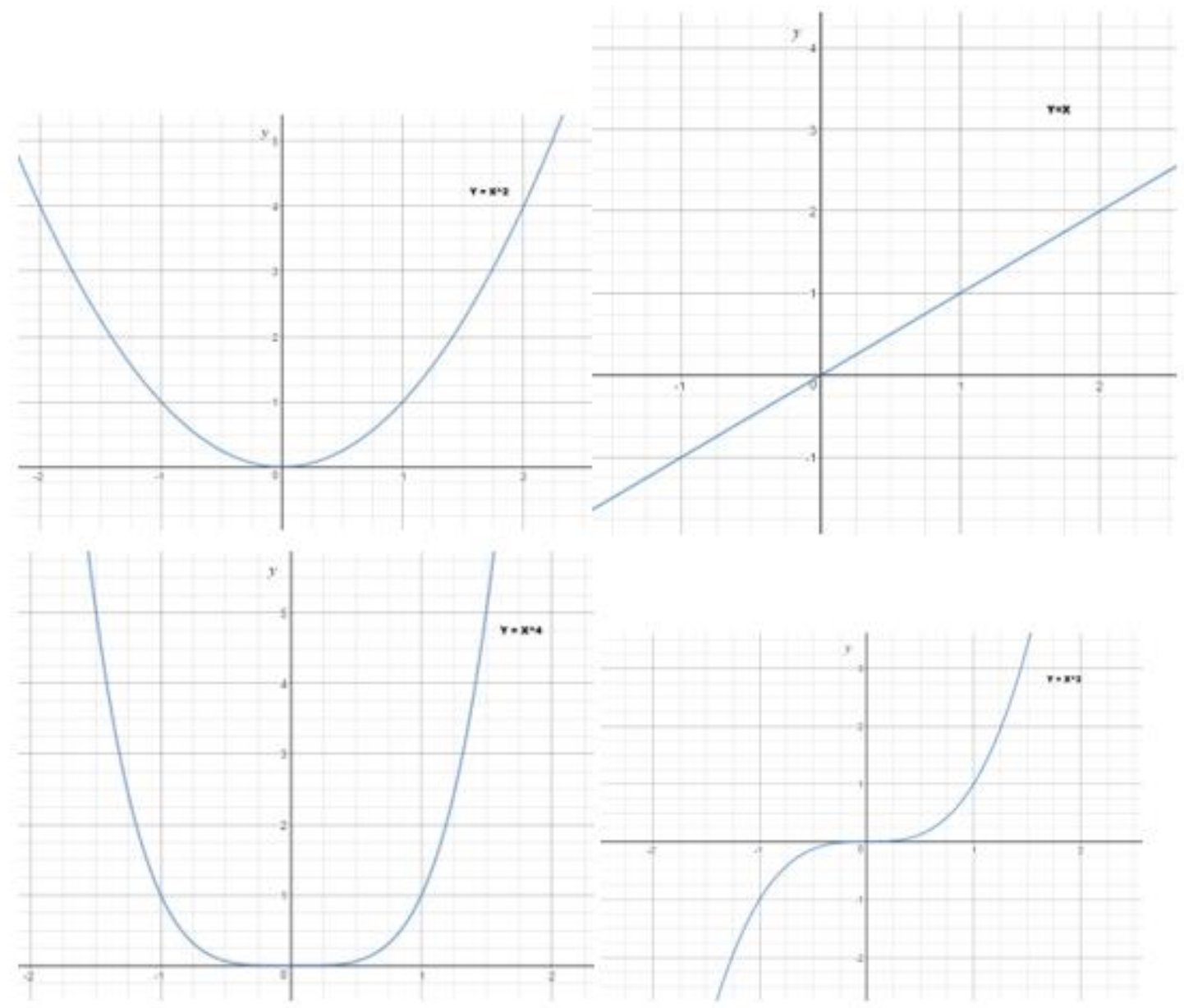

Figura 45 - Exemplos de função potência.

Fonte: Elaboradas pelo autor com o auxílio dos programas Geogebra, Excel e Graph. Foram salvas em jpeg.

Para valores pares de $\mathbf{n}$, as funções $\mathbf{f}(\mathbf{x})=\mathbf{x}^{\mathbf{n}}$ são pares, portanto seus gráficos são simétricos em relação ao eixo y. Os gráficos têm todos o formato geral da parábola (embora não sejam parábolas) e cada gráfico passa pelo ponto $(1,1)$ e $(-1,1)$. A medida que $\mathbf{n}$ cresce, os gráficos ficam mais e mais achatados no intervalo $-1<\mathrm{x}<1$ e mais próximos da vertical nos intervalos $x>1$ e $x<-1$. 


\subsubsection{Família de curvas $\left(y=x^{-n}\right)$}

Uma função da forma $\mathbf{y}=\mathbf{x}^{-\mathbf{n}}$ onde $\mathbf{n}$ é constante ( $\mathbf{n}$ inteiro negativo), é denominada função potência. $O$ gráfico de $\mathbf{y}=\mathbf{1 / x}$ por exemplo, é denominado uma hipérbole equilátera. $O$ formato da curva $\mathbf{y}=\mathbf{1} / \mathbf{x}^{\mathbf{n}}$ depende de $n$ ser par ou ímpar.
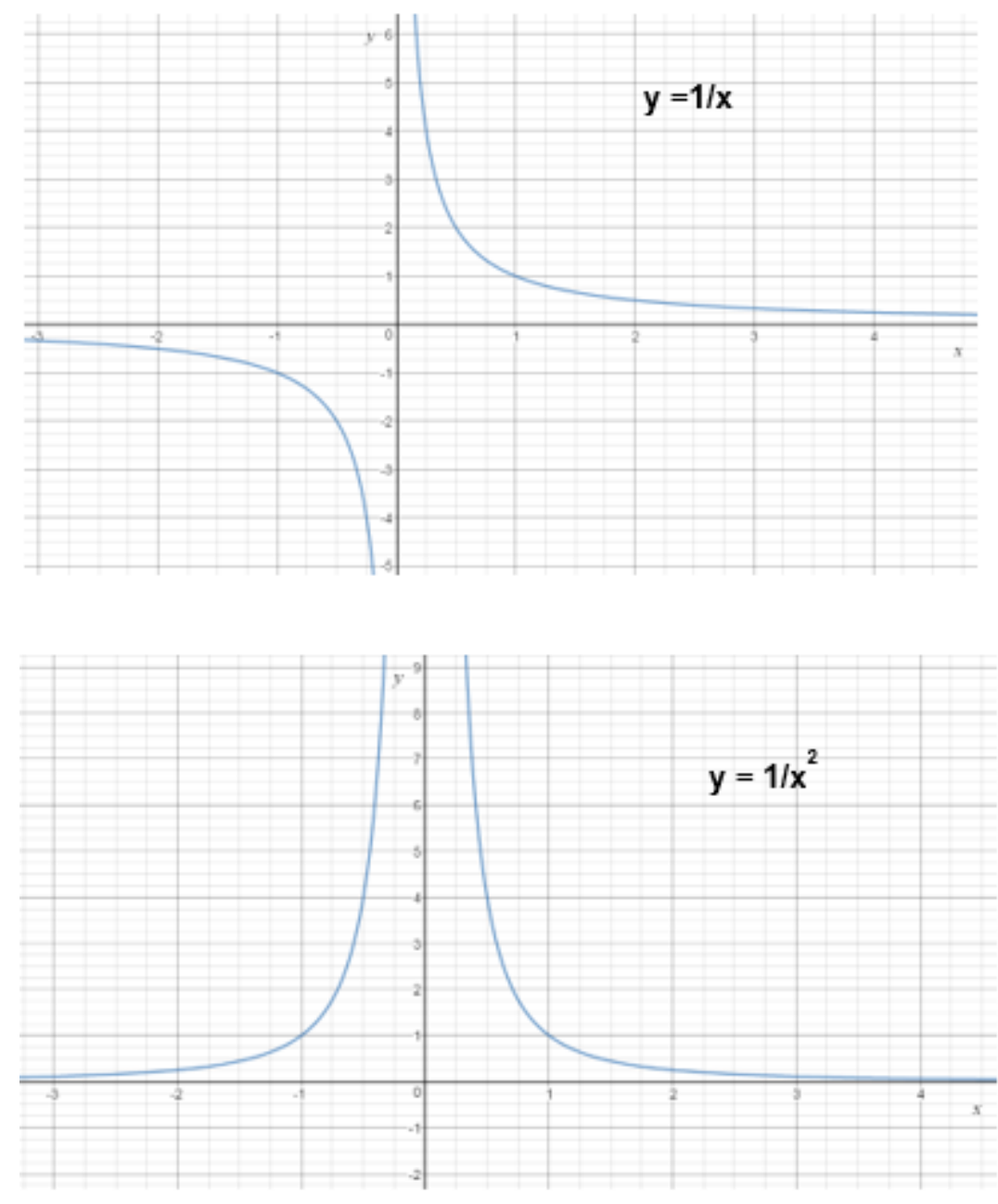

Figura 46 - $O$ primeiro gráfico representa a $f(x)=1 / x$ e o segundo gráfico $f(x)=1 / x^{2}$.

Fonte: Elaboradas pelo autor com o auxílio dos programas Geogebra, Excel e Graph. Foram salvas em jpeg.

Para valores pares de $n$, as funções $f(x)=1 / x^{n}$ são pares, portanto seus gráficos são simétricos em relação ao eixo-y. Os gráficos têm todos o formato geral da curva $f(x)=1 / x^{2}$ e cada gráfico passa pelos pontos $(-1,1)$ e $(1,1)$. À medida que $\mathbf{n}$ cresce, os gráficos ficam mais e mais próximos da vertical nos intervalos $-1<\mathrm{x}<0 \mathrm{e}$ $0<x<1$ e mais e mais achatados nos intervalos $x<1$ e $x<-1$. 


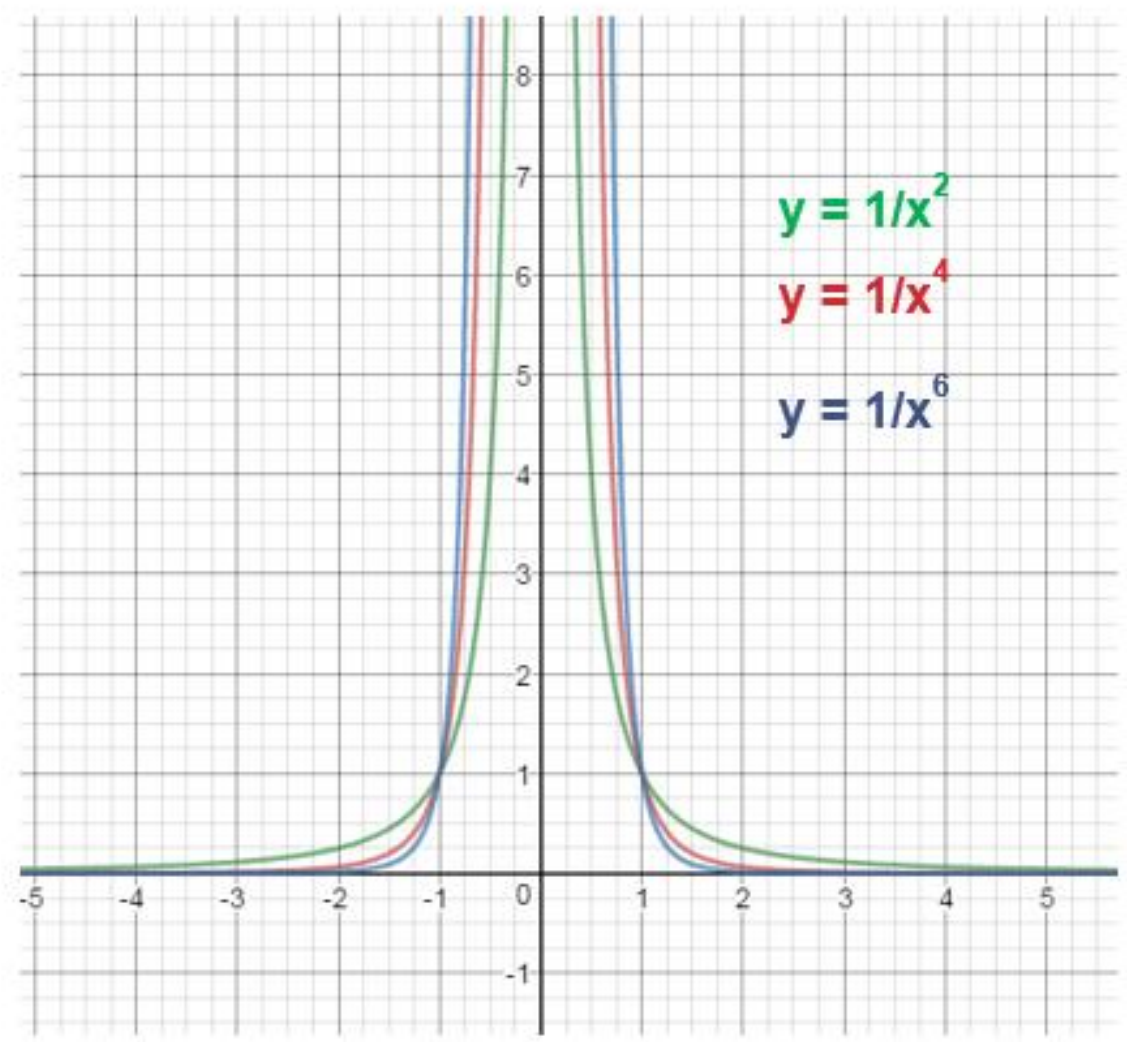

Figura $47-f(x)=1 / x^{n}$, com $n=2, n=4$ e $n=6$.

Fonte: Elaboradas pelo autor com o auxílio dos programas Geogebra, Excel e Graph. Foram salvas em jpeg.

Para valores ímpares de $n$, as funções $f(x)=1 / x^{n}$ são ímpares, portanto seus gráficos são simétricos em relação a origem. Os gráficos têm todos o formato geral da curva $f(x)=1 / x$ e cada gráfico passa pelos pontos $(-1,1)$ e $(1,1)$. À medida que $\mathbf{n}$ cresce, os gráficos ficam mais e mais próximos da vertical nos intervalos $-1<\mathrm{x}<0 \mathrm{e}$ $0<\mathrm{x}<1$ e mais e mais achatados nos intervalos $\mathrm{x}>1$ e $\mathrm{x}<-1$. 


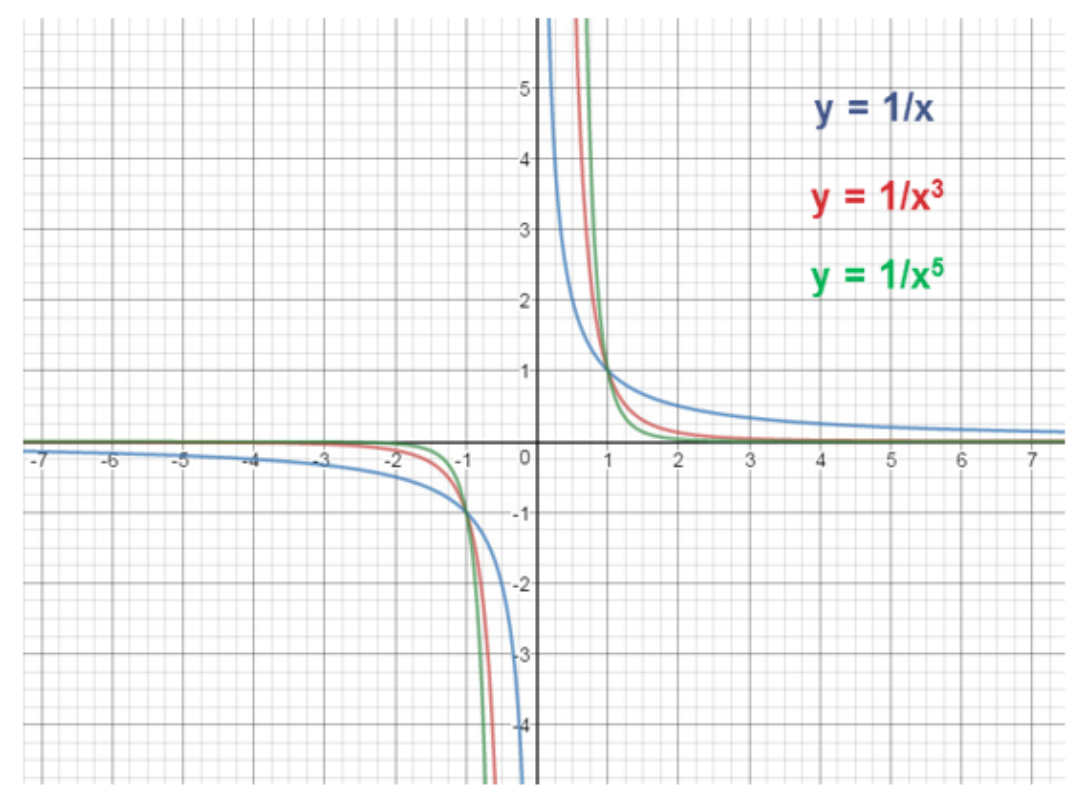

Figura $48-f(x)=1 / x^{n}, \operatorname{com} n=1, n=3$ e $n=5$.

Fonte: Elaboradas pelo autor com o auxílio dos programas Geogebra, Excel e Graph. Foram salvas em jpeg.

\subsection{PROPORÇÕES INVERSAS $y=\frac{k}{x}$}

Lembremos que uma variável $\mathbf{y}$ diz-se inversamente proporcional a uma variável $\mathbf{x}$ se houver uma constante positiva $\mathbf{k}$, denominada constante de proporcionalidade, tal que $y=\frac{k}{x}$.

Uma vez que se supõe $k$ positiva, o gráfico dessa equação tem a mesma forma básica que $y=\frac{1}{x}$, mas é comprimido ou alongado na direção do eixo y. A equação pode ser expressa como $\mathrm{x} \cdot \mathrm{y}=\mathrm{k}$ que nos informa que o produto de grandezas inversamente proporcionais é uma constante positiva.

Essa forma é útil para identificar proporcionalidade inversa em dados experimentais.

\begin{tabular}{|l|l|l|l|l|l|l|}
\hline $\mathbf{x}$ & 0,8 & 1 & 2,5 & 4,0 & 6,25 & 10 \\
\hline $\mathbf{y}$ & 6,25 & 5 & 2 & 1,25 & 0,8 & 0,5 \\
\hline
\end{tabular}

As proporções inversas surgem em várias leis da física. Por exemplo, a lei de Boyle afirma que se uma quantidade fixa de um gás ideal é mantida a uma 
temperatura constante, então o produto da pressão $\mathbf{P}$ exercida pelo gás e o volume $\mathbf{V}$ que ele ocupa é constante.

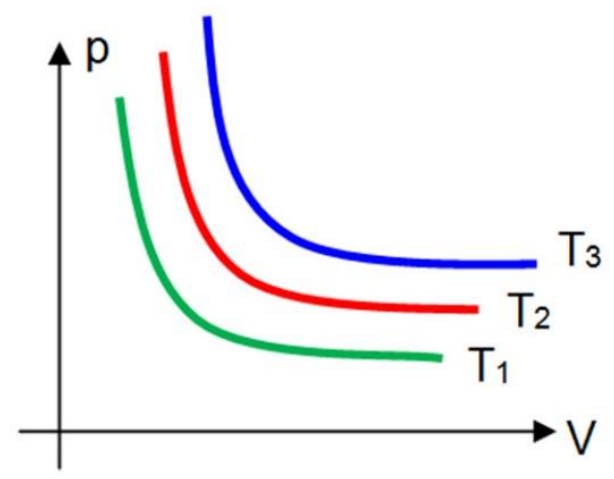

$$
\mathrm{T}_{1}<\mathrm{T}_{2}<\mathrm{T}_{3}
$$

Figura $49-P \cdot V=K$

Fonte: Elaboradas com o auxílio dos programas Geogebra, Graph, Adobe Photoshop e Corel Draw

\subsection{FUNÇÕES RACIONAIS}

Uma função que pode ser expressa como uma razão de dois polinômios é denominada função racional. Se $\mathrm{P}(\mathrm{x})$ e $\mathrm{Q}(\mathrm{x})$ forem polinômios, então o domínio da função racional $f(x)=\frac{P(x)}{Q(x)}$ consiste em todos os valores de $\mathbf{x}$ tais que $\mathrm{Q}(\mathrm{x}) \neq 0$. Por exemplo, o domínio da função racional $f(x)=\frac{x^{2}+2 x}{x^{2}-1}$ consiste em todos os valores de $x$, exceto $x=1$ e $x=-1$, pois zera o denominador.

Os gráficos de funções racionais com denominadores não-constantes diferem dos polinômios. Eles são curvas continuas, mas os racionais têm descontinuidade nos pontos onde o denominador é zero. As funções racionais podem ter números nos quais não estão definidas. 


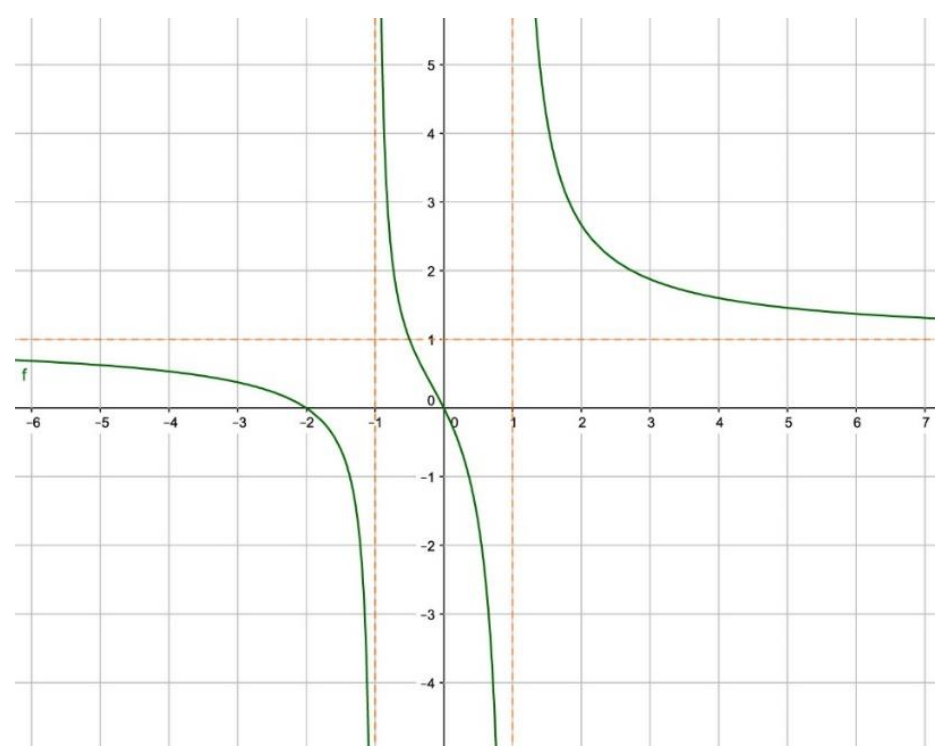

Figura $50-f(x)=\frac{x^{2}+2 x}{x^{2}-1}$

Fonte: Elaboradas pelo autor com o auxílio dos programas Geogebra, Excel e Graph. Foram salvas em jpeg.

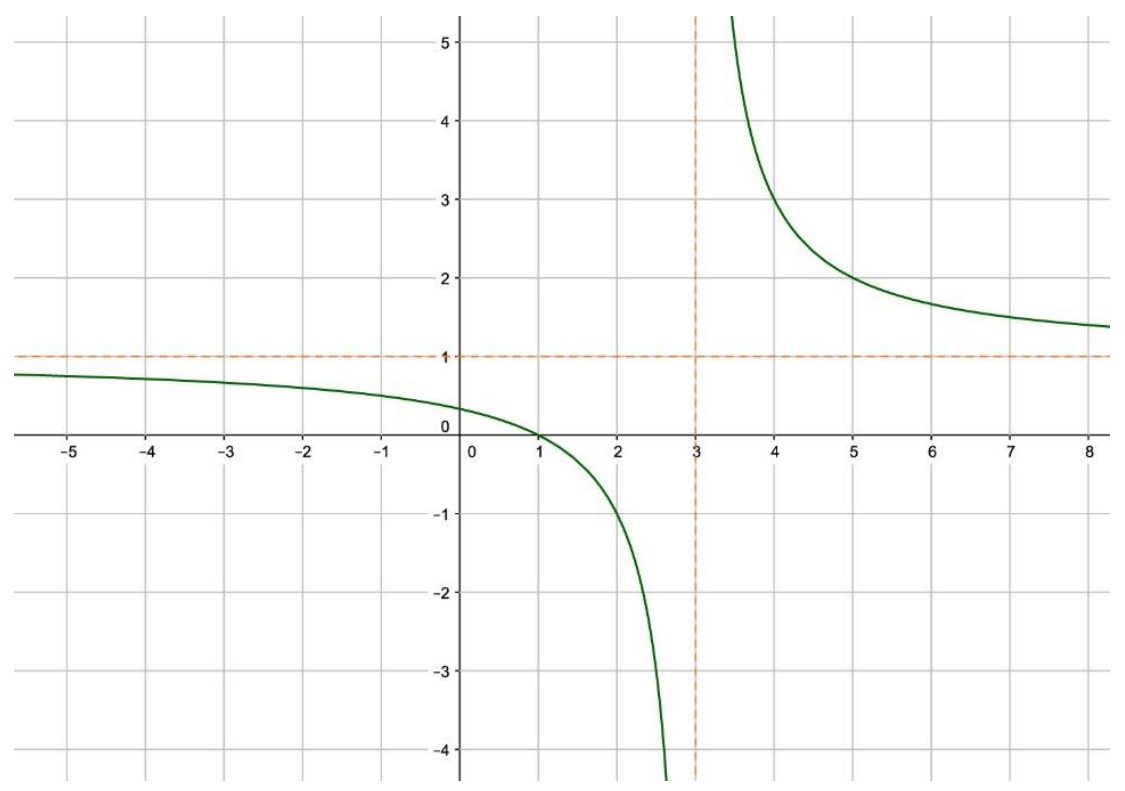

Figura $51-f(x)=\frac{x^{2}-1}{x^{2}-2 x-3}$

Fonte: Elaboradas pelo autor com o auxílio dos programas Geogebra, Excel e Graph. Foram salvas em jpeg.

\subsection{FUNÇÕES ALGÉBRICAS}


As funções que podem ser construídas com polinômios, aplicando-se um número finito de operações algébricas (adição, subtração, divisão e extração de raízes), são denominadas funções algébricas. Exemplos:

$$
\begin{aligned}
& \text { - } f(x)=\sqrt{x^{2}-4} \\
& \text { - } g(x)=3 \sqrt[3]{x}(2+x) \\
& \text { - } h(x)=x^{\frac{2}{3}}(x+2)^{2}
\end{aligned}
$$

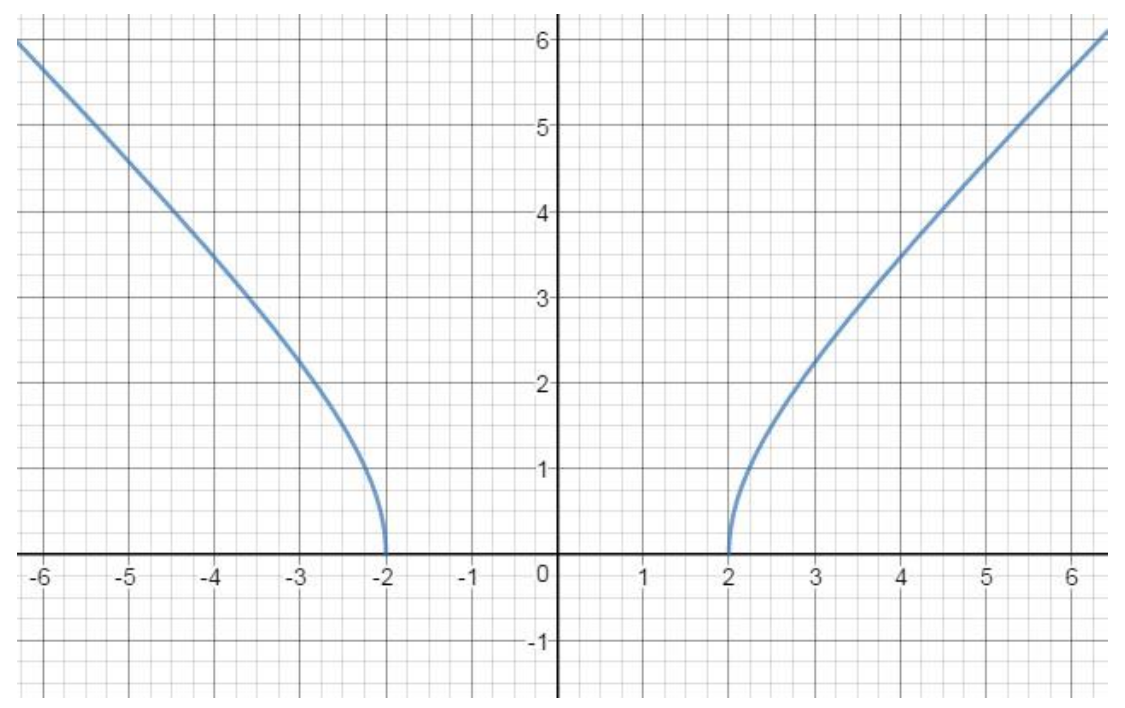

Figura $52-f(x)=\sqrt{x^{2}-4}$

Fonte: Elaboradas pelo autor com o auxílio dos programas Geogebra, Excel e Graph. Foram salvas em jpeg.

4.14 AS FAMÍLIAS $Y=A \cdot S E N(B X-C) E Y=A \cdot \operatorname{COS}(B X-C)$

Se $\mathbf{A}$ e $\mathbf{B}$ forem positivos, então o efeito da constante $\mathbf{A}$ é alongar ou comprimir verticalmente os gráficos de $y=\operatorname{sen}(x)$ e $y=\cos (x)$ por um fator $\mathbf{A}$, enquanto $\mathbf{B}$ é fazer o mesmo, porém horizontalmente.

Em geral se $\mathbf{A}$ e $\mathbf{B}$ forem números positivos, então os gráficos de oscilam entre -A e $\mathbf{A}$ e repetem-se a cada $\frac{|B|}{2 \pi}$. E definimos frequência dessas funções como sendo o recíproco do período, ou seja, $T=\frac{2 \pi}{|B|}$.

Se A e B forem negativos, além de compressão e alongamento, teremos reflexões dos gráficos pelos dois eixos:

- Amplitude $=|\mathrm{A}|$ 
- $\quad$ Período $=\frac{2 \pi}{|B|}$

- $\quad$ Frequência $=\frac{|B|}{2 л}$

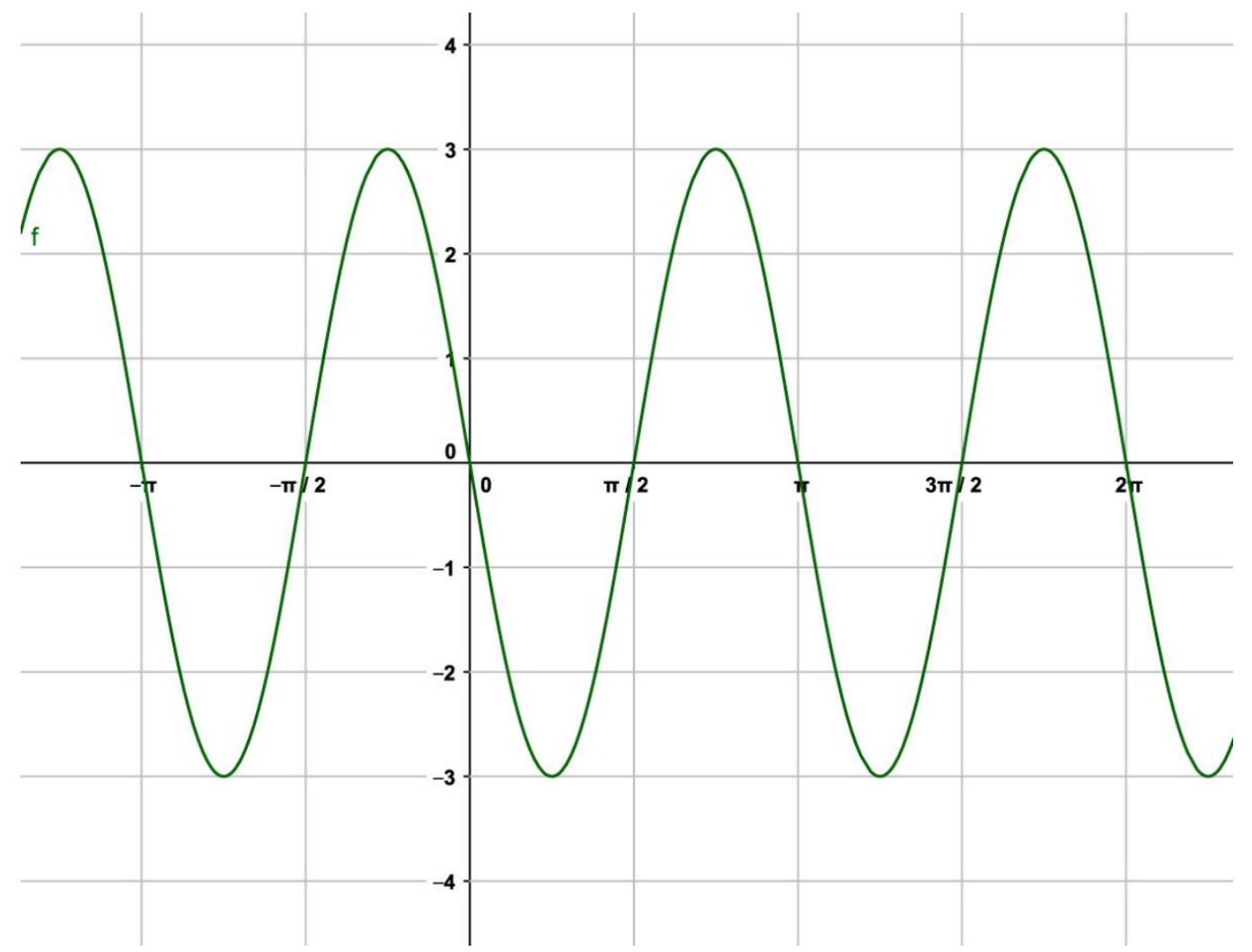

Figura $53-y=3 \cdot \cos (2 x+2)$

Fonte: Elaboradas pelo autor com o auxílio dos programas Geogebra, Excel e Graph. Foram salvas em jpeg.

\subsection{FUNÇÕES INVERSAS}

Em Matemática o termo inverter é utilizado para descrever uma função que troca de volta o que uma outra função faz, ou seja, cada uma desfaz o efeito da outra. A ideia de resolver uma equação $y=f(x)$ para $x$ como uma função de $y$, digamos $\mathrm{x}=\mathrm{g}(\mathrm{y})$ é uma das ideias mais importantes na Matemática.

Por exemplo, para $y=x^{3}+1$, temos: $f(x)=x^{3}+1$ e $g(x)=\sqrt[3]{y-1}$. Assim:

$$
\begin{gathered}
g(f(x))=\sqrt[3]{f(x)-1}=\sqrt[3]{\left(x^{3}+1\right)-1}=x \\
f(g(x))=[g(x)]^{3}+1=(\sqrt[3]{y-1})^{3}=y
\end{gathered}
$$

Se as funções $\mathbf{f}$ e $\mathbf{g}$ satisfazem as condições, podemos definir:

- $g(f(x))=x$ para todo $x$ no domínio de $f$ 
- $\mathrm{f}(\mathrm{g}(\mathrm{y}))=\mathbf{y}$ para todo $\mathbf{y}$ no domínio de $\mathbf{g}$, dizemos que $\mathbf{f}$ e $\mathbf{g}$ são funções inversas uma da outra, ou então, que f é uma inversa de $\mathbf{g}$ e $\mathbf{g}$ é uma inversa de $\mathbf{f}$.

Podemos usar outra notação para $\mathbf{g}: \mathrm{f}^{-1}(\mathrm{y})=\sqrt[3]{y-1}$. Ou seja:

- $\mathbf{f}^{-1}(\mathbf{f}(\mathbf{x}))=\mathbf{x}$ para todo $\mathbf{x}$ no domínio de $\mathbf{f}$

- $f\left(f^{-1}(y)\right)=y$ para todo $y$ no domínio de $f^{-1}$

\subsubsection{Mudança da variável independente}

As fórmulas acima usam $\mathbf{x}$ como variável independente para $\mathbf{f}$ e $\mathbf{y}$ como variável dependente para $\mathrm{f}^{-1}$, mas se quisermos esboçar os gráficos de $\mathrm{f}$ e $\mathrm{f}^{-1}$ juntos no mesmo sistema de coordenadas $\mathbf{x y}$, usaremos a mesma variável independente $\mathbf{x}$ e a mesma variável dependente y para ambas as funções. Veja:

- $\mathrm{y}=\mathrm{x}^{3}+1$

- $y=\sqrt[3]{x-1}$

\subsubsection{Domínio e imagem das funções inversas}

As fórmulas acima usam $\mathbf{x}$ como variável independente para $\mathbf{f}$ e $\mathbf{y}$ como variável dependente para $\mathrm{f}^{-1}$, mas se quisermos esboçar os gráficos de $f$ e $\mathrm{f}^{-1}$ juntos no mesmo sistema de coordenadas $\mathbf{x y}$, usaremos a mesma variável independente $\mathbf{x}$ e a mesma variável dependente y para ambas as funções.

Portanto, as relações entre os domínios e imagens de $\mathbf{f e}^{\mathrm{f}} \mathbf{f}^{-1}$, podem ser dadas por:

- Domínio de $f^{-1}=$ imagem de $f$

- Imagem de $\mathrm{f}^{-1}=$ domínio de $f$

\subsubsection{Existência de função inversa}

Se uma função $f$ tem uma inversa, então ela deve associar saídas distintas a entradas distintas. Por exemplo, a função $f(x)=x^{2}$ não pode ter uma inversa porque associa o mesmo valor a $x=2$ e a $x=-2$, a saber, $f(2)=f(-2)=4$. Assim, se $f(x)=x^{2}$ tivesse uma inversa, então a equação $f(2)=4$ implicaria que $f^{-1}(4)=2$ e a equação $f(-$ 
2) $=4$ implicaria que $\mathrm{f}^{-1}(4)=-2$. Mas isso é impossível, porque $\mathrm{f}^{-1}(4)$ não pode ter dois valores diferentes.

\subsection{FUNÇÃO INJETORA}

Uma função que associa saídas distintas a entradas distintas é denominada injetora ou, então, invertível. Uma função tem uma inversa, se e somente se, f é injetora

Algebricamente, isso significa que uma função é injetora, se e somente se, $f\left(x_{1}\right) \neq f\left(x_{2}\right)$ sempre que $x_{1} \neq x_{2}$, geometricamente, uma função é injetora se, e somente se, o gráfico de $y=f(x)$ é cortado no máximo, uma única vez por qualquer reta horizontal.

\subsubsection{O teste da reta horizontal}

Uma função tem uma inversa se, e somente se, seu gráfico é cortado, no máximo, uma única vez por qualquer reta horizontal.
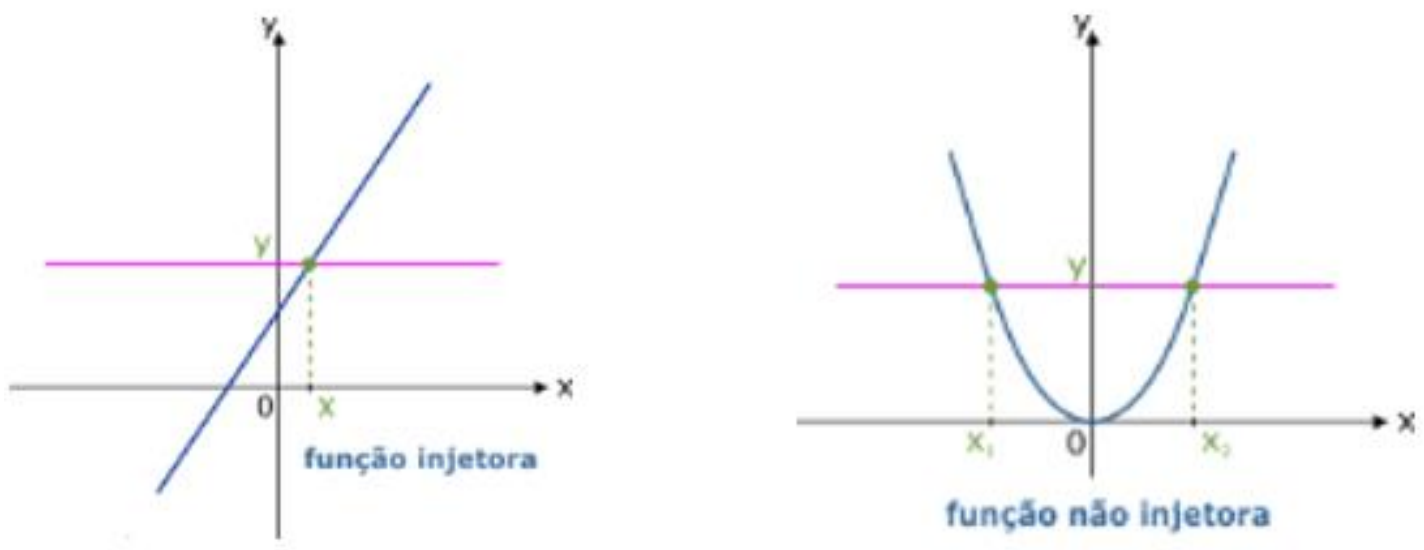

Figura 54 - Exemplos de função injetora.

Fonte: Elaboradas com o auxílio dos programas Geogebra, Graph, Adobe Photoshop e Corel Draw

Se cada uma das retas cortar o gráfico em um só ponto, então a função é bijetora. 

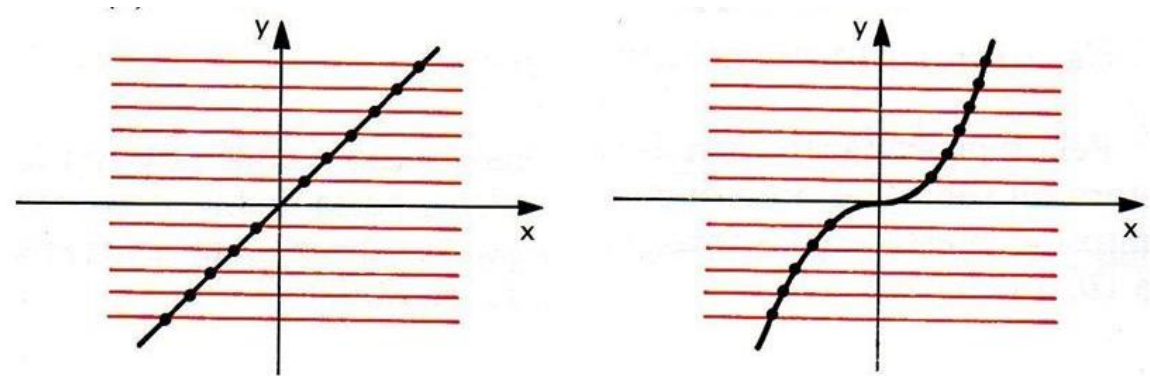

Figura 55 - Exemplos de função bijetora.

Fonte: Elaboradas com o auxílio dos programas Geogebra, Graph, Adobe Photoshop e Corel Draw

\subsection{FUNÇÕES EXPONENCIAIS}

Uma função da forma $f(x)=b^{x}$, em que $b>0$, é denominada função exponencial de base b. Note que a função exponencial tem uma base constante e um expoente variável.

$O$ valor de $b^{x}$ cresce com $\mathbf{x}$ crescente se $b>1$, decresce com $\mathbf{x}$ crescente se 0 $<b<1$, e é constante se $b=1$. Se $b>0$, então $f(x)=b^{x}$ está bem definida e tem um valor real para cada valor real de $\mathbf{x}$, de modo que o domínio natural de cada função exponencial é $(-\infty, \infty)$.

Se $b>0$ e $b \neq 0$, então, o gráfico de $y=b^{x}$ cresce sem parar à medida que percorrermos em um sentido e decresce em direção a zero, sem nunca o atingir, à medida que o percorrermos no outro sentido. Isso implica que a imagem de $f(x)=b^{x}$ é $(0,+\infty)$. 


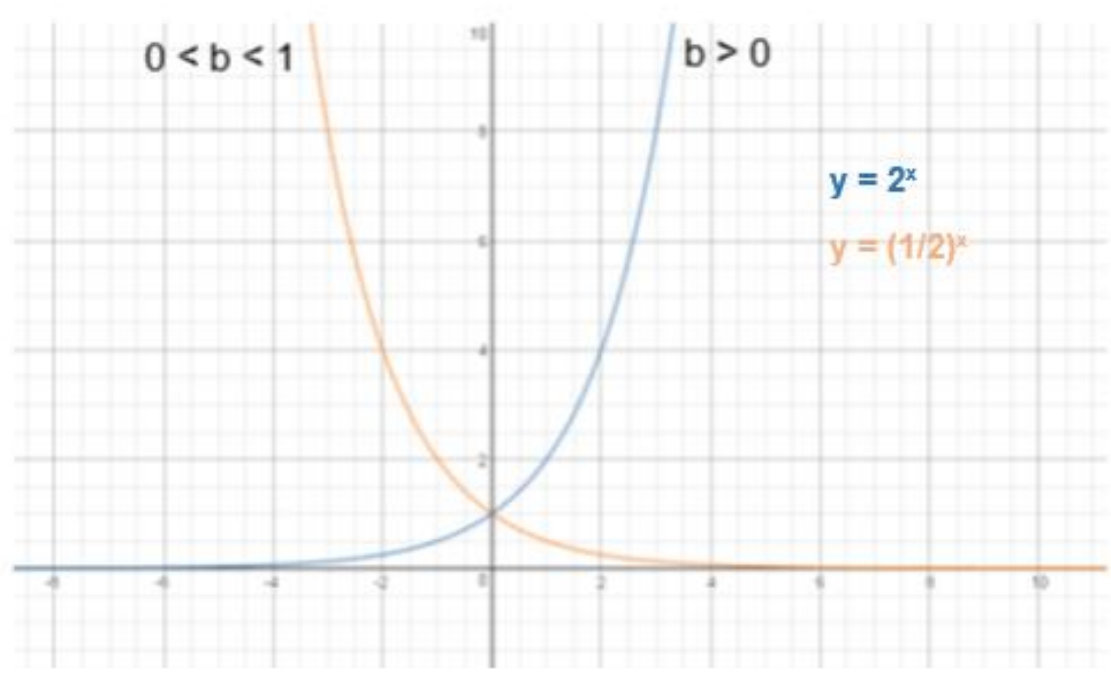

Figura $56-\mathrm{y}=2^{\mathrm{x}}$ e $\mathrm{y}=(1 / 2)^{\mathrm{x}}$.

Fonte: Elaboradas pelo autor com o auxílio dos programas Geogebra, Excel e Graph. Foram salvas em jpeg.

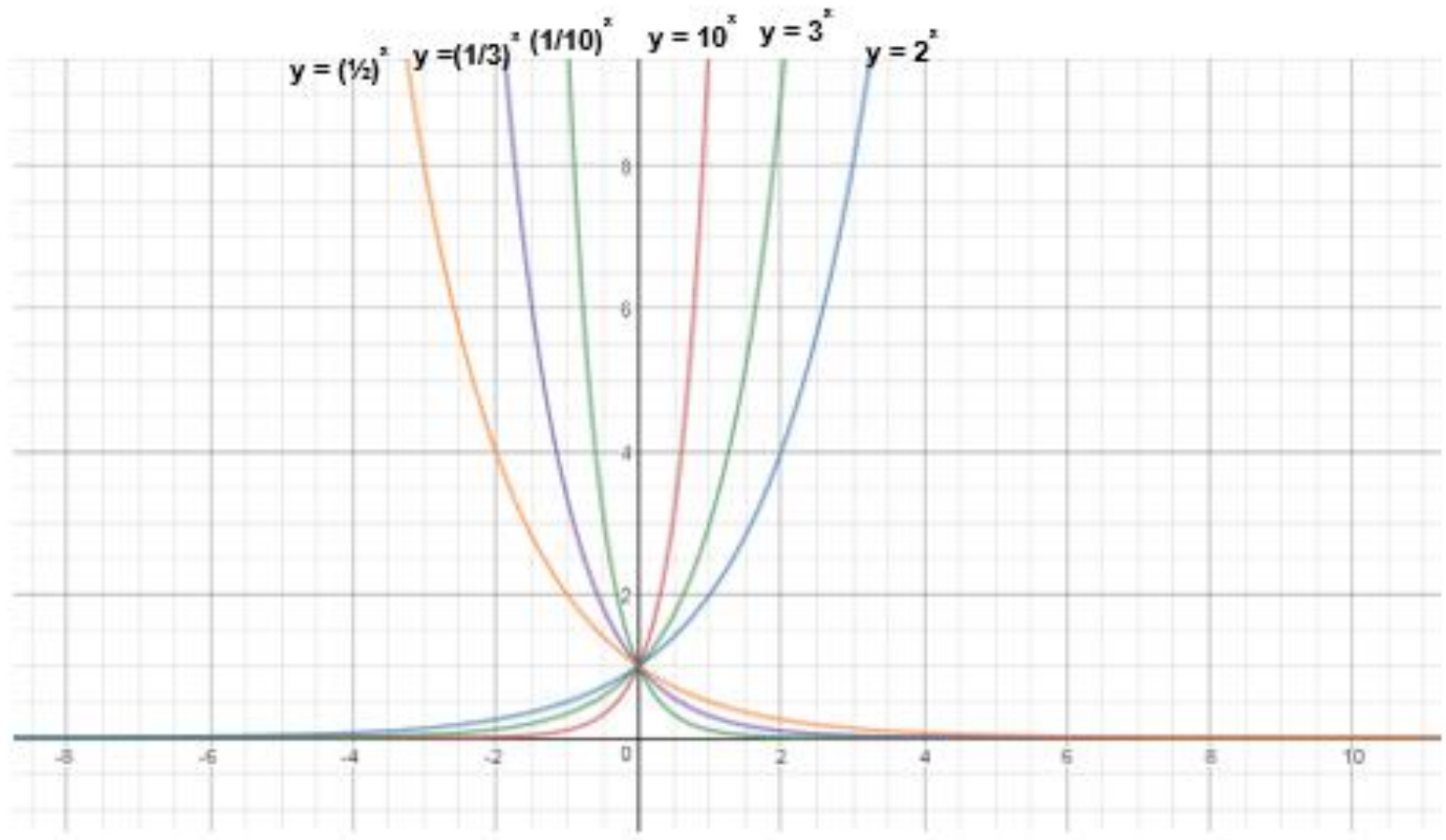

Figura 57 -

Fonte: Elaboradas pelo autor com o auxílio dos programas Geogebra, Excel e Graph. Foram salvas em jpeg.

\subsubsection{A função exponencial natural}

Dentre todas as bases possíveis para as funções exponenciais, há uma em particular que desempenha um papel essencial na Matemática. Essa base, denotada 
pela letra e, é um certo número irracional_cujo valor até a sexta casa decimal é: $e \sim 2,718282$. A função $f(x)=e^{x}$ é denominada função exponencial natural.

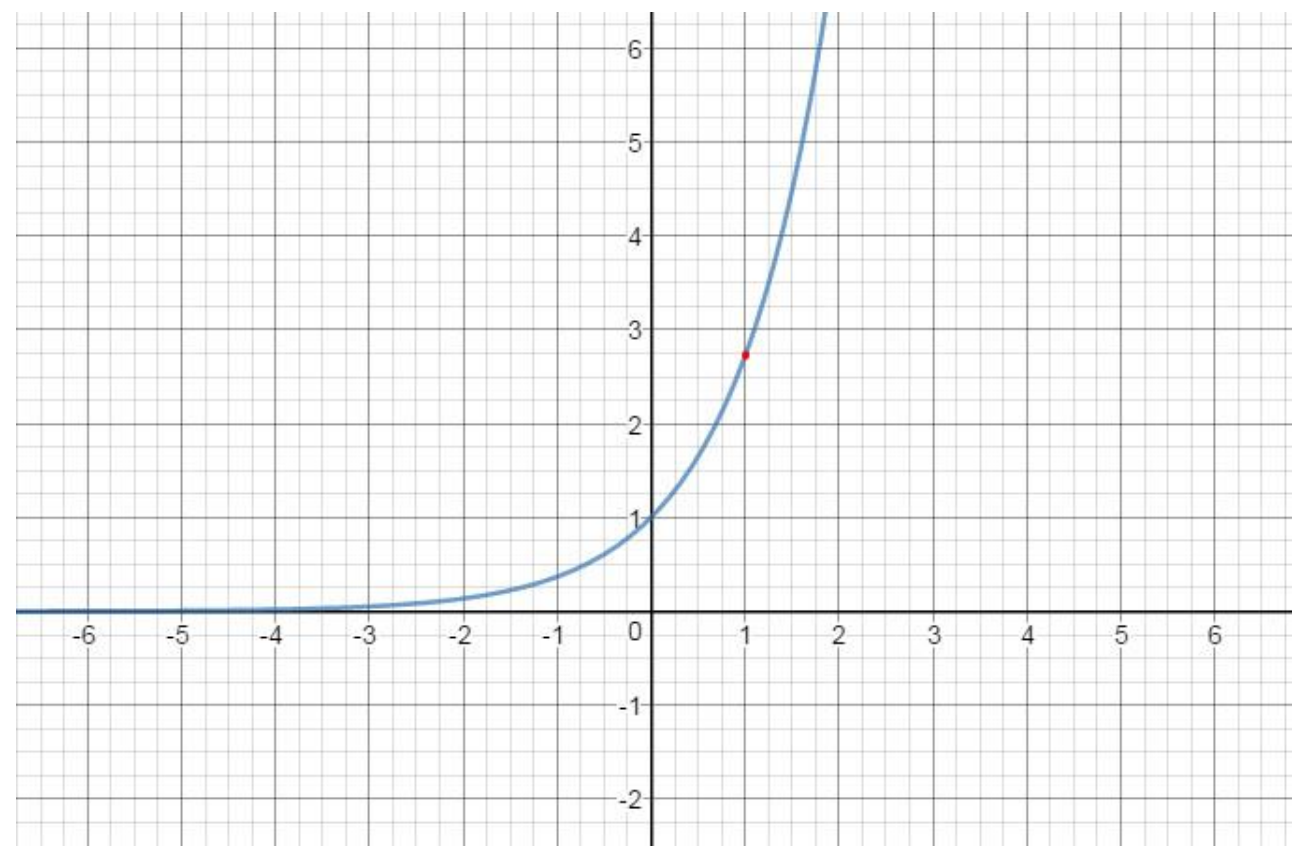

Figura 58 -

Fonte: Elaboradas pelo autor com o auxílio dos programas Geogebra, Excel e Graph. Foram salvas em jpeg.

\subsection{A FUNÇÃO LOGARÍTMICA}

Com $b>0$ e $b \neq 1$ e para um valor positivo de $\mathbf{x}$, a expressão:

$\log _{b} x$ denota aquele expoente ao qual devemos elevar $\mathbf{b}$ para obter $\mathbf{x}$ Veja alguns exemplos:

- $\log _{10} 100=2$

- $\log _{10}(1 / 1000)=-3$

- $\log _{2} 16=4$

- $\log _{b} 1=0$

- $\log _{b} b=1$

A função $f(x)=\log _{b} x$ é denominada função logarítmica de base $b$.

Teorema: se $b>0$ e $b \neq 1$, então $b^{x}$ e $\log _{b} x$ são funções inversas.

O logaritmo mais importante nas aplicações é o de base e, que é denominado logaritmo natural: $\log _{\mathrm{e}} \mathrm{x}=\ln \mathrm{x}$ 


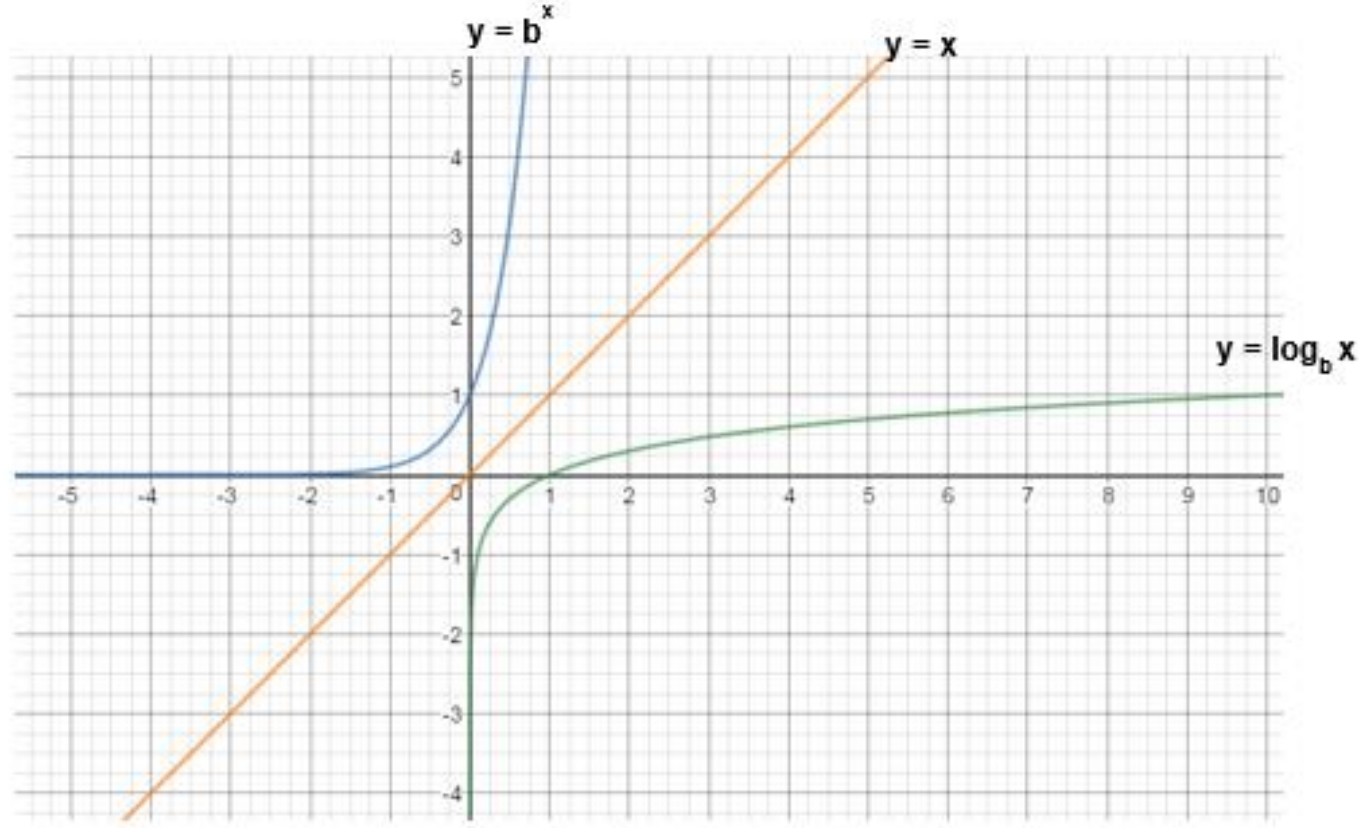

Figura 59 -

Fonte: Elaboradas pelo autor com o auxílio dos programas Geogebra, Excel e Graph. Foram salvas em jpeg.

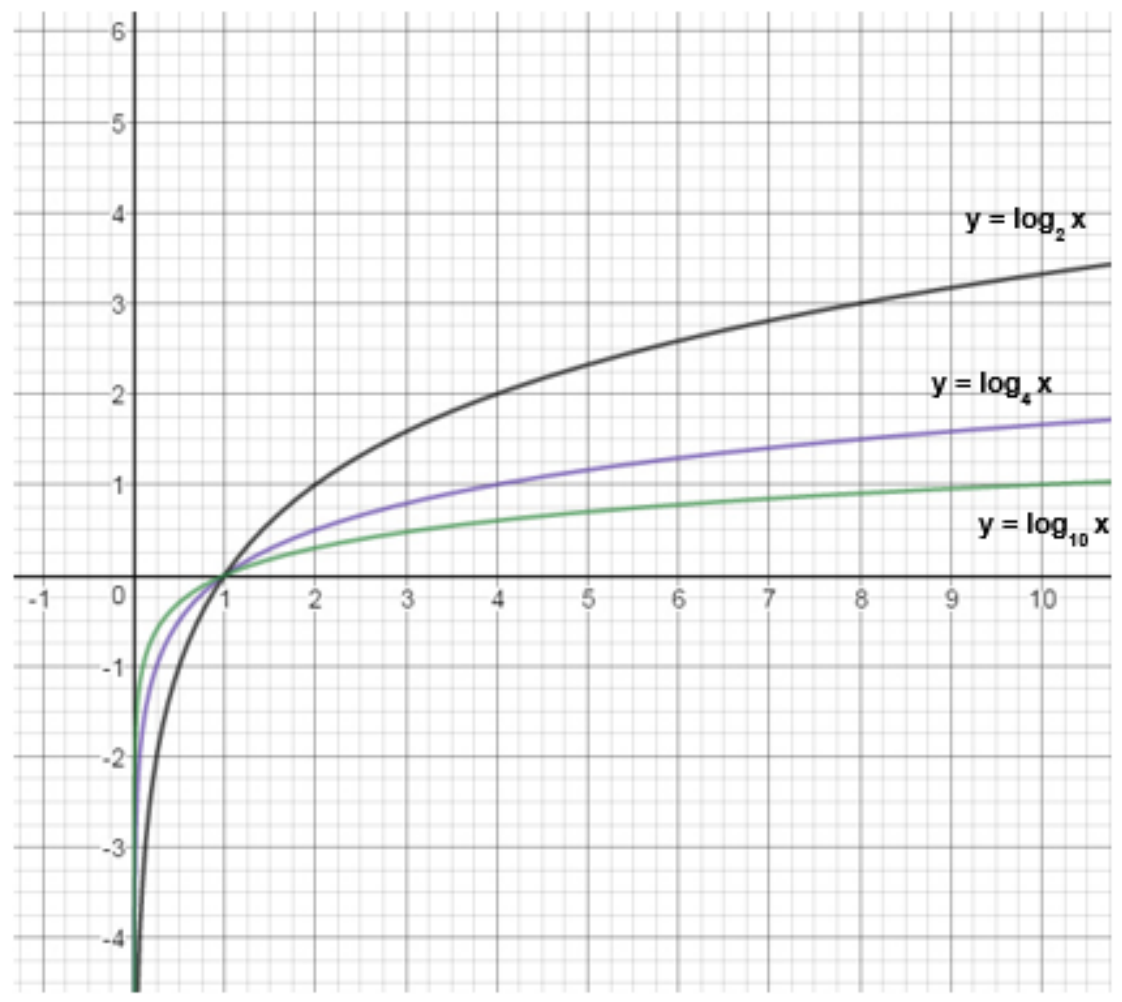

Figura 60 -

Fonte: Elaboradas pelo autor com o auxílio dos programas Geogebra, Excel e Graph. Foram salvas em jpeg. 


\subsubsection{Crescimento exponencial e logarítmico}

As funções $\mathbf{e}^{\mathbf{x}}$ e $\mathbf{I n} \mathbf{x}$, crescem quando $\mathbf{x}$ cresce, mas seus crescimentos são diferentes. A função $\mathrm{e}^{\mathbf{x}}$ cresce extremamente rápido, enquanto o crescimento de $\mathbf{I n} \mathbf{x}$ é extremamente vagaroso. Por exemplo para $\mathrm{x}=10 \mathrm{o}$ valor de $\mathrm{e}^{\mathbf{x}}$ está acima de 22.000 , mas em $x=1.000$ o valor de In $\mathbf{x}$ nem se quer atinge 7 . Observe.

\begin{tabular}{|c|c|c|}
\hline$X(\mathrm{~cm})$ & $e^{\mathrm{x}}$ & $\ln \mathrm{x}$ \\
\hline 1 & $2,72(\mathrm{~cm})$ & $0(\mathrm{~cm})$ \\
\hline 6 & $4,03(\mathrm{~m})$ & $1,79(\mathrm{~cm})$ \\
\hline 10 & $220(\mathrm{~m})$ & $2,3(\mathrm{~cm})$ \\
\hline 24 & $264.891(\mathrm{Km})$ & $3,18(\mathrm{~cm})$ \\
\hline 43 & $4,3($ anos luz) & $3,76(\mathrm{~cm})$ \\
\hline
\end{tabular}

\subsection{O NÚMERO e}

Uma das obras importantes do matemático Jacob Bernoulli foi a descoberta do número e. Ele estava interessado em descobrir para onde convergiam diferentes séries de números (sequências). Examinava a ideia de juros compostos sobre dinheiro. Sabia que se os juros fossem adicionados à soma com maior frequência, digamos: mensalmente ao invés de anualmente, a soma cresceria mais depressa.

Mas o que aconteceria se fossem calculados a cada semana? Ou a cada dia? Ou a cada segundo?

Então descobriu que, se depositasse $R \$ 1,00$ a uma taxa de percentagem anual de 100\%:

- Se capitalizada anualmente, torna-se $R \$ 2,00$

- Se capitalizada semestralmente, torna-se $R \$ 2,25$

- Se capitalizada trimestralmente, torna-se $R \$ 2,44$

- Se capitalizada mensalmente, torna-se $\mathrm{R} \$ 2,61$ 
- Se capitalizada semanalmente, torna-se $\mathrm{R} \$ 2,69$

- Se capitalizada diariamente, torna-se $\mathrm{R} \$ 2,71$

- Se capitalizada continuamente, torna-se $R \$ 2,718 \ldots$

Esse raciocínio nos leva a essa série de números:

$$
\left(1+\frac{1}{1}\right)^{1},\left(1+\frac{1}{2}\right)^{2},\left(1+\frac{1}{3}\right)^{3},\left(1+\frac{1}{4}\right)^{4},\left(1+\frac{1}{5}\right)^{5} \ldots
$$

Calculando cada termo da série: $2 ; 2,25 ; 2,37 ; 2,44 ; 2,488 ; 2,5216 ; \ldots$

Ao chegar no centésimo termo seu valor é: 2,704 e quanto mais adiante na sequência seu valor converge para o número e. Assim:

$$
\lim _{n \rightarrow \infty}\left(1+\frac{1}{n}\right)^{n}=e
$$

A seguir, uma tabela para análise de convergência para valores de $\mathbf{n}$ cada vez maiores:

\begin{tabular}{|c|c|c|}
\hline $\mathbf{n}$ & $\mathbf{1}+\frac{\mathbf{1}}{\mathbf{n}}$ & $\left(\mathbf{1}+\frac{\mathbf{1}}{\mathbf{n}}\right)^{\mathbf{n}}$ \\
\hline 1 & 2 & 2,0000000 \\
\hline 10 & 1,1 & 2,593742 \\
\hline 100 & 1,01 & 2,704814 \\
\hline 1000 & 1,001 & 2,716924 \\
\hline 10000 & 1,0001 & 2,718146 \\
\hline 100000 & 1,00001 & 2,718268 \\
\hline 1000000 & 1,000001 & 2,718280 \\
\hline
\end{tabular}




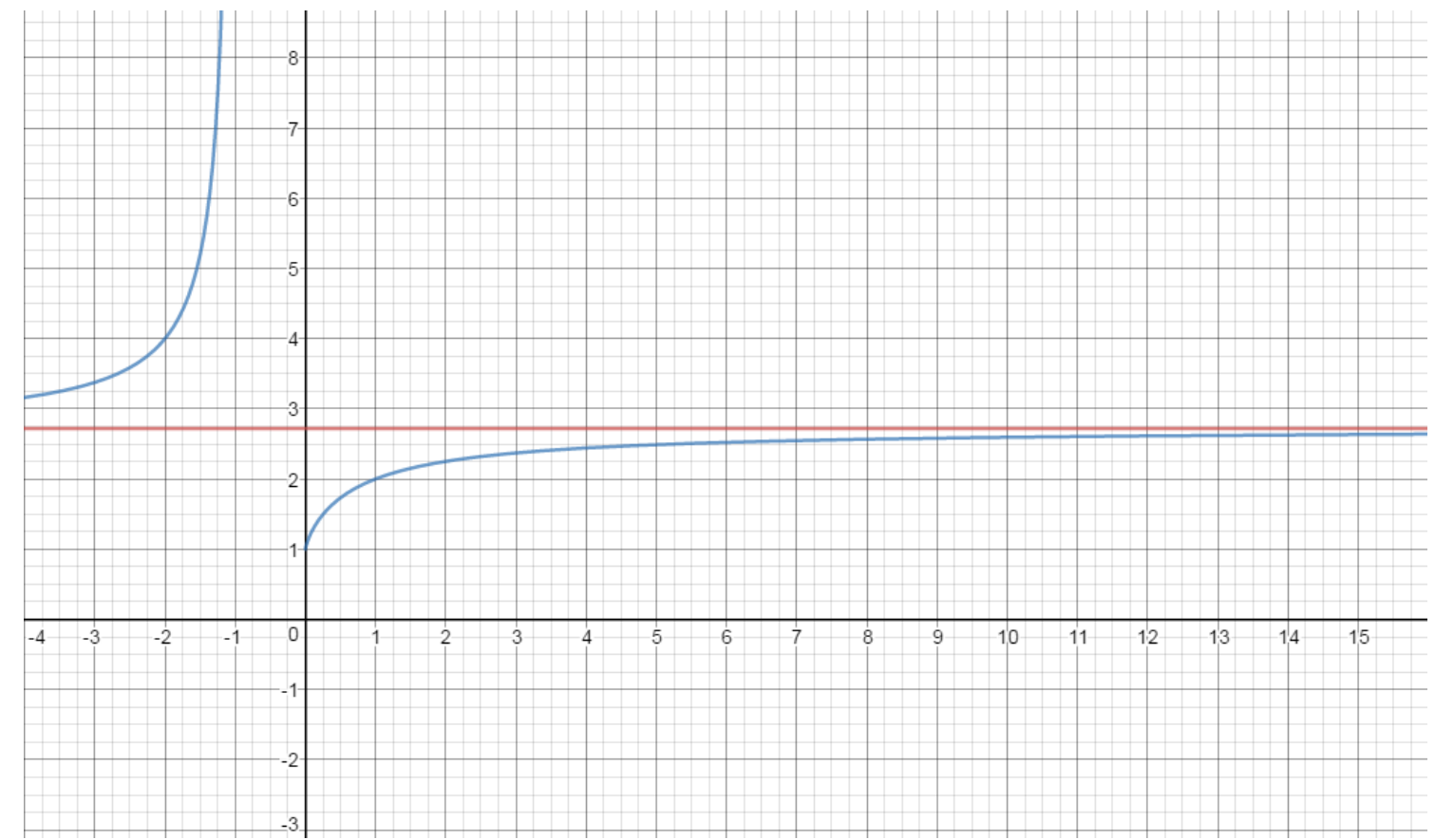

Figura $61-y=\left(1+\frac{1}{x}\right)^{x}$

Fonte: Elaboradas pelo autor com o auxílio dos programas Geogebra, Excel e Graph. Foram salvas em jpeg. 
Apêndice B

Avaliação diagnóstica 

Perguntas investigativas sobre conceito de função e conhecimento de funções elementares

Nome da instituição de ensino:

Série e sala:

Nome (dupla):

1- Dê uma definição informal de função

2- Dê uma definição matemática de função (escrever com o formalismo matemático)

3- Cite 4 exemplos quaisquer de função (linear, quadrática, exponencial, trigonométrica, etc.)

4- Na expressão $\mathbf{y}=\mathbf{f}(\mathbf{x})$, o que significa o $\mathbf{y}$ ? o que é $\mathbf{x}$ ? o que significa $\mathbf{f}$ ?

5- 5x+4=0 é uma função? Justifique sua resposta

6- A expressão $5 x+4$ é uma função de 1o. grau? Justifique

7- $\mathbf{z}=\mathbf{b}^{2} \mathbf{y}+\mathbf{c}$, dados $b, c \in \mathfrak{R}$ e $b \neq 0$, é uma função do 1o. grau? Por quê?

8- $\mathbf{f}(\mathbf{a})=\mathbf{x a}^{\mathbf{2}}+\mathbf{b a}+\mathbf{c}$ é função? Qual é a variável independente? Qual a variável dependente? Explique.

9- $\mathbf{y}^{\mathbf{2}}+\mathbf{x}^{\mathbf{2}}=\mathbf{1}$ é uma função? Justifique sua resposta

10- Quais gráficos abaixo representam função:

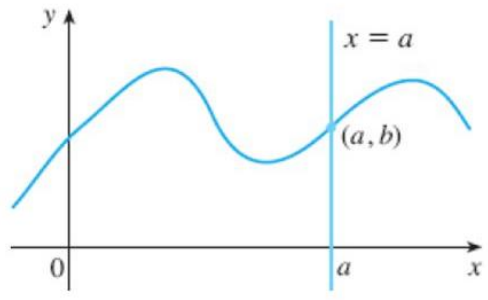

Graf.

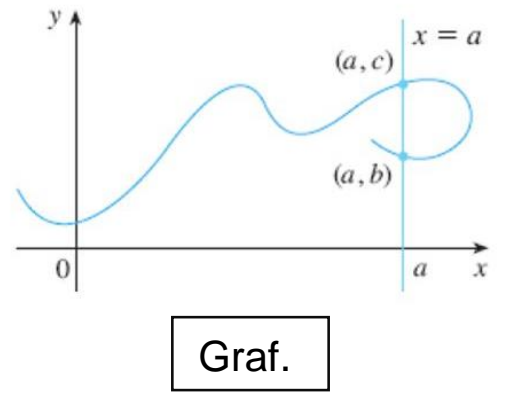

Graf.

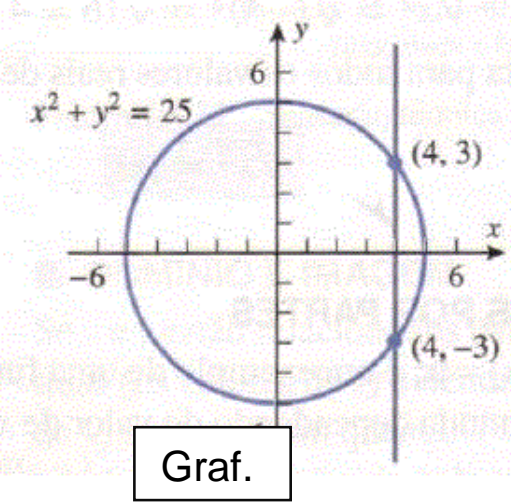

11- Evolução do peso de uma pessoa ao longo dos anos 


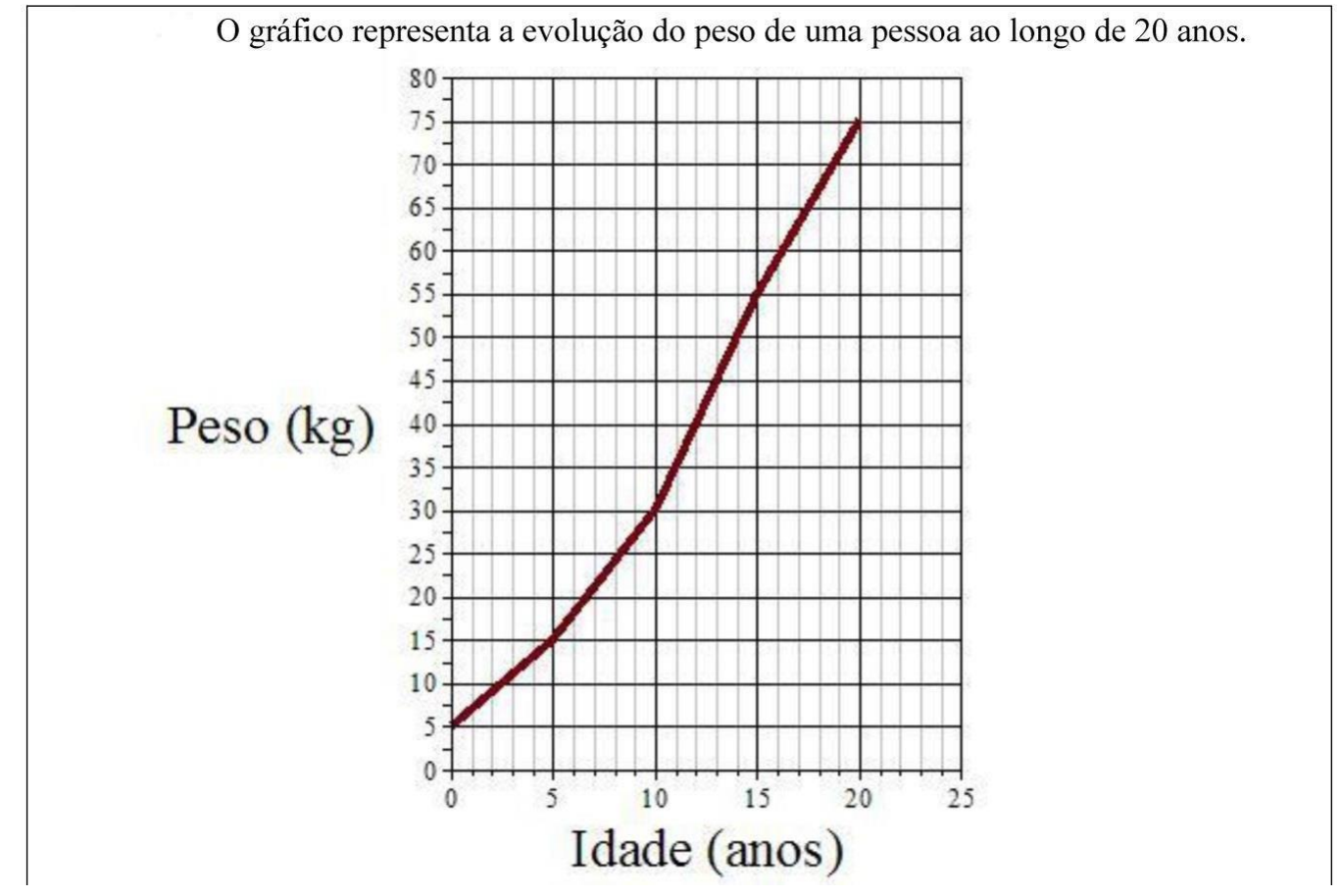

a- Quais a variáveis relacionadas no gráfico? Qual é a variável dependente? E a independente?

b- Considerando a função $\mathbf{p}$, que relaciona o peso da pessoa com a sua idade $\mathbf{i}$, indique o valor de $\mathrm{p}(10)$ e $\mathrm{p}(0)$. O que significa esses valores?

c- Qual a idade da pessoa quando pesava $75 \mathrm{~kg}$ ?

d- Qual o domínio da função? Qual seu significado no contexto da situação?

e- Qual a imagem da função? Qual seu significado no contexto da situação? 
12- Gráfico de função polinomial de $1^{\circ}$ grau

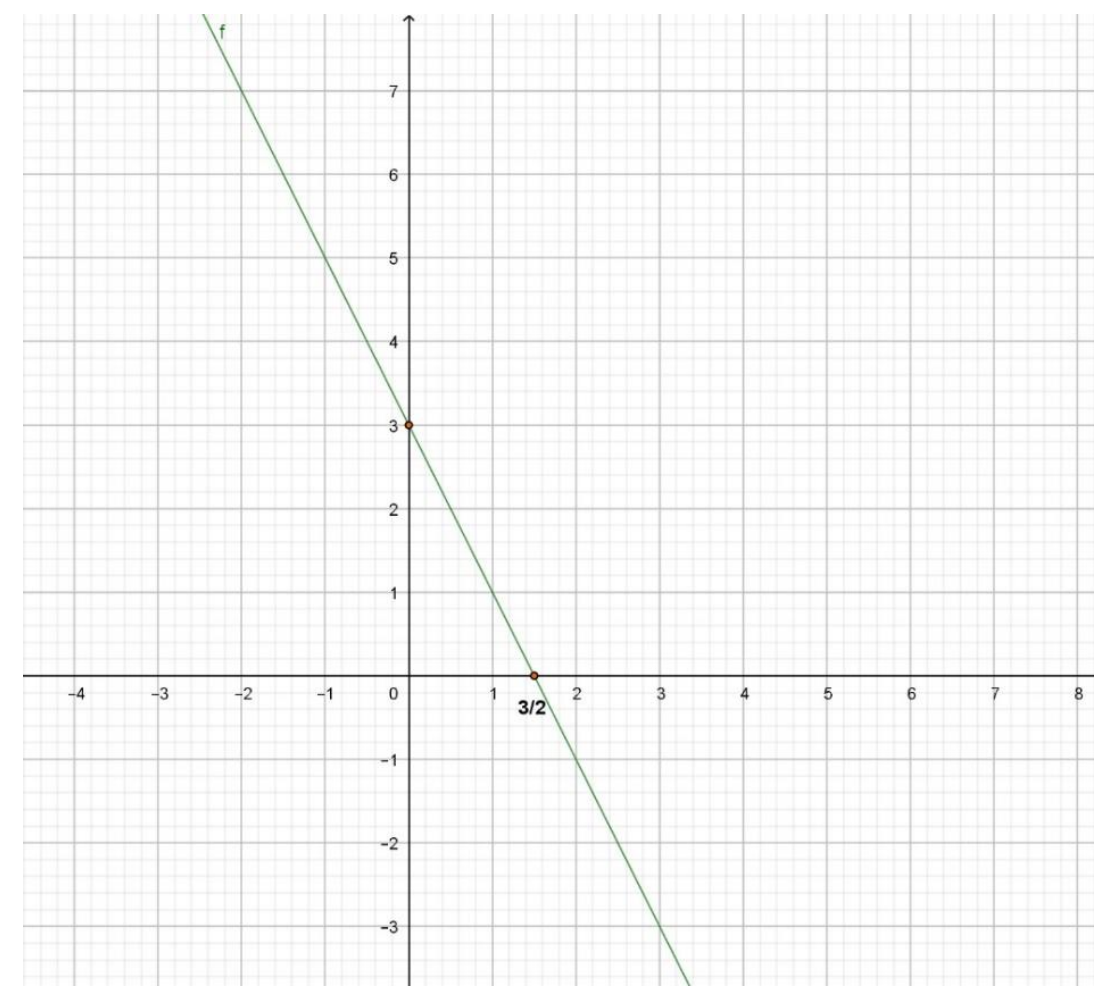

Considere a função polinomial de $1^{\circ}$ grau acima: $\mathbf{f}(\mathbf{x})=\mathbf{a} \cdot \mathbf{x}+\mathbf{b}$

a- Qual é a lei dessa função f?

b- A função é crescente ou decrescente?

c- Qual é o valor do coeficiente angular e linear da reta? 
13- Conceito de função polinomial de $2^{\circ}$ grau

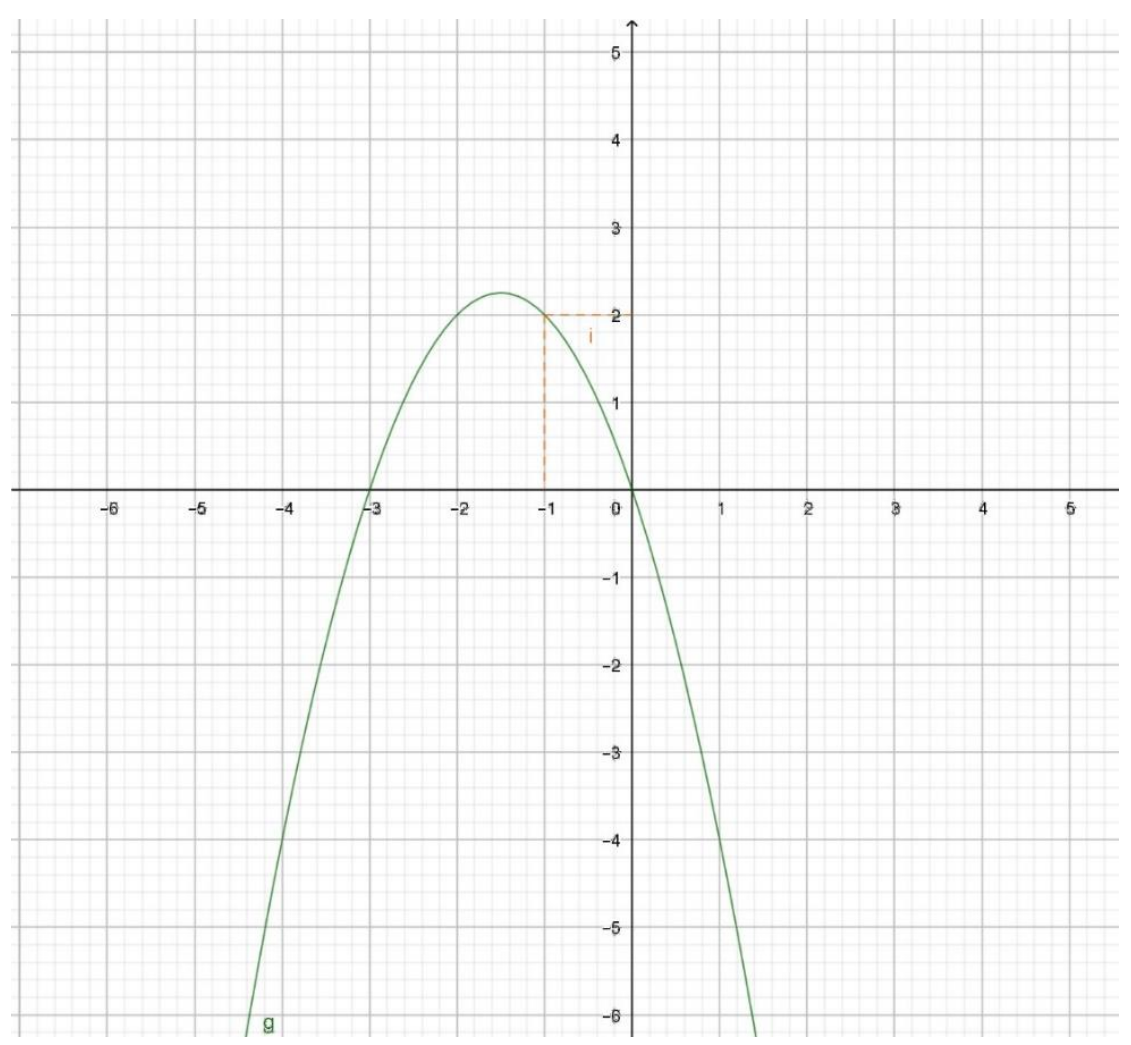

O gráfico acima representa uma função polinomial de $2^{\circ}$ grau

a- Qual é a lei da função?

b- Qual é a coordenada do vértice da parábola?

c- Qual é o ponto de máximo da parábola?

d- Qual é imagem dessa função? 


\section{4- Taxas de variação}

Se uma equação linear é usada para relacionar duas grandezas reais $\boldsymbol{x}$ e $\boldsymbol{y}$, então a inclinação da

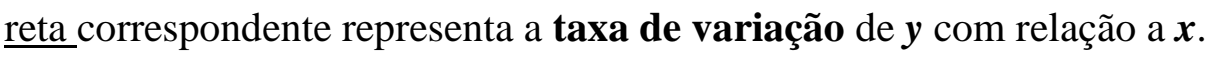

\section{Problema: Projeto de uma estrada}

Um engenheiro precisa projetar uma estrada que desça de um ponto que está a $50 \mathrm{~m}$ de altura até um ponto que está na altura $0 \mathrm{~m}$, com um declive de $6 \%$. Defina uma equação que forneça a altura $(\boldsymbol{y})$ da estrada em relação ao deslocamento horizontal $(\boldsymbol{x})$. Determine, também, o comprimento horizontal da rampa.

O termo "declive" é equivalente a "inclinação negativa". Ou seja, se a estrada tem um declive de 6\%, então sua inclinação é $\boldsymbol{m}=-\mathbf{6} / \mathbf{1 0 0}$.

Observe que o declive não tem unidade, de modo que a estrada desce $\mathbf{6} \mathbf{~ m}$ a cada $\mathbf{1 0 0}$ metros de distância horizontal, o que é o mesmo que dizer que ela desce $6 \mathrm{~cm}$ a cada $100 \mathrm{~cm}-$ ou $1 \mathrm{~m}$ - percorrido na horizontal. Nesse caso, dizemos que a inclinação é a razão entre a variação da altura e a variação da posição horizontal.

Supondo, então, que a estrada comece no ponto $\boldsymbol{x}=\mathbf{0}$, no qual a altura é igual a $50 \mathrm{~m}$, podemos dizer que o ponto $(\mathbf{x} 1, \mathbf{y} 1)=(0,50)$ satisfaz a equação que desejamos encontrar. Qual é essa equação? 
15- Função exponencial

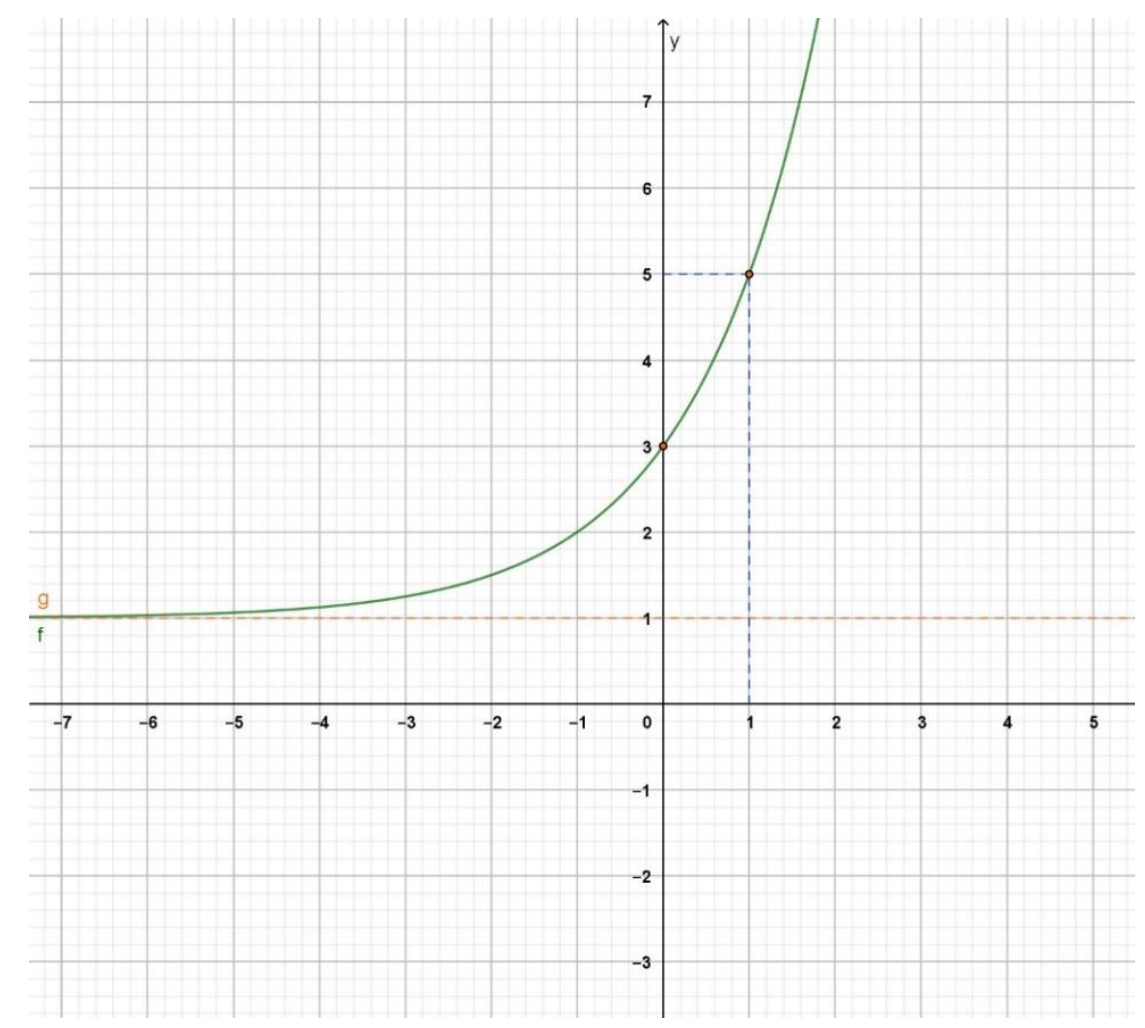

O gráfico acima representa uma função exponencial $\mathbf{f}$ cuja lei é $\mathbf{f}(\mathbf{x})=\mathbf{a}+\mathbf{b . 2} \mathbf{x}$ Sendo a e b constantes positivas.

a- Determine a e b

b- Qual é o conjunto imagem de f?

c- Calcule $\mathrm{f}(-2)$

16- Esboce o gráfico da função $\mathbf{f}(\mathbf{x})=(\mathbf{1} / 2)^{\mathbf{x}}+\mathbf{1}$

a- A função é crescente ou decrescente?

b- Qual o valor da assíntota? 


\section{Função trigonométrica}

17- Dada as funções do tipo: $\mathbf{f}(\mathbf{x})=\mathbf{a}+\mathbf{b} \cdot \operatorname{sen}(\mathbf{c} \cdot \mathbf{x}+\mathbf{d})$ ou $\mathbf{g}(\mathbf{x})=\mathbf{a}+\mathbf{b} \cdot \cos (\mathbf{c} \cdot \mathbf{x}+\mathbf{d})$

Com $\mathbf{D}=\mathbf{R}$ e conjunto imagem com intervalo fechado de extremidades $\mathbf{a}+\mathbf{b}$ e $\mathbf{a}-\mathbf{b}$

Com período $\mathbf{p}=\mathbf{2 . \Omega} / \mathbf{c} \mid$

Dada a função $\mathbf{f}(\mathbf{x})=1+3 \cdot \operatorname{sen}(2 \cdot x-\pi / 5)$

a- Qual é a imagem da função?

b- Qual o período $\mathbf{p}$ da função?

18- Dado o gráfico abaixo, responda:

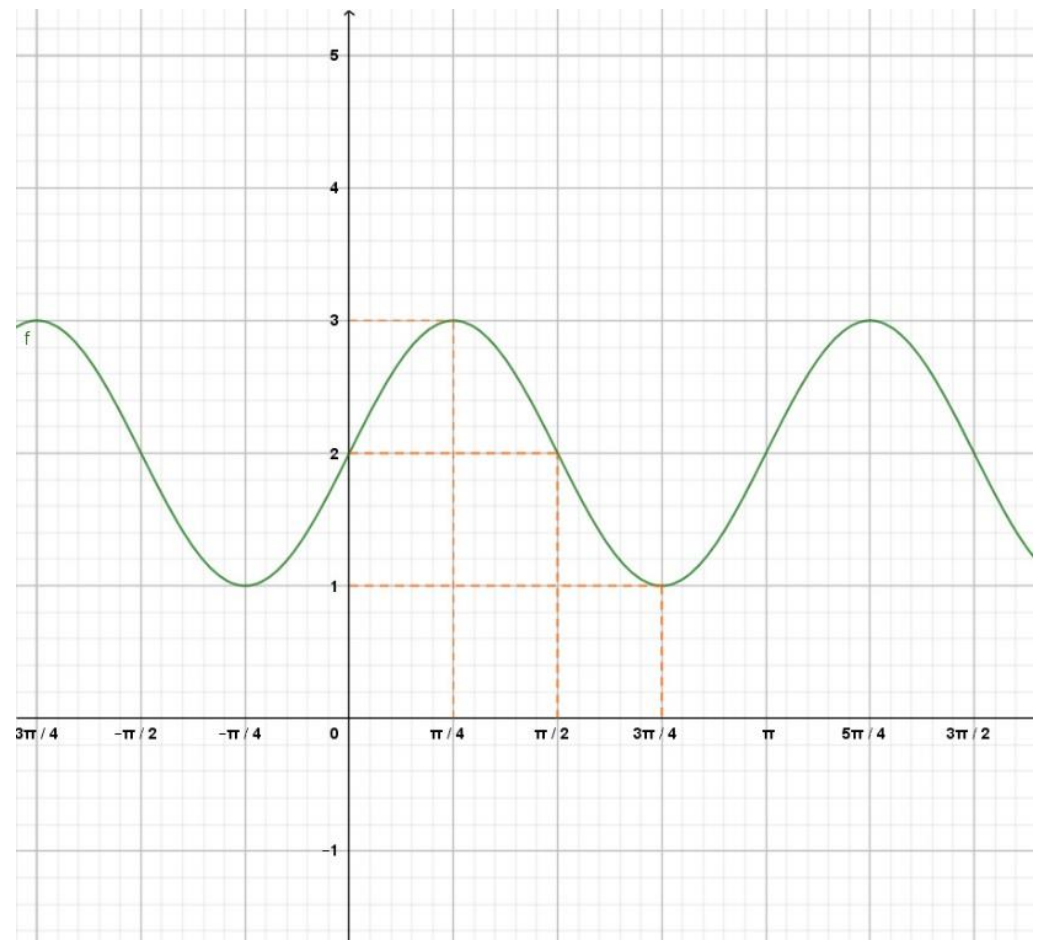

Determine o período, conjunto imagem, a amplitude e a lei de formação da função do tipo $=\mathbf{a}+\mathbf{b} \cdot \operatorname{sen}((\mathbf{c} . x)$ 

Apêndice C

Análise a posteriori do conhecimento sobre funções elementares 



\section{Análise a posteriori do conhecimento sobre funções elementares}

Revisitando conceito de função e conhecimento de funções elementares

Nome (dupla): Elisa/Isabelle (grupo1)

Com relação às questões que vocês responderam no início das atividades de Modelagem Matemática, revejam as questões abaixo:

- Revendo as questões 1 e 2 , tem algo que vocês mudariam nas respostas?

- Na questão 4, qual é o significado de f?

- Com relação a questão $6,5 \mathbf{x}+4$ é uma função de $1^{\circ}$ grau?

- Reveja a questão 7: $\mathbf{z}=\mathbf{b}^{2} \mathbf{y}+\mathbf{c}$ é função?

- Revendo a questão 8: $\mathbf{f}(\mathbf{a})=\mathbf{x} \cdot \mathbf{a}^{2}+\mathbf{b} \cdot \mathbf{x}+\mathbf{c}$ é função? Qual é a variável dependente e a independente?

- Na questão $9, \mathbf{y}^{2}+\mathbf{x}^{2}=1$ é uma função?

- Com relação aos três gráficos da questão 10, qual representam função?

- Revendo a questão 12 calcule o coeficiente angular e linear da reta. Depois expresse a lei de formação da função.

- Na questão 13, tente responder as questões a, b, $\mathbf{c}$ e $\mathbf{d}$.

- Depois de nossos estudos sobre taxa de variação, tente resolver a questão 14

- No exercício 16 revejam a questão b e tente achar o valor da assíntota

- Na questão 18 , ache os valores de $\mathbf{a}, \mathbf{b}$ e $\mathbf{c}$ e dê a lei completa de formação. 


\section{Análise a posteriori do conhecimento sobre funções elementares}

Revisitando conceito de função e conhecimento de funções elementares

\section{Nome (dupla): Giovanna/Victor (grupo2)}

Com relação às questões que vocês responderam no início das atividades de Modelagem Matemática, revejam as questões abaixo:

- Revendo as questões 1 e 2 , tem algo que vocês mudariam nas respostas?

- Reveja a questão 7: $\mathbf{z}=\mathbf{b}^{2} \mathbf{y}+\mathbf{c}$ é função?

- Revendo a questão 8: $\mathbf{f}(\mathbf{a})=\mathbf{x} \cdot \mathbf{a}^{2}+\mathbf{b} \cdot \mathbf{x}+\mathbf{c}$ é função? Qual é a variável dependente e a independente?

- Na questão $9, \mathbf{y}^{2}+\mathbf{x}^{2}=1$ é uma função?

- Com relação aos três gráficos da questão 10, qual representam função?

- Na questão 13 , tente responder as questões a, b, c e d

- Depois de nossos estudos sobre taxa de variação, tente resolver a questão 14

- Na questão 15, determine a e b, e a imagem da função f

- No exercício 16 revejam a questão b e tente achar o valor da assíntota

- Na questão 18 , ache os valores de $\mathbf{a}, \mathbf{b}$ e $\mathbf{c}$ e dê a lei completa de formação 


\section{Análise a posteriori do conhecimento sobre funções elementares}

Revisitando conceito de função e conhecimento de funções elementares

Nome (dupla): Lucas/Ingrid (grupo3)

Com relação às questões que vocês responderam no início das atividades de Modelagem Matemática, revejam as questões abaixo:

- Revendo as questões 1 e 2 , tem algo que vocês mudariam nas respostas?

- Com relação a questão 6 a expressão: $5 x+4$ é uma função?

- Reveja a questão 7: $\mathbf{z}=\mathbf{b}^{2} \mathbf{y}+\mathbf{c}$ é função conhecida?

- Revendo a questão 8: $\mathbf{f}(\mathbf{a})=\mathbf{x} \cdot \mathbf{a}^{2}+\mathbf{b} \cdot \mathbf{x}+\mathbf{c}$ é função? Qual é a variável dependente e a independente?

- Na questão $9, \mathbf{y}^{2}+\mathbf{x}^{2}=\mathbf{1}$ é uma função?

- Com relação aos três gráficos da questão 10, qual representam função?

- Na questão 12, identifique o coeficiente linear e calcule o coeficiente angular

- Na questão 13, tente responder as questões $\mathbf{a}, \mathbf{b}, \mathbf{c}$ e $\mathbf{d}$

- Depois de nossos estudos sobre taxa de variação, tente resolver a questão 14

- No exercício 16 revejam a questão b e tente achar o valor da assíntota 
Apêndice D

\section{Grupo 1}

Material desenvolvido para a Modelagem 



\section{Modelagem Matemática: Fase 1}

Prof. Orientador: Ronaldo Ramunno (IME)

Grupo 1: Isabelle e Elisa

Situação-problema: Qual a relação entre a variação da densidade da solução (água e cloreto de sódio) com a variação da quantidade de cloreto de sódio (Nacl) acrescentada a solução?

Inteiracão: Conhecimentos prévios para definir o problema

Conceito de densidade:

Densidade é a razão entre a massa e o volume. A unidade de volume no SI é o $\mathrm{m}^{3}$ a unidade da massa é o Kg. Logo a unidade da densidade é $\mathbf{K g} / \mathbf{m}^{3}$

$$
D=\frac{\mathbf{m}}{\mathbf{v}}
$$

Muitas vezes aparecem densidades em unidade $\mathbf{g} / \mathbf{c m}^{\mathbf{3}}$ e para convertermos as unidades basta usar o fator de conversão: $1 \mathrm{~g} / \mathrm{cm}^{3}=1000 \mathrm{Kg} / \mathrm{m}^{3}$

A densidade da água é $1 \mathrm{~g} / \mathrm{cm}^{3}$ ou $1000 \mathrm{Kg} / \mathrm{m}^{3}$

Outras substâncias têm densidades diferente, como o álcool: $790 \mathrm{Kg} / \mathrm{m}^{3}$ ou $0,79 \mathrm{~g} / \mathrm{cm}^{3}$

\section{Conceito de Empuxo:}

Como você sabe, uma pedra afunda na água. Já a madeira bóia na superfície de um lago. Uma moeda com massa de poucas gramas afunda, mas um porta aviões de aço maciço flutua. Como podemos entender esses fenômenos tão distintos?

Uma bóia, ou colchão de ar flutua sem problemas sobre a superfície de uma piscina. Todavia, se você já tentou empurrar um colchão de ar para baixo da água, sabe que isso é praticamente impossível, pois exige muita força para fazê-lo. À medida que você pressiona para baixo, a água empurra o colchão de volta para cima. Essa força resultante de um fluido, orientada para cima, é o que se chama de força de empuxo.

Quando um objeto (ou parte de um objeto) é imerso em um fluido, ele desloca uma parcela de fluido que, do contrário, preencheria esse espaço. Esse fluido é chamado de fluido deslocado. 
O volume do fluido deslocado é exatamente o volume da porção do objeto que está imersa no fluido.

Princípio de Arquimedes: Um fluido exerce força de empuxo orientada para cima $\mathbf{F}_{\mathbf{e}}$ sobre um objeto imerso ou que flutua no fluido. O módulo da força de empuxo equivale ao peso do fluido deslocado pelo objeto.

Suponha que um fluido tenha densidade $\mathbf{d f}$ e que o objeto desloque um volume vf do mesmo. A massa do fluido deslocado é $\mathbf{m}_{\mathbf{f}}=\mathbf{d}_{\mathbf{f}} \mathbf{x} \mathbf{v}_{\mathbf{f}}$ e, portanto, se peso é $\mathbf{P}=\mathbf{m}_{\mathbf{f}} \mathbf{X} \mathbf{g}=\mathbf{d}_{\mathbf{f}} \mathbf{x} \mathbf{v f} \mathbf{x} \mathbf{g}$ onde $\mathbf{g}$ é gravidade da Terra: $\mathbf{g = 9 , 8 ~} \mathbf{m} / \mathrm{s}^{\mathbf{2}}$

Logo o princípio de Arquimedes em forma de equação é: $\mathbf{F}_{\mathbf{e}}=\mathbf{d}_{\mathbf{f}} \mathbf{x} \mathbf{V} \mathbf{x} \mathbf{g}$

Obs.: É importante distinguir a densidade e o volume do fluido deslocado da densidade e do volume do objeto. Para evitar esse tipo de erro usaremos as letras f e o, em subscrito, para o fluido e para o objeto, respectivamente.

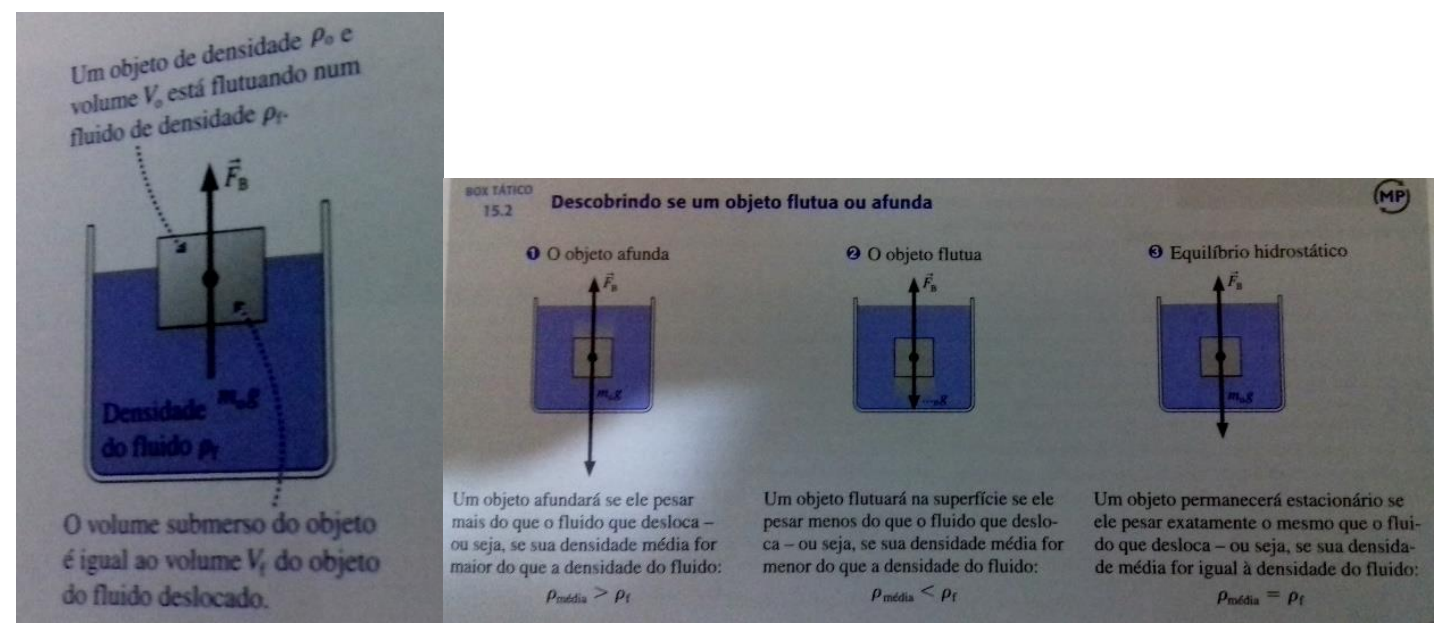

Fonte: RANDALL, DK. Física: Uma abordagem estratégica. São Paulo: Companhia Editora LTDA, 2009.

\section{Flutua ou afunda?}

Se você mantiver um objeto submerso e depois soltá-lo, ele flutuará de volta à superfície, afundará ou permanecerá "suspenso" na água. Como podemos prever o que acontecerá? A força resultante sobre o objeto depois de liberá-lo é $\mathbf{F}_{\mathbf{r}}=\left(\mathbf{F}_{\mathbf{e}}-\mathbf{m}_{\mathbf{0}} . \mathbf{g}\right)$. Se ele apontará para a superfície ou para o fundo dependerá da força de empuxo $\mathbf{F}_{\mathbf{e}}$ ser maior ou menor do que o peso $\underline{\text { do objeto }} \mathbf{p}_{\mathbf{o}}=\mathbf{m}_{\mathbf{0}} . \mathbf{g}$ (ver figuras acima). 
O módulo da força de empuxo é $\mathbf{F} \mathbf{e}=\mathbf{d} \mathbf{x} \mathbf{x} \mathbf{v f} \mathbf{x} \mathbf{g}$. O peso de um objeto uniforme, como um bloco de aço, é $\mathbf{P}_{\mathbf{o}}=\mathbf{d}_{\mathbf{o}} \mathbf{X} \mathbf{v}_{\mathbf{0}} \mathbf{x} \mathbf{g}$. Porém, um objeto composto, como um mergulhador, pode ter partes de densidade variada. Se definirmos a densidade média como $\mathbf{d}_{\mathbf{m}}=\mathbf{m}_{\mathbf{o}} / \mathbf{v}_{\mathbf{o}}$, o peso de um objeto composto será $\mathbf{P}_{\mathbf{o}}=\mathbf{d}_{\mathbf{m}} \cdot \mathbf{v}_{\mathbf{o}} \cdot \mathbf{g}$

Comparando $d_{\mathbf{f}} \mathbf{x} \mathbf{v}_{\mathbf{f}} \mathbf{x} \mathbf{g} \operatorname{com} \mathbf{d}_{\mathbf{m}} \cdot \mathbf{v}_{\mathbf{o}} \cdot \mathbf{g}$ e observando que $\mathbf{v}_{\mathbf{f}}=\mathbf{v}_{\mathrm{o}}$ para um objeto que esteja totalmente submerso, vemos que um objeto flutuará ou afundará dependendo da densidade do fluido $\mathbf{d}_{\mathbf{f}}$ ser maior ou menor do que a densidade média do objeto $\mathbf{d}_{\mathbf{m}}$. $\underline{\text { Repare que os volumes }}$ $\underline{\text { se cancelam na equação, }}$ bem como a gravidade $\mathbf{g}$.

Se as densidades forem iguais, $\mathbf{d}_{\mathbf{m}}=\mathbf{d}_{\mathbf{f}}$ o objeto estará em equilíbrio estático e ficará suspenso, pois a força peso está equilibrada com o empuxo.

O objeto afundará se ele pesar mais do que o fluido deslocado, ou seja, se sua densidade média for maior do que a densidade do fluido: $\mathbf{d}_{\mathbf{m}}>\mathbf{d}_{\mathbf{f}}$

Um objeto flutuará na superfície se ele pesar menos do que o fluido que desloca, ou seja, se sua densidade média for menor do que a densidade do fluido: $\mathbf{d}_{\mathbf{m}}<\mathbf{d}_{\mathbf{f}}$

Como exemplo, o aço é mais denso do que a água, de modo que um bloco de aço afunda. $\mathrm{O}$ óleo é menos denso do que a água; logo, óleo flutua em água.

Definição do problema: Podemos, através de um experimento envolvendo densidade de fluidos e força de empuxo, achar uma função matemática que possa expressar a relação entre a variação da densidade da solução (água e cloreto de sódio) com a variação da quantidade de cloreto de sódio (Nacl) acrescentada a solução? 


\section{Modelagem Matemática: Fase 2}

Prof. Orientador: Ronaldo Ramunno (IME)

Grupo 1: Isabelle e Elisa

Situação-problema: Qual a relação entre a variação da densidade da solução (água e cloreto de sódio) com a variação da quantidade de cloreto de sódio (Nacl) acrescentada a solução?

\section{Experimentacão para obtenç̃̃o de dados:}

Nessa fase precisaremos realizar um experimento de laboratório para obtermos os dados necessários para a modelagem.

Relatório para realizar o experimento:

1- Pesar o Becker e anotar o valor que aparece no visor da balança: $\mathbf{M}_{\mathbf{b}}=$

2- Pese o Becker com os 300ml de água destilada: $\mathbf{M}_{\mathbf{b}+\mathbf{a}}=$

2.1- Como existe uma margem de imprecisão no Becker, ajuste a quantidade de água no Becker para que o peso total: $\mathbf{M}_{\mathbf{b}+\mathbf{a}}=\mathbf{M}_{\mathbf{b}}+\mathbf{3 0 0 g}$. $\mathrm{o} \mathbf{M}_{\mathbf{a}}=300 \mathrm{~g}$ pelo fato de que a densidade da água ser $1 \mathrm{~g} / \mathrm{cm}_{3}$

3- Vamos medir o volume do ovo: Encha o copo plástico com água até a borda e coloque o copo dentro do recipiente plástico. Com a pinça, coloque o ovo com cuidado dentro do copo e deixe a água transbordar e cair no recipiente.

4- Usando a seringa graduada, aspire a água que transbordou no recipiente plástico e meça seu volume de 10 em $10 \mathrm{ml}$ e coloque essa água na proveta graduada. A precisão da seringa é melhor do que a proveta. Anote o volume do ovo: $\mathbf{V}_{\text {ovo }}=$

5- Pese o ovo na balança digital, faça isso duas vezes para ter precisão: Movo=

6- Agora podemos calcular a densidade média do ovo: $\mathbf{D}_{\mathbf{o v o}}=\mathbf{M}_{\mathbf{o}} / \mathbf{V}_{\mathbf{o}} \quad \mathbf{D}_{\mathbf{o v o}}=$

Use 4 casas decimais para maior precisão.

7- Calcule o peso do ovo: $\mathbf{P}_{\mathbf{0}}=\mathbf{M}_{\mathbf{o}} \mathbf{. g}$

7.1- A massa do ovo que está em gramas deverá ser expressa em Kg. Exemplo: Suponha uma massa de 65,3g ela equivale a 0,0653Kg. A gravidade da Terra: $\mathbf{g}_{\mathbf{t}}=\mathbf{9 . 8} \mathbf{~ m} / \mathbf{s}^{\mathbf{2}}$

Então o peso do ovo será: $\mathbf{P}_{\mathbf{0}}=\mathbf{0 , 0 6 5 3} \times \mathbf{9 , 8}=\mathbf{0 , 6 3 9 9} \mathrm{N}$

8- Cálculo do Empuxo: Fe df • vf • g 
8.1- Veja esse exemplo de cálculo: Suponha uma densidade do fluido que no nosso caso é a água, a densidade da água é $\mathbf{d}_{\mathbf{a}}=\mathbf{1} \mathbf{g} / \mathbf{c m}^{\mathbf{3}}$ mas para calcular a força de empuxo a unidade de densidade deve estar em $\mathbf{K g} / \mathbf{m}^{3}$. O volume também deverá estar em $\mathbf{m}^{\mathbf{3}}$ e a gravidade já está na unidade correta $\mathbf{m} / \mathbf{s}^{2}$

Veja esse cálculo hipotético: $\mathrm{d}_{\mathrm{f}}=1 \mathrm{~g} / \mathrm{cm}^{3}$ precisa passar para $\mathrm{Kg} / \mathrm{m}^{3}$, mas sabemos que $1 \mathrm{~g} / \mathrm{cm}^{3}=10^{3} \mathrm{Kg} / \mathrm{m}^{3}, \operatorname{logo}$ a densidade da água será $10^{3} \mathrm{Kg} / \mathrm{m}^{3}$

$\mathrm{O}$ volume do fluido $\mathrm{V}_{\mathrm{f}}=58 \mathrm{~cm}^{3}$ então precisamos mudar a unidade de volume para $\mathrm{m}^{3}$ $58 \mathrm{~cm}^{3}=58 \times 10^{-6} \mathrm{~m}^{3}$ assim o cálculo do empuxo será:

$F_{e}=\left[\left(10^{3} \mathrm{Kg} / \mathrm{m}^{3}\right) .\left(58 \times 10^{-6} \mathrm{~m}^{3}\right) .\left(9.8 \mathrm{~m} / \mathrm{s}^{2}\right)\right]=568,4 \times 10^{-3} \mathrm{~N}=F_{\mathrm{e}}=0,5684 \mathrm{~N}$

9- Vamos agora relacionar as forças do empuxo e o peso do ovo:

$\mathbf{F}_{\mathbf{e}}=\mathbf{0 , 5 6 8 4} \mathbf{N}$ e o $\mathbf{P}_{\mathbf{0}}=\mathbf{0 , 6 3 9 9} \mathbf{N}$ perceba que a $\mathbf{F}_{\mathbf{e}}<\mathbf{P}_{\mathbf{0}}$ e isso implica que o ovo afundará.

10- Meça a massa do copinho plástico e verifique que sua massa é: $\mathbf{M}_{\mathbf{c}}=\mathbf{1 , 3 g}$

Ele será usado para pesar o sal (Nacl) que será o soluto da solução.

11- Iremos fazer 6 acréscimos de sal no Becker com água. Cada acréscimo será de 10g de sal (cloreto de sódio).

12- Primeiro acréscimo de sal: Coloque as $\mathbf{1 0 g}$ de sal no Becker com os $\mathbf{3 0 0 m l}$ de água.

12.1- Perceba que ao pesar o copinho com o sal a balança deverá registrar 11,3g pois ela está medindo os $10 \mathrm{~g}$ de sal mais a massa do copinho $1,3 \mathrm{~g}$.

13- Meça a massa do conjunto: Becker + água + sal = desconte a massa do Becker: $\mathbf{M}_{\mathbf{b}}=\mathbf{1 6 0 g}$. então a massa da água $+\mathrm{sal}=\mathbf{M}_{\mathbf{a}+\mathbf{s a l}}=$

14- Agora que o sal foi acrescentado a solução de 300ml de água seu volume irá aumentar e precisamos calcular esse volume para calcular a nova densidade da solução: Mexa sempre bem a solução até o sal se dissolver completamente na água.

14.1- Retire com a seringa a solução até que o Becker fique com os $300 \mathrm{ml}$ ou $300 \mathrm{~cm}^{3}$ anteriores, mas como o Becker não tem muita precisão de volume, vamos retirar o volume suficiente para que o Becker mais a água volte no peso anterior, ou seja, $\mathbf{M}_{\mathbf{a}+\text { sal }}$

15- O cálculo do volume retirado é feito com a seringa graduada e despejado na proveta.

16- Cálculo do novo volume: $\mathrm{V}_{\mathrm{T}}=\mathrm{V}_{\mathrm{B}}+\mathrm{V}_{\mathrm{R}}$ ( o volume total da primeira solução de água com sal será o volume total que é a soma do volume do Becker $(300 \mathrm{ml})$ mais o volume retirado com a seringa. $\mathbf{V}_{\mathbf{T} 1}=$

17- Agora que temos a massa dos $10 \mathrm{~g}$ de sal mais os $300 \mathrm{ml}$ de água: $\mathbf{M}_{\mathbf{a}+\mathbf{s a l}}$ e temos o volume VT1 podemos calcular a nova densidade da solução: D1

18- Calcule a nova densidade: $\mathbf{D}_{1}=\mathbf{M}_{1} / \mathbf{V}_{1}$ a unidade será $\mathrm{g} / \mathrm{cm}^{3}$ 
19- Esse mesmo procedimento realizado a partir do passo 12 que é o acréscimo de $\mathbf{1 0 g}$ de sal será repetido 6 vezes até o acréscimo de $60 \mathrm{~g}$ de sal.

20- Sendo assim teremos 6 densidades obtidas para cada acréscimo de $10 \mathrm{~g}$ de sal, obtendo 6 massas do conjunto Becker mais água e 6 volumes da diferença dos 300ml do Becker.

21- Provavelmente ao calcular a densidade 5, está será muito próxima ou igual à densidade do ovo; $\mathbf{D}_{5}=\mathbf{D}_{\text {ovo }}$ quando isso ocorrer, coloque o ovo na solução e repare que ele irá boiar. Isso se deve pelo fato da força de empuxo do fluido da solução se igualar a força peso do ovo.

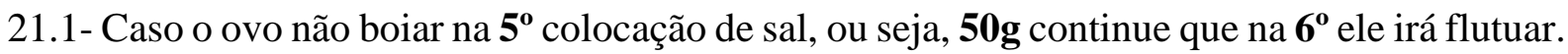
22- Calcule o empuxo nas densidades: D5 e $\mathbf{D}_{6}$ e se por exemplo ao calcular o empuxo $\mathbf{F}_{\mathbf{E}}$ e esse empuxo for maior que o peso do ovo, pare o experimento.

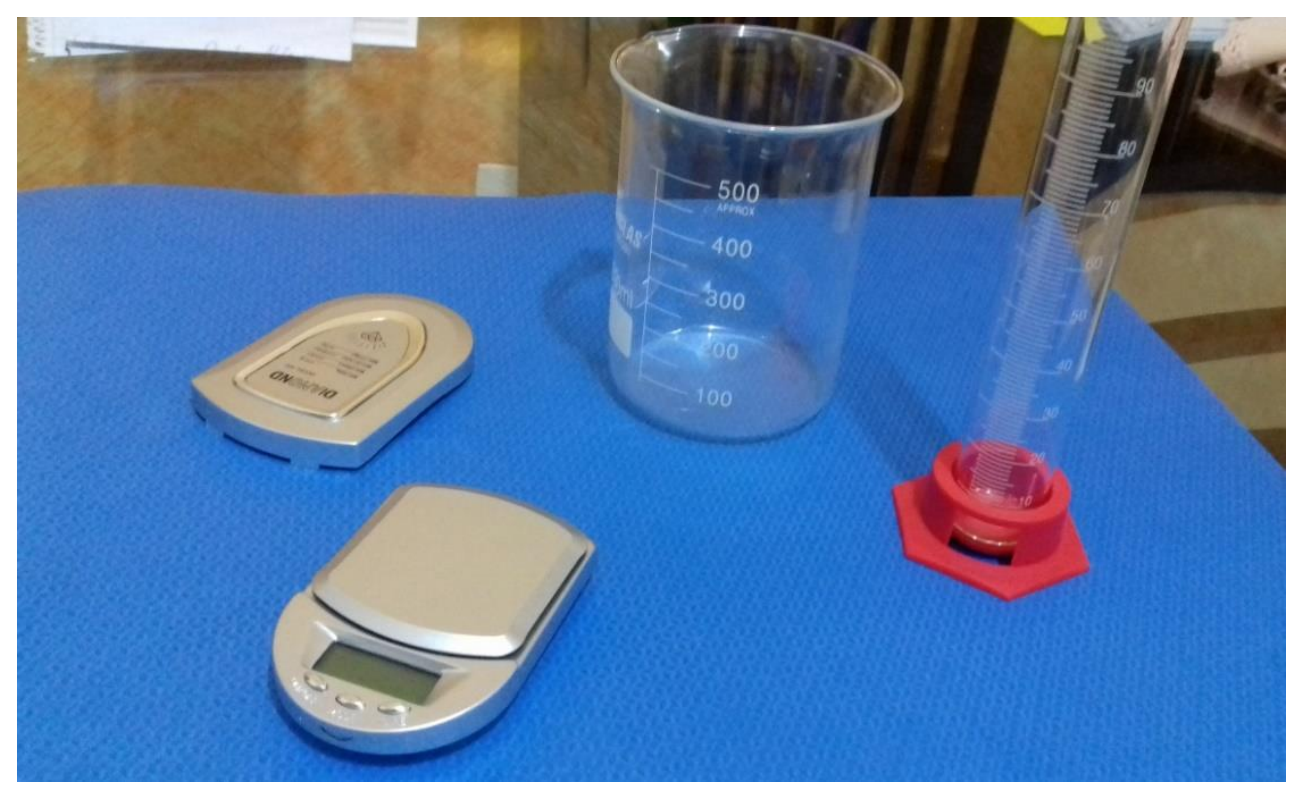

Fonte: Foto tirada pelo grupo 1 durante o experimento

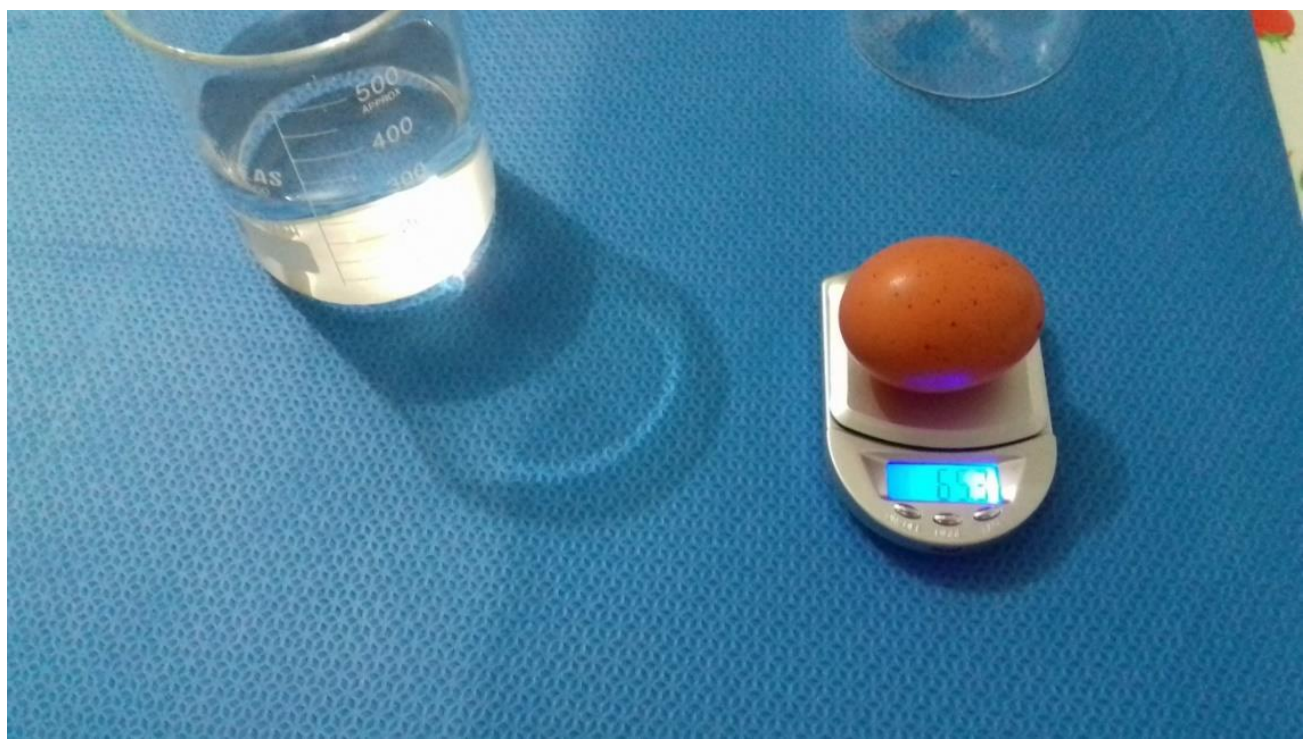




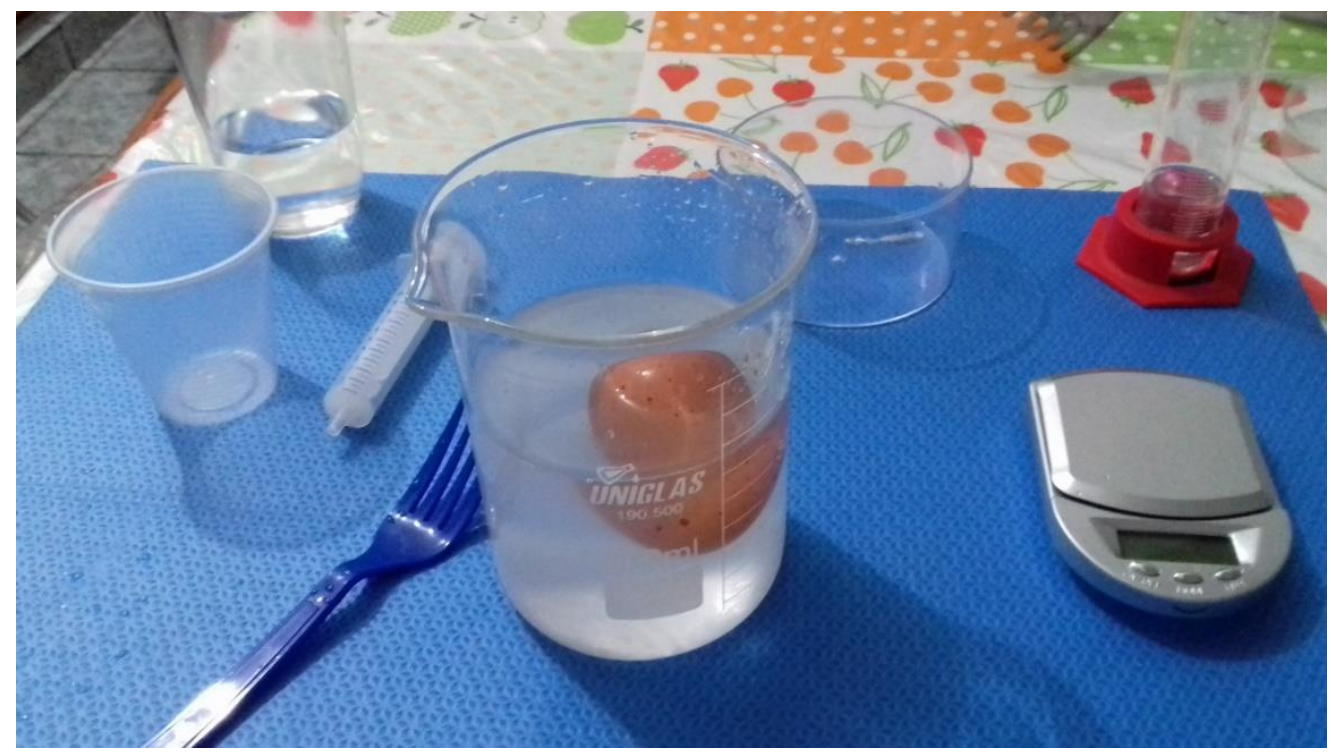

Fonte: Foto tirada pelo grupo 1 durante o experimento

\section{Experimento:}

Massa do Becker: $\mathbf{M}_{\mathbf{B}}=\mathbf{1 6 0 g}$ Massa do copinho plástico: 1,3g

Cálculo da densidade do ovo:

$D_{\text {ovo }}=M_{\text {ovo }} / V_{\text {ovo }}=65,3 \mathrm{~g} / 58 \mathrm{~cm}^{3}=1,1258 \mathrm{~g} / \mathrm{cm}^{3}$

Cálculo do Empuxo que o fluido (solução de água + sal (Nacl) exerce sobre o ovo):

$F_{e}=$ df $\cdot$ vf $\cdot g \quad F_{e}=\left[\left(10^{3} \mathrm{Kg} / \mathrm{m}^{3}\right) \cdot\left(58 \times 10^{-6} \mathrm{~m}^{3}\right) \cdot\left(9.8 \mathrm{~m} / \mathrm{s}^{2}\right)\right]=568,4 \times 10^{-3} \mathrm{~N}$
$F_{e}=0,5684 \mathrm{~N}$

Cálculo do peso do ovo:

$\mathbf{P}_{\mathbf{o}}=\mathbf{M}_{\mathbf{0}} \mathbf{x} \mathbf{g} \quad \mathrm{P}_{\mathrm{o}}=(0,0653 \times 9,8)=0,6399 \mathrm{~N} \mathbf{P}_{\mathbf{o}}=\mathbf{0 , 6 3 9 9} \mathbf{N}$ 


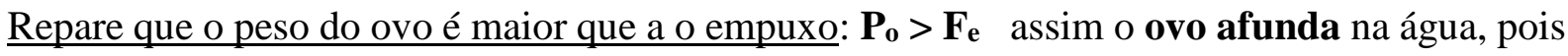
a sua densidade média é maior do que a da água. Isso mudará quando ao acrescentar o sal na solução, a densidade irá aumentar e superar a densidade do ovo.

Veja como ficou os dados do experimento do grupo na tabela abaixo:

\begin{tabular}{|l|l|l|l|l|}
\hline $\begin{array}{l}\text { Massa da } \\
\text { solução }(\mathrm{g})\end{array}$ & $\begin{array}{l}\text { Volume da } \\
\text { solução }\left(\mathrm{cm}^{3}\right)\end{array}$ & $\begin{array}{l}\text { Densidade } \\
\text { solução } \\
\left(\mathrm{g} / \mathrm{cm}^{\mathbf{3}}\right)\end{array}$ & $\begin{array}{l}\text { Volume } \\
\text { deslocado } \\
\left(\mathrm{cm}^{\mathbf{3}}\right)\end{array}$ & $\begin{array}{l}\text { Força } \\
\text { empux0: FE }(\mathrm{N})\end{array}$ \\
\hline $\mathbf{M}_{\mathbf{0}}=\mathbf{3 0 0}$ & $\mathbf{V}_{\mathbf{0}}=\mathbf{3 0 0}$ & $\mathbf{D}_{\mathbf{0}}=\mathbf{1 , 0 0 0 0}$ & $\mathbf{5 8}$ & $\mathbf{0 , 5 6 8 4}$ \\
\hline $\mathrm{M}_{1}=310$ & $\mathrm{~V} 1=305$ & $\mathrm{D}_{1}=1,0164$ & 58 & 0,5777 \\
\hline $\mathrm{M}_{2}=320$ & $\mathrm{~V} 2=308$ & $\mathrm{D}_{2}=1,0390$ & 58 & 0,5906 \\
\hline $\mathrm{M}_{3}=330$ & $\mathrm{~V} 3=310$ & $\mathrm{D}_{3}=1,0645$ & 58 & 0,6051 \\
\hline $\mathrm{M}_{4}=340$ & $\mathrm{~V} 4=313$ & $\mathrm{D}_{4}=1,0863$ & 58 & 0,6174 \\
\hline $\mathrm{M}_{5}=350$ & $\mathrm{~V} 5=314$ & $\mathrm{D}_{5}=1,1146$ & 58 & 0,6335 \\
\hline $\mathrm{M}_{6}=360$ & $\mathrm{~V} 6=316$ & $\mathbf{D}_{6}=\mathbf{1 , 1 3 9 2}$ & 58 & $\mathbf{0 , 6 4 7 5}$ \\
\hline
\end{tabular}

Repare na tabela que ao colocar 60g de sal a densidade da solução $\mathbf{D}_{\mathbf{6}}=\mathbf{1 , 1 3 9 2}$ ficou maior que a densidade do ovo: $\mathbf{D}_{\mathbf{o}}=\mathbf{1 , 1 2 5 8}$ e o ovo flutuou como esperado!

$$
P_{0}=0,6399 \mathrm{~N}<F_{E 6}=0,6475 \mathrm{~N}
$$

A próxima fase nós vamos tentar estabelecer uma relação matemática entre a variação da densidade da solução com a variação da quantidade de sal acrescentada a mesma.

Será que conseguiremos fazer um modelo matemático com alguma função matemática conhecida? 


\section{Modelagem Matemática: Fase 3}

Prof. Orientador: Ronaldo Ramunno (IME)

Grupo 1: Isabelle e Elisa

Matematização: Revisão dos conceitos de função exponencial

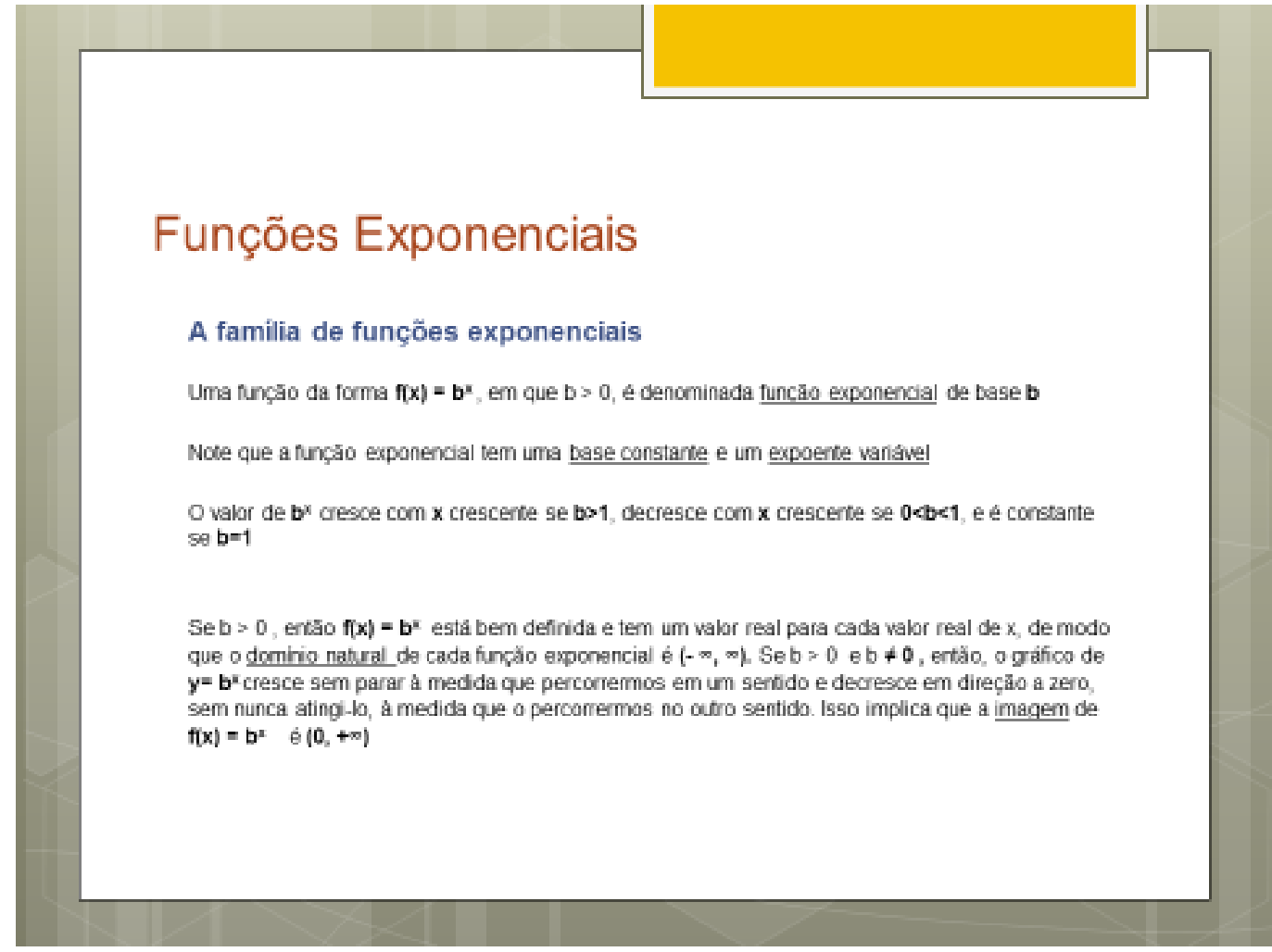

Fonte: ANTON, Howard. Cálculo. 8 ed. Porto Alegre: Bookman, 2007. p. 452-494. 


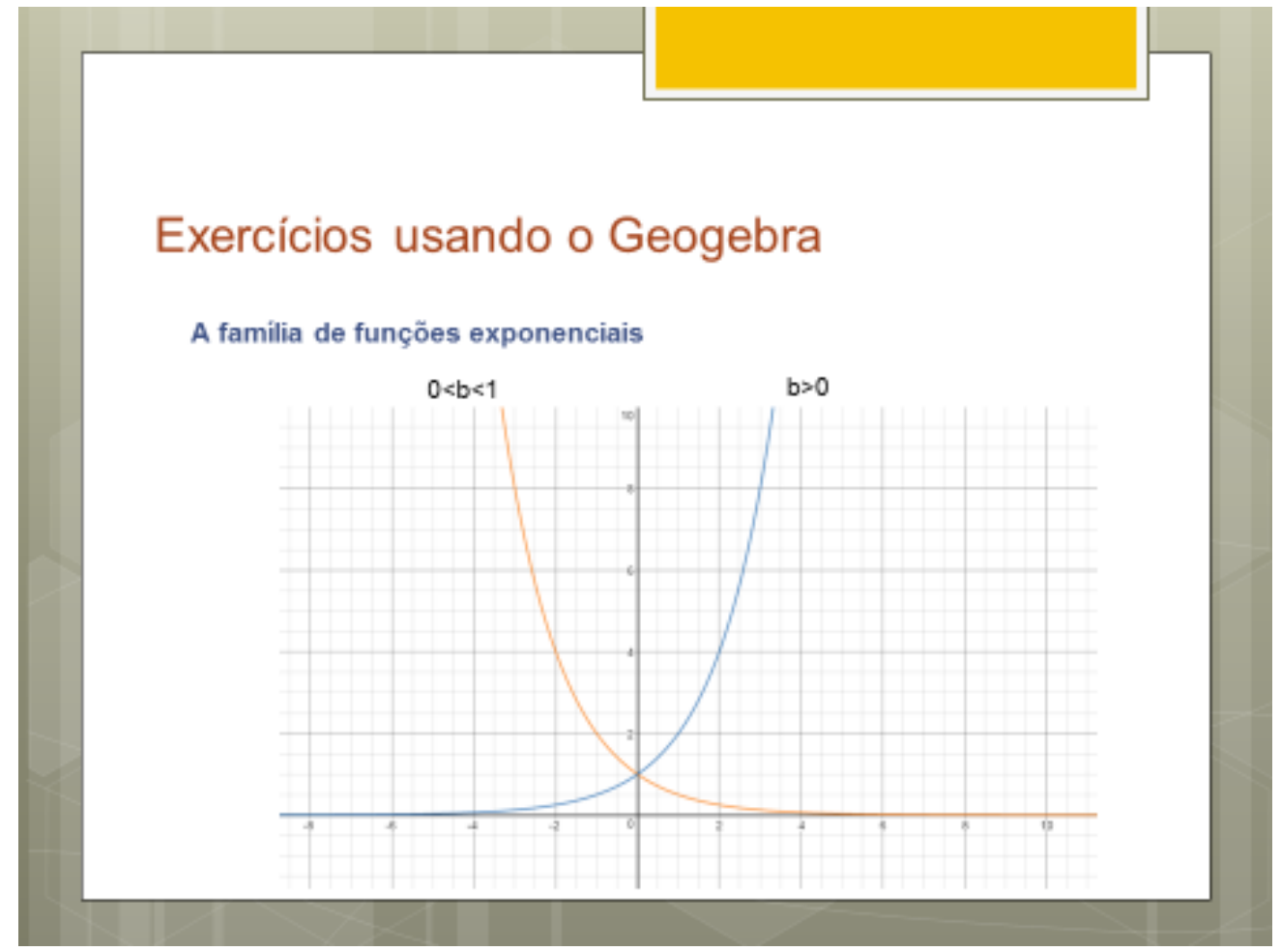

Fonte: ANTON, Howard. Cálculo. 8 ed. Porto Alegre: Bookman, 2007. p. 452-494.

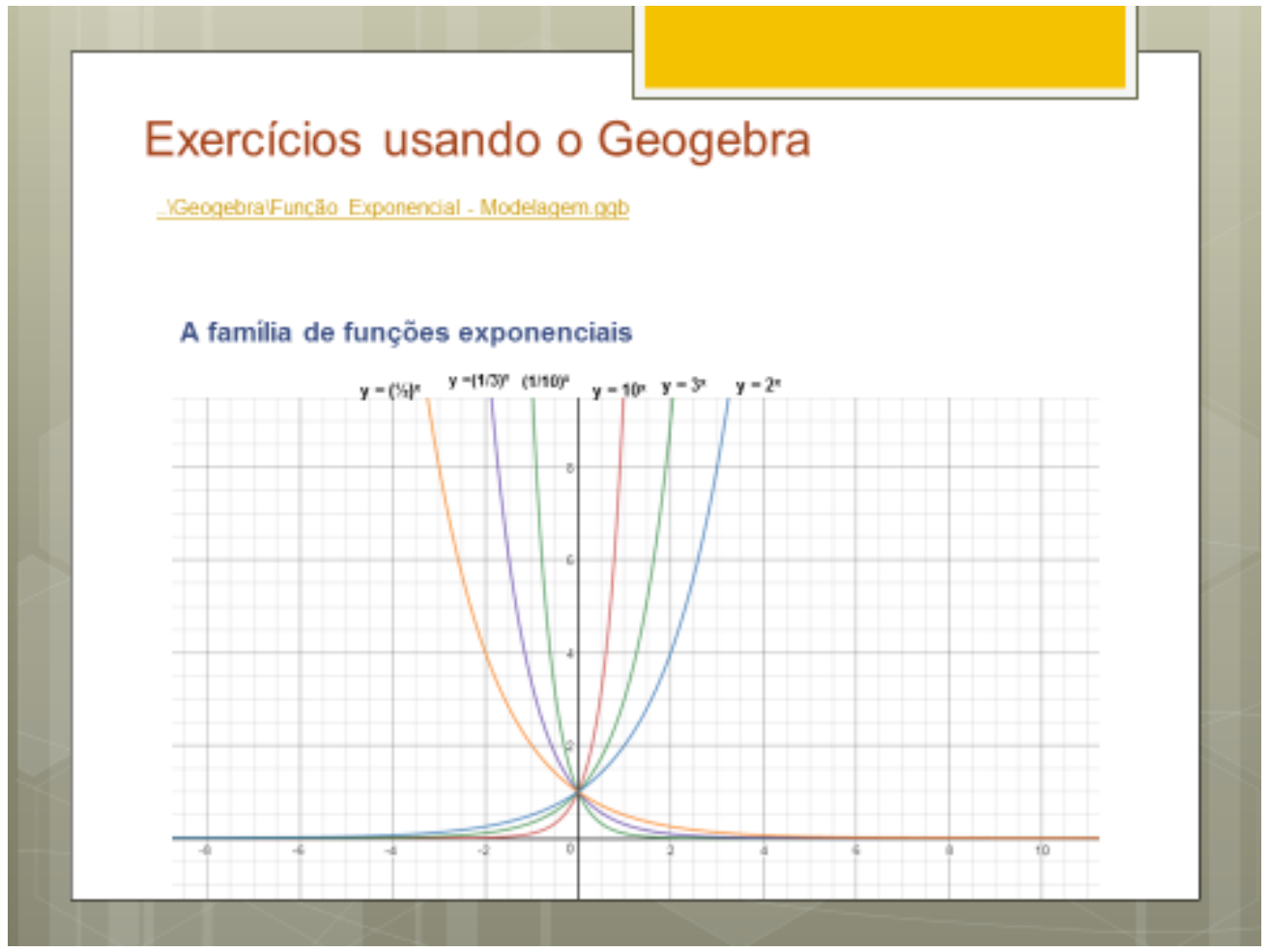

Fonte: ANTON, Howard. Cálculo. 8 ed. Porto Alegre: Bookman, 2007. p. 452-494. 


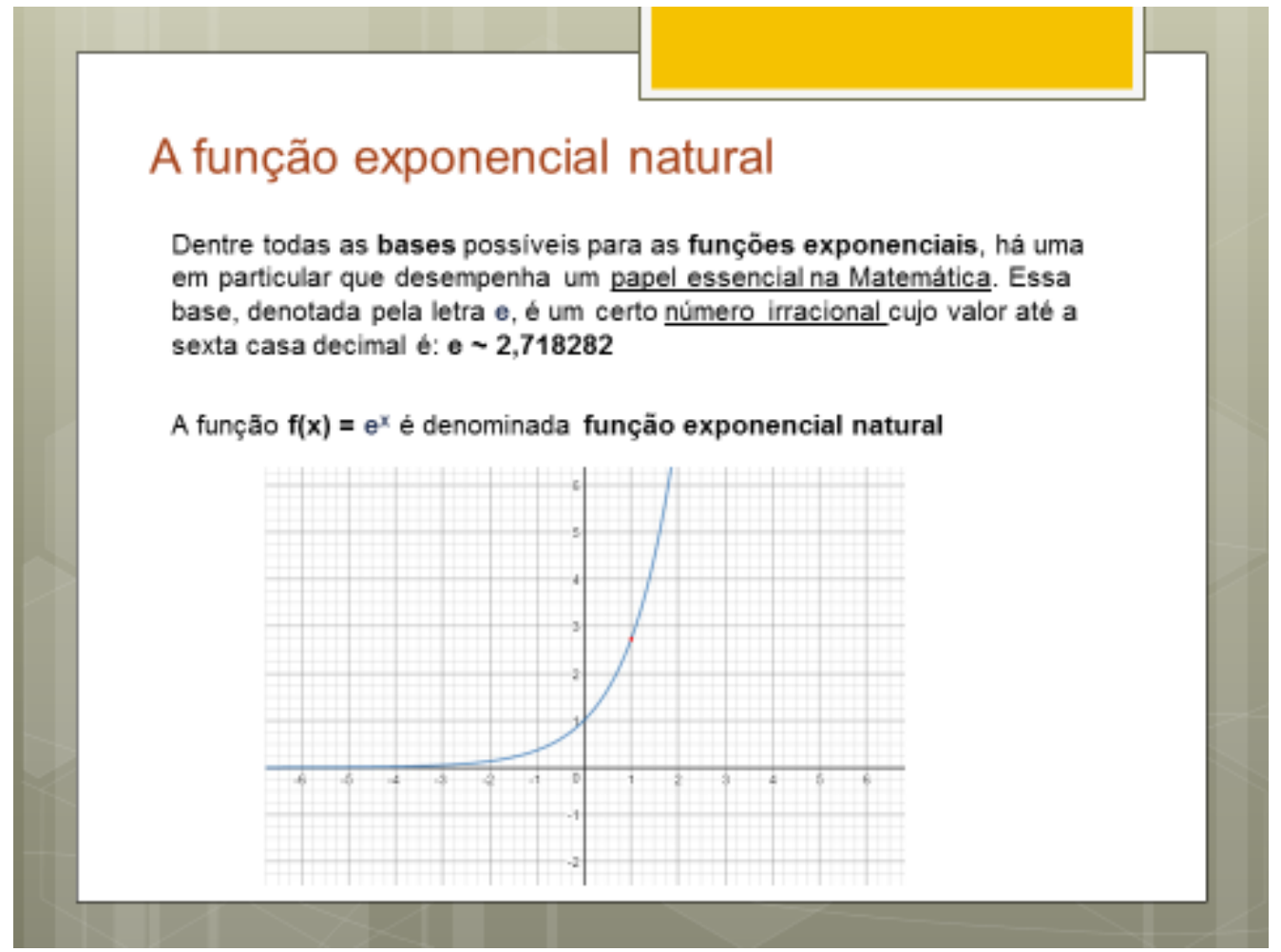

Fonte: ANTON, Howard. Cálculo. 8 ed. Porto Alegre: Bookman, 2007. p. 452-494.

Exercício proposto: Crescimento Exponencial

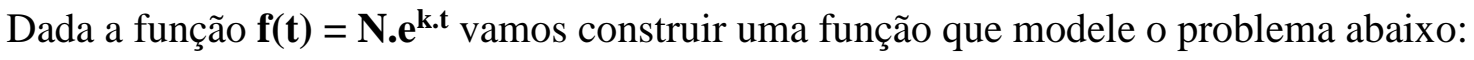

Um grupo de cientistas conduzem um experimento para determinar a efetividade de um agente biológico elaborado para acelerar o crescimento de uma bactéria específica. Eles introduziram 40 colônias de bactérias num meio aquoso de crescimento, e exatamente $\mathbf{2}$ horas mais tarde o número de colônias cresceu para 200. Eles observaram que o número de colônias cresceu exponencialmente durante as $\mathbf{5}$ primeiras horas do experimento.

Construa uma função $\mathbf{f}(\mathbf{t})$ que modele o número de colônias de bactérias em $\mathbf{t}$ horas depois do experimento ter começado (assuma $\mathbf{0} \leq \mathbf{t} \leq \mathbf{5}$ ) e que inclua a constante $\mathbf{k}$ de proporcionalidade.

\section{Solução:}

Sabemos que a população que exibe crescimento exponencial é modelada pela função $\mathbf{f}(\mathbf{t})=$

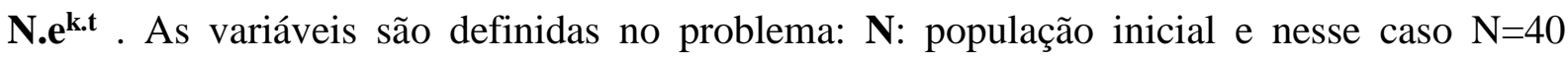
colônias, t: número de horas decorridos e $\mathbf{k}$ é a constante de proporcionalidade.

Temos então: $\mathbf{f}(\mathbf{t})=\mathbf{4 0 .} \mathbf{e}^{\mathrm{k} . \mathrm{t}}$ 
Cálculo da constante $\mathbf{k}$ :

Sabemos que em exatamente $\mathrm{t}=2$ horas depois de iniciado o experimento, o número de colônias das bactérias era $\mathrm{f}(2)=200$. Então:

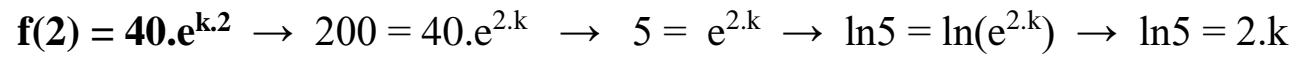

$\mathbf{k}=\ln 5 / 2 \rightarrow \mathrm{k} \approx 0,8047$

Logo temos nosso modelo: $\mathbf{f}(\mathbf{t})=\mathbf{4 0 .} \mathrm{e}^{(\ln 5 / 2) \cdot t}$

Exercício: Calcule agora o número de colônias que estavam presente 5 horas depois do experimento ter começado. (Arredondar para número inteiro).

\section{Comparação entre funções lineares e exponencial}

Toda função exponencial varia segundo um percentual constante ou taxa relativa. Por exemplo, uma população de um país pode aumentar segundo uma taxa de $2,6 \%$ ao ano. Toda função linear varia segundo uma taxa constante. Por exemplo, o recorde olímpico com salto de vara aumentou 2 polegadas $(\approx 5 \mathrm{~cm})$ por ano.

Uma função linear tem taxa de variação constante

Uma função exponencial tem taxa de variação relativa (ou percentual) constante.

Veja esse exemplo: A quantidade de adrenalina no corpo pode variar muito rápido. Suponha que a quantidade inicial seja de $15 \mathrm{mg}$. Obtenha a fórmula para $\mathbf{A}(\mathbf{t})$, a quantidade em $\mathrm{mg}$, o tempo $\mathbf{t}$ em min depois se $\mathrm{A}(\mathrm{t})$ está:

1- Aumentando a $0,4 \mathrm{mg}$ por minuto

2- Diminuindo a $0,4 \mathrm{mg}$ por minuto

3- Aumentando a $3 \%$ por minuto

4- Diminuindo a $3 \%$ por minuto 


\section{Solução:}

1- Esta é uma de função linear com quantidade inicial 15 e inclinação 0,4 :

$A(t)=15+0,4 . t$

2- Esta é uma de função linear com quantidade inicial 15 e inclinação - 0,4:

$A(t)=15$ - 0,4.t

3- Esta é uma função exponencial com quantidade inicial 15 e base $(1+0,03)=1,03$ $A(t)=15 .(1,03)^{t}$

4- Esta é uma função exponencial com quantidade inicial 15 e base $(1-0,03)=0,97$ $A(t)=15 .(0,97)^{t}$

Veja esse padrão matemático na nossa experiência da solução salina:

\begin{tabular}{|c|c|c|c|c|}
\hline $\begin{array}{l}\text { Massa da } \\
\text { solução (g) }\end{array}$ & $\begin{array}{l}\text { Volume da } \\
\text { solução }\left(\mathrm{cm}^{3}\right)\end{array}$ & $\begin{array}{l}\text { Densidade } \\
\text { solução } \\
\left(\mathrm{g} / \mathrm{cm}^{3}\right)\end{array}$ & $\begin{array}{l}\text { Volume } \\
\text { deslocado } \\
\left(\mathrm{cm}^{3}\right)\end{array}$ & $\begin{array}{l}\text { Força de } \\
\text { empuxo: } F_{E}(N)\end{array}$ \\
\hline$M_{0}=300$ & $V_{0}=300$ & $D_{0}=1,0000$ & 58 & 0,5684 \\
\hline $\mathrm{M}_{1}=310$ & $\mathrm{~V} 1=305$ & $\mathrm{D}_{1}=1,0164$ & 58 & 0,5777 \\
\hline $\mathrm{M}_{2}=320$ & $\mathrm{~V} 2=308$ & $\mathrm{D}_{2}=1,0390$ & 58 & 0,5906 \\
\hline $\mathrm{M}_{3}=330$ & $\mathrm{~V} 3=310$ & $\mathrm{D}_{3}=1,0645$ & 58 & 0,6051 \\
\hline $\mathrm{M}_{4}=340$ & $\mathrm{~V} 4=313$ & $\mathrm{D}_{4}=1,0863$ & 58 & 0,6174 \\
\hline $\mathrm{M}_{5}=350$ & $V 5=314$ & $\mathrm{D}_{5}=1,1146$ & 58 & 0,6335 \\
\hline $\mathrm{M}_{6}=360$ & $V 6=316$ & $D_{6}=1,1392$ & 58 & 0,6475 \\
\hline
\end{tabular}

Se calcularmos as razões das densidades, verificamos um padrão constante (não exato, pois se trata de uma modelagem e nesse caso temos margem de erro do experimento).
$\mathrm{D}_{1} / \mathrm{D}_{0}=1,0164$
$\mathrm{D}_{2} / \mathrm{D}_{1}=1,0222$
$\mathrm{D}_{3} / \mathrm{D}_{2}=1,0245$
$\mathrm{D}_{4} / \mathrm{D}_{3}=1,0205$
$\mathrm{D}_{5} / \mathrm{D}_{4}=1,0260$
$\mathrm{D}_{6} / \mathrm{D}_{5}=1,0221$

Fazendo uma média temos: $\mathbf{1 , 0 2 2 2}$

Veja: $(\mathbf{1}+\mathbf{k})=(\mathbf{1}+\mathbf{0 , 0 2 2 2})=(1,0222)$ o que significa um crescimento de 0,0222 ou $\mathbf{2 , 2 2} \%$ de densidade a cada $\mathbf{1 0 g}$ de sal acrescentada.

Os programas excel e geogebra nos forneceu uma função exponencial: $\mathbf{f}(\mathbf{x})=\mathbf{e}^{\mathbf{0 , 0 0 2 1 . x}}$ 
Se fizermos uma mudança de base, encontraremos a função equivalente na base: $(1,0222)$

$$
f(x)=(1,0222)^{0,0956 . x}
$$

Faça os cálculos usando as duas funções com bases diferentes, usando $\mathrm{x}=10 \mathrm{~g}, 20 \mathrm{~g}$ e assim por diante, e veja que o resultado é muito próximo do nosso experimento! 


\section{Modelagem Matemática: Fase 4}

Prof. Orientador: Ronaldo Ramunno (IME)

Grupo 1: Isabelle e Elisa

\section{Matematização: Modelo Matemático / Validação}

\section{Experimento: Densidade e solução salina(Nacl)}

Material Utilizado; Becker, proveta graduada, balança digital, ovos, sal (Nacl), água destilada, seringa graduada, pinça, copo plástico, recipiente cilíndrico.

Vocês construíram a tabela através do experimento, então agora podemos relacionar a variação da densidade da solução com a variação da quantidade de sal (Nacl) acrescentado à solução.

\begin{tabular}{|c|c|c|c|c|}
\hline $\begin{array}{l}\text { Massa da } \\
\text { solução (g) }\end{array}$ & $\begin{array}{l}\text { Volume da } \\
\text { solução }\left(\mathrm{cm}^{3}\right)\end{array}$ & $\begin{array}{l}\text { Densidade } \\
\text { solução } \\
\left(\mathrm{g} / \mathrm{cm}^{3}\right)\end{array}$ & $\begin{array}{l}\text { Volume } \\
\text { deslocado } \\
\left(\mathrm{cm}^{3}\right)\end{array}$ & $\begin{array}{l}\text { Força de } \\
\text { empuxo: } F_{E}(N)\end{array}$ \\
\hline $\mathbf{M}_{0}=\mathbf{0}$ & $V_{0}=300$ & $D_{0}=1,0000$ & 58 & 0,5684 \\
\hline $\mathrm{M}_{1}=10$ & $V 1=305$ & $\mathrm{D}_{1}=1,0164$ & 58 & 0,5777 \\
\hline$M_{2}=20$ & $V 2=308$ & $\mathrm{D}_{2}=1,0390$ & 58 & 0,5906 \\
\hline $\mathrm{M}_{3}=30$ & $\mathrm{~V} 3=310$ & $\mathrm{D}_{3}=1,0645$ & 58 & 0,6051 \\
\hline $\mathrm{M}_{4}=40$ & $\mathrm{~V} 4=313$ & $\mathrm{D}_{4}=1,0863$ & 58 & 0,6174 \\
\hline $\mathrm{M}_{5}=50$ & $\mathrm{~V} 5=314$ & $\mathrm{D}_{5}=1,1146$ & 58 & 0,6335 \\
\hline$M_{6}=60$ & $V 6=316$ & $D_{6}=1,1392$ & 58 & 0,6475 \\
\hline
\end{tabular}

Nessa fase da modelagem, nós vamos tentar estabelecer uma relação matemática entre a variação da densidade da solução com a variação da quantidade de sal acrescentada a mesma.

Será que conseguiremos fazer um modelo matemático com alguma função matemática conhecida?

Vamos começar definindo nossas variáveis: 
Ds: Densidade da solução $\left(\mathrm{g} / \mathrm{cm}^{3}\right)$

$\mathbf{M}_{\text {Nacl: }}$ Massa do sal (Nacl) acrescentada à solução (g)

$\mathbf{F}_{\mathbf{E}}$ : Força de empuxo $(\mathrm{N})$

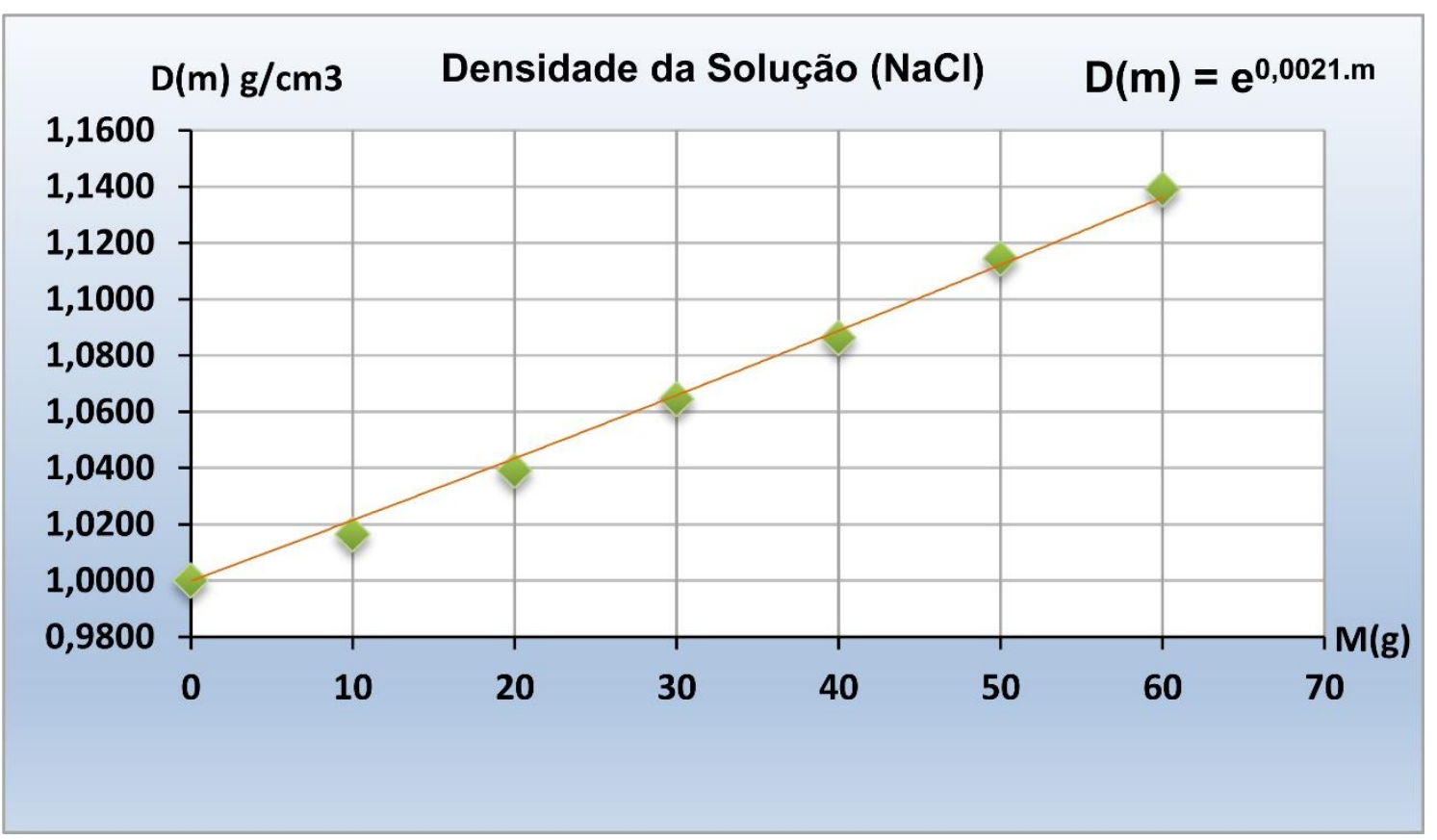

Fonte: Grupo 1 - gráfico feito no programa Excel

O gráfico acima parece ser de uma função linear, mas será esse o caso?

Veja que o excel nos forneceu uma função exponencial, mas por que o gráfico parece ser de uma função linear?

Repare que a função $\mathbf{D}(\mathbf{m})=\mathbf{e}^{\mathbf{0 , 0 0 2 1 . m}}$ tem um valor constante $\mathbf{k}=\mathbf{0 , 0 0 2 1}$, ou seja, a função cresce muito lentamente!

Podemos usar o programa geogebra para verificar o gráfico dessa função aplicando a ferramenta zoom, assim poderemos ver melhor o traço desse gráfico. 


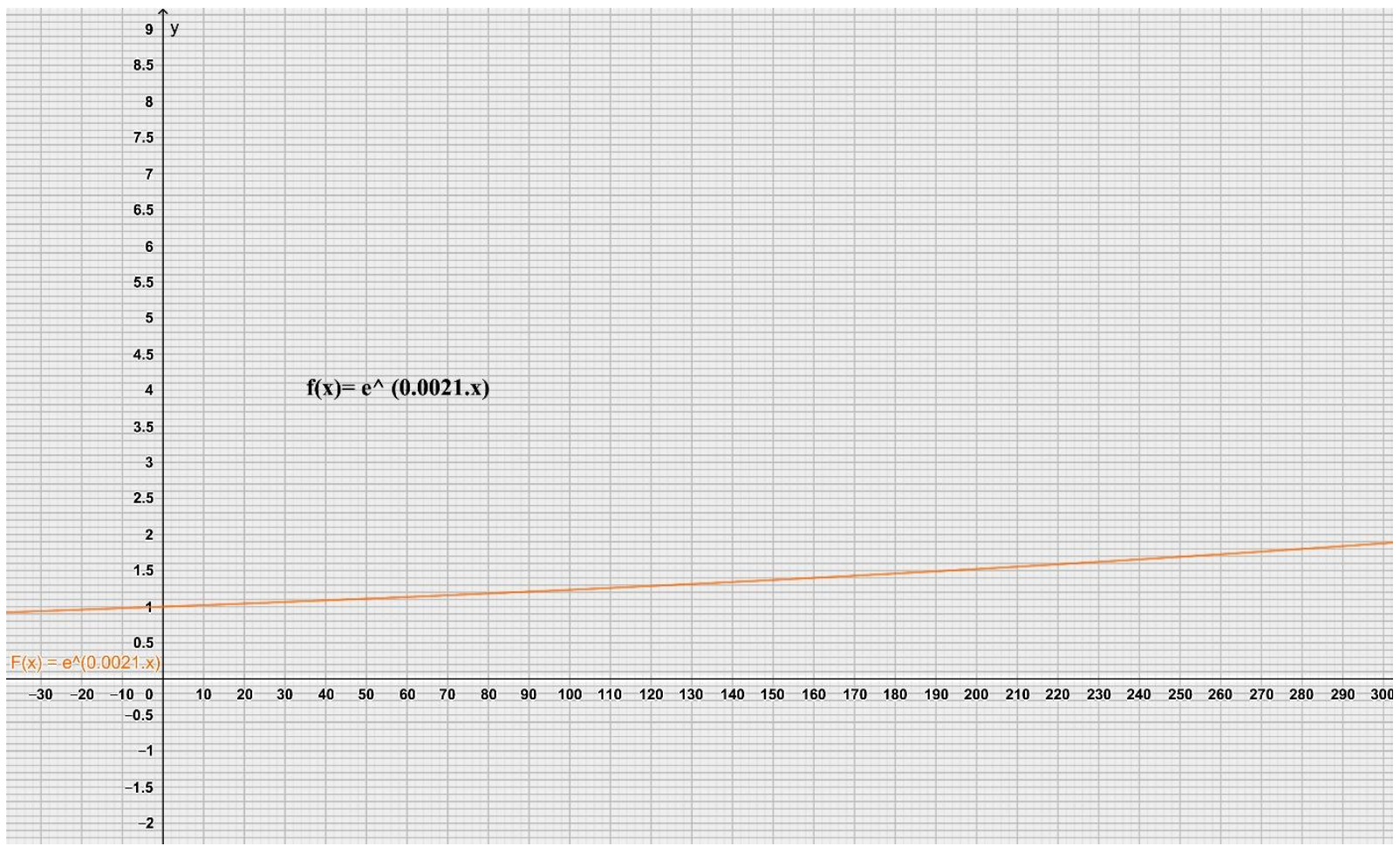

Fonte: Grupo 1 - gráfico feito no programa Geogebra (usando a ferramenta Zoom)

\section{Validação do Modelo:}

Usando o nosso modelo $\mathbf{D}(\mathbf{m})=\mathbf{e}^{\mathbf{0 , 0 0 2 1} . \mathbf{m}}$ vamos comparar os valores teóricos obtidos através da função do modelo com os dados da tabela (experimento).

\begin{tabular}{|c|c|c|}
\hline Massa da solução $(\mathrm{g})$ & $\begin{array}{c}\text { Densidade solução }\left(\mathrm{g} / \mathrm{cm}^{\mathbf{3}}\right) \\
\text { dados do experimento }\end{array}$ & $\begin{array}{c}\text { Modelo térico: } \\
\mathbf{D}(\mathbf{m})=\mathbf{e}^{\mathbf{0}, 0021, \mathrm{~m}}\end{array}$ \\
\hline $\mathbf{M}_{\mathbf{0}}=\mathbf{0}$ & $\mathbf{D}_{\mathbf{0}}=\mathbf{1 , 0 0 0 0}$ & $\mathbf{D}(\mathbf{0})=\mathbf{1 , 0 0 0 0}$ \\
\hline $\mathrm{M}_{1}=10$ & $\mathrm{D}_{1}=1,0164$ & $\mathrm{D}(10)=1,0212$ \\
\hline $\mathrm{M}_{2}=20$ & $\mathrm{D}_{2}=1,0390$ & $\mathrm{D}(20)=1,0429$ \\
\hline $\mathrm{M}_{3}=30$ & $\mathrm{D}_{3}=1,0645$ & $\mathrm{D}(30)=1,0650$ \\
\hline $\mathrm{M}_{4}=40$ & $\mathrm{D}_{4}=1,0863$ & $\mathrm{D}(40)=1,0876$ \\
\hline $\mathrm{M}_{5}=50$ & $\mathrm{D}_{5}=1,1146$ & $\mathrm{D}(50)=1,1107$ \\
\hline $\mathbf{M}_{\mathbf{6}}=\mathbf{6 0}$ & $\mathbf{D}_{\mathbf{6}}=\mathbf{1 , 1 3 9 2}$ & $\mathbf{D}(\mathbf{6 0})=\mathbf{1 , 1 3 4 3}$ \\
\hline
\end{tabular}

Comparando os valores obtidos através do experimento e os obtidos pelo modelo matemático, vemos que excetuando $\mathrm{D}(10)$ os valores são muitos próximos!

Portanto conseguimos um modelo matemático usando função exponencial com uma boa precisão. Visualizando o gráfico $\mathbf{D}(\mathbf{m}) \mathbf{x}(\mathbf{m})$ verificamos que o traço da função passa muito 
próximo aos dados experimentais, confirmando assim, o bom resultado de nosso modelo matemático!

\section{Relação entre as variáveis $F_{E}$ e ds}

Qual será a relação entre as variáveis força de empuxo $\mathbf{F}_{\mathbf{E}}(\mathbf{d})$ e a densidade $\mathbf{d}_{\mathbf{s}}$ ?

Partindo dos dados da nossa tabela construída através do experimento da solução salina (água + Nacl) e o cálculo da força de empuxo do fluido (solução) sobre o ovo, temos:

O gráfico abaixo nos mostra uma função polinomial de $1^{\circ}$ grau: $\mathbf{F}(\mathbf{d})=\mathbf{0 , 5 6 8 4 . d s}$

\begin{tabular}{|c|r|c|r|}
\hline Volume $(\mathrm{cm} 3)$ & densidade (g/cm3) & g (gravidade) & Força de Empuxo (N) \\
\hline 58 & $\mathbf{1 , 0 0 0 0}$ & 9,8 & $\mathbf{0 , 5 6 8 4}$ \\
\hline 58 & $\mathbf{1 , 0 1 6 4}$ & 9,8 & $\mathbf{0 , 5 7 7 7}$ \\
\hline 58 & $\mathbf{1 , 0 3 9 0}$ & 9,8 & $\mathbf{0 , 5 9 0 6}$ \\
\hline 58 & $\mathbf{1 , 0 6 4 5}$ & 9,8 & $\mathbf{0 , 6 0 5 1}$ \\
\hline 58 & $\mathbf{1 , 0 8 6 3}$ & 9,8 & $\mathbf{0 , 6 1 7 5}$ \\
\hline 58 & $\mathbf{1 , 1 1 4 6}$ & 9,8 & $\mathbf{0 , 6 3 3 5}$ \\
\hline 58 & $\mathbf{1 , 1 3 9 2}$ & 9,8 & $\mathbf{0 , 6 4 7 5}$ \\
\hline & & & \\
\hline
\end{tabular}

$\mathrm{F}(\mathrm{d}) \mathrm{N} \quad$ Força de Empuxo (N)

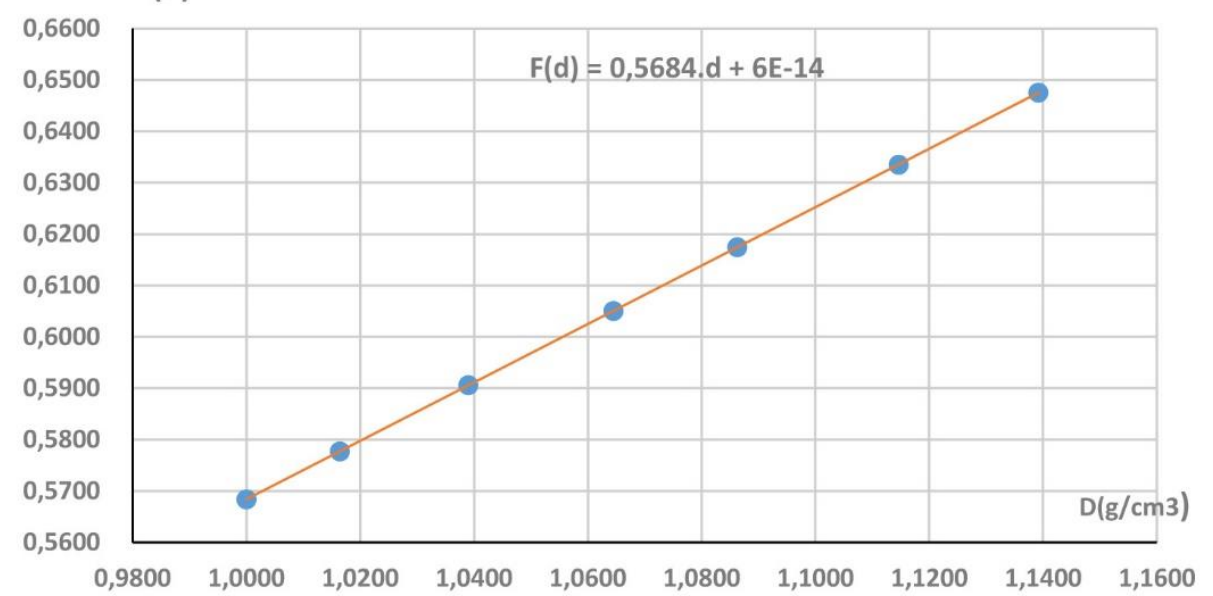

Fonte: Grupo 1 - gráfico feito no programa Excel 


\section{Modelagem Matemática - Atividades Geogebra}

Prof. Orientador: Ronaldo Ramunno (IME)

Grupo 1: Isabelle e Elisa

\section{Atividades com Geogebra 1}

\section{Manipulando a Função Exponencial no Geogebra}

O arquivo do geogebra foi previamente construído, pois não havia tempo hábil para construir junto com os alunos, mas foi fornecido material em PDF para posterior estudo dos alunos. As atividades foram feitas por eles.

\section{Analisando o parâmetro a:}

O que ocorre com o gráfico da função alterando o parâmetro a?

Qual a relação entre o parâmetro a e a assíntota?

Ao analisar o comportamento do gráfico da função com a alteração do parâmetro a o aluno perceberá a consequente translação vertical e que a assíntota tem equação $\mathbf{y}=\mathbf{a}$

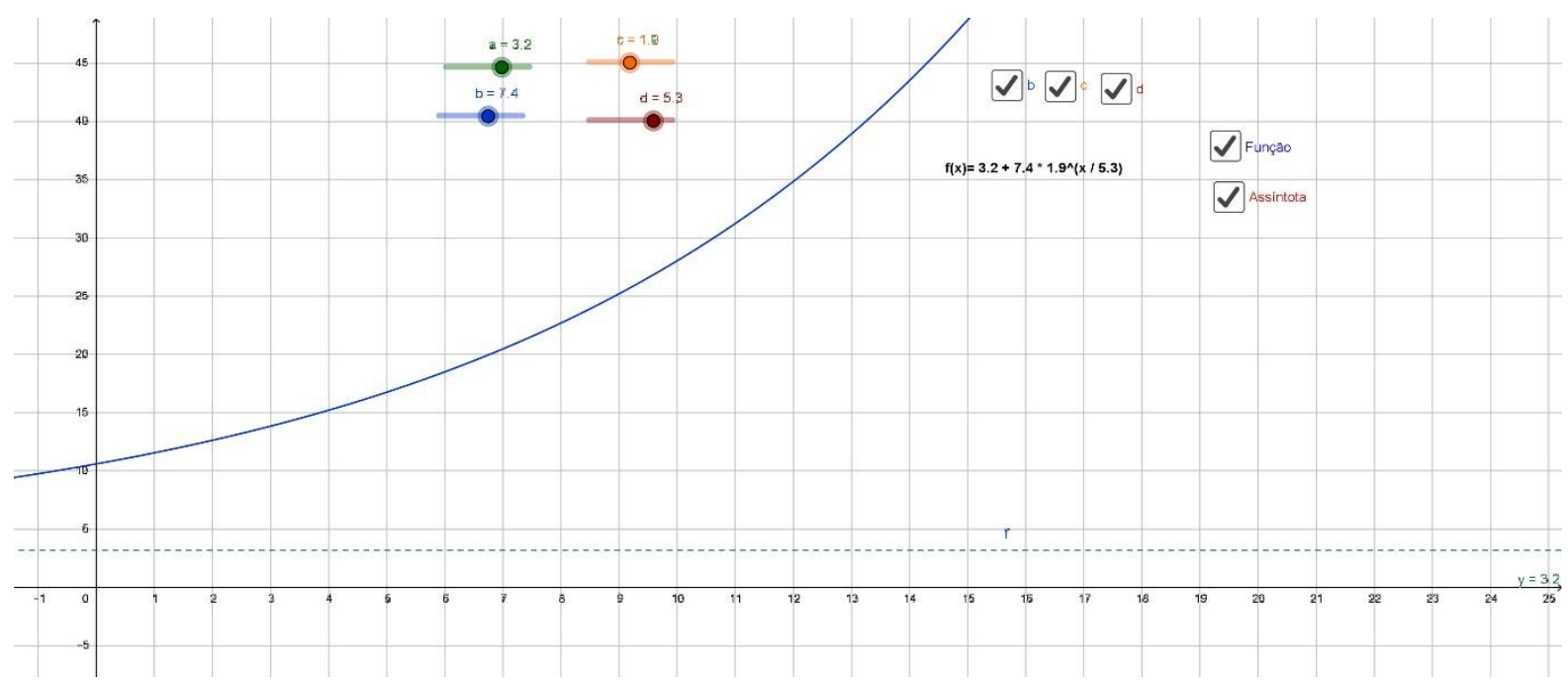

Fonte: Grupo 1 - gráfico feito no programa Geogebra 


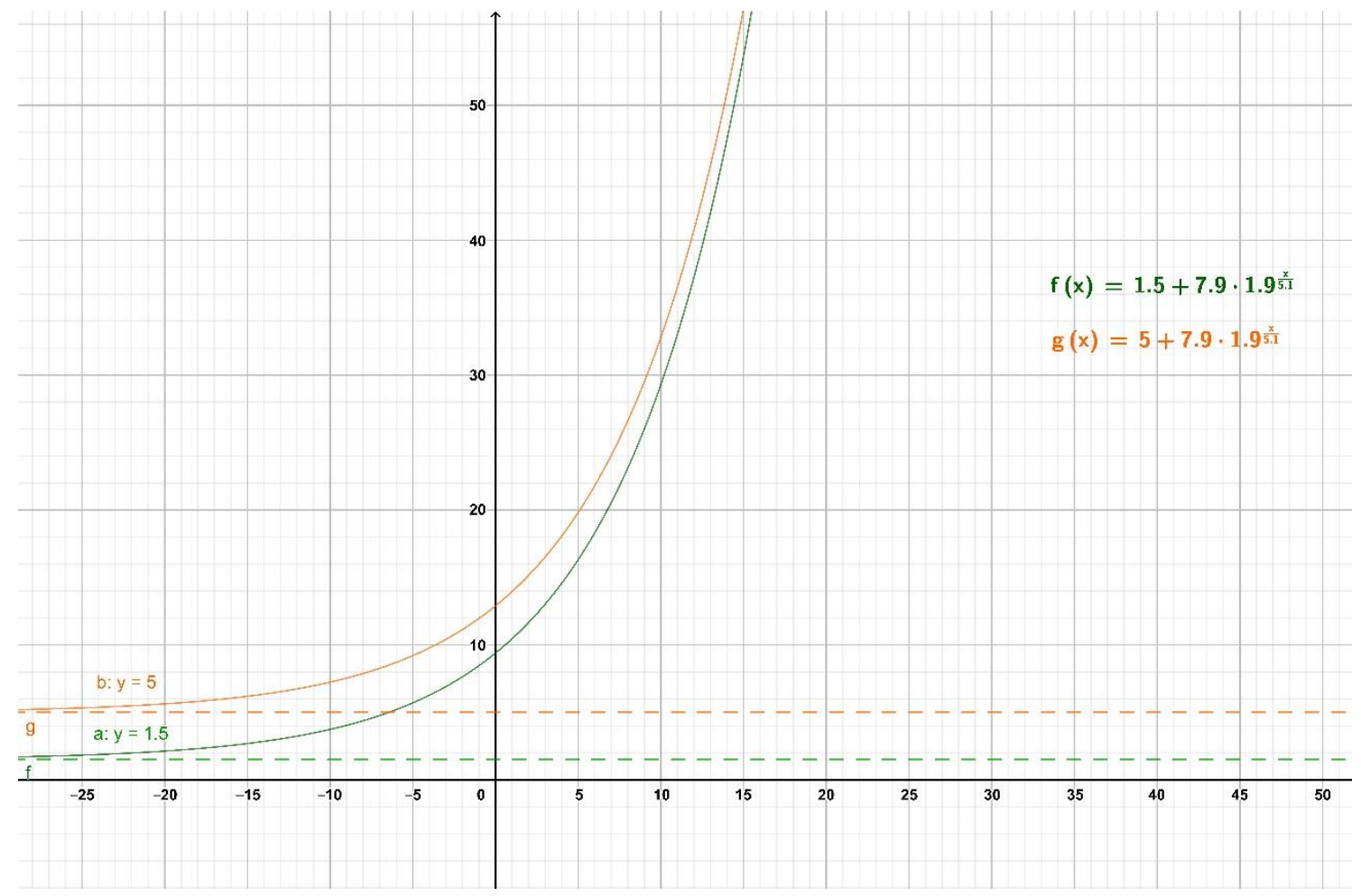

Fonte: Grupo 1 - gráfico feito no programa Geogebra

\section{Analisando o parâmetro b:}

Analisar o parâmetro b, convém atribuir o valor zero para o parâmetro a

Fazendo $\mathbf{a}=\mathbf{0}$ e alterando o valor de $\mathbf{b}$ o que pode ser observado no gráfico?

Qual a relação entre o parâmetro b e o ponto de intersecção entre a função e o eixo das ordenadas?

O aluno observará que a função intersectará o eixo vertical no ponto $(\mathbf{0}, \mathbf{a}+\mathbf{b})$ 


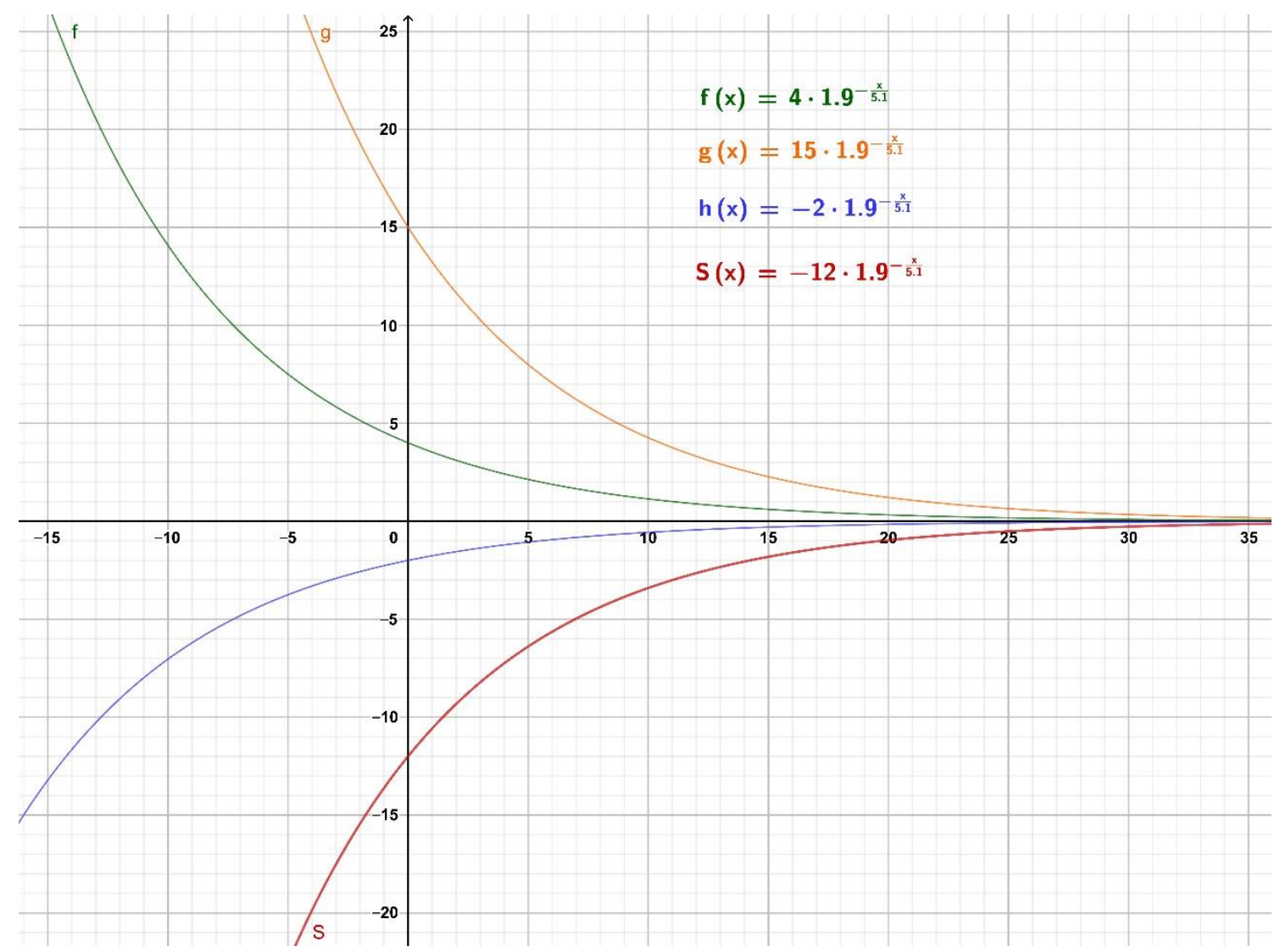

Fonte: Grupo 1 - gráfico feito no programa Geogebra

\section{Alterando o valor do parâmetro C}

Fazendo $\mathbf{d}=\mathbf{1}$, o termo $\mathbf{c}^{\mathbf{1} / \mathbf{d}}$ com base $\mathbf{c}$ e expoente $1 / \mathrm{d}$

O importante nessa atividade é que o aluno distinga quando a função é crescente ou decrescente.

O aluno perceberá que base maior que 1 a função é crescente e base entre 0 que 1 a função é decrescente.

O que ocorre alterando o parâmetro d?

Para $\mathbf{c}=\mathbf{0 . 5}$ o que representa $\mathbf{d}$ ?

O importante é que o aluno relacione $\mathbf{d}$ com a velocidade de crescimento/decrescimento da função. 


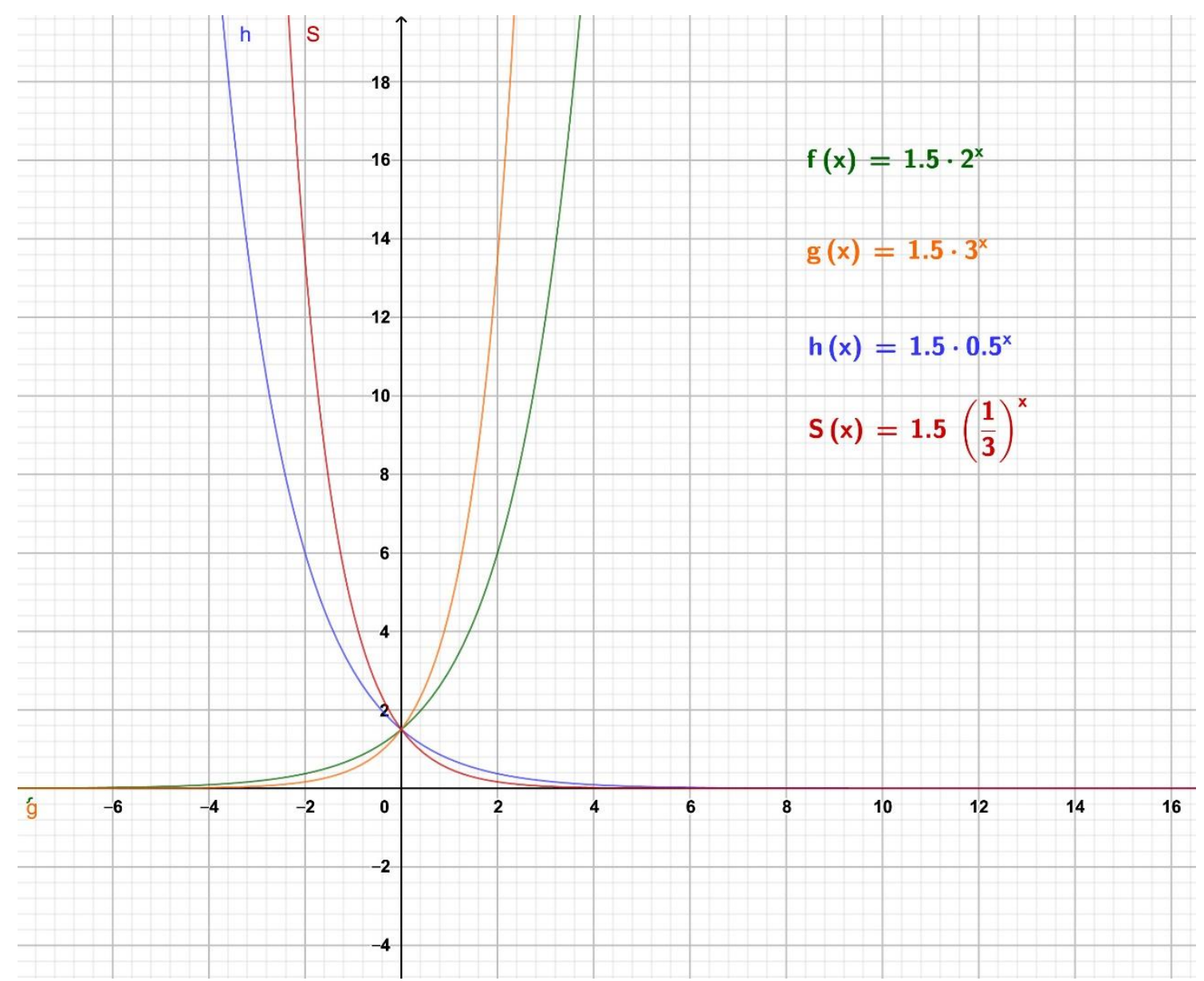

Fonte: Grupo 1 - gráfico feito no programa Geogebra

O significado de "meia vida" nas funções exponenciais

Fazendo d ser "meia vida" e fixando $c=0.5, b=5$ e $a=0$ 


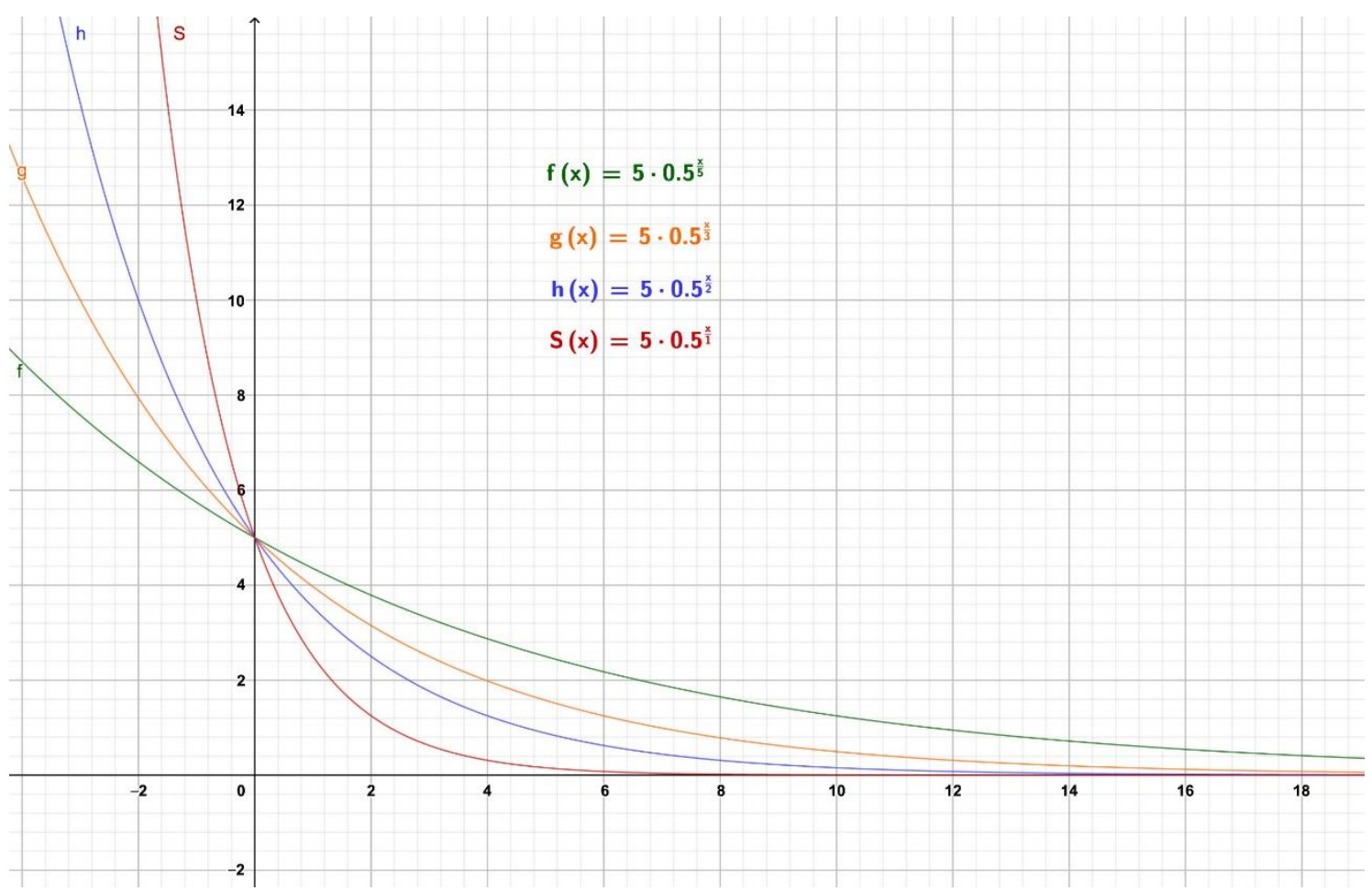

Fonte: Grupo 1 - gráfico feito no programa Geogebra

Manipulação da função exponencial com base $\mathbf{e}$

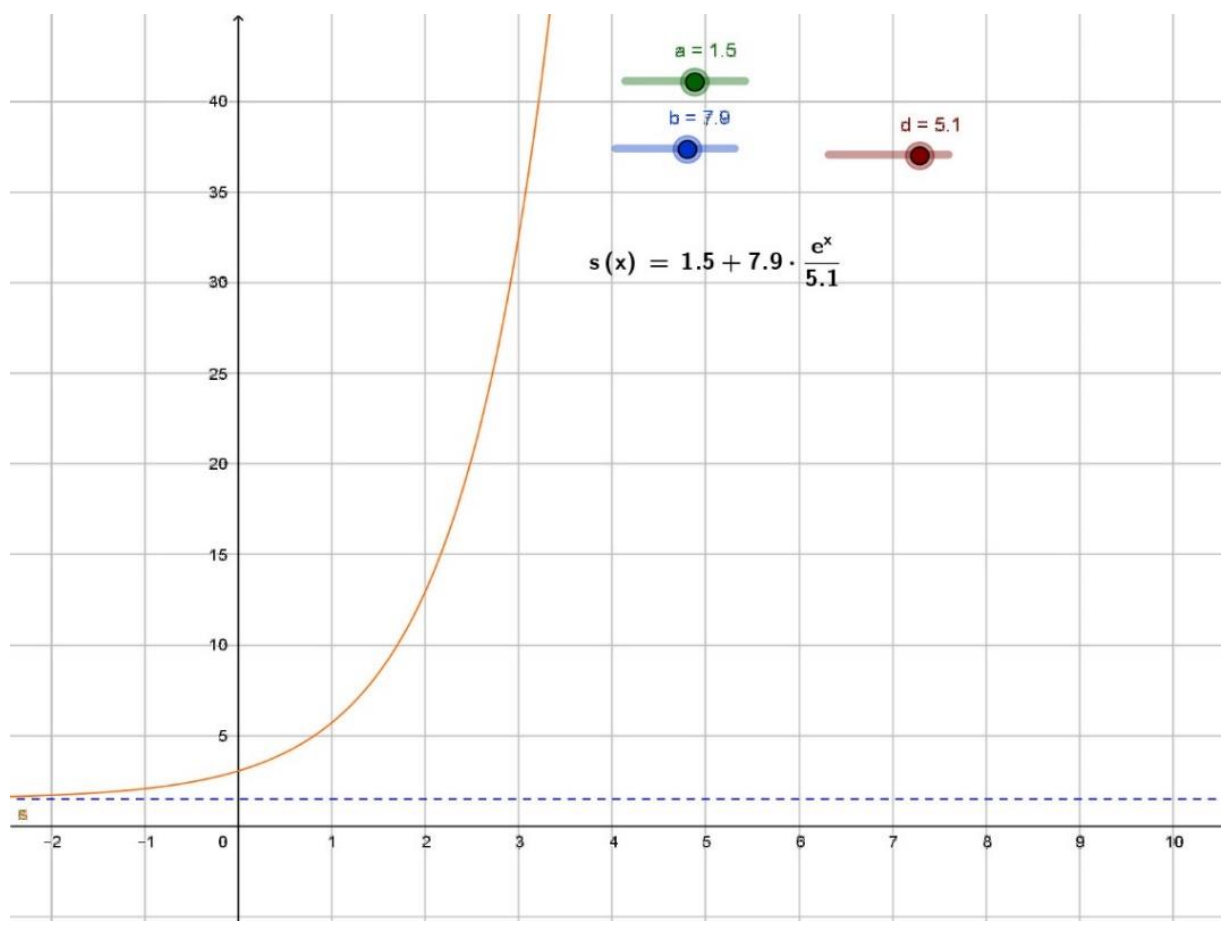



Apêndice E

Grupo 2

Material desenvolvido para a Modelagem 



\section{Modelagem Matemática: Fase 1}

Prof. Orientador: Ronaldo Ramunno (IME)

Grupo 2: Victor e Giovana

Situação-problema: Qual é a relação entre a distância percorrida pela bola e o tempo de queda da mesma? Qual é a relação entre a velocidade de um corpo em queda livre e o tempo de queda? Podemos calcular a velocidade média entre dois intervalos de tempo, mas podemos calcular a velocidade instantânea em qualquer intervalo de tempo da queda livre?

Inteiracão: Conhecimentos prévios para definir o problema

\section{As equações cinemáticas de aceleração constante}

Considere um objeto cuja aceleração a, mantém-se constante durante o intervalo de tempo $\Delta \mathbf{t}=\mathbf{t}_{\mathbf{f}}-\mathbf{t}_{\mathbf{i}}$. No início do intervalo, o instante $\mathbf{t}_{\mathbf{i}} \mathbf{o}$ objeto tem velocidade inicial $\mathbf{v}_{\mathbf{i}}$ e posição inicial $\mathbf{s}$. Note que $\mathbf{t}_{\mathbf{i}}$ geralmente é zero, mas não tem de ser esse valor. Nós desejamos determinar a posição final sf do objeto e sua velocidade final $\mathbf{v}_{\mathbf{f}}$, no instante $\mathbf{t}_{\mathbf{f}}$. A velocidade do objeto está variando porque ele está acelerando. Ver fig. abaixo.

$$
a=\frac{\Delta V}{\Delta T}=\frac{V_{f}-V_{i}}{\Delta T}
$$

Essa equação pode ser rearranjada para a forma: $\mathbf{V}_{\mathbf{f}}=\mathbf{V}_{\mathbf{i}}+\mathbf{a . \Delta t}$

O gráfico da velocidade versus o tempo é uma linha reta que inicia em $\mathbf{v}_{\mathbf{i}}$ e tem a por declividade. Sabemos que a posição final do objeto é a área sob a curva.

$$
S_{f}=S_{i}+V_{i} \cdot \Delta t+\frac{1}{2} \cdot a \cdot(\Delta t)^{2}
$$




\section{Queda Livre}

O movimento de um objeto movendo-se apenas sob a influência da gravidade, e nenhuma outra força, é chamada de queda livre. Estritamente falando, a queda livre ocorre somente no vácuo, onde não há resistência do ar., mas o efeito da resistência do ar é pequeno no caso dos “objetos pesados", de modo que cometeremos apenas um pequeno erro em tratar estes objetos como se eles estivessem em queda livre. No caso de objetos leves, tais como uma pena de pássaro, ou objetos que caem por longas distâncias e adquirem altas velocidades, o efeito da resistência do ar não é desprezível.

\section{Exemplo: No parque em queda livre (vídeo)}

Atividade: Assistir ao vídeo: A lei da queda dos corpos (Universo mecânico)

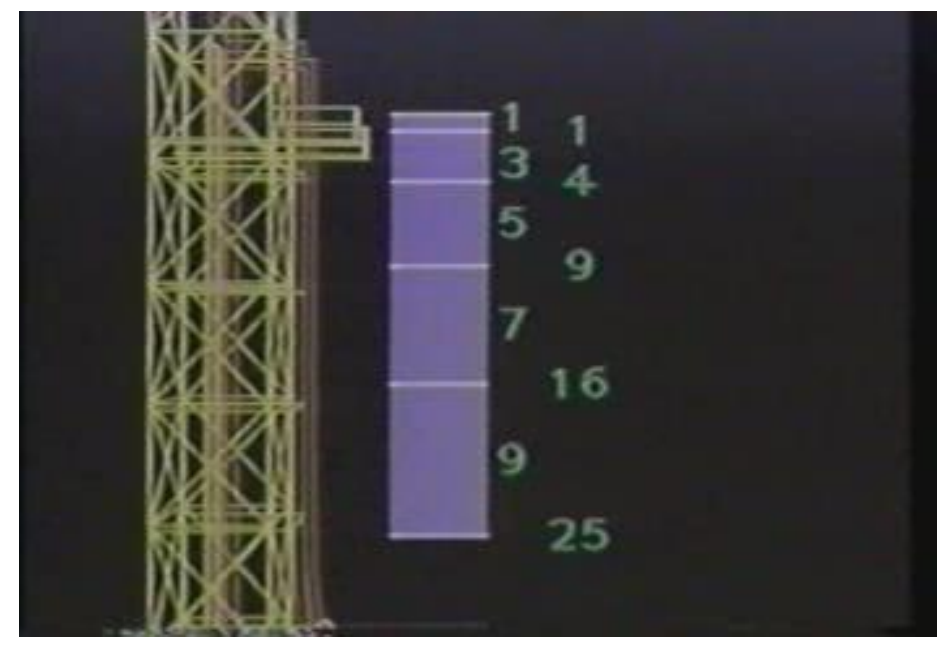

Fonte: Universo Mecânico: Caltech

Como visto no vídeo, Galileu deduziu usando planos inclinados que um objeto em queda livre percorre em intervalos de tempo iguais, distâncias que aumentavam em números ímpares, ou 
seja, uma unidade de distância no $1^{\circ}$ intervalo de tempo, 3 unidades de distância no $2^{\circ}$ intervalo de tempo, 5 unidades de distância no $3^{\circ}$ intervalo de tempo e assim por diante seguindo a ordem dos números ímpares $(1,3,5,7,9, \ldots)$. As distâncias caídas eram proporcionais aos números ímpares. Galileu percebeu um padrão: Após o $1^{\circ}$ intervalo de tempo, 1 unidade de distância, após o $2^{\circ}$ intervalo 4 unidades $(1+3)$, após o $3^{\circ}$ intervalo 9 unidades $(1+3+5)$, após o $4^{\mathrm{o}}$ intervalo, 16 unidades de distância e assim por diante. Assim temos o padrão de distâncias caídas: $1,4,9,16,25, \ldots$, e esses números são quadrados perfeitos, logo a distância de queda é proporcional ao quadrado do tempo de queda: Assim a lei de Galileu relaciona o espaço $\mathbf{S}$ e o tempo $\mathbf{t}$ na função $\mathbf{S}(\mathbf{t})=$ c.t $^{2}$ logo temos distância em função do tempo! Fazendo $\mathbf{S}$ em metros e $\mathbf{t}$ em segundos.

No instante $\mathbf{S}(\mathbf{1})=$ c. $(1)^{2}=\mathbf{c}$ (fazendo experimentos pode se chegar a um valor aproximado de $\mathrm{S}(1)=\mathbf{c}=\mathbf{4 , 9} \mathbf{m}$ e $\left(\mathrm{S}(2)=\mathrm{c} .(2)^{2}\right.$ então $\mathrm{S}(2)=4 . \mathrm{c}=19,6 \mathrm{~m}$

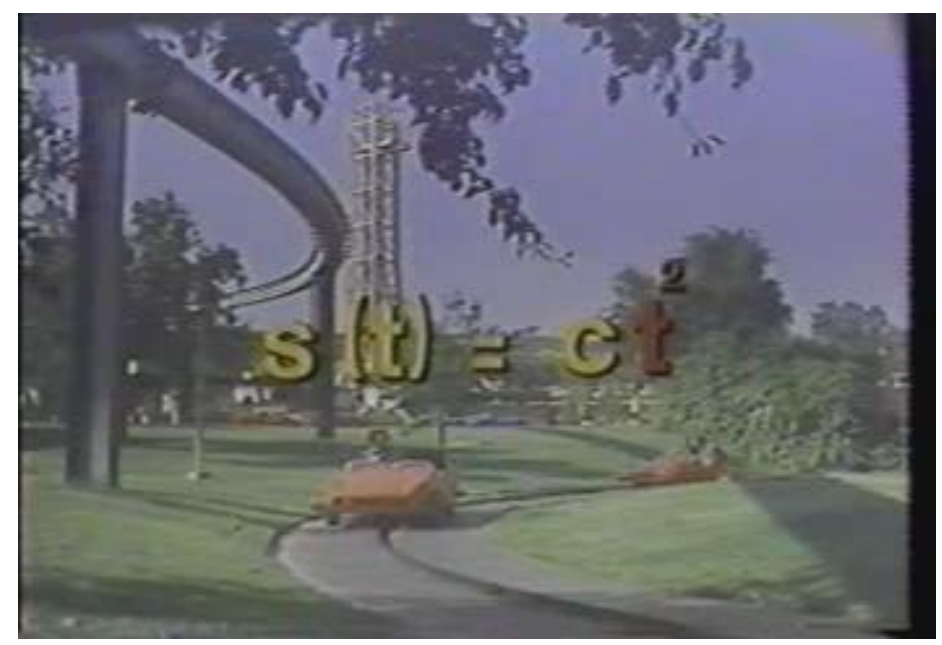

Fonte: Universo Mecânico: Caltech

\section{Sobre o programa Tracker}

O programa Tracker é uma aplicação gráfica em java construída na Open Source Physics (OSP), comunidade científica que desenvolve e disponibiliza gratuitamente recursos para o ensino de Física e de modelagem computacional. 
Este software é destinado à análise de vídeos do ponto de vista físico, podendo ser uma ferramenta para modelagem. Através dele, é possível estudar diversos tipos de movimento a partir de filmagens feitas com câmeras digitais.

O Tracker pode ser obtido no endereço eletrônico: https://physlets.org/tracker/

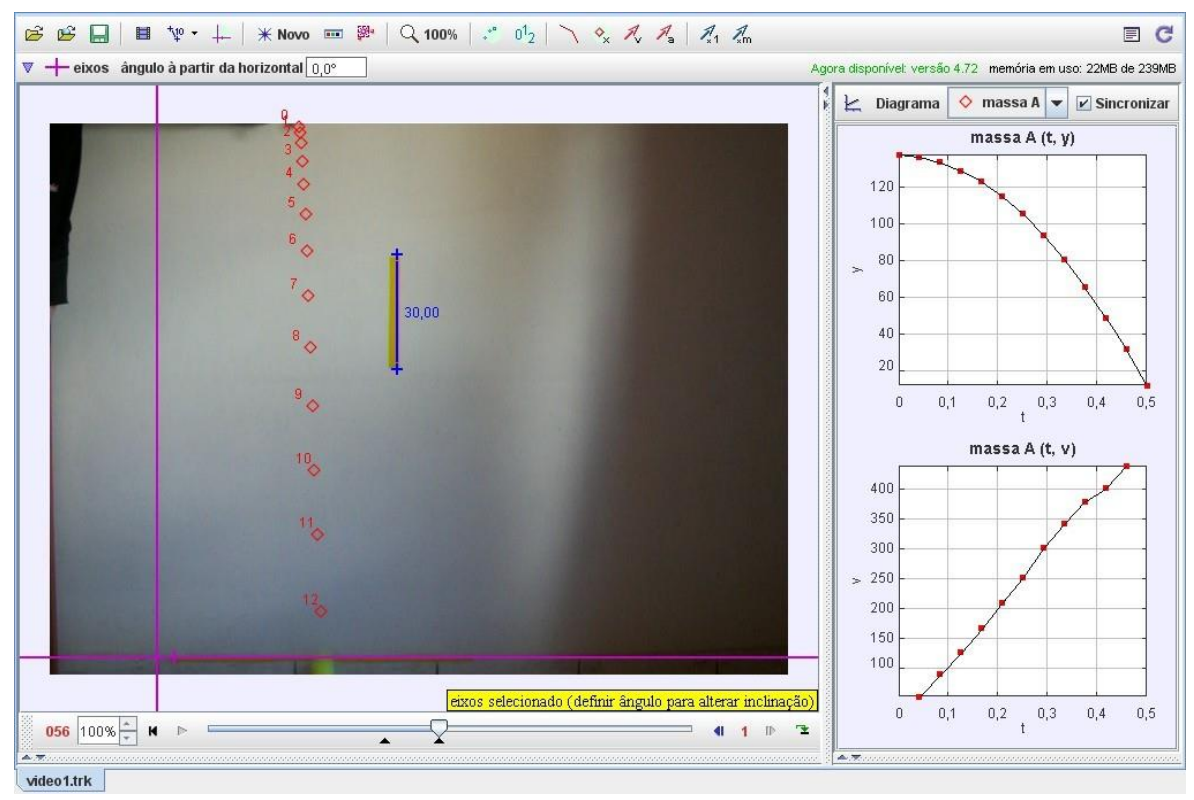

Criando um vídeo para o programa Tracker 


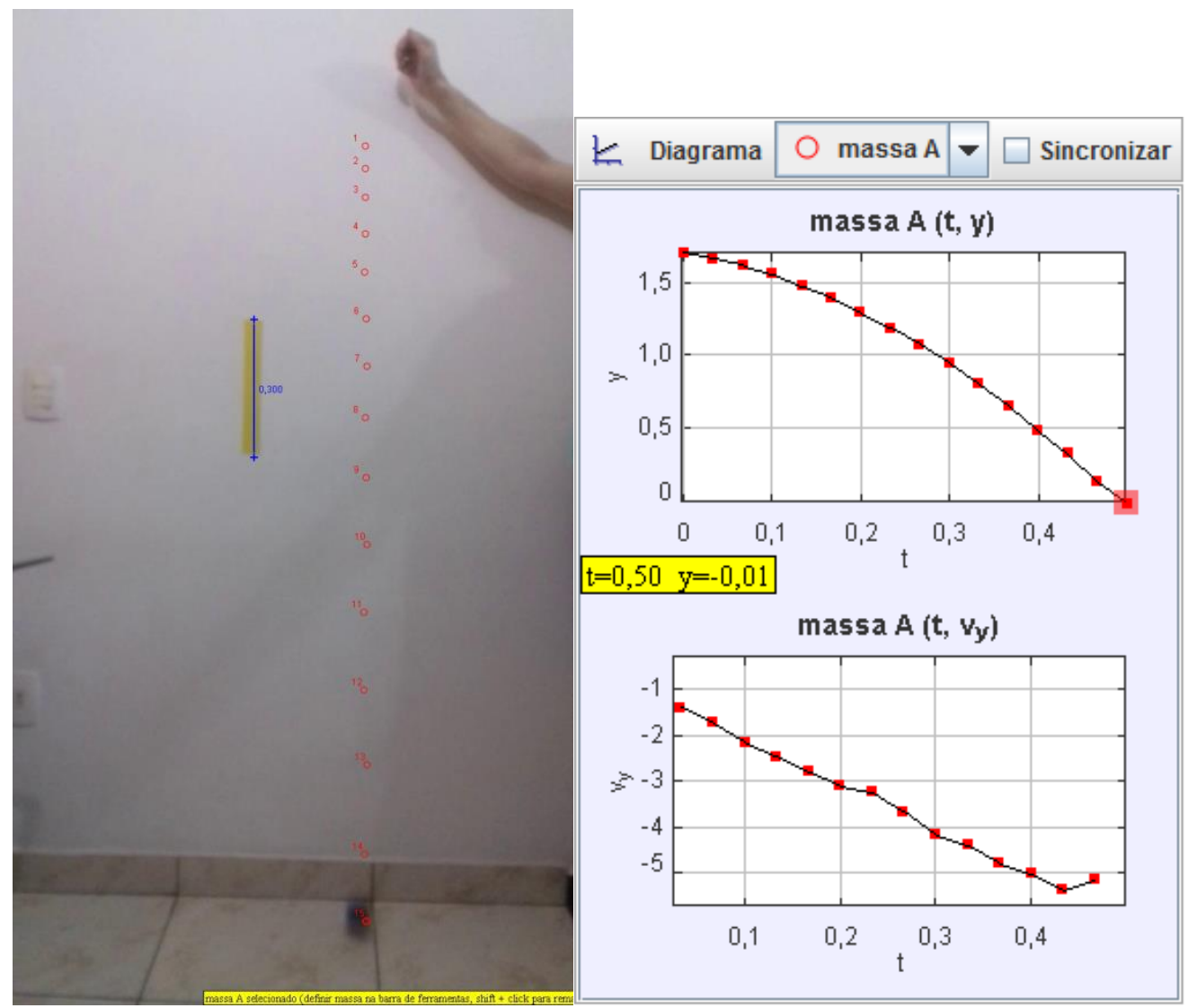

Fonte: Grupo2: Programa Tracker: https://physlets.org/tracker 
Prof. Orientador: Ronaldo Ramunno (IME)

Grupo 2: Victor e Giovana

Situação-problema: Qual é a relação entre a distância percorrida pela bola e o tempo de queda da mesma? Qual é a relação entre a velocidade de um corpo em queda livre e o tempo de queda? Podemos calcular a velocidade média entre dois intervalos de tempo, mas podemos calcular a velocidade instantânea em qualquer intervalo de tempo da queda livre?

Veja esse exemplo feito a partir dos dados gerados pelo programa Tracker

\begin{tabular}{|r|r|}
\hline tempo $(\mathrm{t})$ & $\mathrm{y}(\mathrm{t})$ \\
\hline 0,000 & 1,720 \\
\hline 0,040 & 1,715 \\
\hline 0,079 & 1,685 \\
\hline 0,119 & 1,643 \\
\hline 0,158 & 1,585 \\
\hline 0,198 & 1,520 \\
\hline 0,237 & 1,440 \\
\hline 0,277 & 1,346 \\
\hline 0,316 & 1,228 \\
\hline 0,356 & 1,110 \\
\hline 0,395 & 0,950 \\
\hline 0,435 & 0,790 \\
\hline 0,474 & 0,611 \\
\hline 0,514 & 0,420 \\
\hline 0,553 & 0,210 \\
\hline 0,593 & 0,000 \\
\hline
\end{tabular}

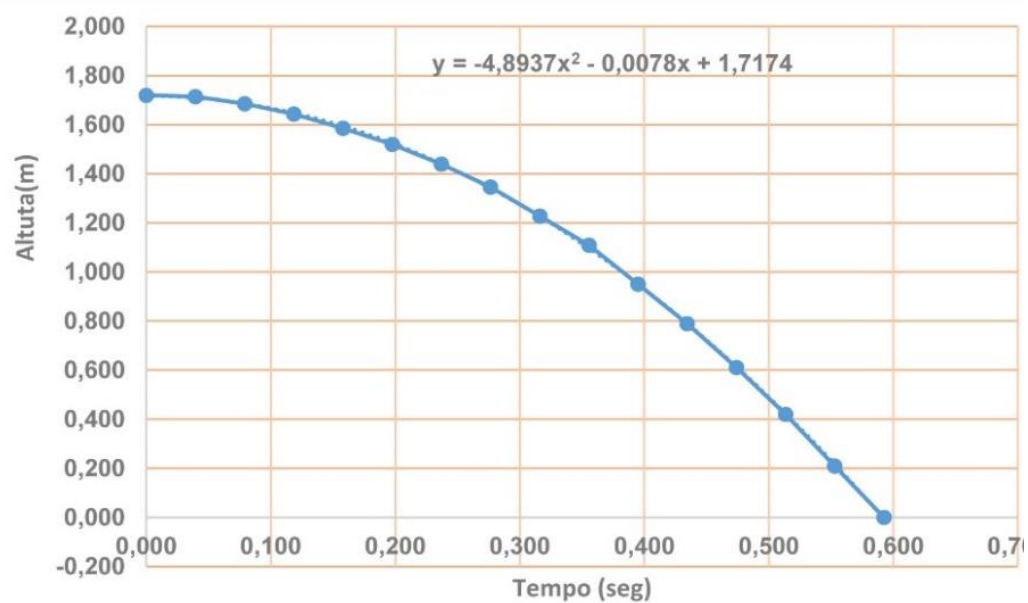

\begin{tabular}{|r|r|}
\hline tempo $(\mathrm{t})$ & $\mathrm{v}(\mathrm{m} / \mathrm{s})$ \\
\hline 0,000 & 0,000 \\
\hline 0,040 & 0,380 \\
\hline 0,079 & 0,770 \\
\hline 0,119 & 1,161 \\
\hline 0,158 & 1,540 \\
\hline 0,198 & 1,929 \\
\hline 0,237 & 2,315 \\
\hline 0,277 & 2,715 \\
\hline 0,316 & 3,088 \\
\hline 0,356 & 3,475 \\
\hline 0,395 & 3,852 \\
\hline 0,435 & 4,198 \\
\hline 0,474 & 4,600 \\
\hline 0,514 & 5,012 \\
\hline 0,553 & 5,401 \\
\hline 0,593 & 5,819 \\
\hline
\end{tabular}

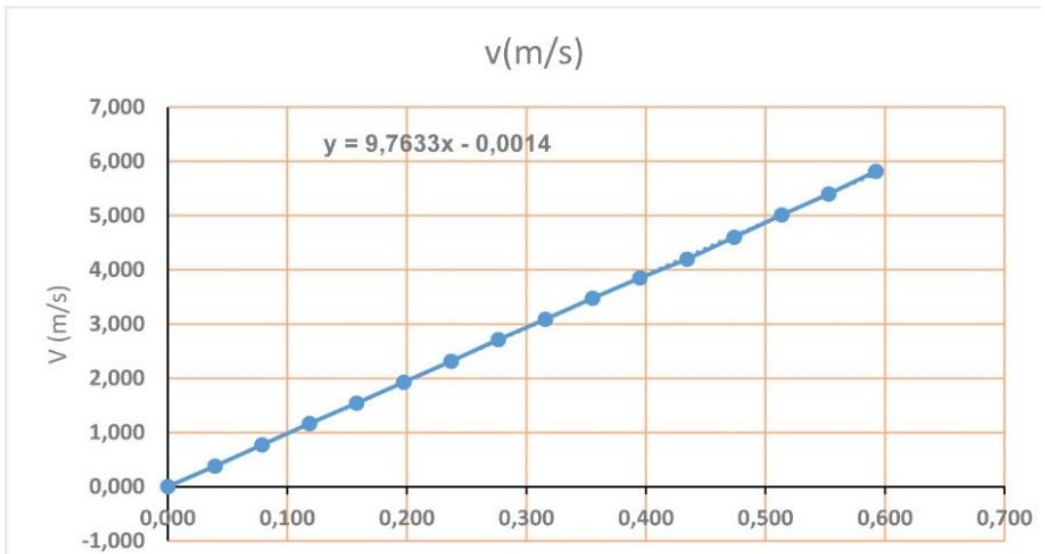

Fonte: Grupo 2 - gráfico feito no programa Excel 

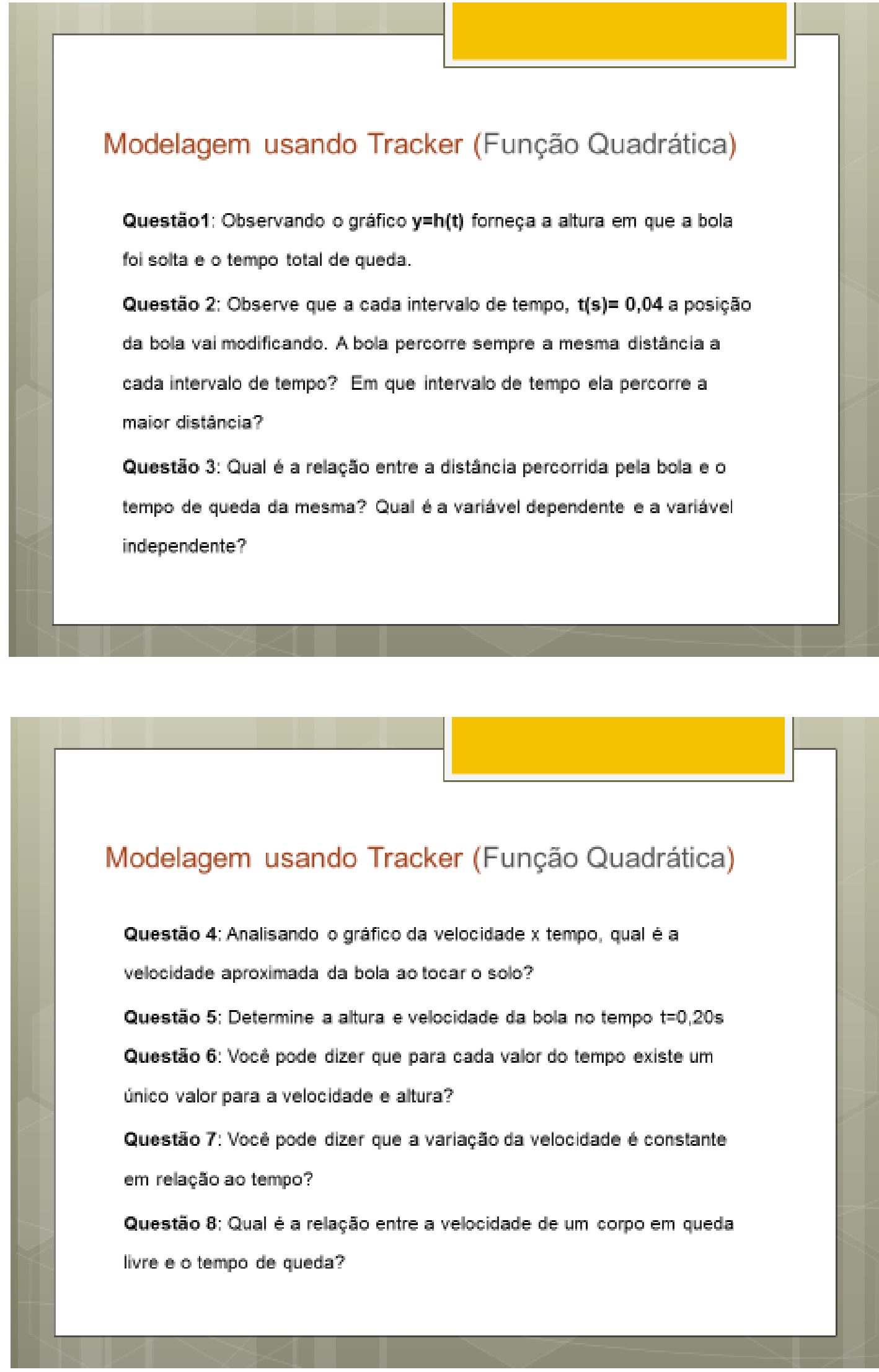

Cálculo da velocidade média e aceleração num intervalo de tempo: 
Sabemos que podemos calcular a velocidade média através da definição:

$$
V_{m}=\Delta S / \Delta T=\left(S_{f}-S_{i}\right) /\left(T_{f}-T_{i}\right)
$$

1- Calcule a velocidade média no intervalo de tempo ( $\Delta$ T): 0,198 a $0,316 \mathrm{seg}$

Sabemos que podemos calcular a aceleração média através da definição:

$$
\mathbf{a}_{\mathrm{m}}=\Delta \mathrm{V} / \Delta \mathbf{T}=\left(\mathbf{V}_{\mathbf{f}}-\mathbf{V}_{\mathbf{i}}\right) /\left(\mathbf{T}_{\mathbf{f}}-\mathbf{T}_{\mathbf{i}}\right)
$$

2- Calcule a aceleração no intervalo $\Delta \mathbf{T}$ acima

$$
a_{m}=\Delta V / \Delta T=\left(V_{f}-V_{i}\right) /\left(T_{f}-T_{i}\right) \rightarrow(3.088-1.929) /(0.316-0.198)=9.82 \mathrm{~m} / \mathrm{s}^{2}
$$

2- Calcule a aceleração em outro intervalo qualquer da queda livre

$t_{1}=0.474$ e $t_{2}=0.593$

$a_{m}=\Delta V / \Delta T=\left(V_{f}-V_{i}\right) /\left(T_{f}-T_{i}\right) \rightarrow(5.819-4.600) /(0.593-0.474)=10.24 \mathrm{~m} / \mathrm{s}^{2}$

Repare que o valor da aceleração é constante para qualquer intervalo de tempo escolhido da queda livre e seu valor é muito próximo da aceleração $\mathbf{g}$ da gravidade $9.81 \mathrm{~m} / \mathbf{s}^{2}$ 


\section{Modelagem Matemática: Fase 3}

Prof. Orientador: Ronaldo Ramunno (IME)

Grupo 2: Giovanna e Victor

Matematização: Modelagem Matemática - Revisão Teórica

\section{Função Linear}

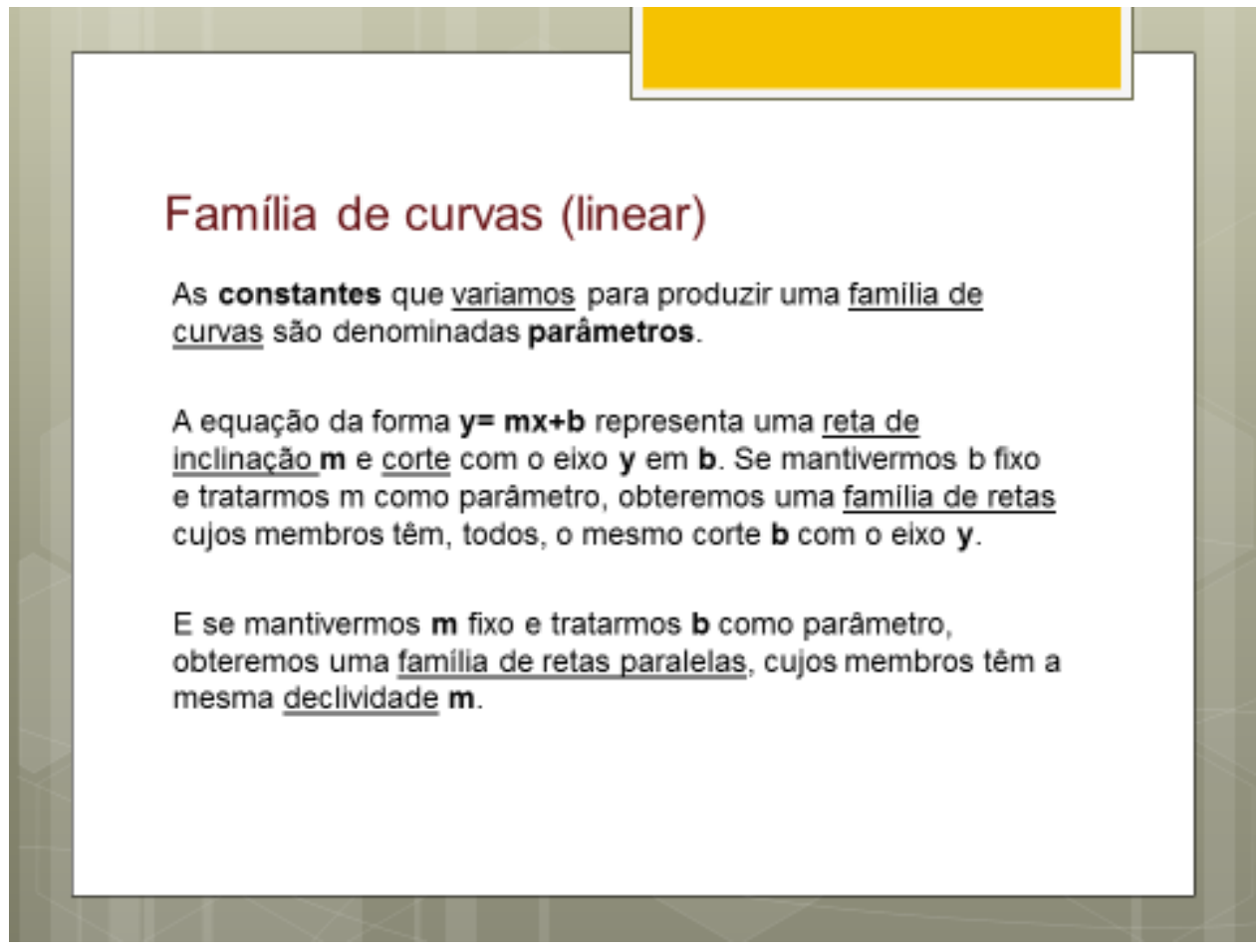

Fonte: ANTON, Howard. Cálculo. 8 ed. Porto Alegre: Bookman, 2007. p. 452-494. 


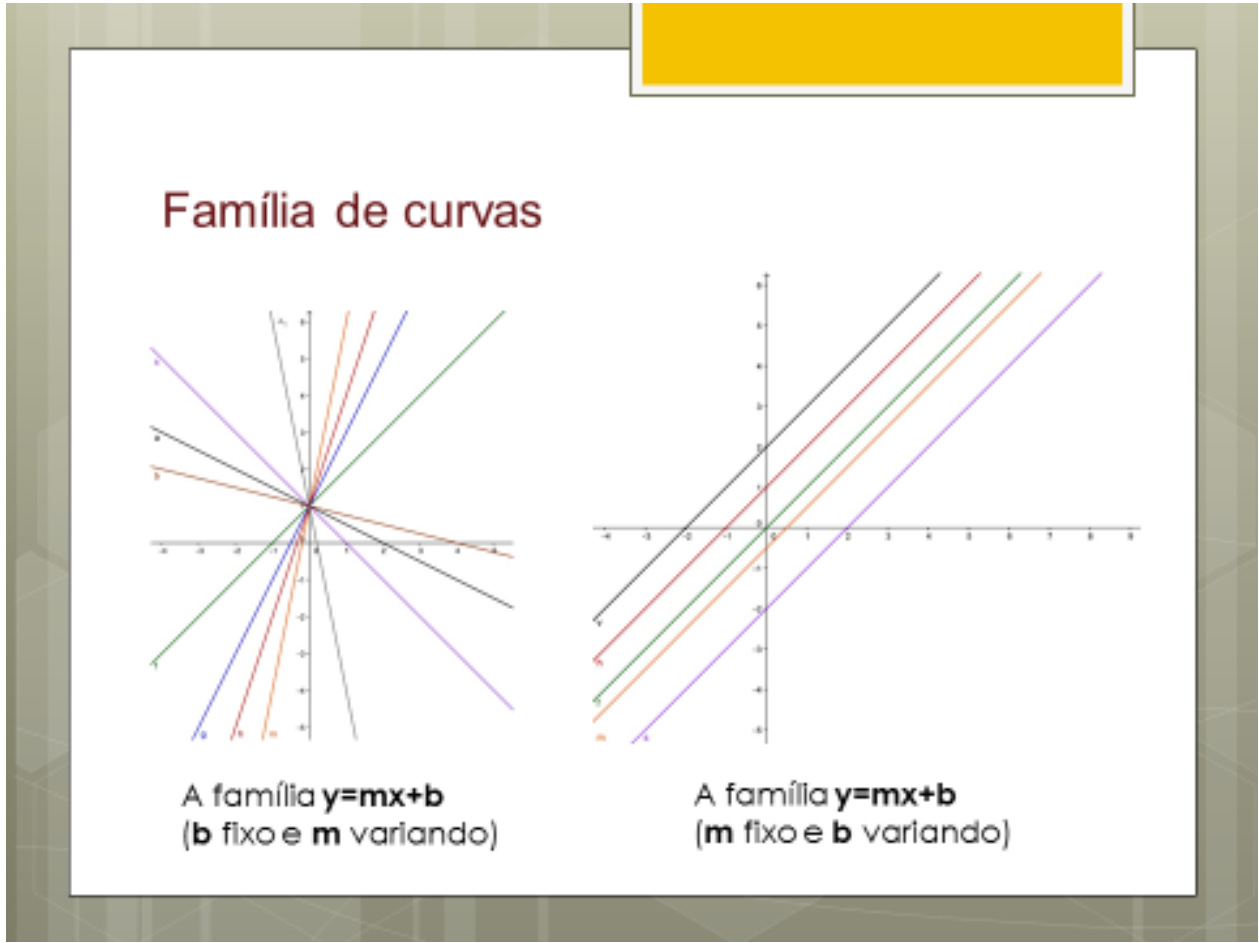

\section{Função polinomial de $2^{\circ}$ grau}

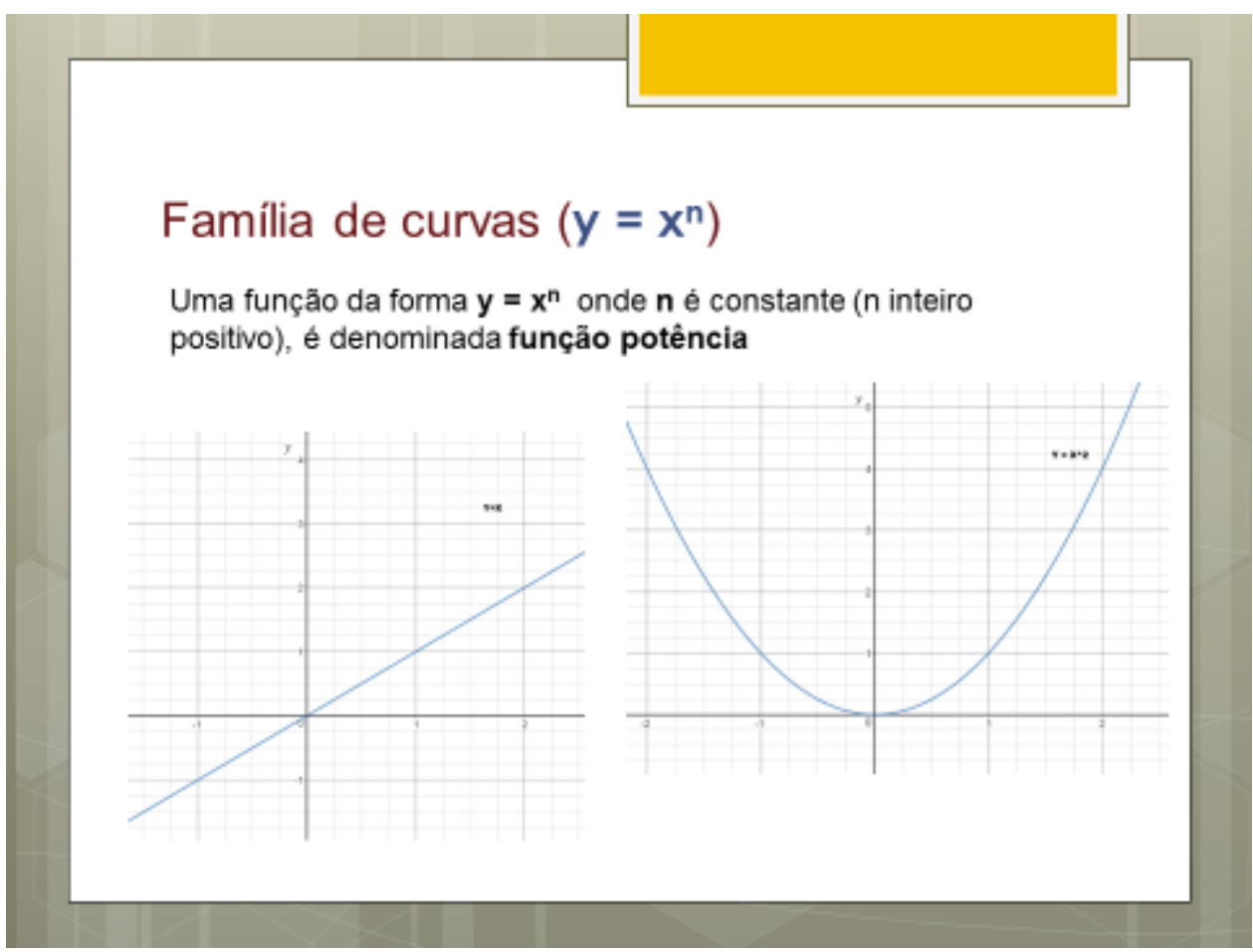

Fonte: ANTON, Howard. Cálculo. 8 ed. Porto Alegre: Bookman, 2007. p. 452-494. 


\section{Função Polinomial de $2^{\circ}$ grau}

Uma função $\mathbf{f}$ definida no conjunto $\mathbf{R}$ dos números reais e com contradomínio nesse mesmo conjunto, que associa a cada número real $\mathbf{x}$ o número real $\mathbf{a} \cdot \mathbf{x}^{\mathbf{2}}+\mathbf{b} \cdot \mathbf{x}+\mathbf{c}$ onde $\mathrm{a}, \mathrm{b}$ e c são números reais e $\mathrm{a} \neq 0$

$\mathbf{f : ~} \mathbf{R} \rightarrow \mathbf{R}, \quad \mathbf{f}(\mathbf{x})=\mathbf{a} \cdot \mathbf{x}^{2}+\mathbf{b} \cdot \mathbf{x}+\mathbf{c} \quad \mathbf{f}$ é denominada função polinomial de $2^{\circ}$ grau

O gráfico de uma função quadrática é uma parábola cuja concavidade está associada ao sinal do coeficiente a. O vértice da parábola é o ponto de coordenadas:

$\mathrm{V}:(-\mathrm{b} / 2 . \mathrm{a},-\Delta / 4 . \mathrm{a})$

Para $\mathbf{a}<0$ temos um ponto de máximo da parábola

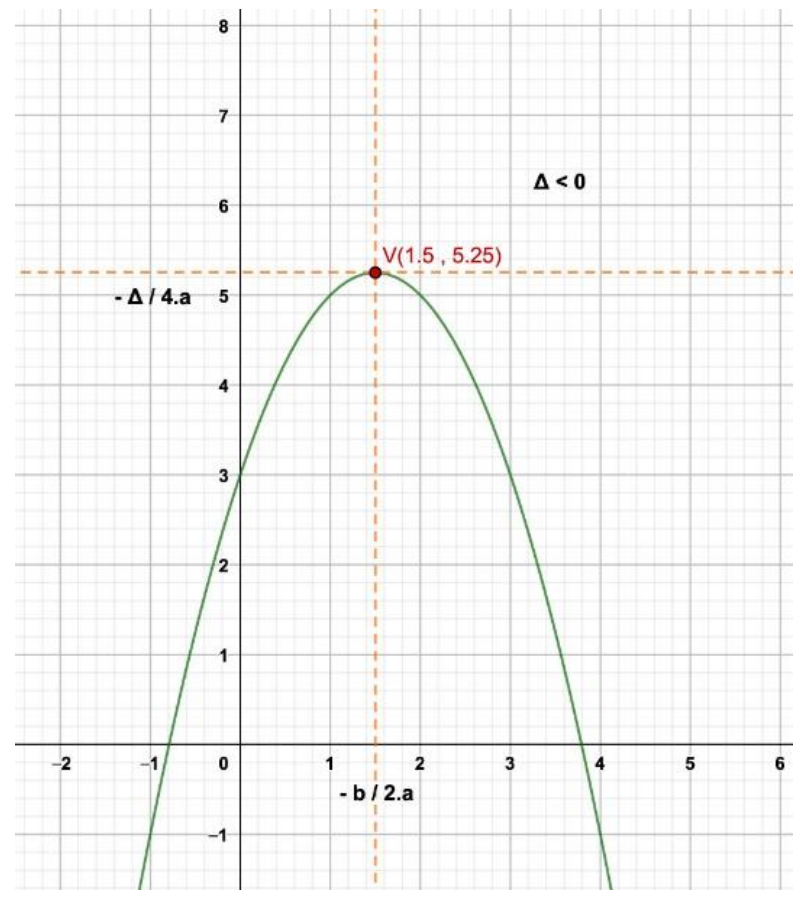

Fonte: Grupo 2 - gráfico feito no programa Geogebra 
Para $\mathbf{a}>\mathbf{0}$ temos um ponto de mínimo da parábola

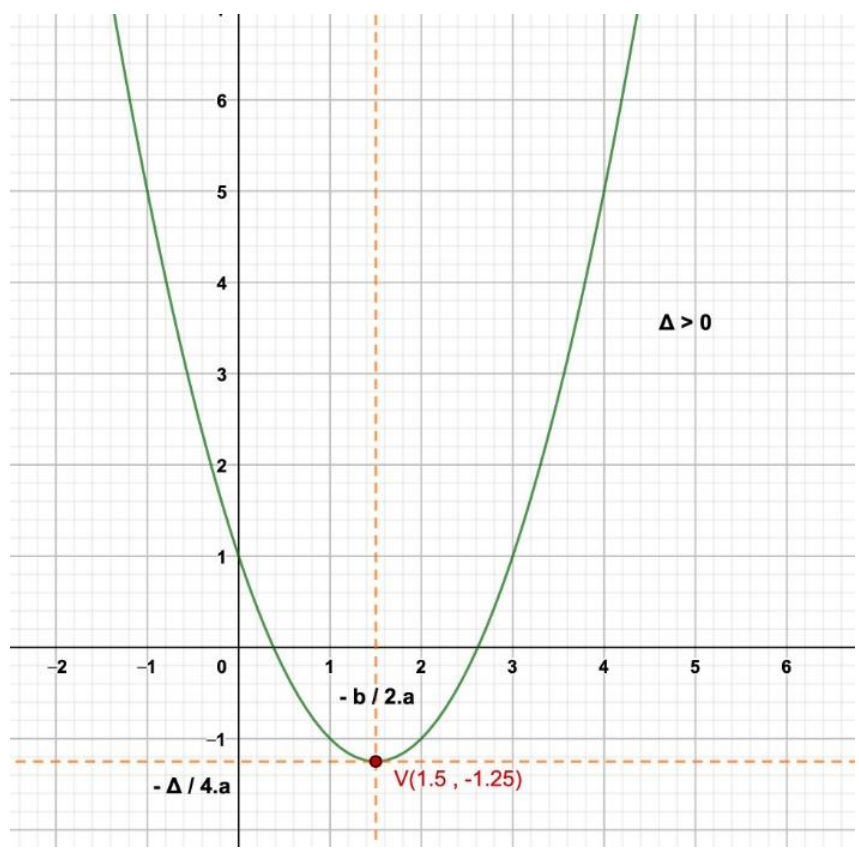

Fonte: Grupo 2 - gráfico feito no programa Geogebra

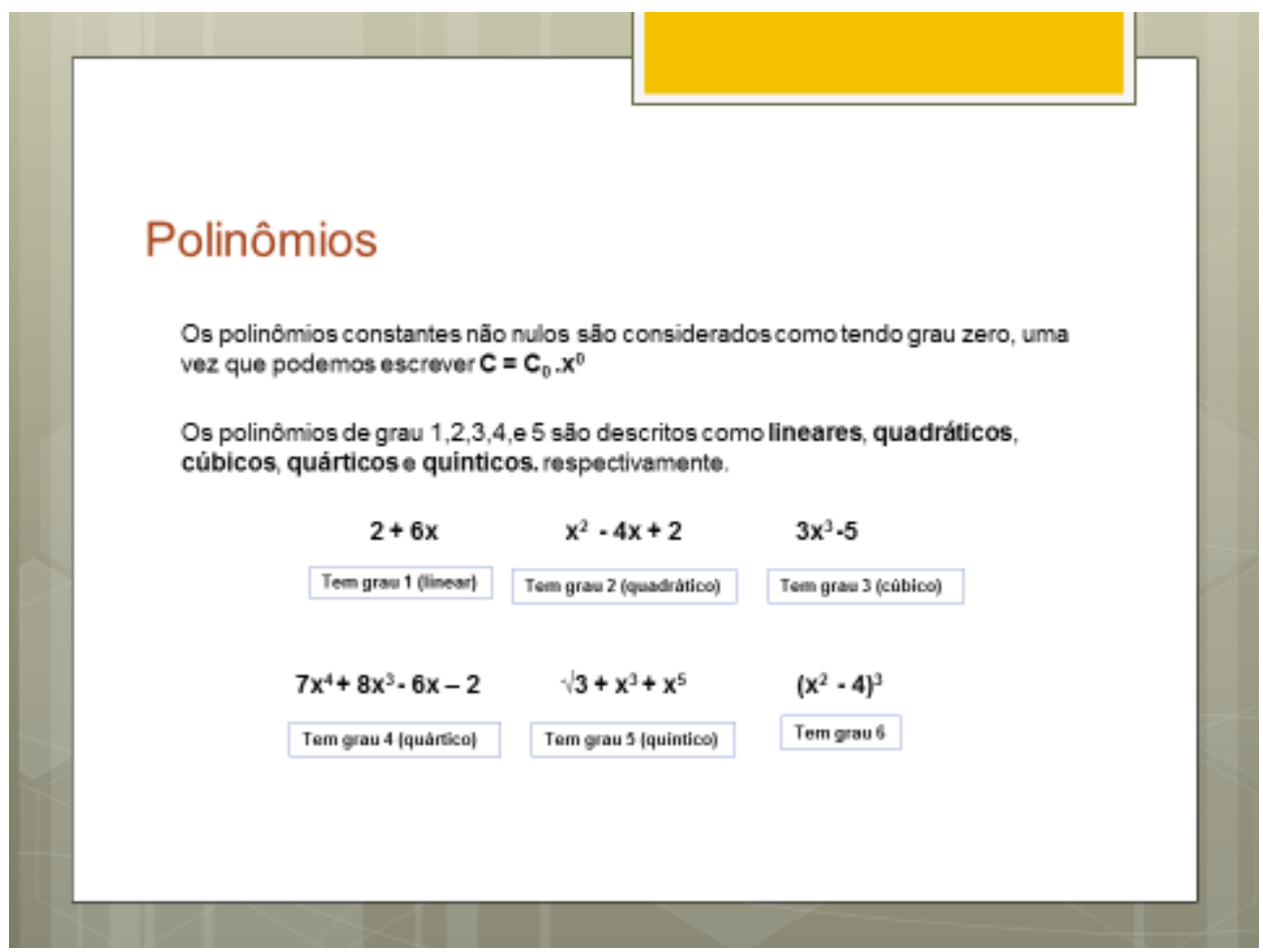




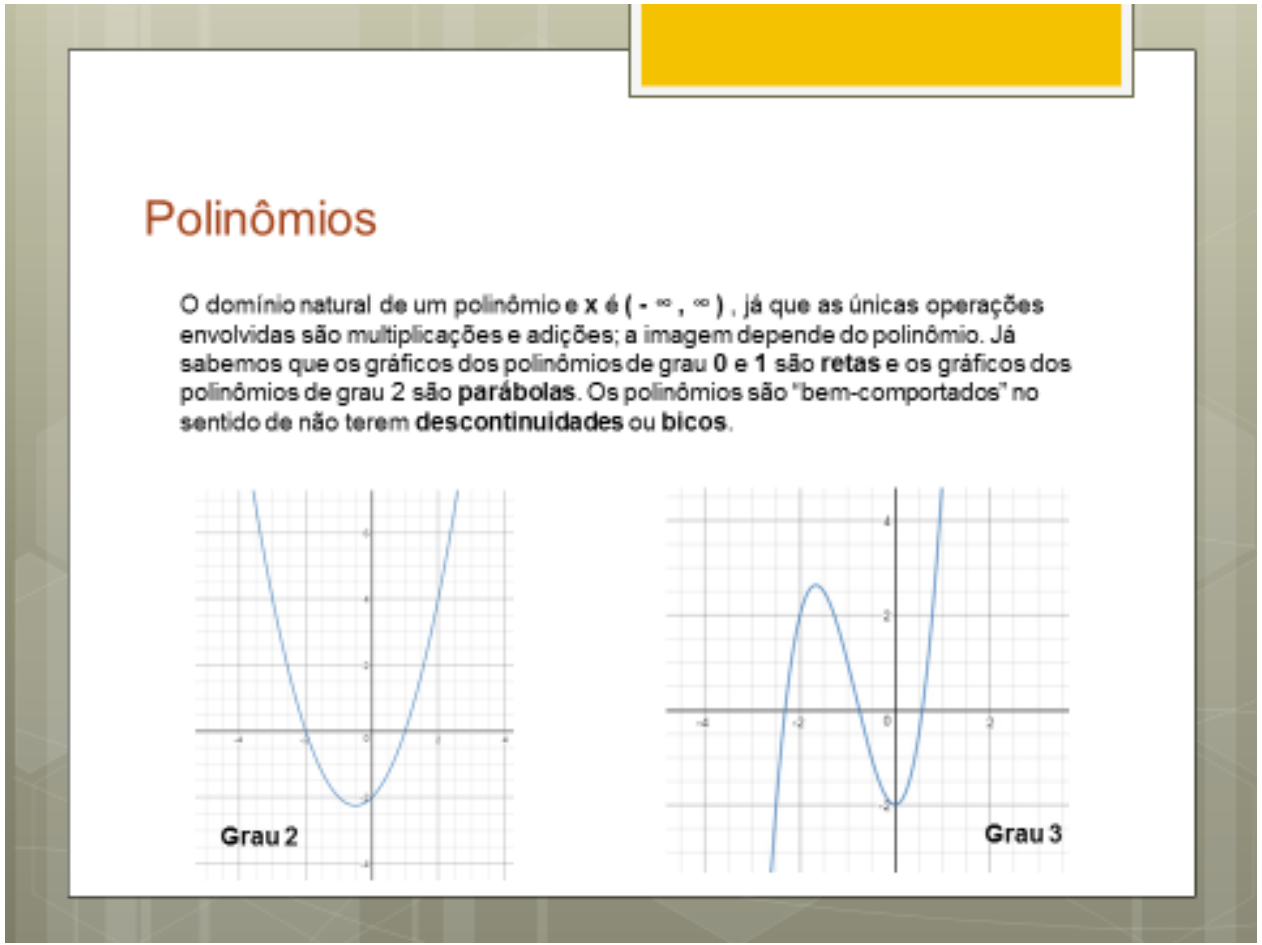

Fonte: ANTON, Howard. Cálculo. 8 ed. Porto Alegre: Bookman, 2007. p. 452-494.

\section{Taxa de Variação}

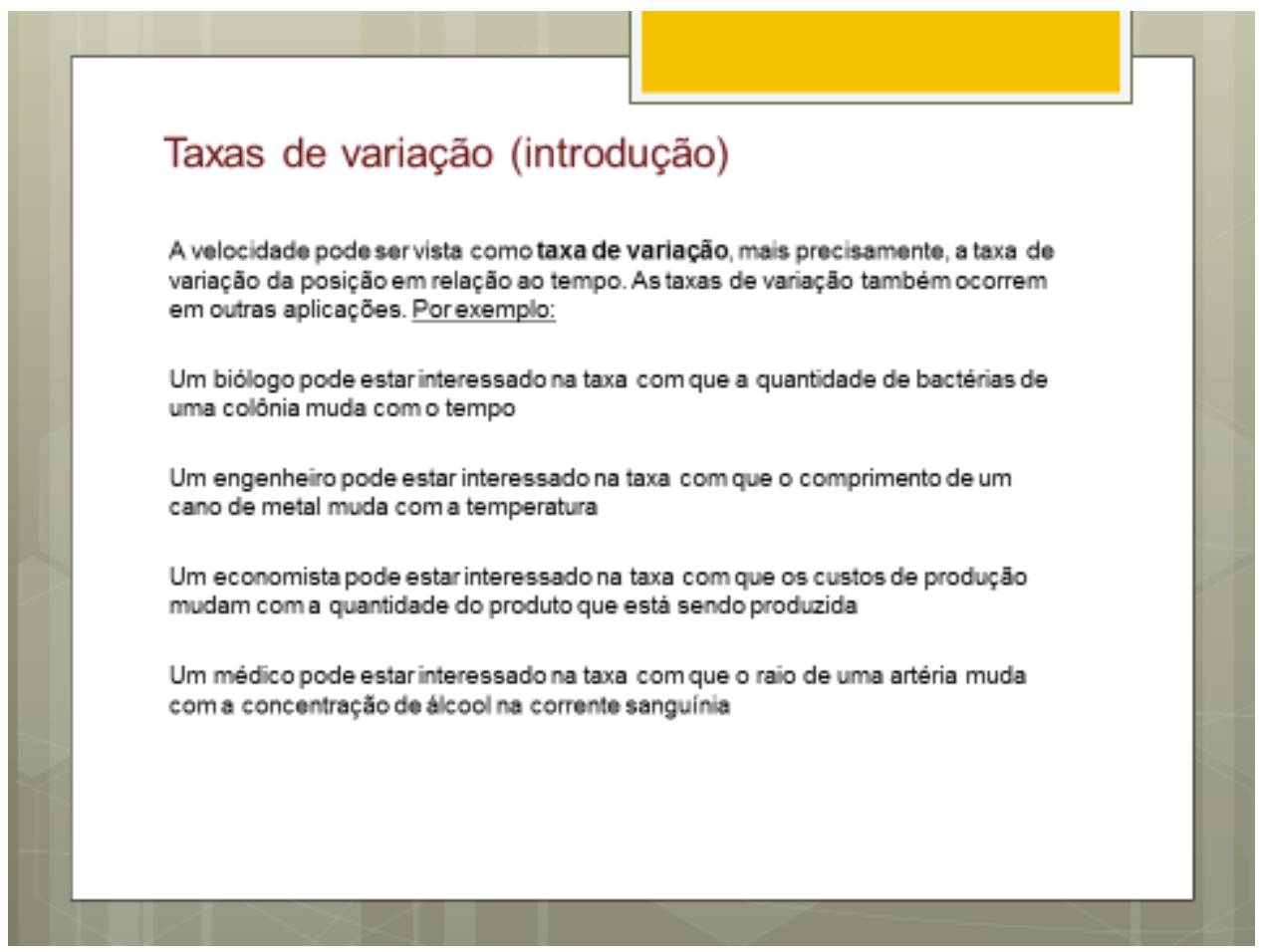




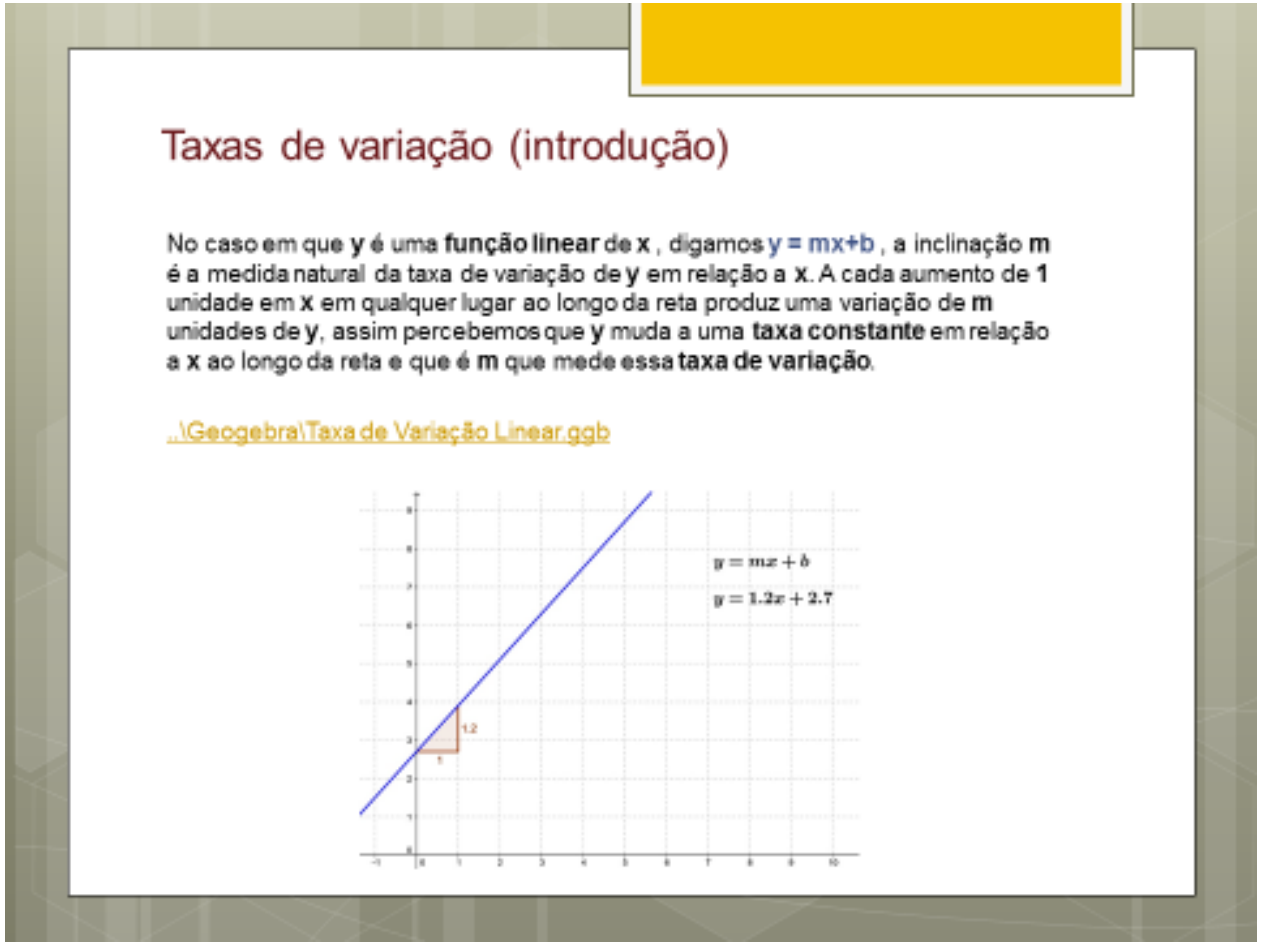

Fonte: ANTON, Howard. Cálculo. 8 ed. Porto Alegre: Bookman, 2007. p. 452-494.

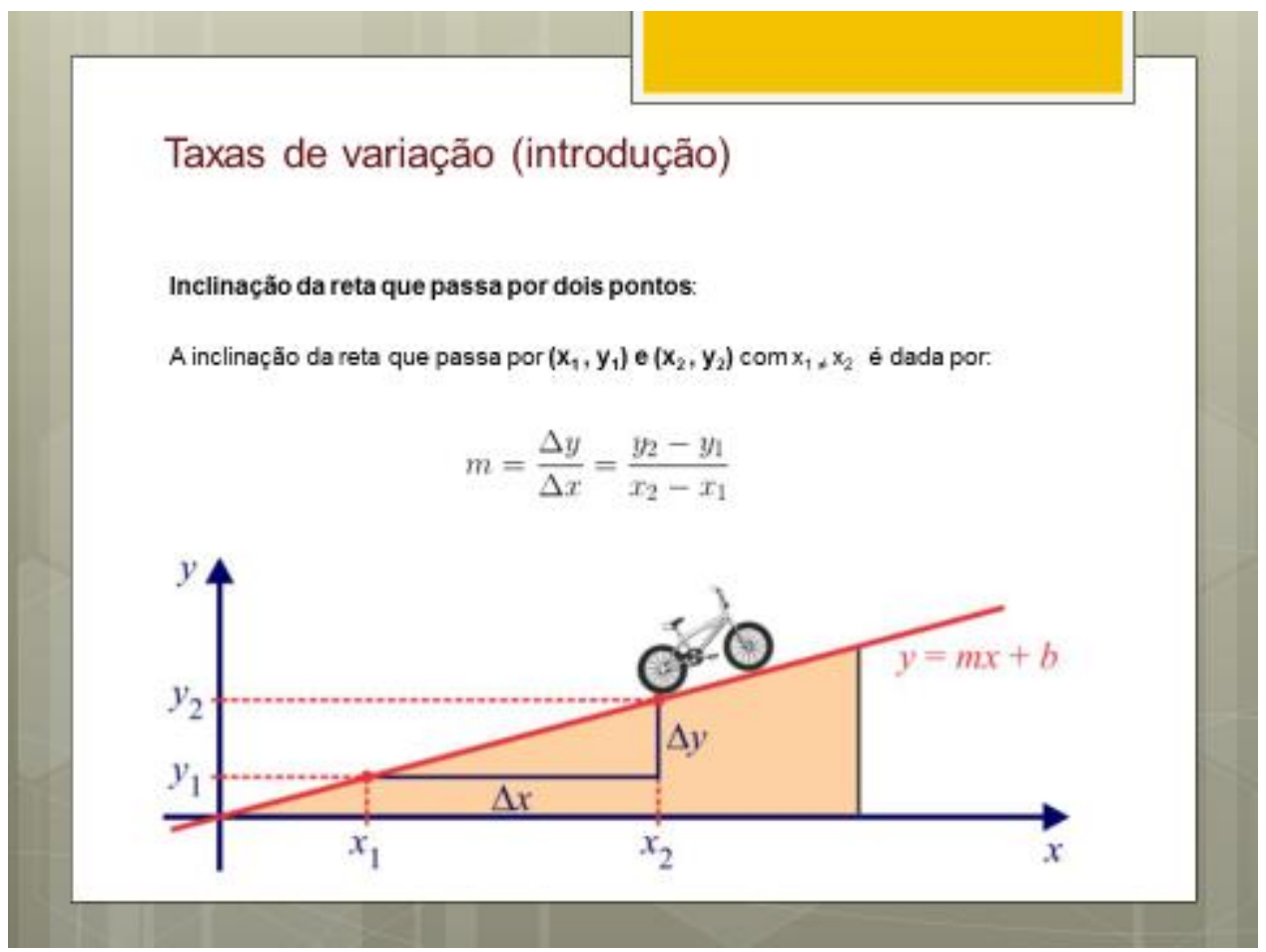

Fonte: ANTON, Howard. Cálculo. 8 ed. Porto Alegre: Bookman, 2007. p. 452-494. 


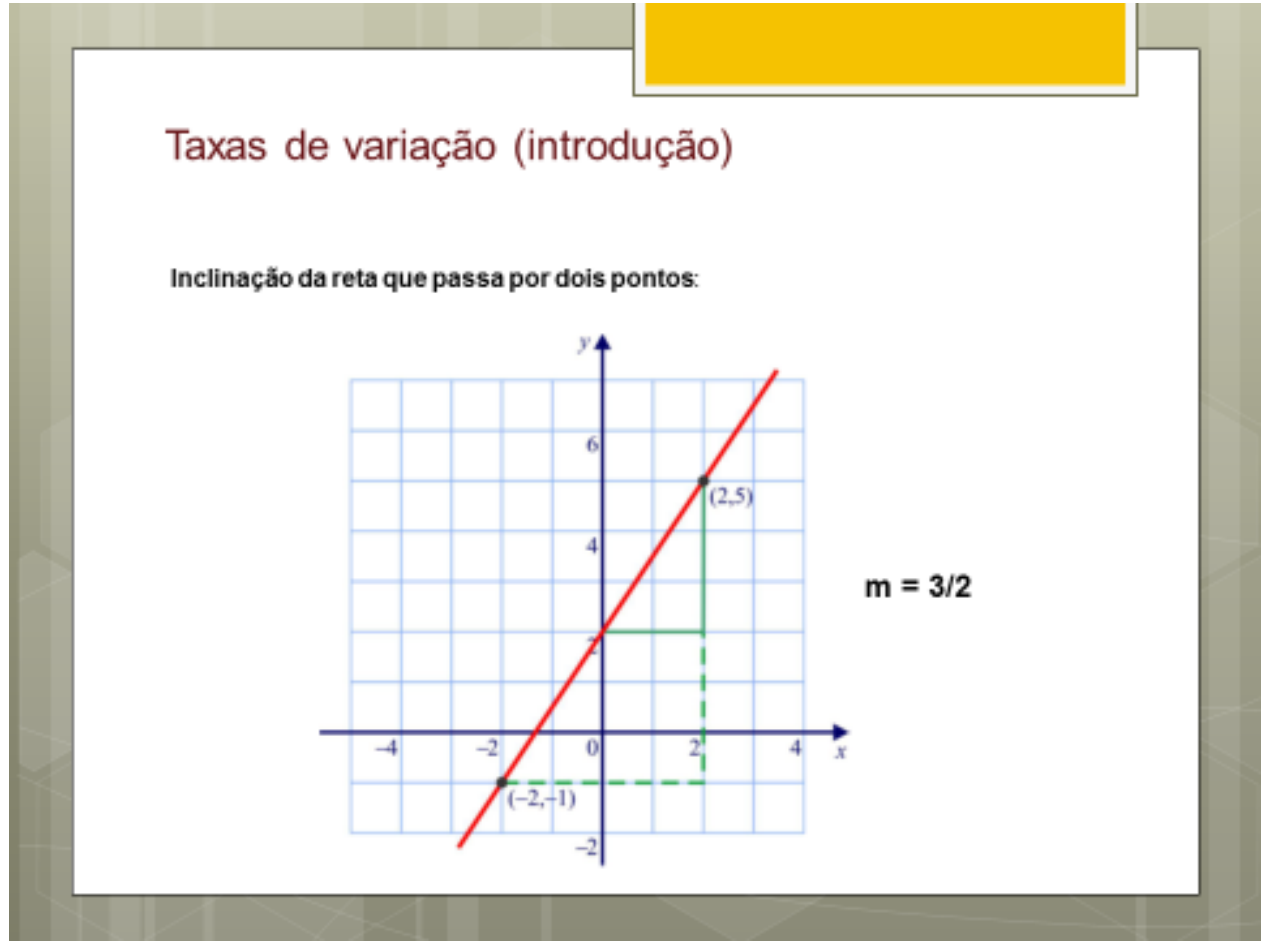

Fonte: Elaboradas com o auxílio dos programas Geogebra, Graph, Adobe Photoshop e Corel Draw

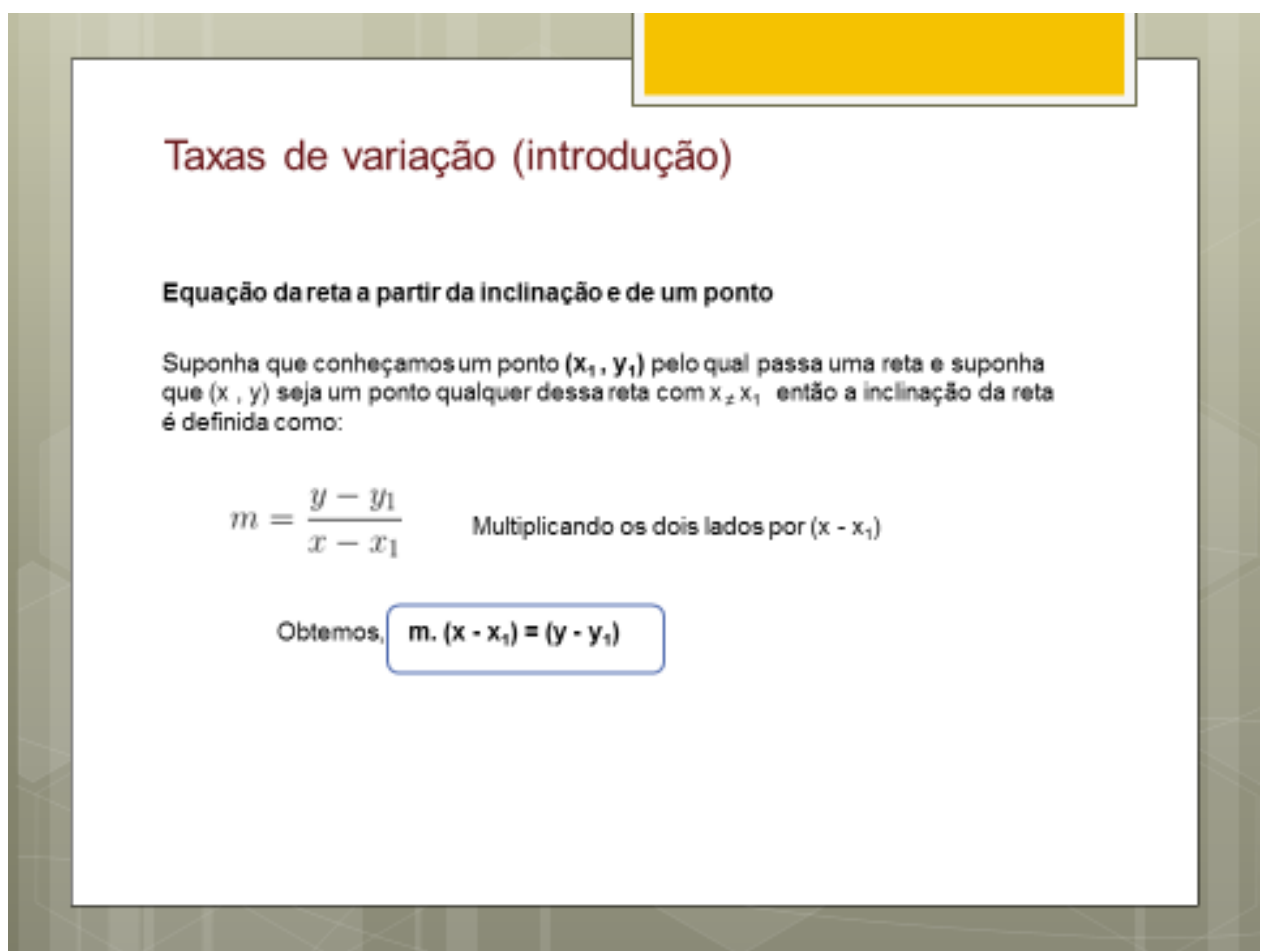

Fonte: ANTON, Howard. Cálculo. 8 ed. Porto Alegre: Bookman, 2007. p. 452-494. 


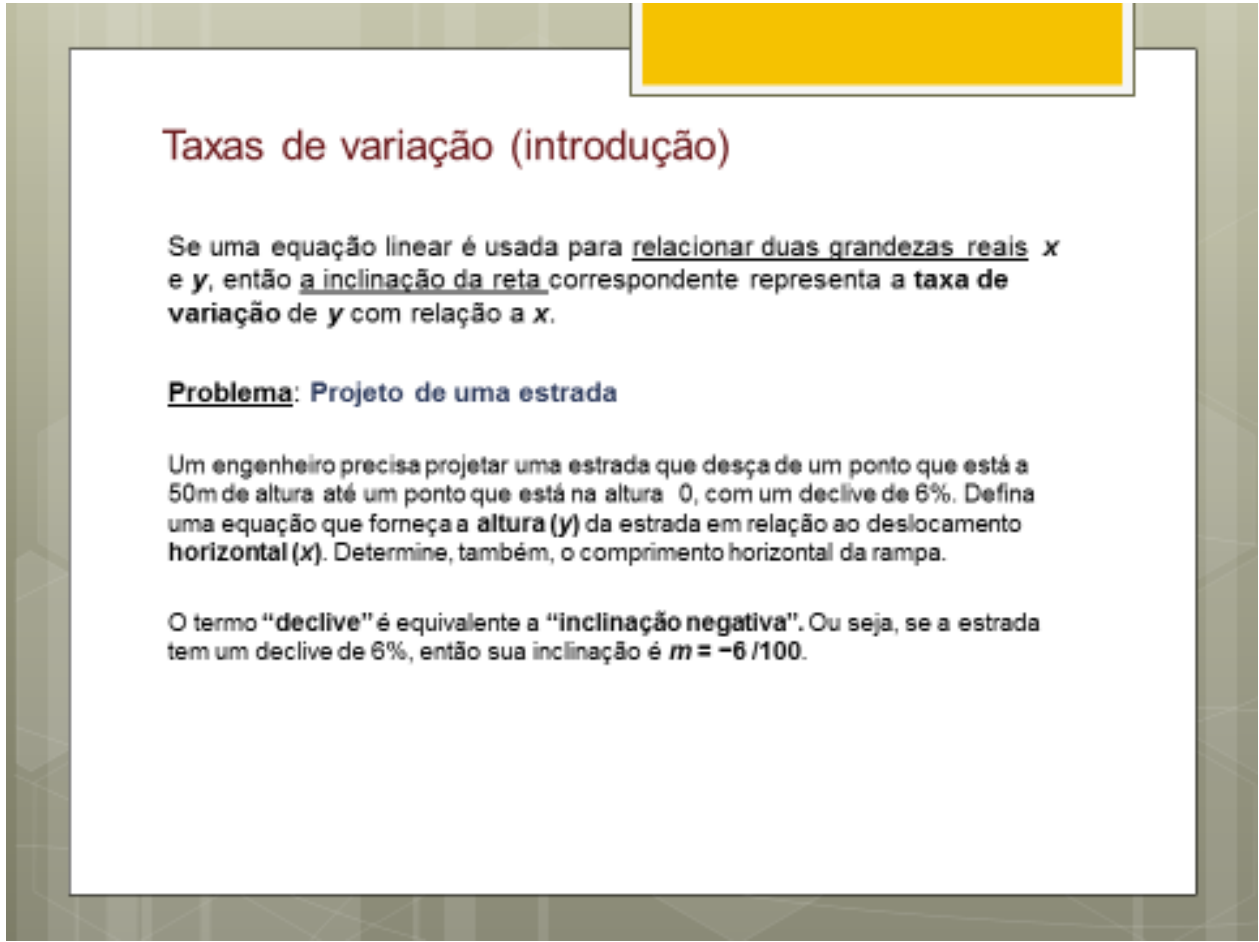

Fonte: ANTON, Howard. Cálculo. 8 ed. Porto Alegre: Bookman, 2007. p. 452-494.

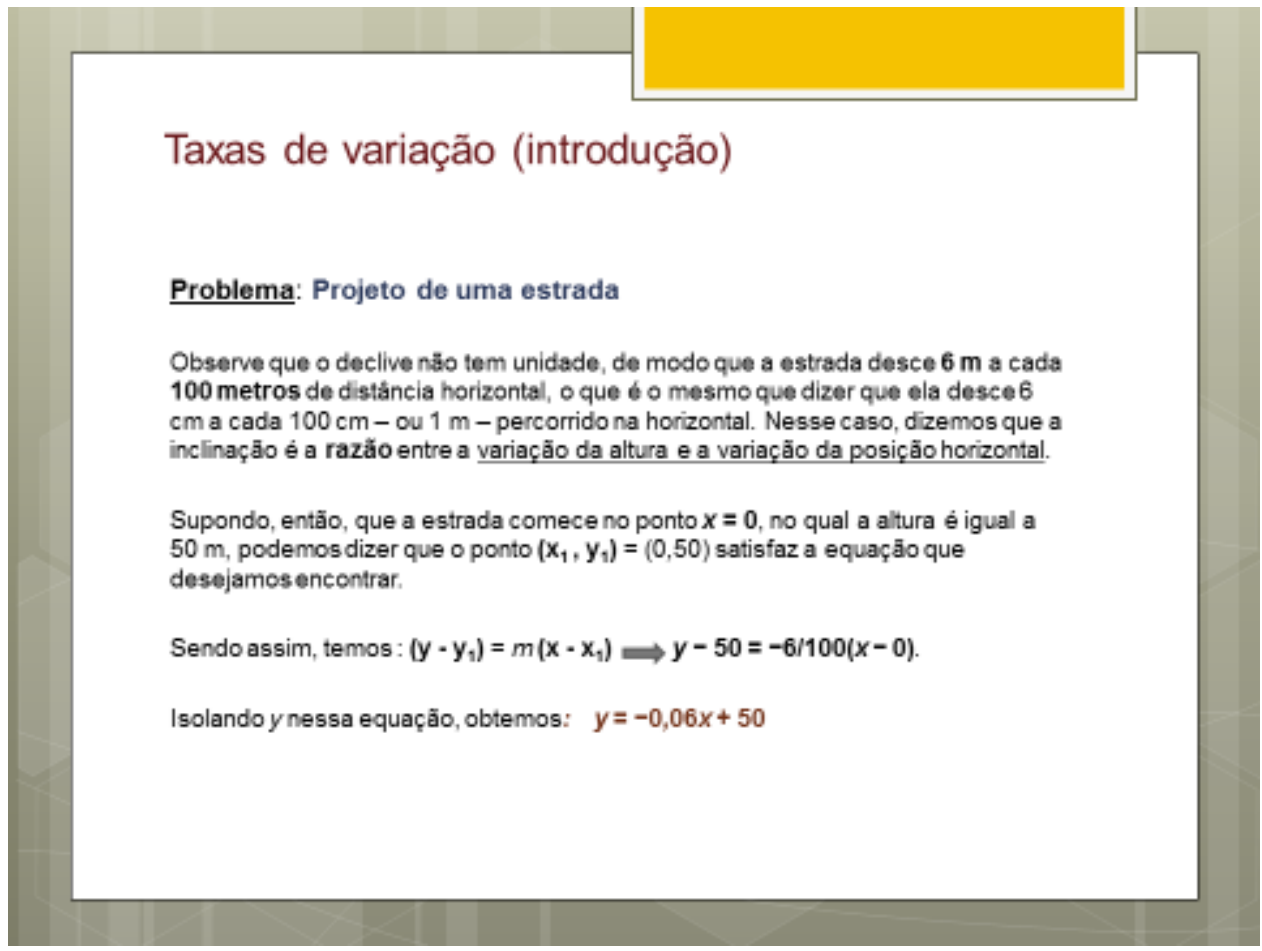




\section{Modelagem Matemática: Fase 4}

Prof. Orientador: Ronaldo Ramunno (IME)

Grupo 2: Giovanna e Victor

Matematização: Introdução ao conceito de taxa de variação instantânea

Vamos construir as bases conceituais para poder responder a uma das perguntas da nossa modelagem matemática!

Situação-problema: Podemos calcular a velocidade média entre dois intervalos de tempo, mas podemos calcular a velocidade instantânea em qualquer intervalo de tempo da queda livre?

\section{Calculando a velocidade média (queda livre)}

Sabemos da Física que um corpo em queda livre (desprezando a resistência do ar), tem sua função do espaço x tempo:

$$
\begin{aligned}
& h(t)=g \cdot t^{2} / 2\left(\operatorname{com} g_{T}=9.8 \mathrm{~m} / \mathrm{s}\right) \text { temos }: h(t)=4,9 . t^{2} \\
& V_{m}=\Delta S / \Delta t \quad V_{m}=\left(S_{f}-S_{i}\right) / \Delta t
\end{aligned}
$$

Se colocarmos $\mathbf{t}=\mathbf{1}$ seg na função $\mathbf{h}(\mathbf{t})$ obtemos $\mathbf{4 , 9 m}$, ou seja, a bola caiu 4,9 m durante o primeiro segundo, e durante os 2 primeiros segundos a bola cai $\mathbf{1 9 , 6 m}$

Agora, e se você quisesse determinar a velocidade da bola a exatamente 1seg depois que você a jogou?

Usando a fórmula da velocidade, podemos descobrir facilmente a velocidade média da bola no intervalo de 1 a 2 seg da sua queda.

Temos: $\mathbf{V}_{\mathbf{m}}=(19,6-4,9) /(2-1)=\mathbf{1 4 , 7} \mathbf{~ m} / \mathbf{s}$ 
Mas essa não é a resposta que queremos, pois, a bola está acelerando, ou seja, ela cai cada vez mais rápido e queremos saber a velocidade a exatamente 1 s depois que a jogamos.

\begin{tabular}{|c|c|c|c|c|c|c|c|}
\hline$t(\operatorname{seg})$ & 2,0000 & 1,5000 & 1,2500 & 1,1000 & 1,0100 & 1,0010 & 1,0001 \\
\hline Vm $(\mathrm{m} / \mathrm{s})$ & 14,7000 & 12,2500 & 11,0250 & 10,2900 & 9,8490 & $\mathbf{9 , 8 0 4 9}$ & $\mathbf{9 , 8 0 0 5}$ \\
\hline
\end{tabular}

À medida que $\mathbf{t}$ se aproxima cada vez mais de 1s, a velocidade média se aproxima cada vez mais de $9,8 \mathrm{~m} / \mathbf{s}$.

Veja a fórmula que fornece a velocidade_entre $\mathbf{1}$ seg e $\mathbf{t}$ segundos

$$
V_{m}=\frac{4,9 \cdot t^{2}-4,9 \cdot(1)}{t-1}=\frac{4,9 \cdot\left(t^{2}-1\right)}{t-1}=\frac{(4,9 \cdot(t-1)(t+1))}{(t-1)}=4,9 . t+4,9(t \not \equiv 1)
$$

Portanto a velocidade instantânea da bola no tempo 1 seg: $V_{i}=4,9 . t+4,9$ $\log _{0} V_{i}(\mathbf{1})=9,8 \mathrm{~m} / \mathrm{s}$

Lembra da conclusão que chegamos ao assistir o vídeo do Universo Mecânico?

No instante $\mathbf{S}(\mathbf{1})=\mathbf{c} .(1)^{2}=\mathbf{c}$ (fazendo experimentos pode se chegar a um valor aproximado de $\mathrm{S}(1)=\mathbf{c}=\mathbf{4 , 9} \mathrm{m} \mathrm{e}\left(\mathbf{S}(2)=\mathrm{c} .(2)^{2}\right.$ então $\mathrm{S}(2)=4 . \mathbf{c}=\mathbf{1 9 , 6} \mathbf{m}$

Sabemos a função em queda livre: $\mathbf{S}(\mathbf{t})=$ c.t $^{2}$

No problema do vídeo se quiséssemos calcular a velocidade média entre os instantes $t=0 \mathrm{~s}$ e $\mathrm{t}=2 \mathrm{~s}$ e sabendo que o carro caiu $19,6 \mathrm{~m}$, então a $\mathbf{V} \mathbf{m}=\mathbf{1 9 , 6} \mathbf{m} / \mathbf{2} \mathbf{s}=\mathbf{9 , 8} \mathbf{m} / \mathbf{s}$ repare que em $\mathrm{t}=2 \mathrm{~s}$ o carro caia muito mais rápido do que $9,8 \mathrm{~m} / \mathrm{s}$ e no tempo $\mathrm{t}=0$ s estava parado.

Mas se quiséssemos calcular a velocidade num instante qualquer?

O problema é que para calcular a velocidade num instante exato usando a fórmula da velocidade média, teríamos a razão 0/0 que é uma indeterminação matemática! 
Mas ao invés de perguntar pela velocidade instantânea num exato momento t, podemos perguntar qual é a velocidade média do carrinho entre o instante $\mathbf{t}$ e $\mathbf{h}$ segundos mais tarde num instante $(\mathbf{t}+\mathbf{h})$ e como sabemos que a distância de queda é $\mathbf{S}(\mathbf{t})=\mathbf{c . t}^{2}$

Então a distância no intervalo $(\mathrm{t}+\mathrm{h}): \mathbf{S}(\mathbf{t}+\mathbf{h})=\mathbf{c} .(\mathbf{t}+\mathbf{h})^{\mathbf{2}}$ e a $\mathbf{V}_{\mathbf{m}}=\left[(\mathbf{S t}+\mathbf{h})^{\mathbf{2}}-\mathbf{S}(\mathbf{t})\right] / \mathbf{h}$

$\mathbf{V}_{\mathbf{m}}=\left[\mathrm{c} .(\mathrm{t}+\mathrm{h})^{2}-\mathrm{c} \cdot \mathrm{t}^{2}\right] / \mathrm{h}=\left(\mathrm{c} . \mathrm{t}^{2}+2 . c . t . h+\mathrm{c} \cdot \mathrm{h}^{2}-\mathrm{c} \cdot \mathrm{t}^{2}\right) / \mathrm{h}=\left(2 . \mathrm{c} \cdot \mathrm{t} \cdot \mathrm{h}+\mathrm{c} \cdot \mathrm{h}^{2}\right) / \mathrm{h}=$ h. $(2 . \mathrm{c} . \mathrm{t}+\mathrm{c} . \mathrm{h}) / \mathrm{h}$

$V_{m}=(2 . c . t+c . h)$

Podemos fazer $\mathbf{h}$ um tempo cada vez menor, indo de $1 \mathrm{seg}, 0.5 \mathrm{seg}, 0.01 \mathrm{seg}$ e tão próximo quanto queremos de zero pois não estamos mais dividindo por zero! Então c.h se torna desprezível e ficamos com a expressão: $\mathbf{V}_{\mathbf{i}}=\mathbf{2 . c . t}$ e fazendo $\mathrm{c}=4,9$ temos:

$$
V_{i}=9,8 . t
$$

\section{Voltando aos dados obtidos com o programa Tracker}

Vamos calcular a velocidade da bola no tempo em que esta chega ao solo com o programa Tracker, $\mathbf{t}_{\mathbf{q}}=\mathbf{0 , 0 5 9 3} \mathrm{seg}$

Assumindo $\mathbf{S}_{\mathbf{0}}=\mathbf{0}$ (solo) e $\mathbf{V}_{\mathbf{0}}=\mathbf{0}$ (pois a bola foi solta em queda livre), e desprezando a resistência do ar, então $S(t)=\mathbf{4 . 9} t^{2}$ e $V_{\mathbf{i}}=\mathbf{9 , 8 . t}$

$V_{i}=9,8 .(0.0593)=5,811 \mathrm{~m} / \mathrm{s}$

Veja o programa Tracker nos forneceu a velocidade nesse mesmo instante de tempo igual a 5.819 m/s. uma aproximação muita boa!

Na verdade, devido ao efeito da resistência do ar a velocidade registrada no Tracker deveria ser menor que a velocidade teórica calculada e deu um pouco maior, mas o programa juntamente com o vídeo causa erros, mas o erro foi muito pequeno! 
Substituindo $\mathbf{t}$ por $\mathbf{x}$ e $\mathbf{t}_{0}$ por $\mathbf{x}_{\mathbf{0}}$ onde $\mathbf{x}_{\mathbf{0}}$ é fixo e $\mathbf{x}$ se aproxima cada vez mais de $\mathbf{x}_{\mathbf{0}}$

Se fizermos $\mathbf{h}=\mathbf{x}-\mathbf{x} \mathbf{0}$ então quando $\mathbf{x}$ se aproximar cada vez mais de $\mathbf{x} \mathbf{0}, \mathbf{h}$ tenderá a zero

Então a expressão: $\left[\left(\mathbf{F}(\mathbf{x})-\mathbf{F}\left(\mathbf{x}_{0}\right)\right] /\left(\mathbf{x}-\mathbf{x}_{0}\right)\right.$ equivale a: $\left[\mathbf{F}\left(\mathbf{x}_{0}+\mathbf{h}\right)-\mathbf{F}\left(\mathbf{x}_{0}\right)\right] /(\mathbf{h})$

Dada uma função polinomial de 2 grau: $\mathbf{F}(\mathbf{x})=\mathbf{a} \cdot \mathbf{x}^{2}+\mathbf{b} \cdot \mathbf{x}+\mathbf{c}$ e usando a expressão:

e generalizando $\mathbf{x} 0$ para qualquer valor $\mathbf{x}$

$[\mathbf{F}(\mathbf{x}+\mathbf{h})-\mathbf{F}(\mathbf{x})] / \mathbf{h}$

$\left.\left[a \cdot(x+h)^{2}+b \cdot(x+h)+c\right]-\left(a \cdot x^{2}+b \cdot x+c\right)\right] / h$

$\left.\left.\left[a \cdot\left(x^{2}+2 \cdot a \cdot x \cdot h+h^{2}\right)+b \cdot x+b \cdot h\right)+c\right]-\left(a \cdot x^{2}+b \cdot x+c\right)\right] / h$

$\left.\left[\left(2 \cdot a \cdot x \cdot h+a \cdot h^{2}\right)+b \cdot h\right)\right] / h$

h. $(2 \cdot a \cdot x+a \cdot h+b) / h=(2 \cdot a \cdot x+a \cdot h+b)$ e fazendo $\mathbf{h}$ muito próximo de zero

$F^{\prime}(x)=2 . a . x+b$

Definimos essa função como a derivada de $\mathbf{F}(\mathbf{x})$ e denotamos $\mathbf{F}^{\mathbf{9}}(\mathbf{x})$

Logo

$F^{\prime}(x)=\lim _{h \rightarrow 0}[F(x+h)-F(x)] / h$

E para a função polinomial de 2 grau temos: $\mathbf{F}^{\prime}(\mathbf{x})=\mathbf{2 . a . x}+\mathbf{b}$

A velocidade pode ser vista como uma taxa de variação da posição em relação ao tempo. Repare que esse conceito pode ser generalizado para qualquer função como fizemos para a função polinomial de $2^{\circ}$.

\section{As aplicações desse conceito de derivada são imensas:}

Um biólogo pode estar interessado na taxa com que a quantidade de bactérias de uma colônia muda com o tempo. Nesse caso precisaríamos calcular a derivada de uma função exponencial Um engenheiro pode estar interessado na taxa com que o comprimento de um cano de metal muda com a temperatura. 
Taxa de variação média: $\mathbf{T V M}=[\mathbf{f}(\mathbf{x}+\mathbf{h})-(\mathbf{f}(\mathbf{x})] / \mathbf{h}$

Taxa de variação instantânea: $\mathbf{F}^{\prime}(\mathbf{x})=\lim _{\mathbf{h} \rightarrow \mathbf{0}}[\mathbf{F}(\mathbf{x}+\mathbf{h})-\mathbf{F}(\mathbf{x})] / \mathbf{h}$ 


\section{Atividades com Geogebra: Funções lineares e quadráticas}

\section{Grupos 2}

\section{Função linear e Afim}

O que acontece com o gráfico se alterarmos o valor do coeficiente angular a ?

Variando o coeficiente a os alunos perceberam que a inclinação da reta mudava e que se o valor de a for maior que zero a função será crescente e se o coeficiente a for menor que zero a função será decrescente. Então o valor do coeficiente angular mede a inclinação da reta e também seu sinal determina se a função será crescente ou decrescente.

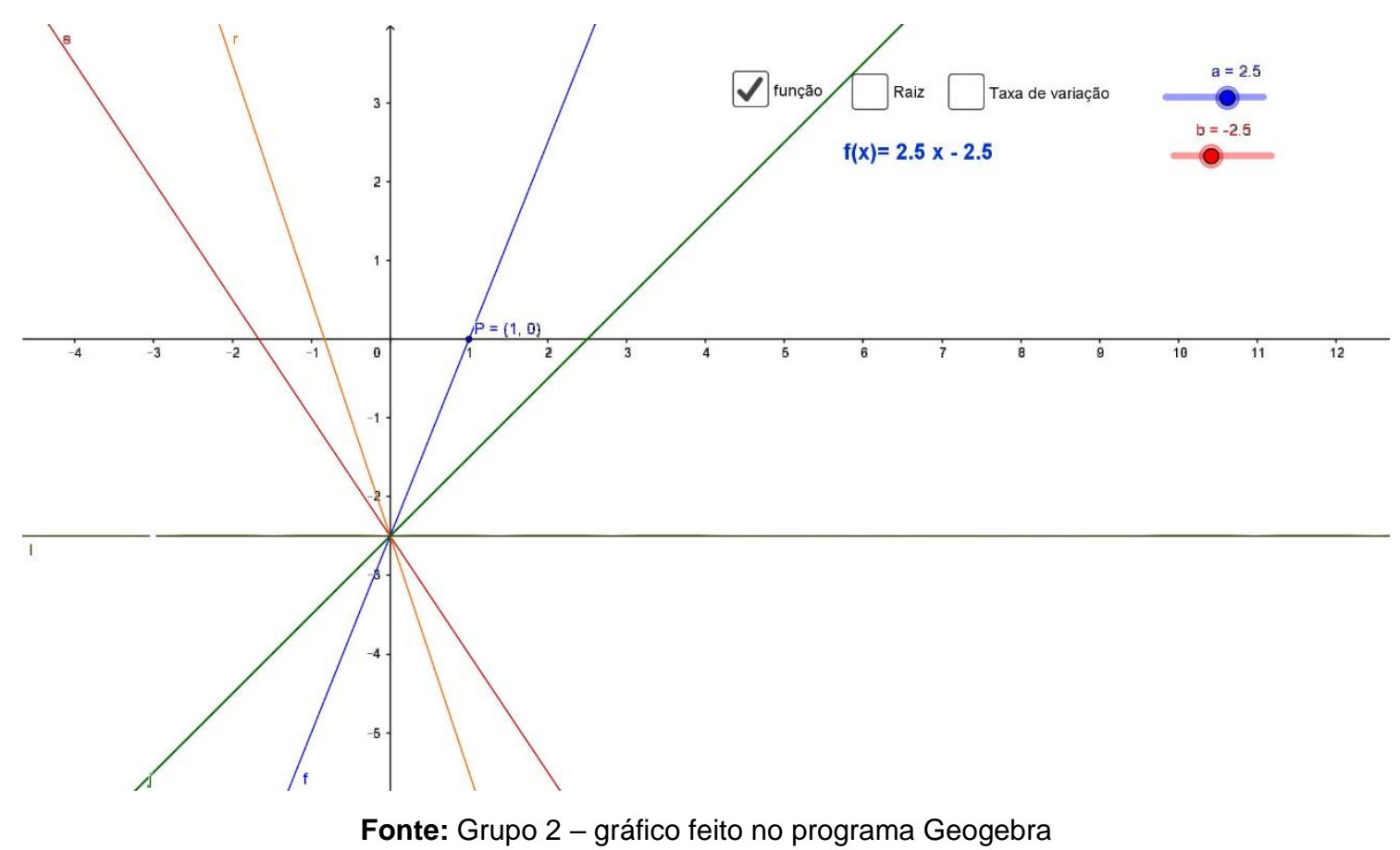

O que acontece com o gráfico se alterarmos o valor do coeficiente linear $\mathbf{b}$ ?

Que comportamento da função permite identificar o coeficiente linear $\mathbf{b}$ ?

Que ponto no gráfico está relacionado com o coeficiente linear?

Quais as coordenadas do ponto em torno do qual o gráfico gira?

Quando se varia o coeficiente angular têm se mudanças na inclinação da reta em torno do ponto $(\mathbf{0 , b})$, o que pode se esperar ao fixar o coeficiente angular e varia o valor do coeficiente b? 


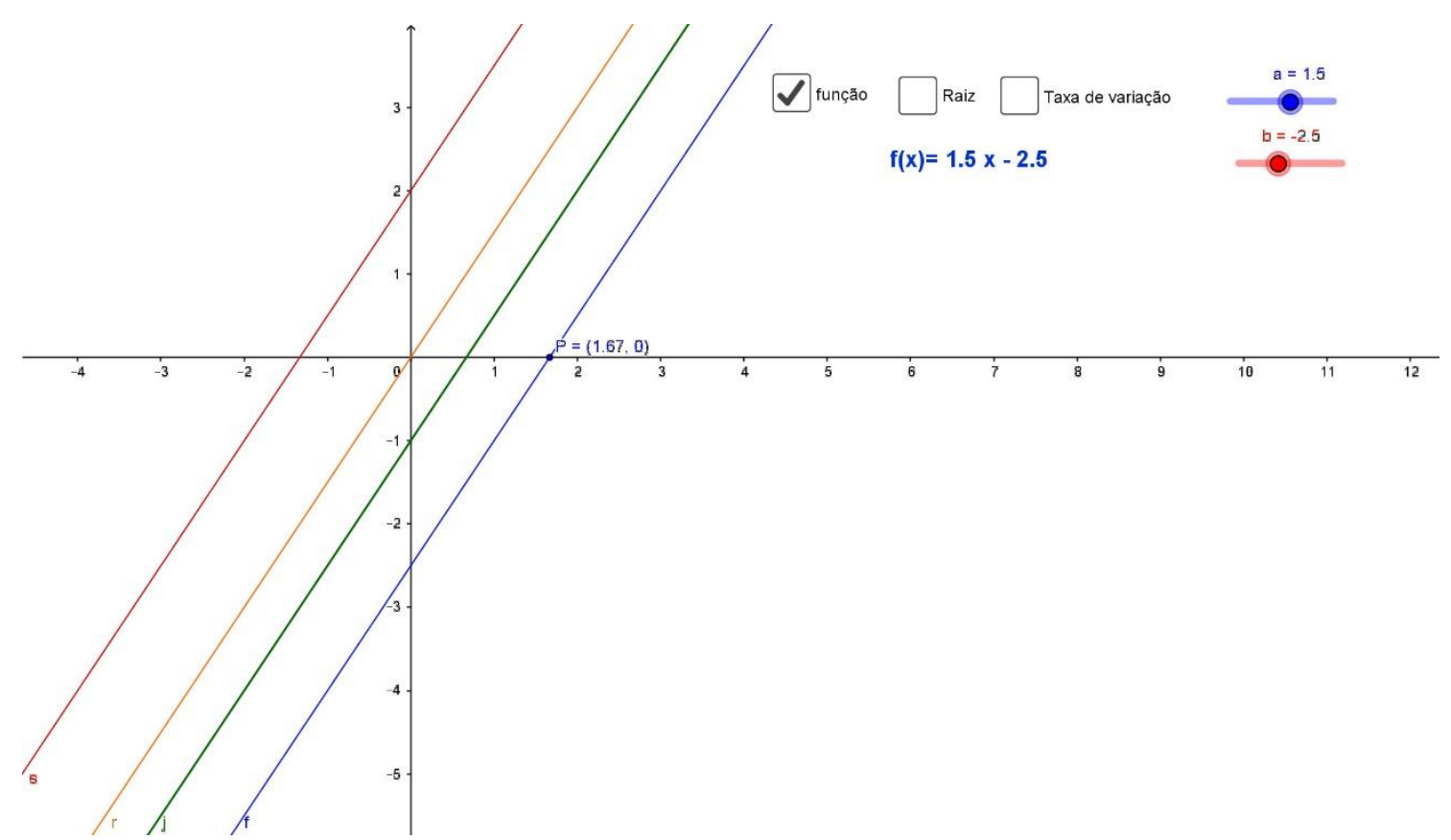

Fonte: Grupo 2 - gráfico feito no programa Geogebra

Através do gráfico fica fácil identificar o coeficiente b como o ponto de intersecção com o eixo y e que b está relacionado também com a translação da reta. Pode também verificar com os alunos que a raiz da função como ponto de intersecção da reta com o eixo $\mathbf{x}$.

\section{Taxa de variação e coeficiente angular da reta}

O geogebra permite calcular a taxa de variação, o coeficiente angular da reta e o ângulo entre a reta e a horizontal.

Os alunos podem manipular a reta e perceber por manipulação e experimentação as propriedades da função afim.

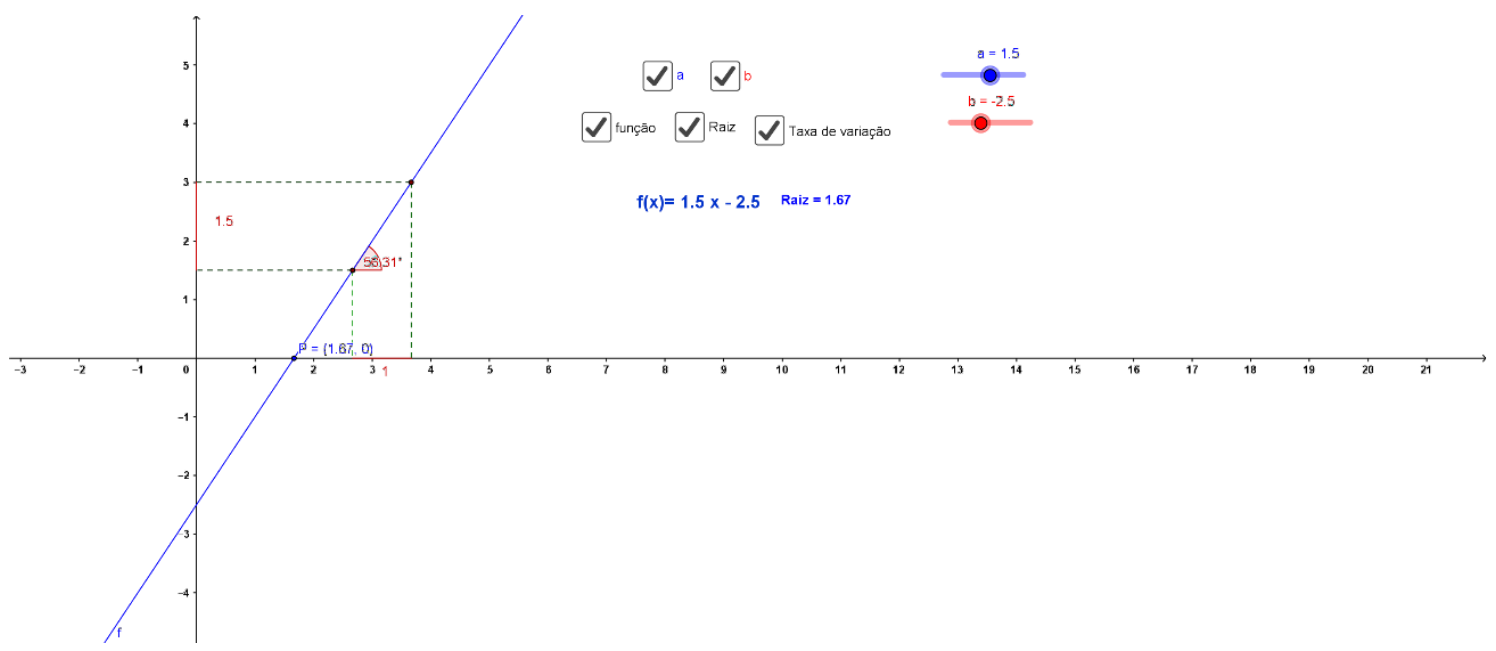

Fonte: Grupo 2 - gráfico feito no programa Geogebra 


\section{Função quadrática}

Manipulação da função quadrática no geogebra

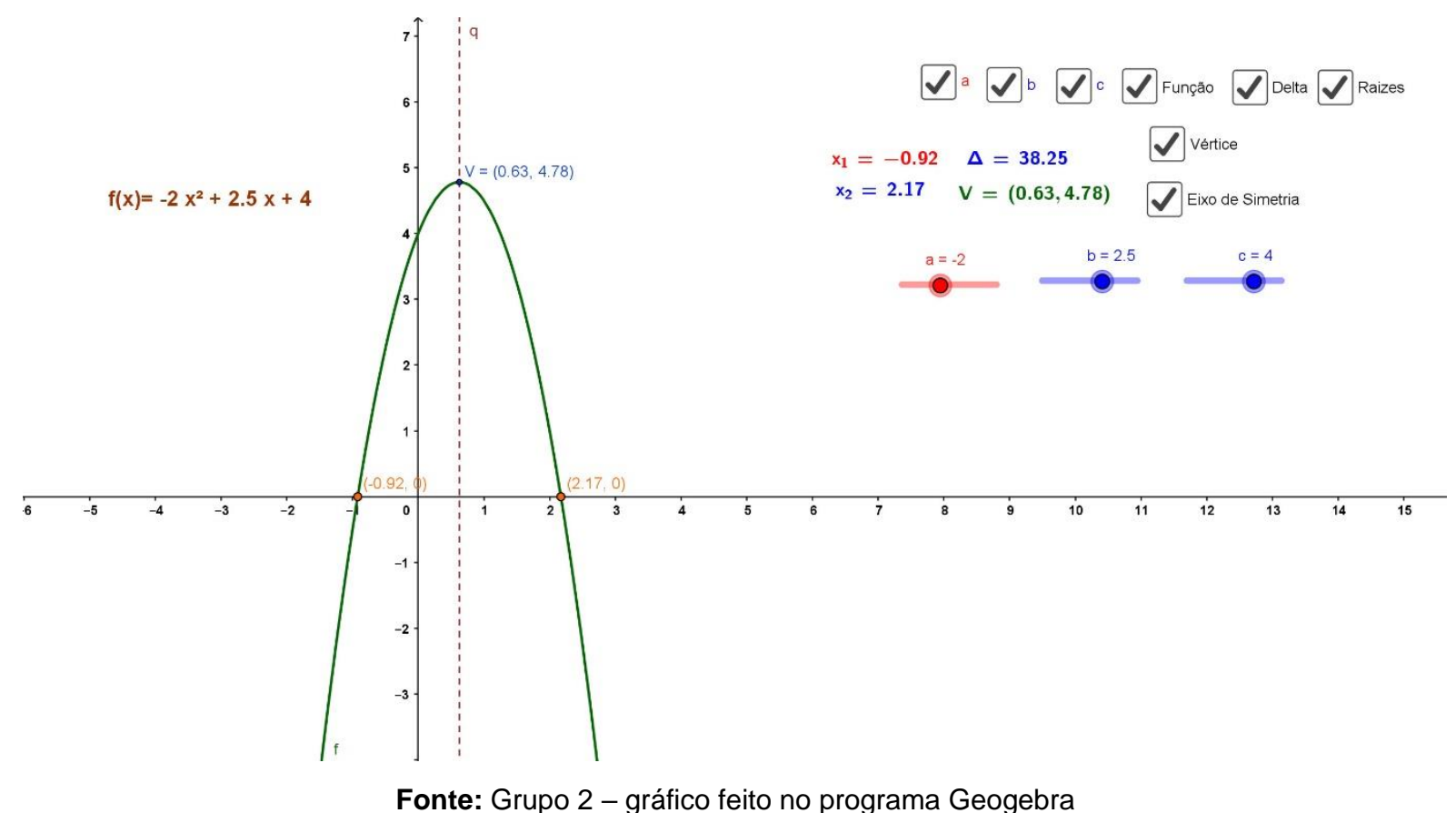

Comportamento do gráfico com a manipulação dos coeficientes da função

Variando o coeficiente a da função

Assumindo valores positivos e crescente do coeficiente a da função o que é observado no comportamento da parábola?

Assumindo valores negativos e decrescentes do coeficiente a da função o que é observado no comportamento da função?

Qual o comportamento do gráfico da parábola ao alternar valores positivos e negativos do coeficiente $\mathbf{a}$ ?

E se a assumisse o valor zero ainda teríamos uma parábola ou função quadrática?

Reparem que valores de a menores que 1 a parábola fica mais "aberta" e valores maiores que 1 a parábola fica mais "fechada". 


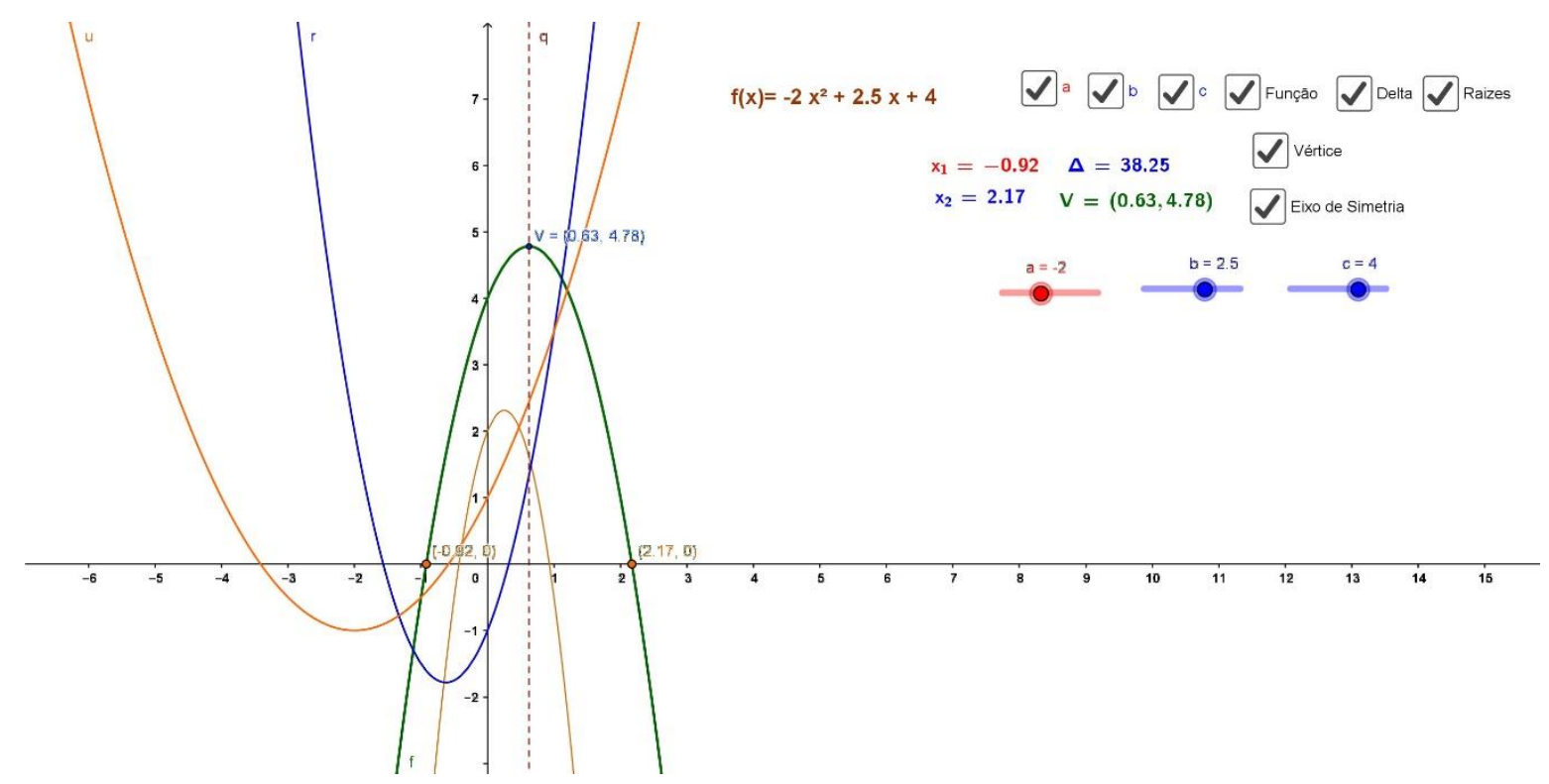

Fonte: Grupo 2 - gráfico feito no programa Geogebra

Variando o coeficiente b da função quadrática

Ao variar o coeficiente b da função percebe se uma mudança de posição da parábola, e após algumas manipulações pelos alunos eles perceberam que o coeficiente b é responsável pela translação da parábola

O que observamos quando fazemos o coeficiente b igual a zero?

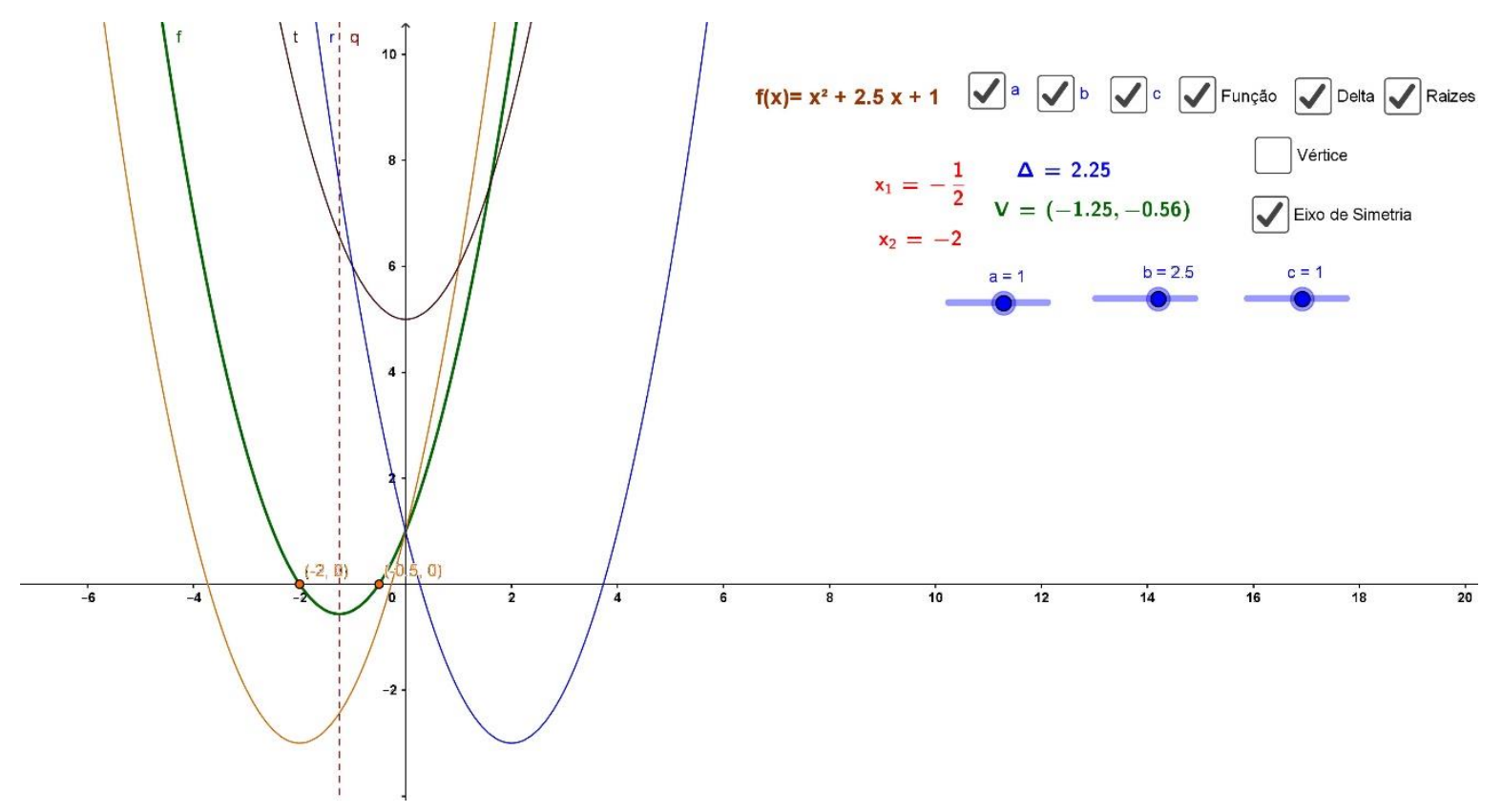

Fonte: Grupo 2 - gráfico feito no programa Geogebra 
Variando o coeficiente c da função quadrática

Ao alterar o valor do coeficiente c, o aluno percebe a translação vertical da parábola

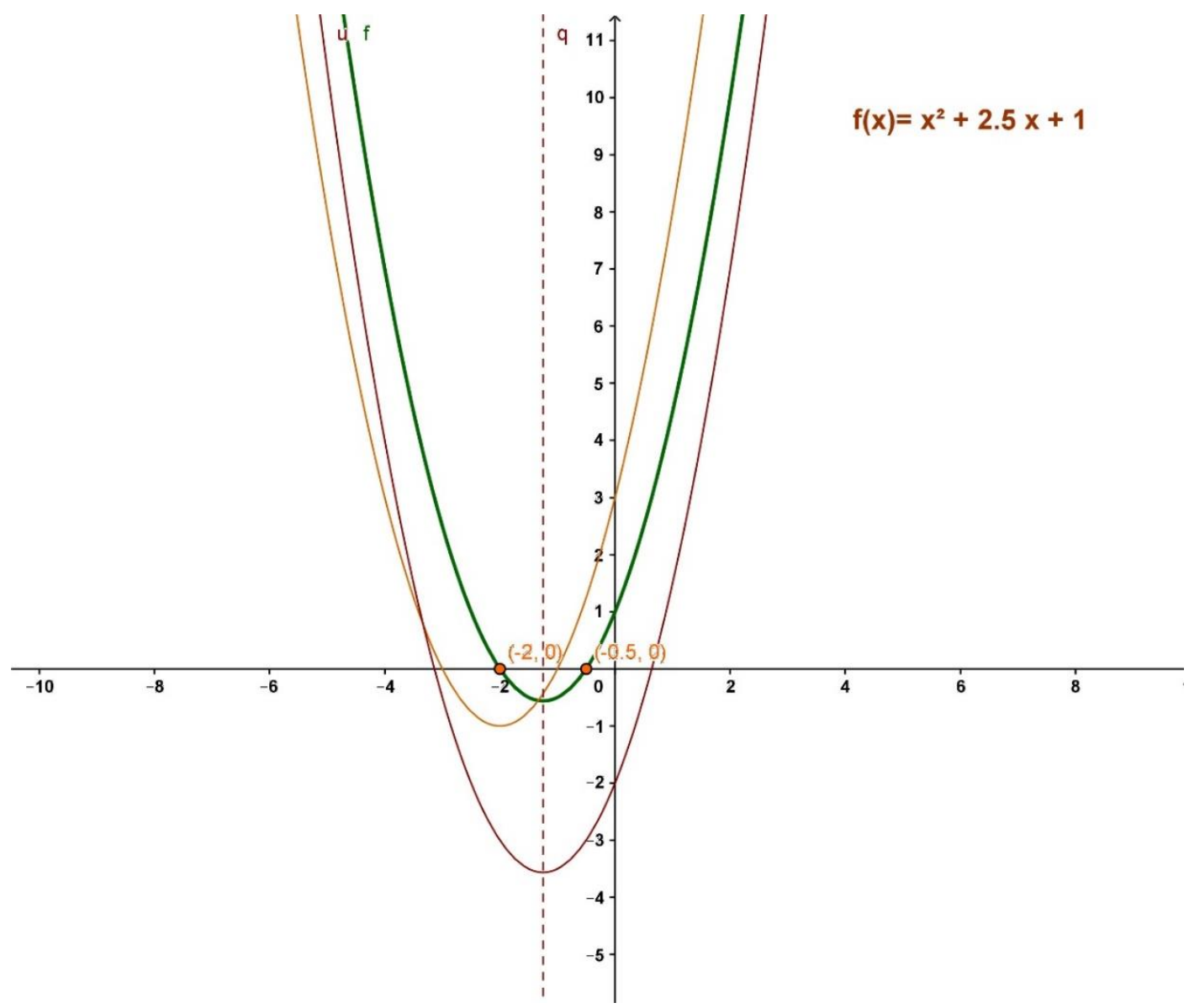

Fonte: Grupo 2 - gráfico feito no programa Geogebra 
Apêndice $F$

Grupo 3

Material desenvolvido para a Modelagem 



\section{Modelagem Matemática: Fase 1}

Prof. Orientador: Ronaldo Ramunno (IME)

Grupo 3: Lucas e Ingrid

Situação inicial (problemática): Qual a relação entre a idade da gestante e Síndrome de Down?

Inteiracão: Conhecimentos prévios para definir o problema: coleta de dados em livros e internet

Os dados desta atividade foram retirados de: A vida por trás dos olhos amendoados: Um livro reportagem sobre os portadores da Síndrome de Down. Londrina; Eduel, 2002

Como a idade afeta a fertilidade feminina

Quando pensa em ter filhos, a primeira coisa que toda mulher quer saber é quanto tempo vai demorar para engravidar. É aí que a idade pode fazer a diferença.

De modo geral, o intervalo entre 20 e 30 anos é o período mais fértil da vida da mulher, é quando a gravidez acontece mais rápido, embora o número de mulheres acima de 30 engravidando seja cada vez maior.

\section{Como a idade afeta a fertilidade?}

A fertilidade da mulher começa a diminuir por volta dos 30 anos, com as chances de gravidez caindo ainda mais significativamente a partir dos 35 anos.

Depois dos 35, aumenta a proporção de mulheres com problemas de fertilidade, abortos espontâneos ou outras complicações com o bebê. Portanto, do ponto de vista puramente biológico, o ideal é tentar engravidar antes $\operatorname{dos} 35$.

Os homens continuam férteis por bem mais tempo. Hoje se sabe que a fertilidade masculina também é afetada pela idade, só que de modo mais gradual. O declínio da fertilidade 
masculina pode impactar, por exemplo, a saúde dos filhos que o homem venha a ter.

A tabela abaixo mostra as chances de gravidez de acordo com cada idade. Tenha em mente que a tabela é um comparativo geral, feito com mulheres em ótimo estado de saúde.

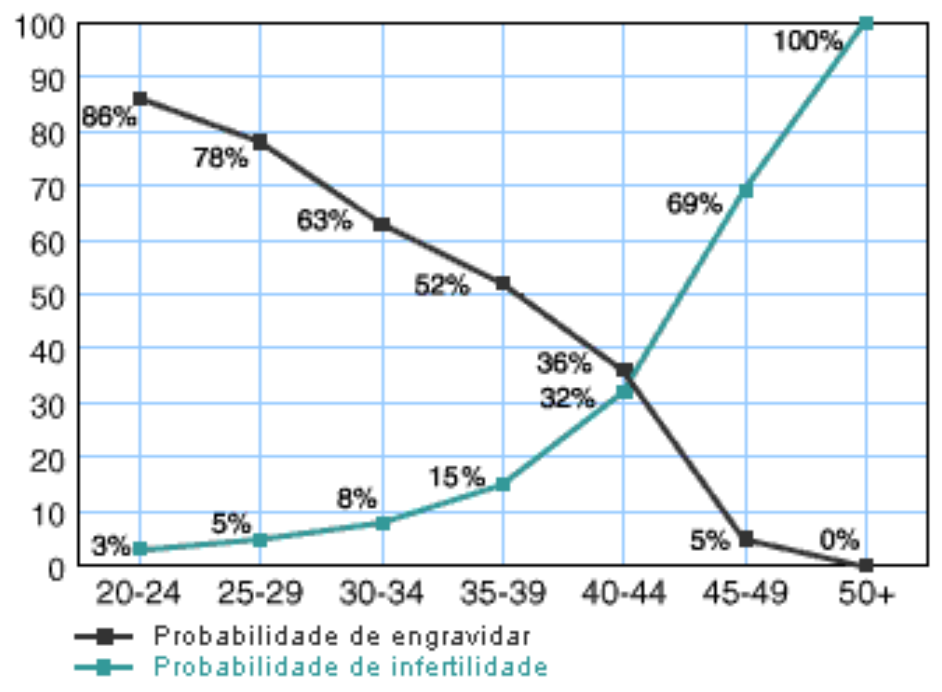

Fonte: Management of the Infertile Woman, de Helen A. Carcio

Dados mostram que a idade de maior fertilidade feminino está no intervalo de 20 a 24 anos. Depois disso, a fertilidade tende a diminuir consideravelmente. Ver gráfico acima.

Enquanto a probabilidade de uma mulher engravidar diminui de acordo com a idade, a literatura aponta que, com a idade, o envelhecimento dos óvulos aumenta as chances de uma mulher gerar uma criança com Síndrome de Down, embora não seja apenas esse o motivo que implica a incidência dessa Síndrome. Ver tabela abaixo:

Essa modelagem precisará estudar a probabilidade de uma mulher engravidar dada a idade que tem e a probabilidade que essa mulher, uma vez grávida, tem de gerar uma criança com Síndrome de Down.

\section{Incidência de crianças com Síndrome de Down}

\begin{tabular}{|c|c|}
\hline Idade da mãe & Incidência de crianças com SD \\
\hline 15 a 19 anos & 1 a cada 2400 nascimentos \\
\hline
\end{tabular}




\begin{tabular}{|l|c|}
\hline 20 a 24 anos & 1 a cada 1500 nascimentos \\
\hline 25 a 29 anos & 1 a cada 1200 nascimentos \\
\hline 30 a 34 anos & 1 a cada 900 nascimentos \\
\hline 35 a 39 anos & 1 a cada 300 nascimentos \\
\hline 40 a 44 anos & 1 a cada 100 nascimentos \\
\hline 45 a 49 anos & 1 a cada 400 nascimentos \\
\hline
\end{tabular}

Fonte: Bressan, F. G. A Vida por trás dos olhos amendoados

Um pouco sobre a Síndrome de Down: É um problema genético que atinge cerca de 1 bebê a cada 600 nascidos vivos. É uma Síndrome que atua nos cromossomos do indivíduo. Cada pessoa possui 46 cromossomos no núcleo de todas as suas células, onde ficam os genes. As únicas células que têm menos cromossomos são o óvulo e o espermatozoide, que se juntam para que a célula inicial que dá origem a uma criança possua 46 cromossomos. No entanto, às vezes, acontecem erros durante o processo de concepção e multiplicação das primeiras células do embrião. A Síndrome de Down é um desses erros. O que ocorre é que um terceiro cromossomo se infiltra no cromossomo 21 do bebê. Dos 23 pares de cromossomos, $\mathbf{2 1}^{\mathbf{0}}$ fíca com três cromossomos em vez de dois, e o equívoco passa a ser reproduzido nas células da criança.

Definição do problema: Em que idade o risco de uma mulher engravidar e ter um filho com Síndrome de Down é maior? Podemos achar uma função matemática que expresse essa relação?

\section{Conceitos importantes para a Modelagem:}

Probabilidade Condicional: A probabilidade condicional $\mathrm{P}(\mathrm{A} / \mathrm{B})$ entre os eventos A e B pode ser obtida como resultado da divisão da probabilidade conjunta $\mathrm{P}(\mathrm{A}$ e $\mathrm{B})$ pela probabilidade do evento B.

$$
P(A / B)=P(A \cap B) / P(B)
$$


Exemplo: Sabendo que no lançamento de 3 moedas não aconteceram duas nem três coroas, qual a probabilidade de que as três moedas sejam cara?

O grupo completou o exercício proposto com acerto. 


\section{Modelagem Matemática: Fase 2}

Prof. Orientador: Ronaldo Ramunno (IME)

Grupo 3: Lucas e Ingrid

Matematização: Definindo variáveis e tratamento dos dados do gráfico e tabela

Através dos dados analisados na fase de interação, notamos que com o aumento da idade da gestante, aumenta a incidência da Síndrome de Down (SD).

Agora podemos investigar o seguinte problema: Em que idade o risco de uma mulher engravidar e ter um filho com Síndrome de Down é maior?

Para responder a esse problema, teremos que trabalhar com as probabilidades do gráfico já visto na fase de interação, definir as variáveis e construir a tabela abaixo:

\begin{tabular}{|c|c|c|}
\hline $\begin{array}{l}\text { Idade } \\
\text { mulher - i }\end{array}$ & $\begin{array}{l}\text { Risco de uma mulher } \\
\text { engravidar - Rg (i) }\end{array}$ & $\begin{array}{l}\text { Incidências de crianças com } \\
\text { Sindrome de Down- } \mathbf{R} \text { s/g (i) }\end{array}$ \\
\hline 22 & $86 \%$ & $1 / 1500=0,067 \%$ \\
\hline 27 & $78 \%$ & $1 / 1200=0,083 \%$ \\
\hline 32 & $63 \%$ & $1 / 900=0,111 \%$ \\
\hline 37 & $52 \%$ & $1 / 300=0,333 \%$ \\
\hline 42 & $36 \%$ & $1 / 100=1,000 \%$ \\
\hline 47 & $5 \%$ & $1 / 400=0,250 \%$ \\
\hline
\end{tabular}

\section{Definindo as variáveis:}

i: idade da gestante em anos $\quad \mathbf{R}_{\mathbf{g} \wedge \mathbf{s}}(\mathbf{i})$ : Risco de engravidar e ter um filho com SD

$\mathbf{R}_{\mathbf{g}}(\mathbf{i})$ : Risco de a mulher engravidar $\mathbf{R}_{\mathbf{s} / \mathbf{g}}(\mathbf{i})$ : Risco de ter filho com SD dado que está $\mathrm{G}$

Para responder ao problema, vamos tentar encontrar um modelo matemático que relacione o risco de uma mulher engravidar e ter um filho com SD, dado a idade que tem, logo precisamos encontrar $\mathbf{R}_{\mathbf{g} \wedge \mathbf{s}} \mathbf{( i )}$.

Veja que temos algumas limitações nos dados, pois vamos considerar mulheres na faixa de idade 20/49 anos, haja vista que a tabela não tem informações sobre idades inferiores a 20 anos. 
Repare que na tabela, a coluna: idade da mulher (i), foi feita a média aritmética para cada intervalo de idade.

O próximo passo será usar o conceito de probabilidade condicional

Dados dois eventos A e B, a probabilidade condicional de A dado que ocorreu B é representada por:

$$
P(A / B)=P(A \cap B) / P(B)
$$

Onde $\mathrm{P}\left(\mathrm{A}^{\wedge} \mathrm{B}\right)$ é a probabilidade de ocorrência dos eventos $\mathrm{A}$ e $\mathrm{B}$ e $\mathrm{P}(\mathrm{B})$ é a probabilidade de ocorrência do evento B.

Veja que podemos rearranjar essa expressão na forma: $\mathbf{P}\left(\mathbf{A}^{\wedge} \mathbf{B}\right)=\mathbf{P}(\mathbf{A} / \mathbf{B}) . \mathbf{P}(\mathbf{B})$

Transportando esse conceito para a nossa modelagem temos:

$$
\mathbf{R}_{\mathbf{g}^{\wedge} \mathbf{s}}(\mathbf{i})=\mathbf{R}_{\mathbf{s} / \mathbf{g}}(\mathbf{i}) . \mathbf{R}_{\mathbf{g}}(\mathbf{i})
$$

Podemos agora, construir uma nova tabela que relacione os valores de $\mathbf{R}_{\mathbf{s} / \mathbf{g}}(\mathbf{i})$ e $\mathbf{R}_{\mathbf{g}}(\mathbf{i})$

\begin{tabular}{|l|l|l|l|}
$\begin{array}{l}\text { Idade da } \\
\text { mulher (i) }\end{array}$ & $\begin{array}{l}\text { Risco de } \\
\text { engravidar Rg(i) }\end{array}$ & $\begin{array}{l}\text { Incidência de crianças } \\
\text { com SD Rs/g(i) }\end{array}$ & $\begin{array}{l}\text { Risco de engravidar e } \\
\text { ter um fillho com SD } \\
\text { Rg^s(i) }\end{array}$ \\
\hline $\mathbf{2 2}$ & $86 \%$ & $0,067 \%$ & $0,058 \%$ \\
\hline $\mathbf{2 7}$ & $78 \%$ & $0,083 \%$ & $0,065 \%$ \\
\hline $\mathbf{3 2}$ & $63 \%$ & $0,111 \%$ & $0,070 \%$ \\
\hline $\mathbf{3 7}$ & $52 \%$ & $0,333 \%$ & $0,173 \%$ \\
\hline $\mathbf{4 2}$ & $36 \%$ & $1,000 \%$ & $0,360 \%$ \\
\hline $\mathbf{4 7}$ & $\mathbf{5 \%}$ & $0,250 \%$ & $0,013 \%$ \\
\hline
\end{tabular}

Agora temos os pares ordenados $\left(i, \mathbf{R}_{\mathbf{g} \wedge} \mathbf{s}(\mathbf{i})\right)$ da tabela e vamos representa-los no plano cartesiano em busca de algum padrão. 
A análise do gráfico abaixo pode sugerir um modelo definido por duas sentenças, ou seja, função definida por partes.

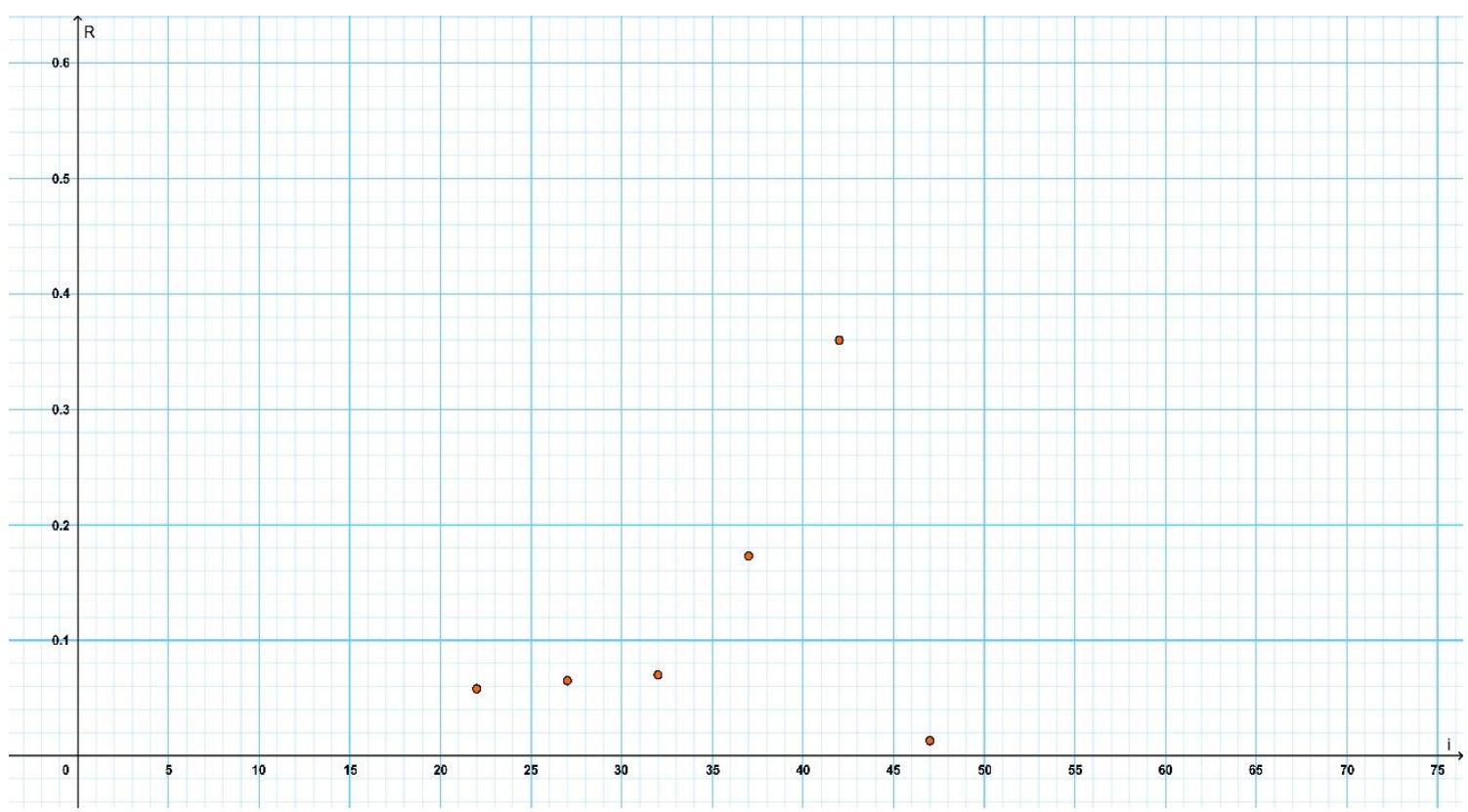

Fonte: Grupo 3 - gráfico feito no programa Geogebra

Na próxima fase de modelagem, poderemos começar a tentar expressar o padrão do gráfico acima em uma função matemática! 


\section{Modelagem Matemática: Fase 3}

Prof. Orientador: Ronaldo Ramunno (IME)

Grupo 3: Lucas e Ingrid

Matematização: Modelagem Matemática - Revisão Teórica

A análise do gráfico de pares ordenados que construímos pode sugerir um modelo matemático utilizando duas funções quadráticas, onde a primeira acontece no intervalo 22 a 37 anos de idade e a segunda, de 37 a 47 anos.

Mas antes disso, vamos rever os conceitos de Função Polinomial de $2^{\mathbf{o}}$ grau

Uma função $\mathbf{f}$ definida no conjunto $\mathbf{R}$ dos números reais e com contradomínio nesse mesmo conjunto, que associa a cada número real $\mathbf{x}$ o número real $\mathbf{a} \cdot \mathbf{x}^{2}+\mathbf{b} \cdot \mathbf{x}+\mathbf{c}$ onde $\mathrm{a}, \mathrm{b}$ e c são números reais e $\mathrm{a} \neq 0$

$\mathbf{f : ~} \mathbf{R} \rightarrow \mathbf{R}, \quad \mathbf{f}(\mathbf{x})=\mathbf{a} \cdot \mathbf{x}^{2}+\mathbf{b . x}+\mathbf{c} \quad \mathbf{f}$ é denominada função polinomial de $2^{\circ}$ grau

O gráfico de uma função quadrática é uma parábola cuja concavidade está associada ao sinal do coeficiente a. O vértice da parábola é o ponto de coordenadas:

$\mathrm{V}:(-\mathrm{b} / 2 . \mathrm{a},-\Delta / 4 . \mathrm{a})$

Para $\mathbf{a}<0$ temos um ponto de máximo da parábola

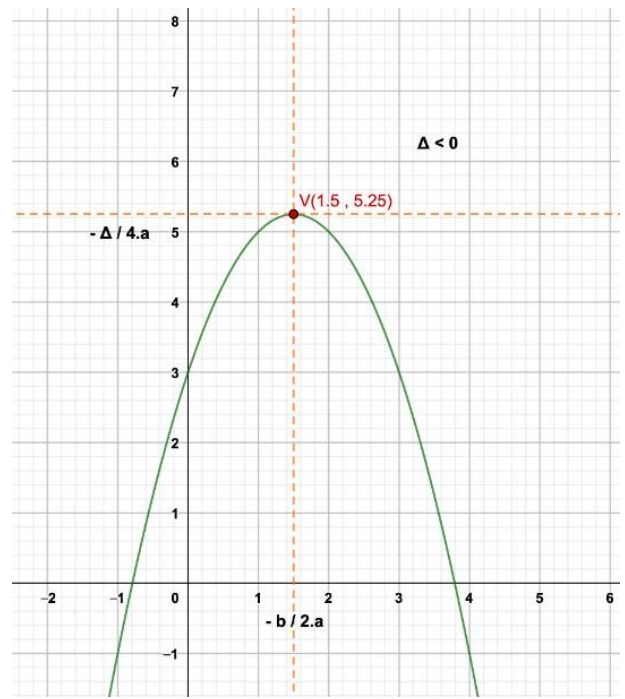

Para $\mathbf{a}>\mathbf{0}$ temos um ponto de mínimo da parábola 


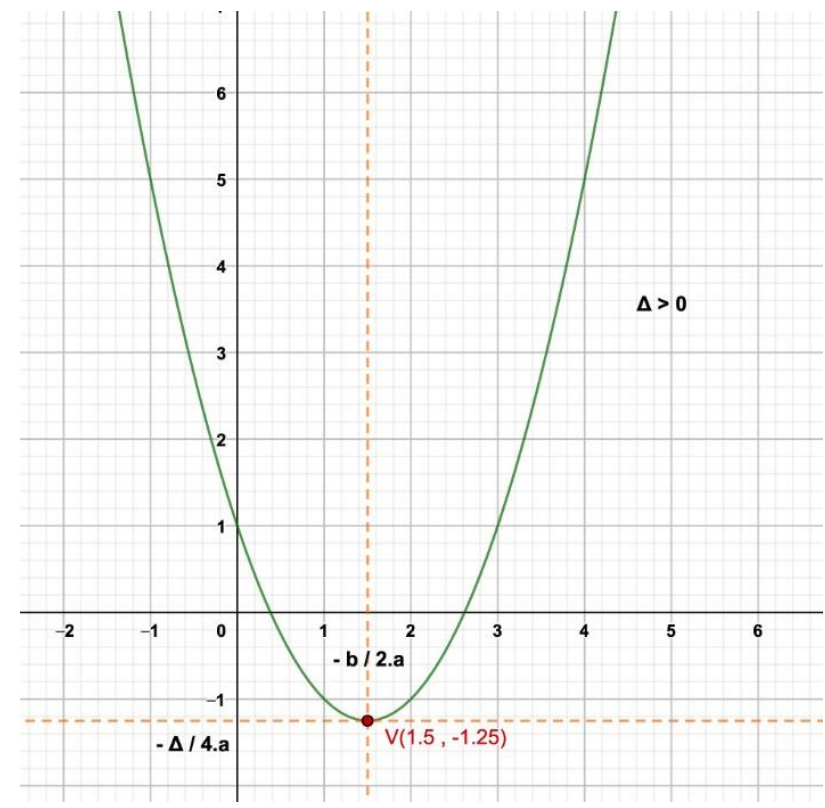

Fonte: Grupo 3 - gráfico feito no programa Geogebra

Como base teórica para a nossa modelagem, temos que rever um método muito útil para resolver sistemas de equações lineares chamada Regra de Cramer

Considere um sistema de equações lineares com $\mathbf{n}$ equações e $\mathbf{n}$ incógnitas, onde os coeficientes $\mathbf{a} 11, \mathbf{a 1 2}, . . .$. , ann são números reais ou complexos, e os termos independentes $\mathbf{b} 1, \mathbf{b} 2$, ...., bn são números reais ou complexos e $\mathbf{x}_{1}, \mathbf{x}_{\mathbf{2}}, \ldots . . ., \mathbf{x}_{\mathbf{n}}$ são as incógnitas do sistema $\mathbf{n x n}$

Seja $\mathbf{D}$ o determinante da matriz formada pelos coeficientes das incógnitas.

Seja Dxi o determinante da matriz que se obtém do sistema dado, substituindo a coluna dos coeficientes da incógnita $\mathbf{X}_{\mathrm{i}}$ : $(i=1,2,3, \ldots \ldots, \mathrm{n})$ pelos termos independentes $\mathrm{b}_{1}, \mathrm{~b}_{2}, \ldots ., \mathrm{b}_{\mathrm{n}}$. A Regra de Cramer permite efetuar os cálculos das incógnitas:

$$
\mathbf{X}_{\mathbf{i}}=\mathbf{D}_{\mathbf{X i}} / \mathbf{D}
$$


$\underline{\text { Exemplo de aplicação da Regra de Cramer }}$

Vamos determinar os valores de $\mathbf{x}, \mathbf{y}$ e $\mathbf{z}$ no sistema abaixo:

$$
\left\{\begin{array}{c}
x+2 y-z=-5 \\
-x-2 y-3 z=-3 \\
4 x-y-z=4
\end{array}\right.
$$

Vamos calcular o valor do determinante D:

$$
\begin{aligned}
& D=\left|\begin{array}{ccc}
1 & 2 & -1 \\
-1 & -2 & -3 \\
4 & -1 & -1
\end{array}\right|=-36 \neq 0 \\
& D_{x}=\left|\begin{array}{ccc}
-5 & 2 & -1 \\
-3 & -2 & -3 \\
4 & -1 & -1
\end{array}\right|=-36 \quad D_{y}=\left|\begin{array}{ccc}
1 & -5 & -1 \\
-1 & -3 & -3 \\
4 & 4 & -3 \\
1
\end{array}\right|=72 \quad D_{z}=\left|\begin{array}{ccc}
1 & 2 \\
-1 & -2 \\
4 & -1
\end{array}\right| \begin{array}{l}
-5 \\
-3
\end{array} \mid=-72 \\
& x=D_{x} / D=-36 /-36=1 \quad y=D_{y} / D=72 /-36=-2 \quad z=D_{z} / D=-72 /-36=2
\end{aligned}
$$


Prof. Orientador: Ronaldo Ramunno (IME)

Grupo 3: Lucas e Ingrid - Fase 4

Modelagem Matemática - Resolução/Validação

A análise do gráfico de pares ordenados que construímos pode sugerir um modelo matemático utilizando duas funções quadráticas, onde a primeira acontece no intervalo 22 a 37 anos de idade e a segunda, de 37 a 47 anos.

\begin{tabular}{|l|l|l|l|}
$\begin{array}{l}\text { Idade da } \\
\text { mulher (i) }\end{array}$ & $\begin{array}{l}\text { Risco de } \\
\text { engravidar } \mathbf{R}_{\mathrm{g}}(\mathbf{i})\end{array}$ & $\begin{array}{l}\text { Incidência de crianças } \\
\text { com SD } \mathbf{R}_{\mathrm{s} / \mathrm{g}}(\mathbf{i})\end{array}$ & $\begin{array}{l}\text { Risco de engravidar e } \\
\text { ter um fillho com SD } \\
\mathbf{R}_{\mathrm{g} \wedge \mathrm{s}}(\mathbf{i})\end{array}$ \\
\hline $\mathbf{2 2}$ & $86 \%$ & $0,067 \%$ & $0,058 \%$ \\
\hline $\mathbf{2 7}$ & $78 \%$ & $0,083 \%$ & $0,065 \%$ \\
\hline $\mathbf{3 2}$ & $63 \%$ & $0,111 \%$ & $0,070 \%$ \\
\hline $\mathbf{3 7}$ & $52 \%$ & $0,333 \%$ & $0,173 \%$ \\
\hline $\mathbf{4 2}$ & $36 \%$ & $1,000 \%$ & $0,360 \%$ \\
\hline $\mathbf{4 7}$ & $5 \%$ & $0,250 \%$ & $0,013 \%$ \\
\hline
\end{tabular}

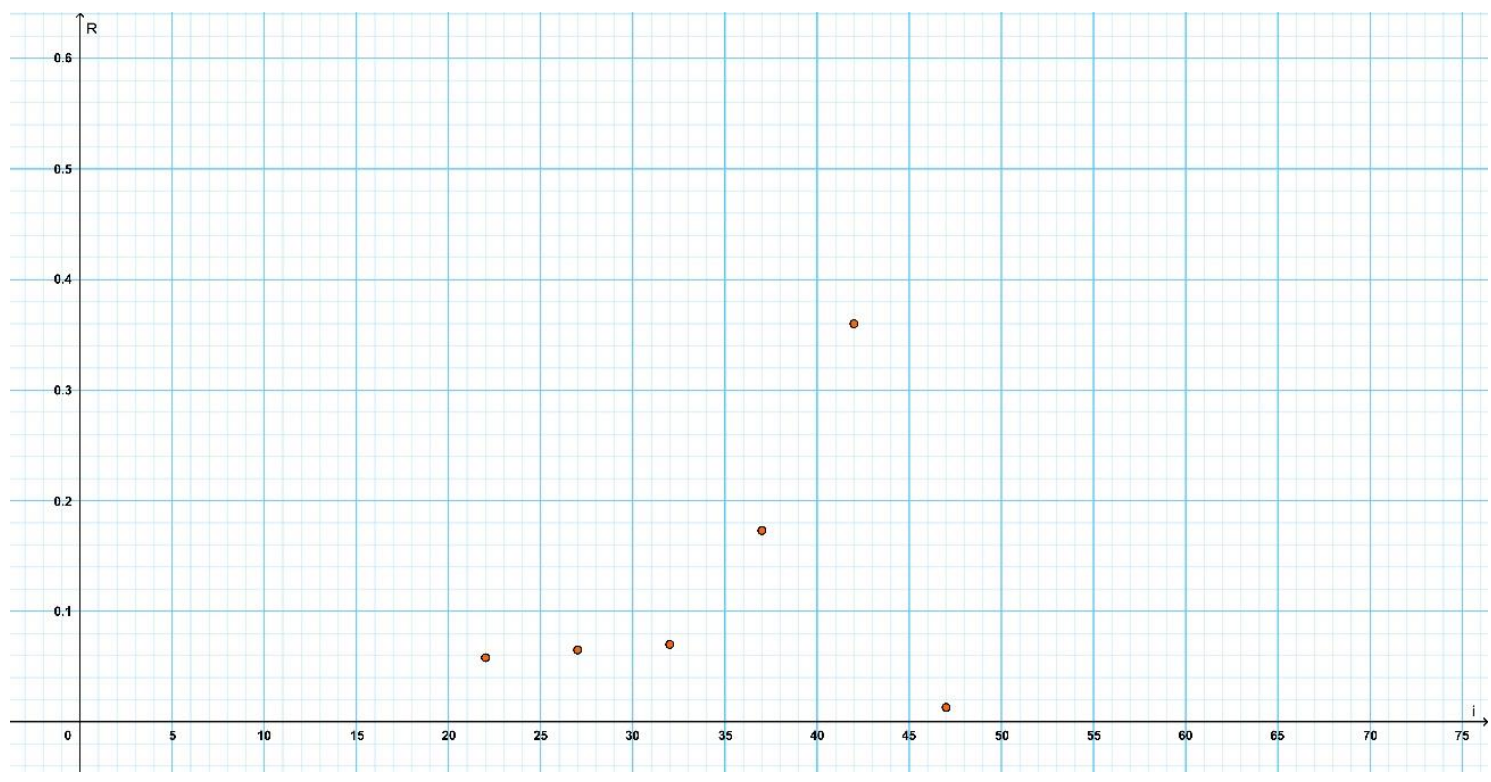

Fonte: Grupo 3 - gráfico feito no programa Geogebra 
Para construirmos o modelo matemático no intervalo de 22 a 37 anos, consideramos três pontos conhecidos: $(\mathbf{2 2 , 0 , 0 5 8}),(\mathbf{3 7 , 0 , 1 7 3 )}$ e a média aproximada dos pontos $(27,0,065),(32,0,07)$, onde obtemos o terceiro ponto $(\mathbf{3 0 ,}, \mathbf{0 , 0 6 7 5})$.

Substituindo os três pares ordenados na expressão geral da função quadrática obtemos o sistema de equações lineares que já sabemos resolver:

$\left\{\begin{array}{c}484 . a+22 . b+c=0,058 \\ 900 . a+30 . b+c=0,0675 \\ 1369 . a+37 . b+c=0,173\end{array} \quad D=\left|\begin{array}{ccc}484 & 22 & 1 \\ 900 & 30 & 1 \\ 1369 & 37 & 1\end{array}\right|=-840\right.$

$D x=\left|\begin{array}{lll}0,0580 & 22 & 1 \\ 0,0675 & 30 & 1 \\ 0,1730 & 37 & 1\end{array}\right|=-0,7775 \quad D y=\left|\begin{array}{ccc}484 & 0,0580 & 1 \\ 900 & 0,0675 & 1 \\ 1369 & 0,1730 & 1\end{array}\right|=39,4325$

$D z=\left|\begin{array}{ccc}484 & 22 & 0,0580 \\ 900 & 30 & 0,0675 \\ 1369 & 37 & 0,1730\end{array}\right|=-539,925$

Tendo os cálculos dos determinantes, podemos calcular os valores dos coeficientes $\mathbf{a}$ b e c do sistema.

$\mathbf{a}=\mathrm{Dx} / \mathrm{D}=-0,7775 /-840=\mathbf{0 , 0 0 0 9 3}$

$\mathbf{b}=\mathrm{Dy} / \mathrm{D}=39,4325 /-840=\mathbf{0 , 0 4 6 9}$

$\mathbf{c}=\mathrm{Dz} / \mathrm{D}=-539,925 /-840=\mathbf{0 , 6 4 2 8}$

Assim temos a primeira parte do modelo definido por partes:

$f(i)=0,00093 . i^{2}-0,0469 . i+0,6428$

Para construirmos o modelo matemático no intervalo de 37 a 47 anos, consideramos três pontos conhecidos: $(37,0,173),(42,0,360)$ e $(47,0,013)$. 
$\left\{\begin{array}{l}1369 . a+37 . b+c=0,173 \\ 1764 . a+42 . b+c=0,360 \\ 2209 . a+47 . b+c=0,013\end{array} \quad D=\left|\begin{array}{lll}1369 & 37 & 1 \\ 1764 & 42 & 1 \\ 2209 & 47 & 1\end{array}\right|=-250\right.$

$D x=\left|\begin{array}{lll}0,173 & 37 & 1 \\ 0,360 & 42 & 1 \\ 0,013 & 47 & 1\end{array}\right|=2,67 \quad D y=\left|\begin{array}{lll}1369 & 0,173 & 1 \\ 1764 & 0,360 & 1 \\ 2209 & 0,013 & 1\end{array}\right|=-220,28$

$D z=\left|\begin{array}{lll}1369 & 37 & 0,173 \\ 1764 & 42 & 0,360 \\ 2209 & 47 & 0,013\end{array}\right|=4451,88$

Tendo os cálculos dos determinantes, podemos calcular os valores dos coeficientes aba e c do sistema.

$\mathbf{a}=\mathrm{Dx} / \mathrm{D}=2,67 /-250=-\mathbf{0 , 0 1 0 6 8}$

$\mathbf{b}=\mathrm{Dy} / \mathrm{D}=-220,28 /-250=\mathbf{0 , 8 8 1 1}$

$\mathbf{c}=\mathrm{Dz} / \mathrm{D}=4451,88 /-250=\mathbf{- 1 7 , 8 0 7 5}$

Assim temos a primeira parte do modelo definido por partes:

$g(i)=-0,01068 . i^{2}+0,8811 . i-17,8075$

E usando as duas funções, temos o Modelo Matemático:

$R_{G \cap S}(i)=\left\{\begin{array}{c}0,00093 . i^{2}-0,0469 . i+0,6428, \text { se } 20 \leq i<37 \\ -0,01068 . i^{2}+0,8811 . i-17,8075, \text { se } 37 \leq i<47\end{array}\right.$

Esse modelo descreve o risco de uma mulher engravidar e ter um filho com Síndrome de Down em função da idade que possui.

Representação gráfica desse modelo: 


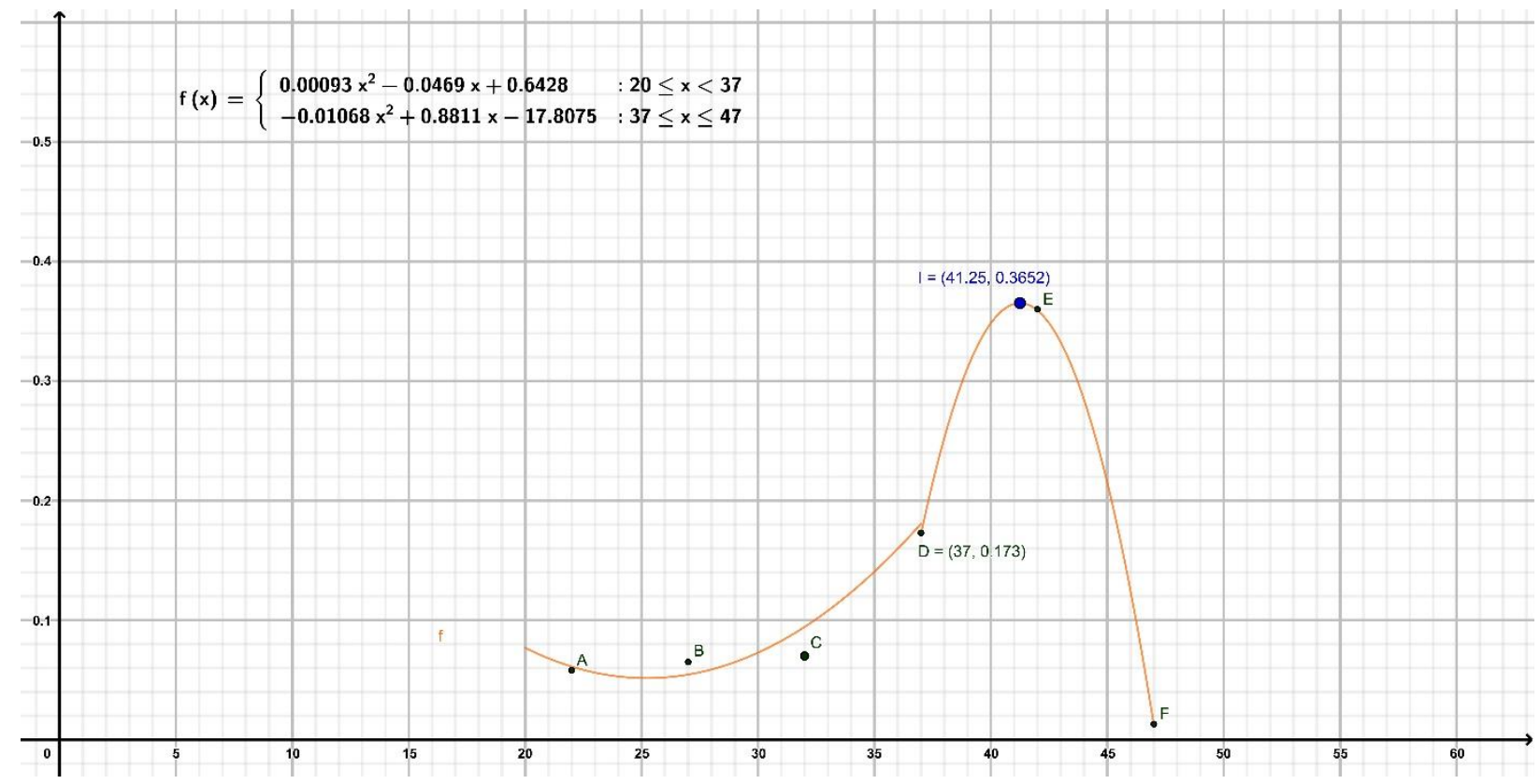

Fonte: Grupo 3 - gráfico feito no programa Geogebra

\section{Validação do Modelo Matemático}

Por meio da representação gráfica da função, é possível perceber que o modelo matemático construído se ajusta bem aos pontos dados inicialmente. No entanto, é interessante realizar a validação do modelo comparando os resultados encontrados pelo modelo com os utilizados para a sua construção. (tabela).

\begin{tabular}{|c|c|c|}
\hline $\begin{array}{c}\text { Idade da mulher } \\
(\mathbf{i})\end{array}$ & $\begin{array}{c}\mathbf{R}\left(\mathbf{G}^{\wedge} \mathbf{S}\right)(\mathbf{i}) \text { dados } \\
(\%)\end{array}$ & $\begin{array}{c}\mathbf{R}\left(\mathbf{G}^{\wedge} \mathbf{S}\right)(\mathbf{i}) \text { Modelo } \\
(\%)\end{array}$ \\
\hline & & \\
\hline 22 & 0,058 & 0,061 \\
\hline 27 & 0,065 & 0,054 \\
\hline 32 & 0,070 & 0,094 \\
\hline 37 & 0,173 & 0,172 \\
\hline 42 & 0,360 & 0,359 \\
\hline 47 & 0,013 & 0,012 \\
\hline
\end{tabular}

Considerando o problema inicial sobre determinar a idade em que o risco de uma mulher engravidar e ter um filho com Síndrome de Down é maior, verifica-se que apenas a segunda 
sentença do modelo construído interessa para responder a questão, já que é nela que acontece um ponto de máximo.

Cálculo do ponto de máximo: Por se tratar de um função polinimial do $2^{\circ}$ grau, o ponto de máximo, também vértice da parábola que representa a função, pode ser encontrado utilizandose o i vértice:

$\mathbf{I}_{\mathbf{v}}=\mathbf{- b} / \mathbf{2} \cdot \mathbf{a}=-0,8811 / 2 \cdot(-0,01068) \rightarrow \mathbf{I}_{\mathbf{v}}=\mathbf{4 1 , 2 5}(41$ anos e 3 meses $)$.

Segundo o modelo, o risco é maior quando a idade da mulher é aproximadamente 41 anos. 


\section{Modelagem Matemática - Atividades Geogebra}

Prof. Orientador: Ronaldo Ramunno (IME)

Grupo 3: Ingrid e Lucas

\section{Atividades com Geogebra}

\section{Manipulando a Função por partes no Geogebra}

O arquivo do geogebra foi previamente construído, pois não havia tempo hábil para construir junto com os alunos, mas foi fornecido material em PDF para posterior estudo dos alunos. As atividades foram feitas por eles.

\section{Função linear com quadrática}

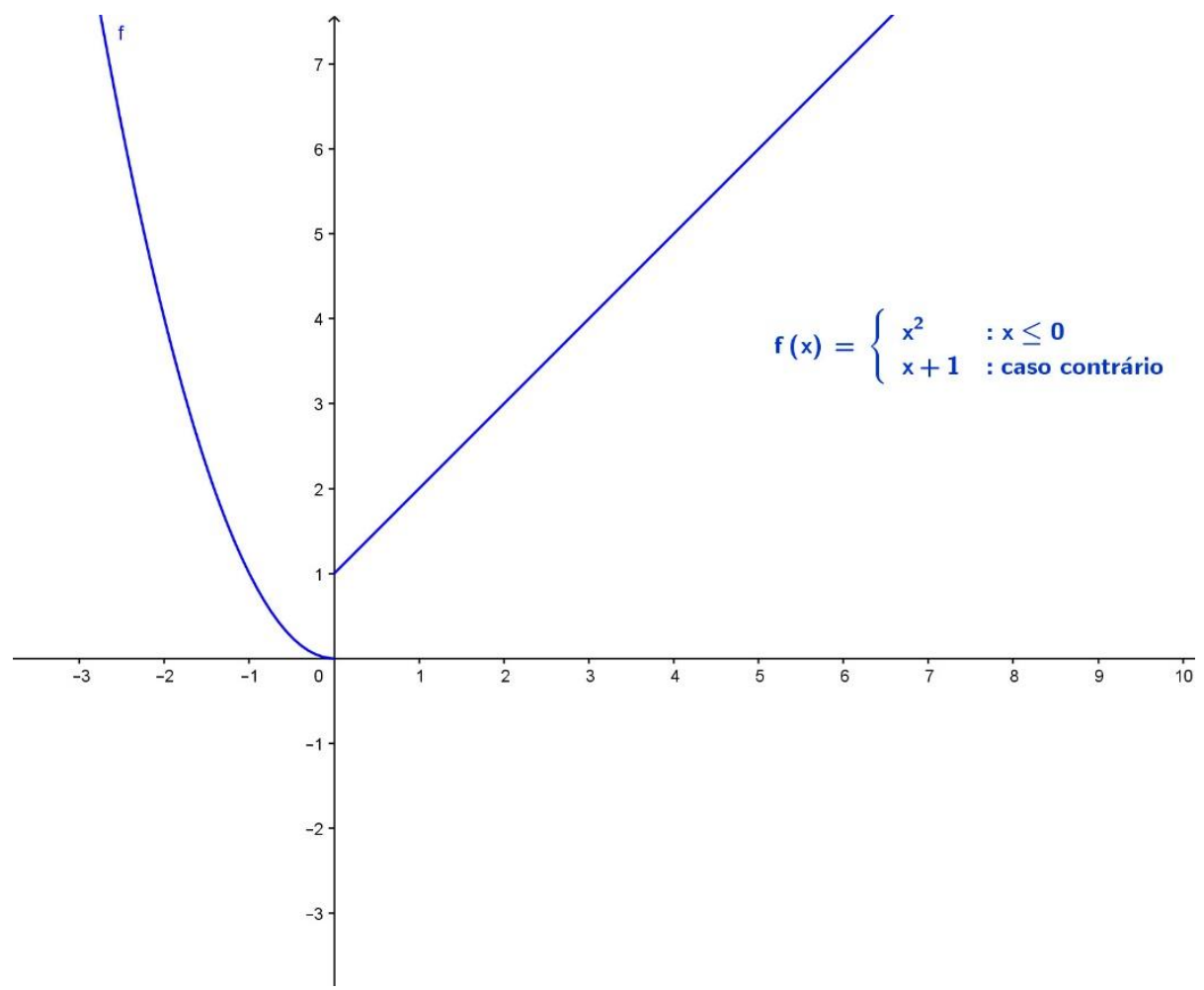

Fonte: Grupo 3 - gráfico feito no programa Geogebra 


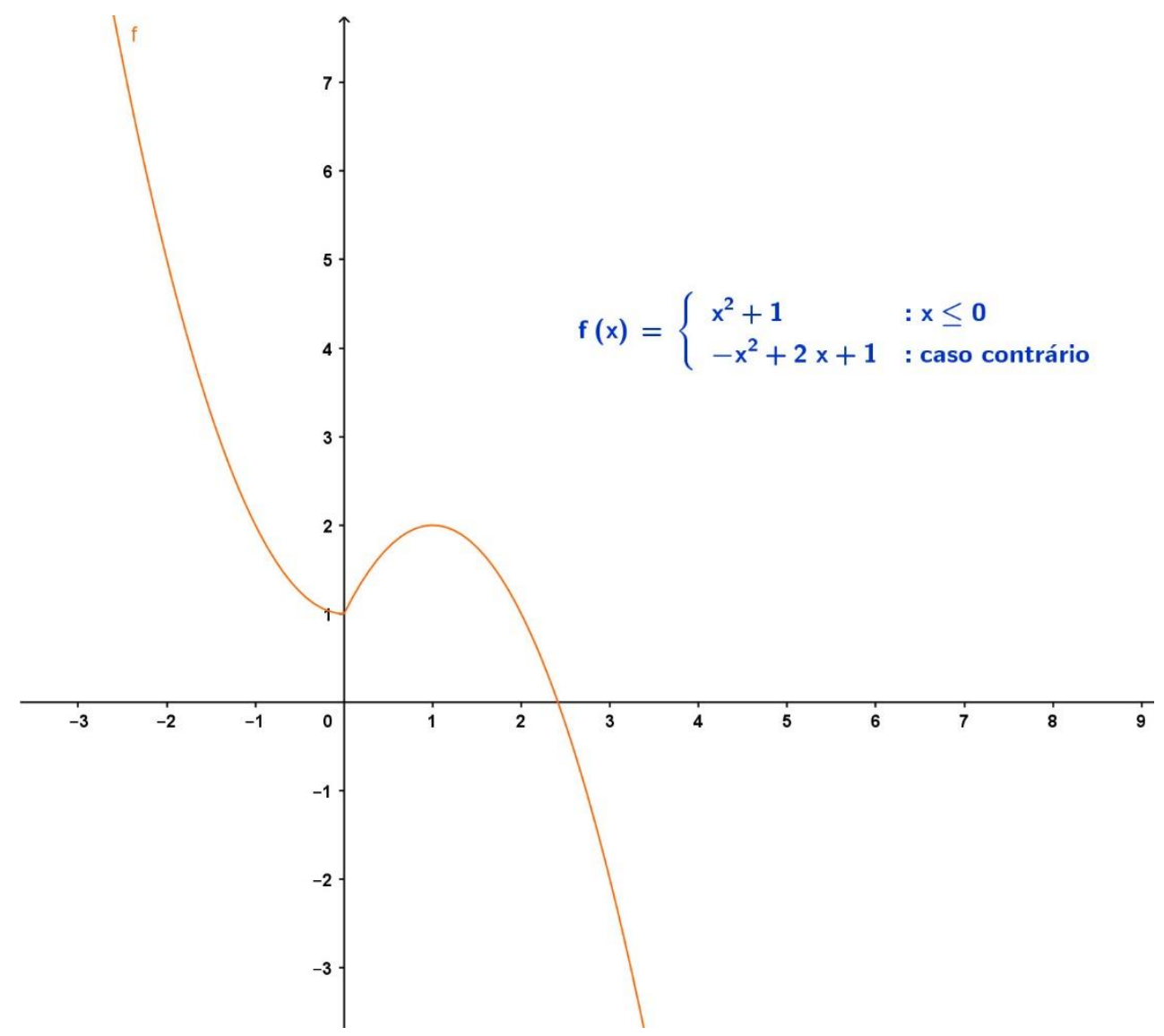

Fonte: Grupo 3 - gráfico feito no programa Geogebra

As atividades com função quadrática no geogebra foram as mesmas do grupo 2 
Apêndice G

Sugestão de atividade de Modelagem Matemática para professores 



\section{Sugestão de atividade de Modelagem Matemática para professores}

A atividade que será descrita não foi realizada nesse trabalho, pois não havia tempo hábil, principalmente devido à complexidade da fase de interação onde vários conceitos de astronomia seriam necessários.

Situação inicial: Previsão do afastamento das galáxias (dados do Hubble)

Fase de interacão: Coleta de dados na internet (HST Key Project)

Definicão problema: Qual a relação entre a velocidade de afastamento das galáxias e a distância entre elas?

Matematização: A função matemática é a função polinomial de $1^{\circ}$ grau Variáveis e constantes: $\mathrm{V}(\mathrm{Km} / \mathrm{s})$ : Velocidade de afastamento em quilômetros por segundo e D(MPS): Distância em megaparsecs

A Matemática do problema: Função polinomial do primeiro grau e reta de regressão

Interpretação e validação: O modelo matemático possibilita prever o afastamento das galáxias e ainda calcular a idade aproximada do universo

Situacão final: Os modelos estão sendo aprimorados com dados de observação cada vez mais precisos.

\section{Fase de Interação:}

Parsec: unidade astronômica de distância que equivale a uma paralaxe anual estelar de um $\begin{array}{llllll}\text { segundo } & \text { e } & \text { a } & \text { anesponde } & \text { a } & \end{array}$

Unidades astronômicas: 1 Parsec: 2,0626 $\times 10^{5}$ ua ou 3,26156 anos-luz 


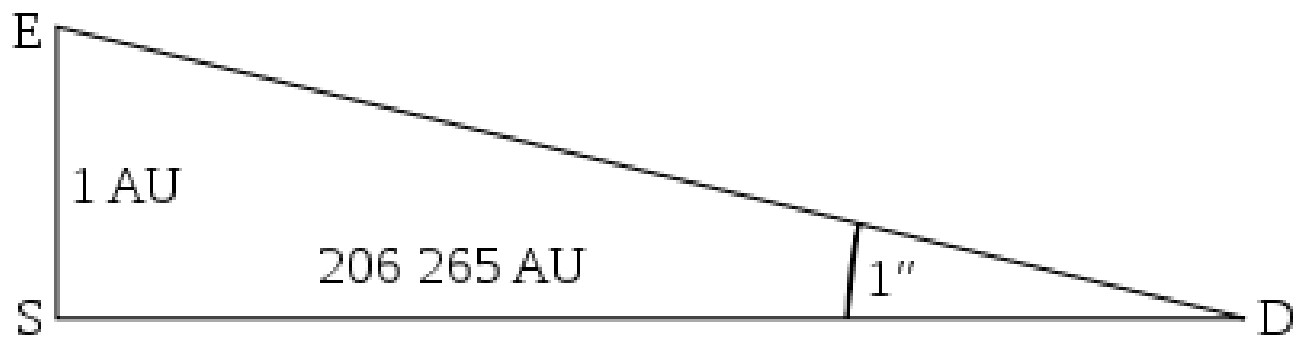

Fonte: A Student's Guide to the Mathematics of Astronomy. Autores: Daniel Fleisch and Julia Kregenow.

Cambridge University Press. Ano, 2013

$S D=\frac{E S}{\operatorname{tg} 1^{\prime \prime}} \quad S D \approx \frac{E S}{\operatorname{tg} 1^{\prime \prime}}=\frac{1 A U}{(1 / 3600) \cdot(\pi / 180)}=\frac{648.000}{\pi} A U \approx$ $206.264 A U$

\section{Definição do problema/ Matematização}

Existe uma relação linear entre a velocidade e a distância de afastamento das galáxias. $\quad \mathbf{V}$ : velocidade (Km/s) e D: Distância em Megaparsecs

$\mathbf{H}_{0}$ : Hubble Constante $\mathbf{V}=\mathbf{H}_{\mathbf{0} . \mathbf{D}}$

Inclinação: $\mathbf{H}_{\mathbf{0}}=\mathbf{4 1 2}(\mathrm{Km} / \mathrm{s}) /(\mathrm{MPS})$

Hubble confundiu RR Lyraes com Cepheids na maioria de suas galáxias.

Quando corrigido, $\mathbf{H}_{\mathbf{0}}=\mathbf{1 0 0}(\mathrm{km} / \mathrm{s}) /(\mathrm{Mpc})$. Durante várias décadas, as medições com velas padrão deu 50 a 100 (km/s/Mpc.)

Veremos que usando $\mathbf{H}_{\mathbf{0}}=\mathbf{4 1 2}(\mathrm{Km} / \mathrm{s}) /(\mathrm{MPS})$, teríamos a idade do Universo em cerca de $\mathbf{2 , 3 8}$

bilhões de anos e não a atual de 13,8 bilhões de anos.

Inclinação: $\mathbf{H o}_{\mathbf{0}} \mathbf{4 1 2}(\mathrm{Km} / \mathrm{s}) /(\mathrm{MPS})$

\begin{tabular}{|rr|}
\hline $\mathrm{D}(\mathrm{mpc})$ & $V(\mathrm{~km} / \mathrm{s})$ \\
0,45 & 200 \\
0,90 & 650 \\
0,90 & 500 \\
1,70 & 960 \\
\hline 2,00 & 850 \\
2,00 & 800 \\
\hline 2,00 & 1090 \\
\hline
\end{tabular}

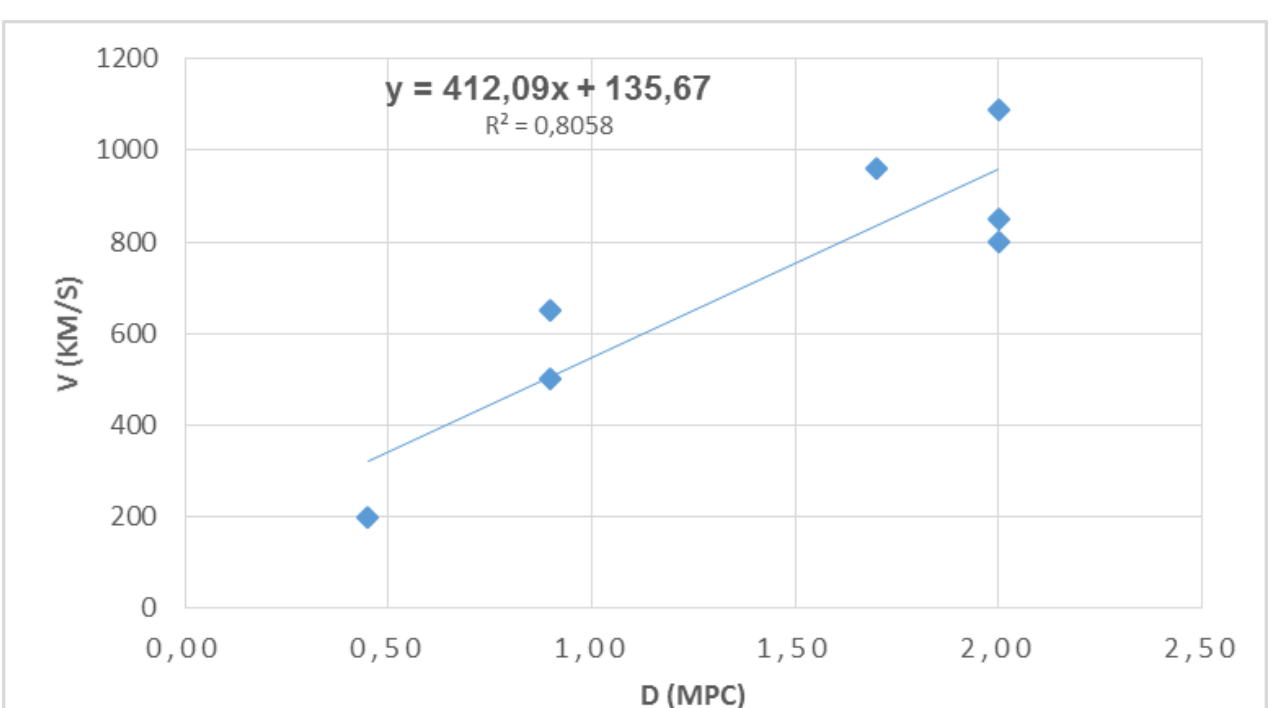




\section{The HST Key Program}

HST: projetado para medir Cepheids em Virgo Cluster, galáxias, dando o nosso primeiro valor mais exato para $\mathbf{H}_{\mathbf{0}}=\mathbf{7 2}(\mathrm{Km} / \mathrm{s}) /(\mathrm{MPS})(+/-\mathbf{8})$

$\underline{\text { Resultado da reta de regressão: }} \mathbf{H}_{0}=\mathbf{7 7 , 0 9}(\mathrm{Km} / \mathrm{s}) /(\mathrm{MPS})$, portanto está dentro da margem de erro

\begin{tabular}{|r|r|}
\hline $\mathrm{D}(\mathrm{MPC})$ & $\mathrm{V}(\mathrm{Km} / \mathrm{s})$ \\
\hline 2,1 & 102 \\
\hline 3,8 & 304 \\
\hline 4,3 & 346 \\
\hline 7,1 & 632 \\
\hline 9,3 & 642 \\
\hline 10,1 & 615 \\
\hline 11,3 & 732 \\
\hline 11,7 & 703 \\
\hline 12,1 & 890 \\
\hline 13,9 & 750 \\
\hline 12,2 & 1115 \\
\hline 15,7 & 1390 \\
\hline 16,3 & 1380 \\
\hline 18,0 & 1601 \\
\hline 22,1 & 1480 \\
\hline
\end{tabular}

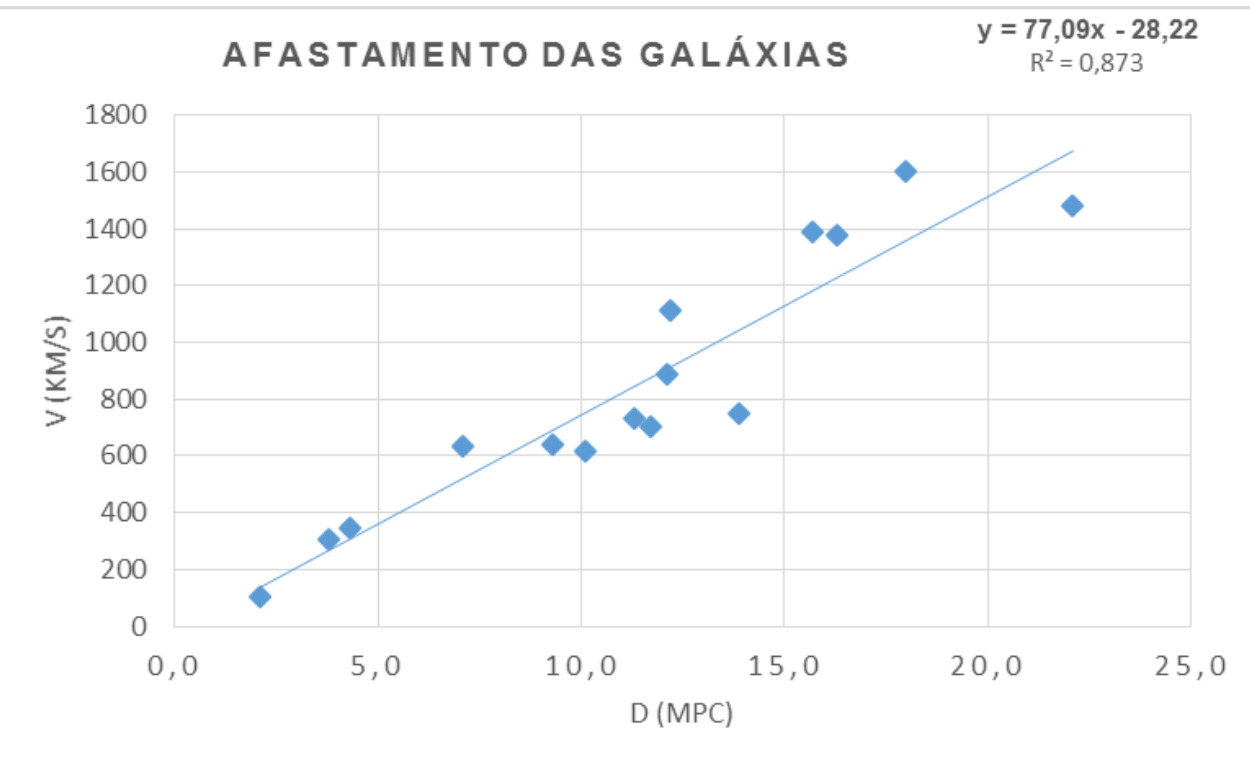

Fonte: A Student's Guide to the Mathematics of Astronomy. Autores: Daniel Fleisch and Julia Kregenow.

Cambridge University Press. Ano, 2013

Resolução e modelo: Cálculo da idade do Universo

Supondo que a velocidade de expansão foi constante de o Big Bang:

$\mathbf{t}_{\mathbf{0}}=\mathbf{D} / \mathbf{V}$ e a lei de Hubble: $\mathbf{V}=\mathbf{H}_{\mathbf{0}} . \mathbf{D}$ então: $\mathbf{t}_{\mathbf{0}}=\mathbf{D} /\left(\mathbf{H}_{\mathbf{0}} . \mathbf{D}\right)$

$\mathbf{t}_{\mathbf{0}}=\mathbf{1} / \mathbf{H}_{\mathbf{0}}$ assim vemos que $\mathrm{H}_{0}$ é igual ao inverso da idade do Universo para velocidade de expansão constante. 
Para uma constante de Hubble com valor $\boldsymbol{H O}=\mathbf{7 1} \mathbf{~ k m} / \mathbf{s} / \mathbf{M p c}(71 \mathrm{~km} / \mathrm{s}-1 \mathrm{Mpc}-1)$, a idade correspondente para o Universo é:

\section{Interpretacão e validação do modelo}

\section{Cálculo da idade do Universo}

Supondo que a velocidade de expansão foi constante de o Big Bang:

$\mathbf{t}_{\mathbf{0}}=\mathbf{D} / \mathbf{V}$ e a lei de Hubble: $\mathbf{V}=\mathbf{H o}$.D então: $\mathbf{t}_{\mathbf{0}}=\mathbf{D} /\left(\mathbf{H}_{\mathbf{0}} . \mathbf{D}\right)$

$\mathbf{t}_{\mathbf{0}}=\mathbf{1} / \mathbf{H}_{\mathbf{0}}$ assim vemos que $\mathbf{H}_{\mathbf{0}}$ é igual ao inverso da idade do Universo para velocidade de expansão constante.

Para uma constante de Hubble com valor $\mathbf{H 0}=71 \mathrm{~km} / \mathbf{s} / \mathbf{M p c}(\mathbf{7 1} \mathrm{km} / \mathbf{s}-1 \mathrm{Mpc}-1)$, a idade correspondente para o Universo é:

$$
\begin{aligned}
& t_{0}=\frac{1}{\left(71 \mathrm{~km} / \mathrm{s}^{-1} \cdot M p c^{-1}\right)} \text { e } 1 M p c=3,09 \cdot 10^{19} \mathrm{~km} \text { e } 1 \text { ano }=3,15.10^{7} \mathrm{seg} \\
& t_{0}=\frac{1}{H_{0}}=\frac{1}{71 \mathrm{~km}_{\mathrm{s}} \mathrm{s}^{-1} \mathrm{Mps}^{-1}}=\left(1 \mathrm{~s} .3,09 \cdot 10^{19} \mathrm{~km}\right) /\left(71 \mathrm{~km} .3,15.10^{7} \mathrm{~s} / \text { ano }\right) \\
& =\left(1 \text { ano } .3,09 \cdot 10^{19}\right) /\left(71 \mathrm{~km} \cdot 3,1510^{7}\right)=1,38 \cdot 1 \mathrm{u}^{\mathbf{1 0}} \text { anos } \\
& \text { Temos, portanto: } \mathbf{t}_{\mathbf{0}}=\mathbf{1} / \mathbf{H}_{\mathbf{0}}=\mathbf{1 3 , 8} \text { bilhões de anos }
\end{aligned}
$$


Apêndice H

Outras Atividades 



\section{Atividades com Geogebra: Funções Trigonométricas}

\section{Atividade Sugerida - - Geogebra}

Nessa atividade vamos propor que os alunos observem o que ocorre com as funções seno e cosseno ao alterar os parâmetros das funções.

Função do tipo: $\mathbf{f}(\mathbf{x})=\mathbf{a}+\mathbf{b} \cdot \operatorname{sen}(\mathbf{c} \cdot \mathbf{x}+\mathbf{d})$ e $\mathbf{g}(\mathbf{x})=\mathbf{a}+\mathbf{b} \cdot \cos (\mathbf{c} \cdot \mathbf{x}+\mathbf{d})$, onde $\mathrm{a}, \mathrm{b}$, c e d são constantes reais.

Os alunos trabalharão com o programa geogebra, transladando, alongando, comprimindo e refletindo os gráficos das funções seno e cosseno.

$\mathrm{O}$ arquivo deve ser previamente criado devido ao fator tempo, assim os alunos focaram na manipulação das funções que é o objetivo principal.

Exemplo de uma construção no geogebra:

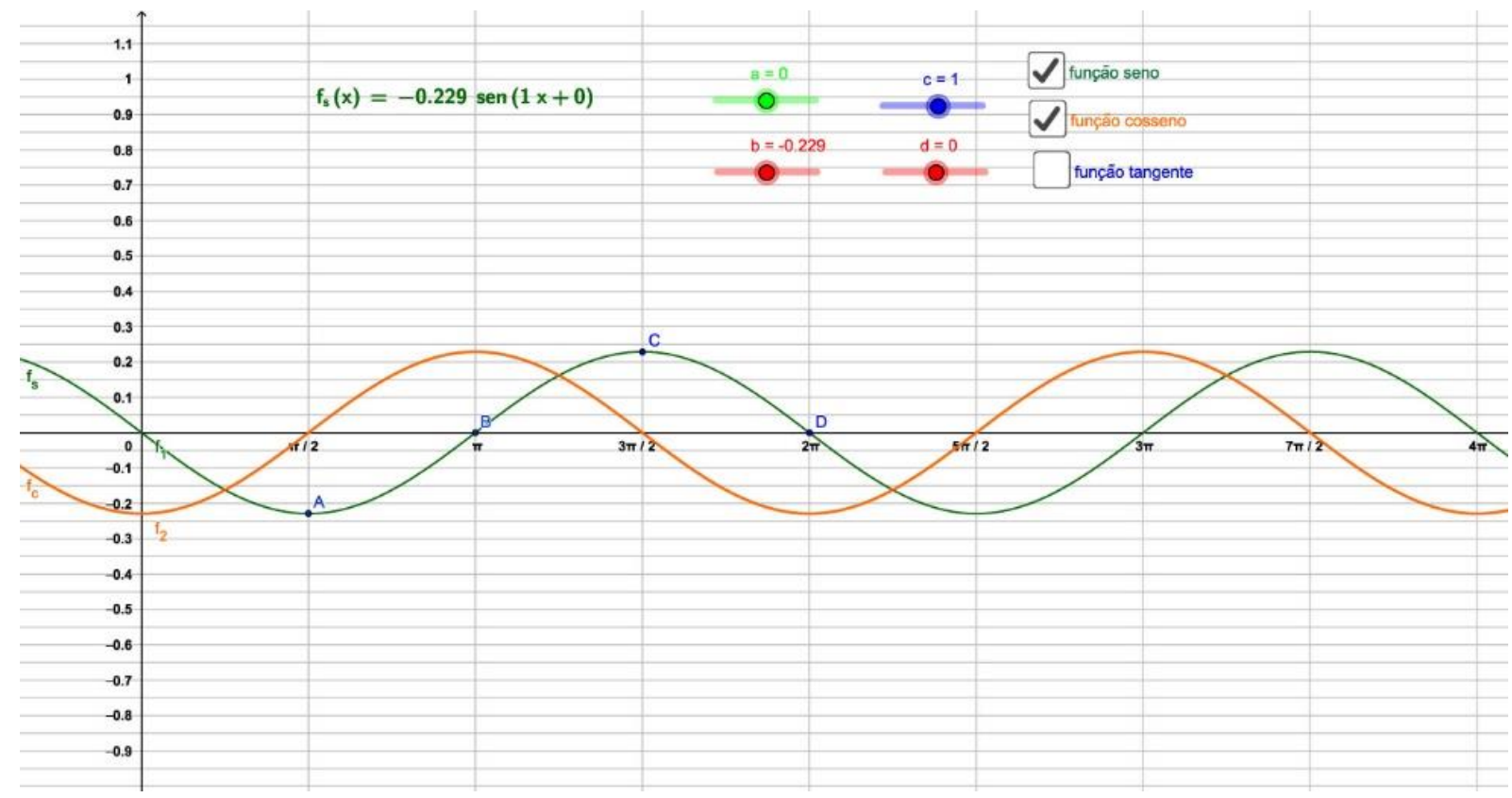

Fonte: Feito pelo autor - gráfico feito no programa Geogebra 
Relacionando o movimento periódico do pêndulo com a função seno e cosseno no geogebra

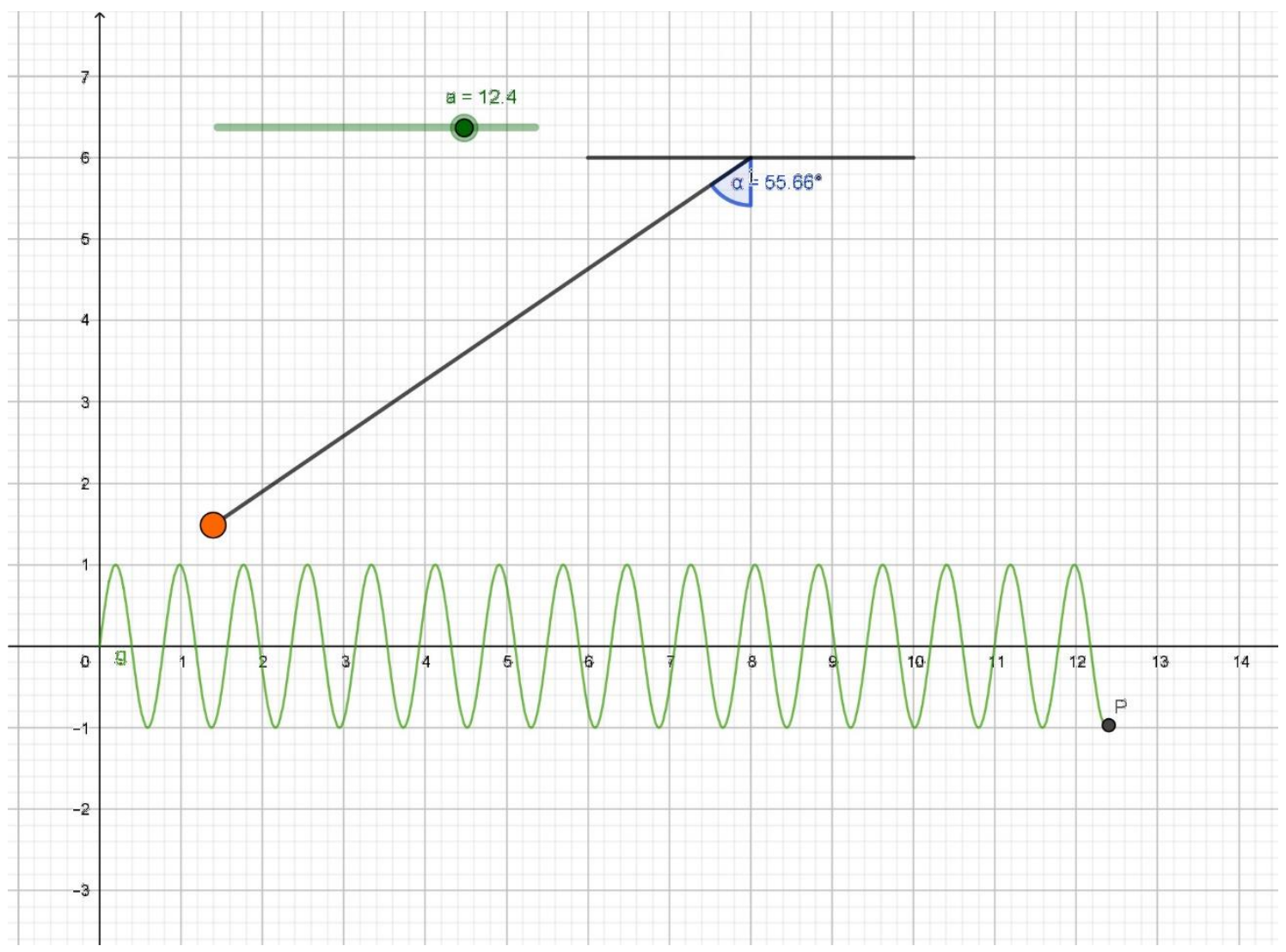

\section{Atividade: Amplitude b}

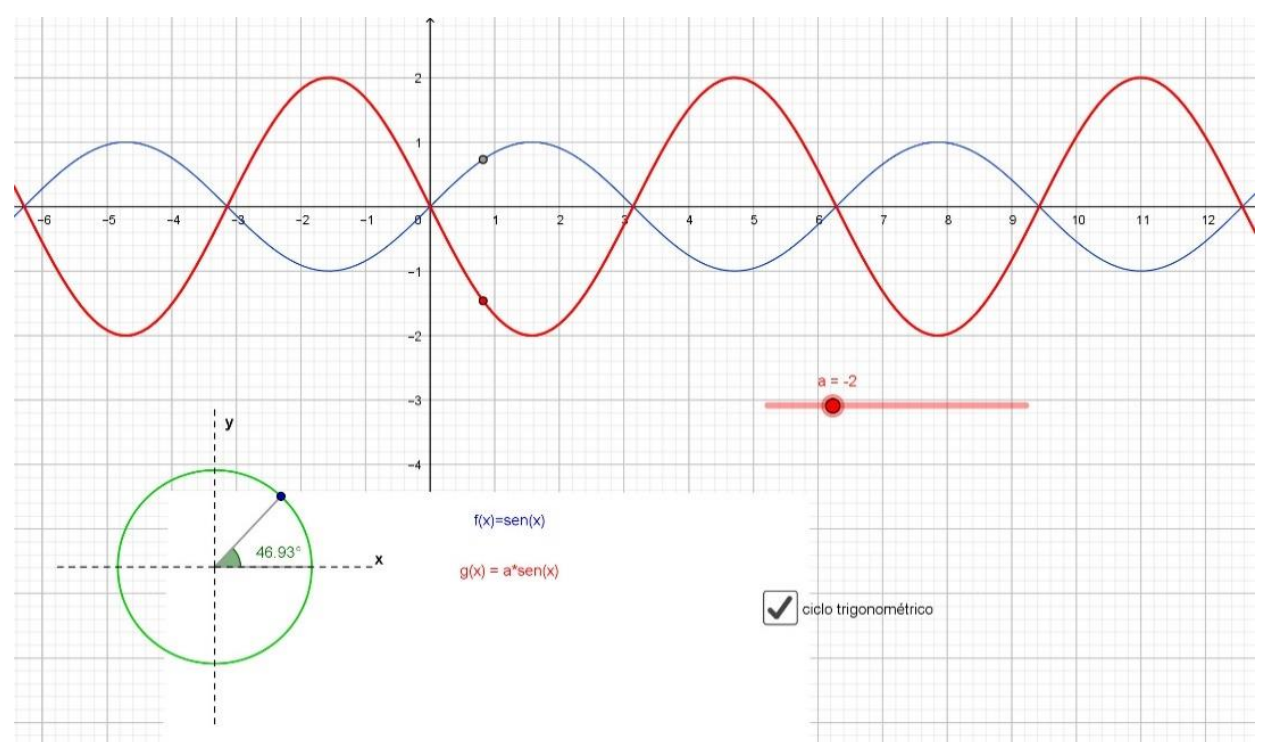

Fonte: Feito pelo autor - gráfico feito no programa Geogebra 


\section{Atividade: frequência c}

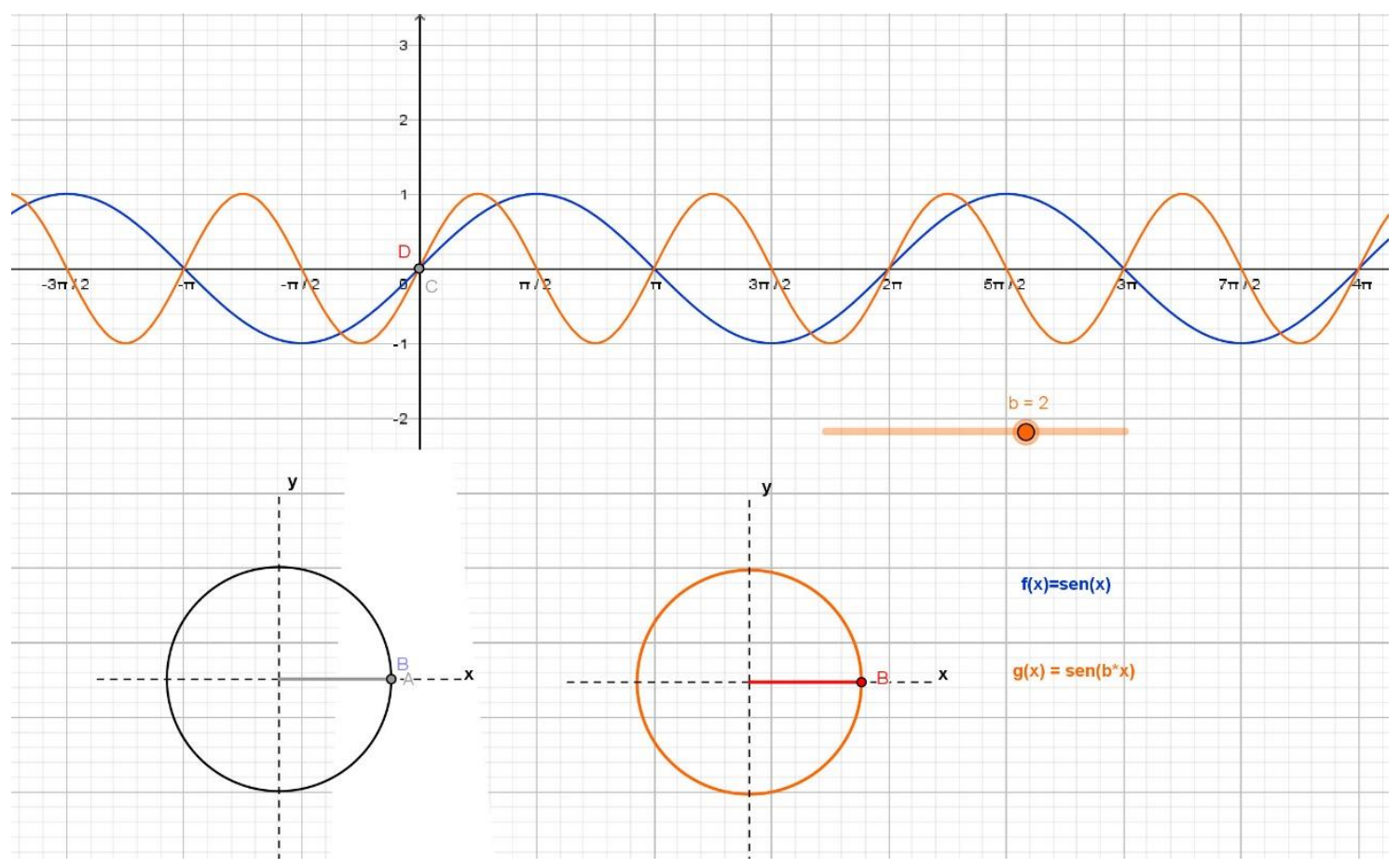

Fonte: Feito pelo autor - gráfico feito no programa Geogebra

\section{Manipulando as Funções Seno e Cosseno}

Estando apenas a função seno habilitada, o que ocorre com o gráfico quando alteramos o parâmetro a?

O que ocorre alterando o parâmetro b?

Qual a relação entre o valor da amplitude da função e o parâmetro b? 


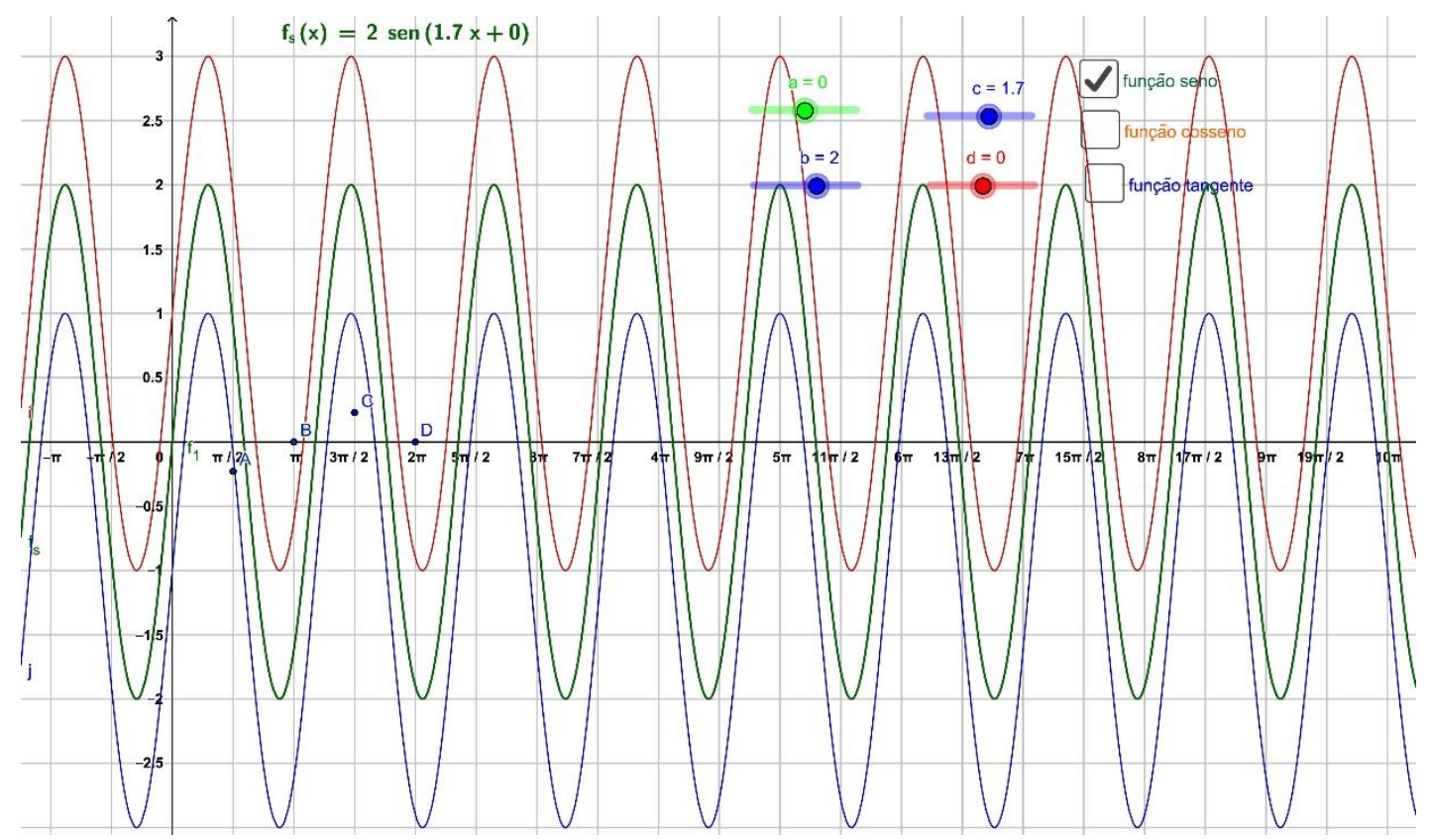

Fonte: Feito pelo autor - gráfico feito no programa Geogebra

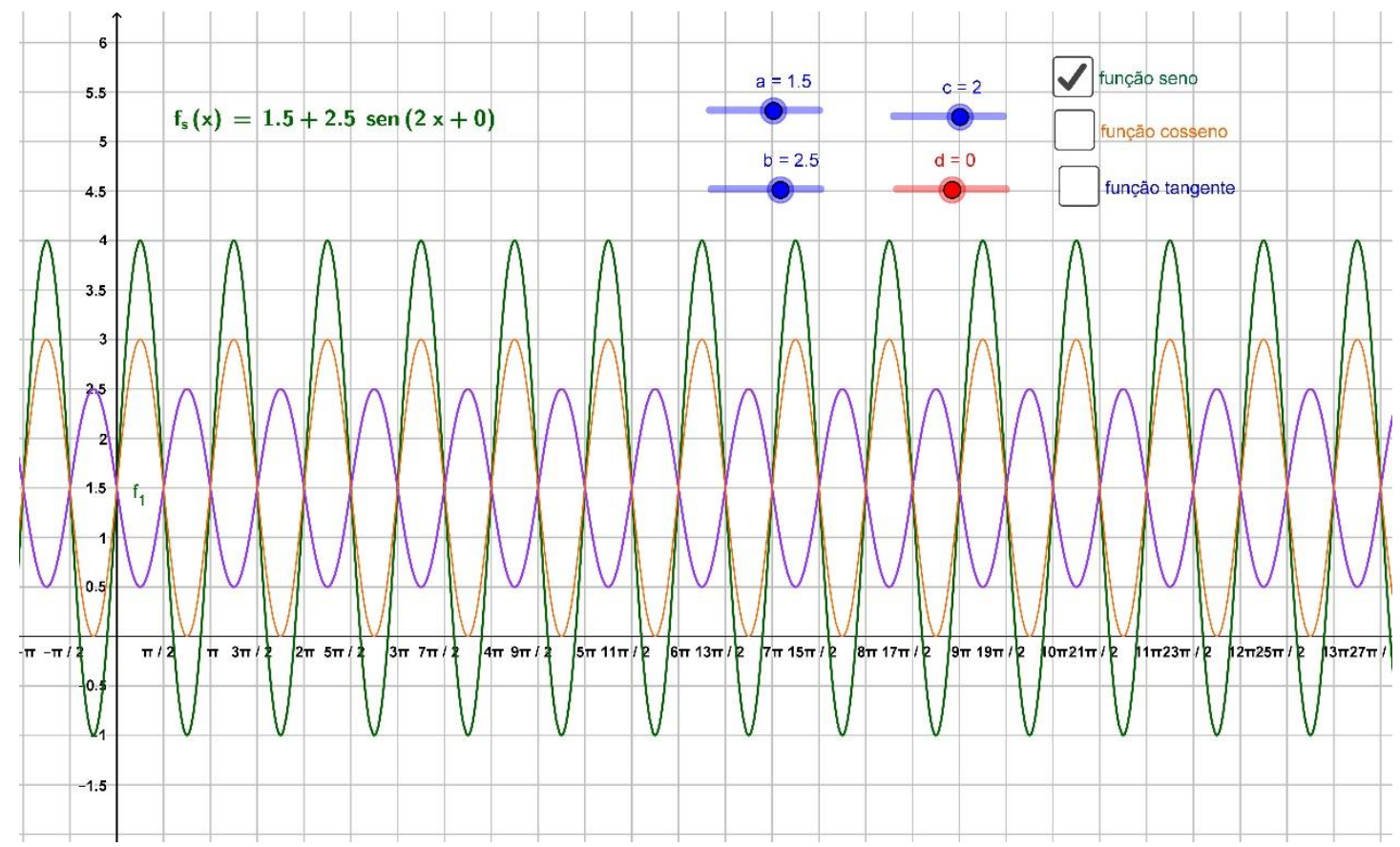

Fonte: Feito pelo autor - gráfico feito no programa Geogebra

Habilitando apenas a função seno, o que ocorre com o gráfico, quando o parâmetro c é alterado? Qual a relação entre o parâmetro c e o período da função?

Ao alterar o parâmetro c alteramos o período da função como mostra o gráfico abaixo: 


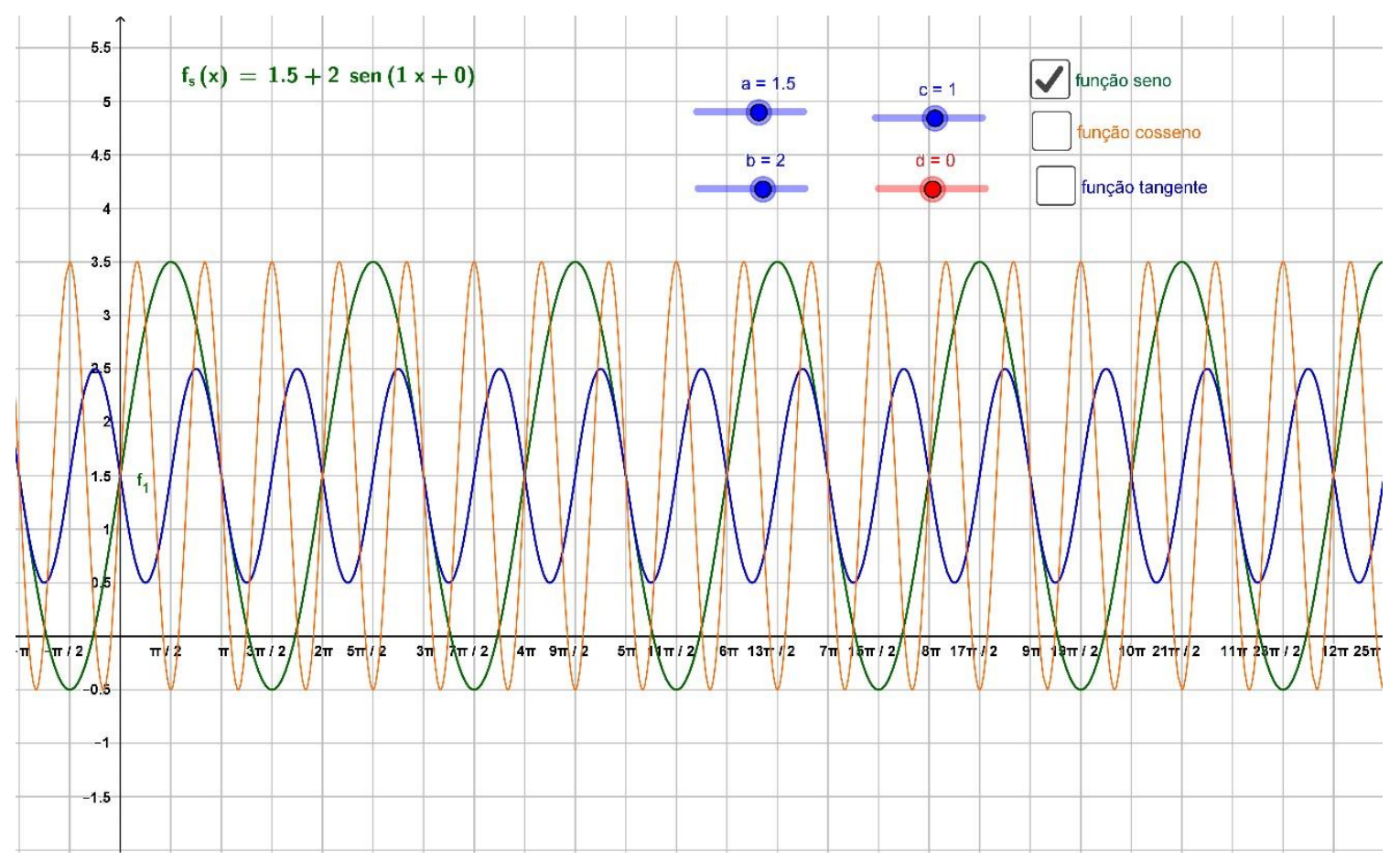

Fonte: Feito pelo autor - gráfico feito no programa Geogebra

O que ocorre se o parâmetro $\mathbf{d}$ for alterado?

O parâmetro d relaciona-se com a translação do gráfico da função

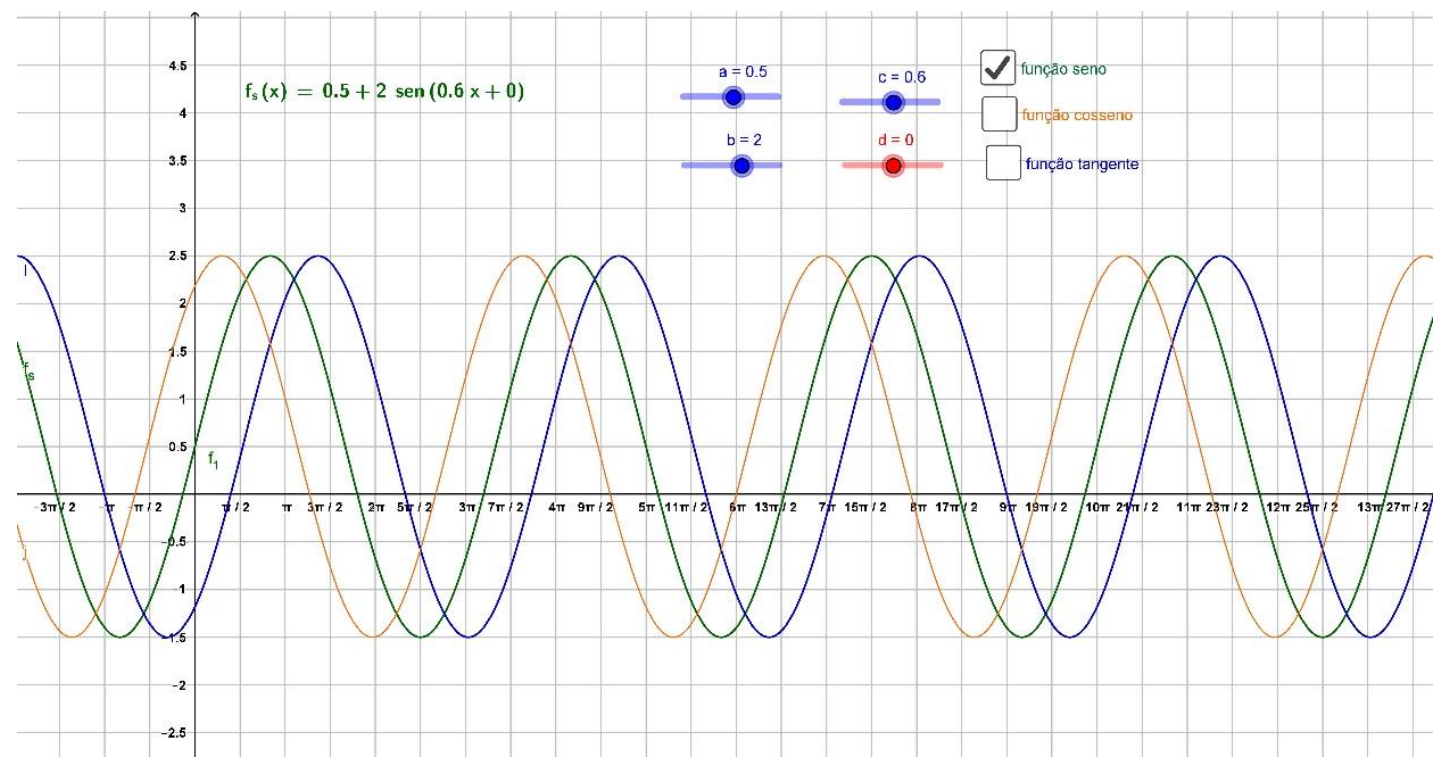

Fonte: Feito pelo autor - gráfico feito no programa Geogebra 
Com a função cosseno a análise foi similar ao realizado com a função seno, bastando habilitar a função cosseno na caixa de opção.
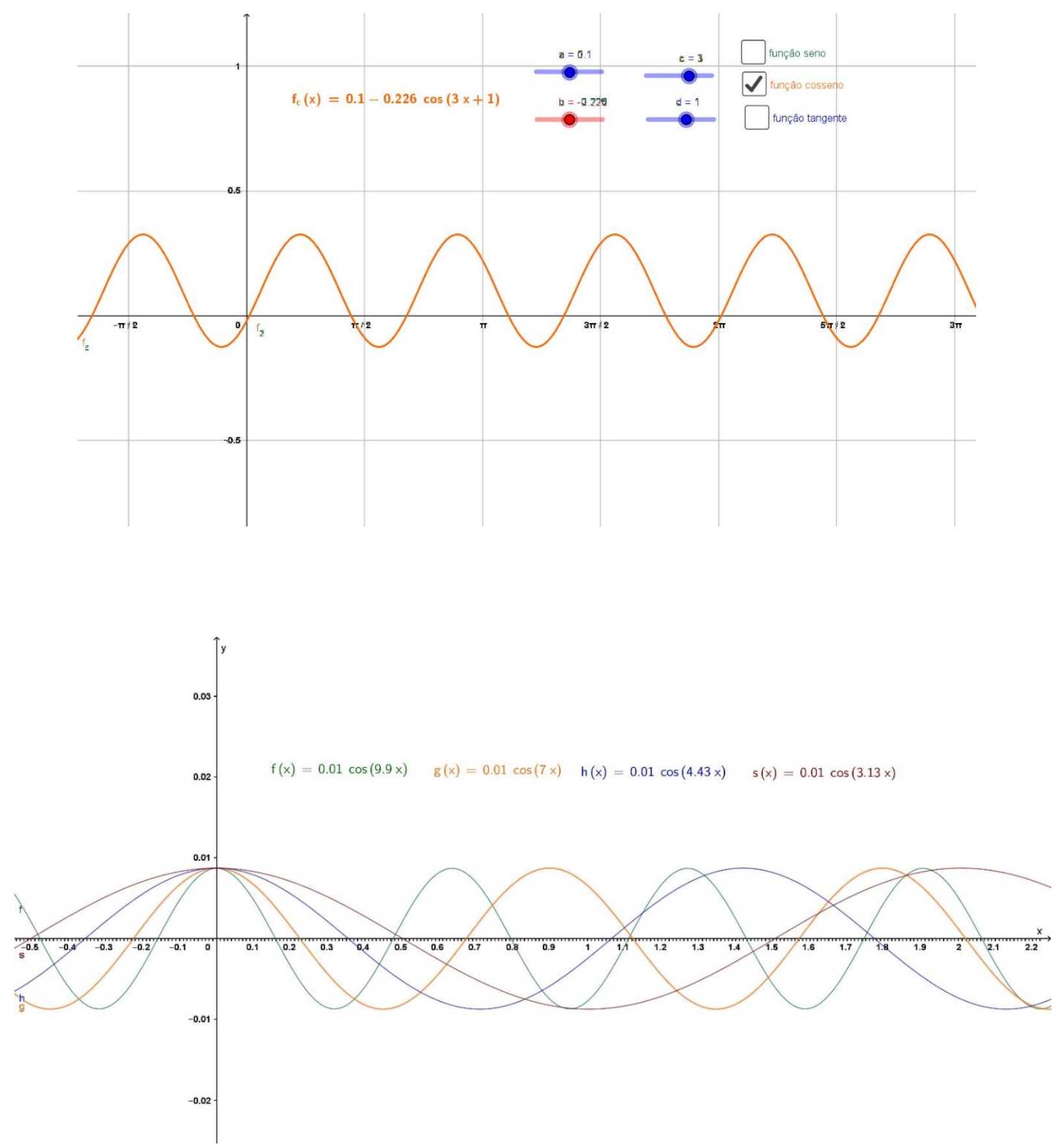

Fonte: Feito pelo autor - gráfico feito no programa Geogebra 


\section{Uma introdução a derivada como taxa de variação instantânea}

\section{Atividade com o geogebra}

Nessa atividade com o Geogebra os três grupos foram guiados pelo professor. Preencheram as tabelas, manipularam o ponto B móvel no gráfico e foram percebendo a tendência da razão $\Delta y / \Delta x$ se aproximar de um valor limite finito.

A generalização do conceito de derivada foi feita pelo professor depois do término das Modelagens dos três grupos.

Variando os pontos A e B podemos variar a taxa de variação média MAB relacionada com a reta secante e a taxa de variação instantânea relacionada com a tangente $\mathbf{m}$

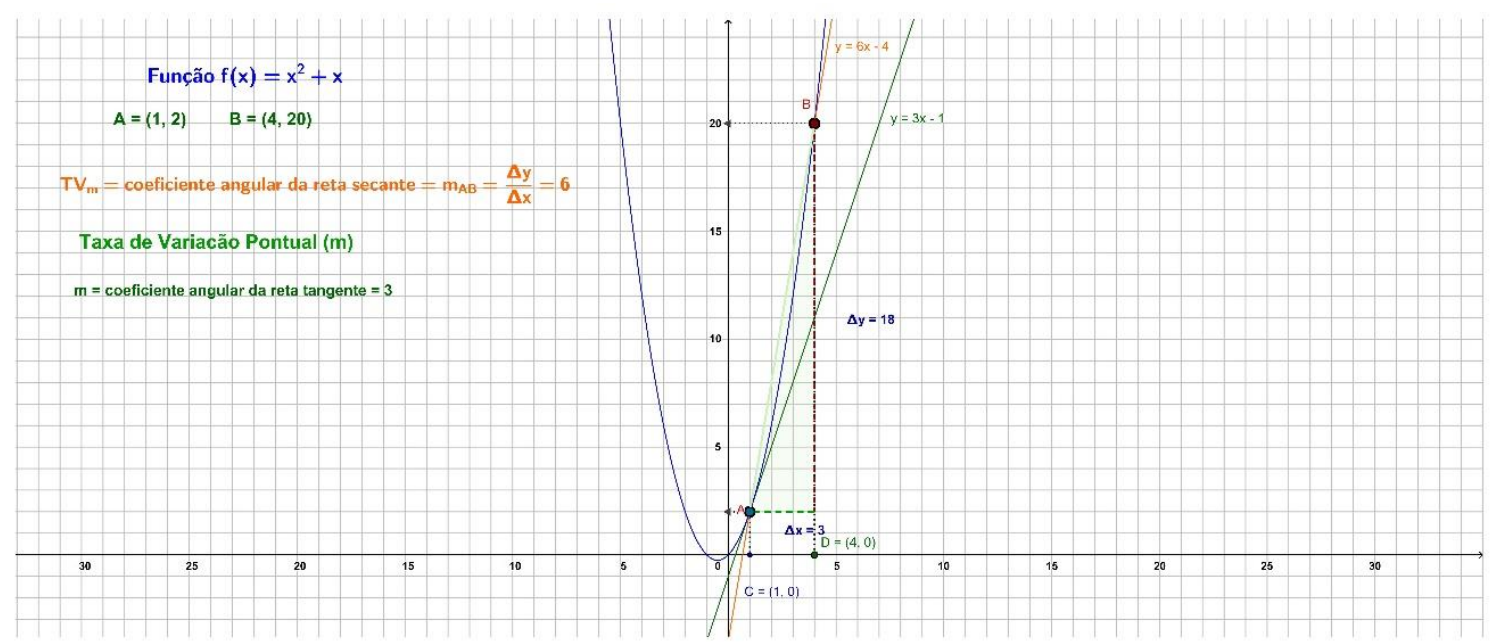

Fonte: Feito pelo autor - gráfico feito no programa Geogebra

Nesse caso específico da figura abaixo temos o coeficiente angular da reta secante $\mathbf{m}_{\mathbf{A B}}=\Delta \mathbf{y} / \mathbf{\Delta x}$ $=\mathbf{6}$ e o coeficiente angular da reta tangente $\mathbf{m}=\mathbf{3}$

Fazendo $\mathbf{x}$ tendendo a $\mathbf{1}$ então a reta secante tende à reta tangente. Vamos fazer alguns cálculos de aproximação da taxa de variação quando o ponto $\mathbf{D}(\mathbf{4 , 0})$ se aproxima do ponto $\mathbf{C}(\mathbf{1 , 0})$

\begin{tabular}{|c|c|c|c|l|}
\hline C(1,0) Fixo & $\mathbf{D}(\mathbf{4 , 0})(\mathbf{v a r})$ & $\boldsymbol{\Delta x}$ & $\boldsymbol{\Delta y}$ & \multicolumn{1}{|c|}{$\boldsymbol{\Delta y} / \mathbf{\Delta x}$} \\
\hline$(1,0)$ & $(2,0)$ & 1 & 4 & 4 \\
\hline$(1,0)$ & $(1.5,0)$ & 0.5 & 1.75 & 3.5 \\
\hline$(1,0)$ & $(1.1,0)$ & 0.1 & 0.31 & 3.1 \\
\hline$(1,0)$ & $(1.01,0)$ & 0.01 & 0.0301 & 3.01 \\
\hline$(1,0)$ & $(1.001,0)$ & 0.001 & 0.003001 & $\mathbf{3 . 0 0 1}$ \\
\hline
\end{tabular}


Repare que a razão $\Delta \mathbf{y} / \Delta \mathbf{x}$ está tendendo para o número $\mathbf{3}$ que é a inclinação da reta tangente $\mathbf{y}=3 . \mathbf{x}-1$ no nosso gráfico. $\mathrm{O}$ ponto $\mathbf{D}$ nunca poderá ser $(1,0)$, ou seja, coincidir com o ponto $\mathbf{C}$, pois teríamos a razão $\mathbf{0 / 0}$ que é uma indefinição matemática, mas no limite para $\mathbf{x}$ tendendo a 1 o limite existe e é 3.

Vamos ver algebricamente como fica esse limite:

$\mathbf{F}(\mathbf{x})=\mathbf{x}^{2}+\mathbf{x}$ então fixando o ponto $\mathbf{C}$ temos a razão: $\lim _{\Delta x \rightarrow 0}=\mathbf{F}(\mathbf{x}+\Delta \mathbf{x})-\mathbf{F}(\mathbf{x}) /(\Delta \mathbf{x})$

$\left.\lim _{\Delta \mathrm{x} \rightarrow 0}=\left[(\mathrm{x}+\Delta \mathrm{x})^{2}+\mathrm{x}+\Delta \mathrm{x}\right)-\left(\mathrm{x}^{2}+\mathrm{x}\right)\right] /(\Delta \mathrm{x})=\left[\left(\mathrm{x}^{2}+2 \cdot \mathrm{x} \cdot \Delta \mathrm{x}+\Delta \mathrm{x}^{2}+\mathrm{x}+\Delta \mathrm{x}\right)-\left(\mathrm{x}^{2}+\mathrm{x}\right)\right] /$ $(\Delta \mathrm{x})=\left(2 \cdot \mathrm{x} \cdot \Delta \mathrm{x}+\Delta \mathrm{x}^{2}+\Delta \mathrm{x}\right) /(\Delta \mathrm{x})=\Delta \mathrm{x}(2 \cdot \mathrm{x}+\Delta \mathrm{x}+1) /(\Delta \mathrm{x})=2 \cdot \mathrm{x}+1+\Delta \mathrm{x}$

$\lim _{\Delta x \rightarrow 0}=(2 . x+1+\Delta x)=\mathbf{2} \cdot \mathbf{x}+\mathbf{1}$ e limite para $\mathbf{x}$ tendendo a 1 é $\mathbf{3}$ 


\section{Modelagem Matemática: Pêndulo - Fase 1}

Prof. Orientador: Ronaldo Ramunno (IME)

\section{Atividade Sugerida}

Situação-problema 1: Determinar a relação entre o período e o comprimento de um pêndulo simples e depois descrever um modelo matemático partindo de um ângulo de lançamento fixado, usando as funções $\mathbf{y}(\mathbf{t}) \times \mathbf{t}$ onde $\mathbf{t}$ é o período e $\mathbf{y}(\mathbf{t})$ é a posição do pêndulo e $\mathbf{v}(\mathbf{t}) \mathbf{x} \mathbf{t}$ onde $\mathbf{t}$ é o período e $\mathbf{v}(\mathbf{t})$ a velocidade da massa do pêndulo.

Existem na natureza diversos fenômenos periódicos, ou seja, cujo comportamento se repete em intervalos regulares de tempo. Por exemplo, a alternância entre dias e noites, o ciclo das estações do ano, a vibração de um diapasão, as batidas do coração, as ondas elétricas do cérebro, etc.

O pêndulo é um objeto bastante simples que possui movimento periódico: ele é constituido por um fio ou haste (de massa desprezível) que possui uma extremidade fixa num ponto de apoio em torno do qual pode girar livremente e uma massa considerável na extremidade livre - conforme a figura.

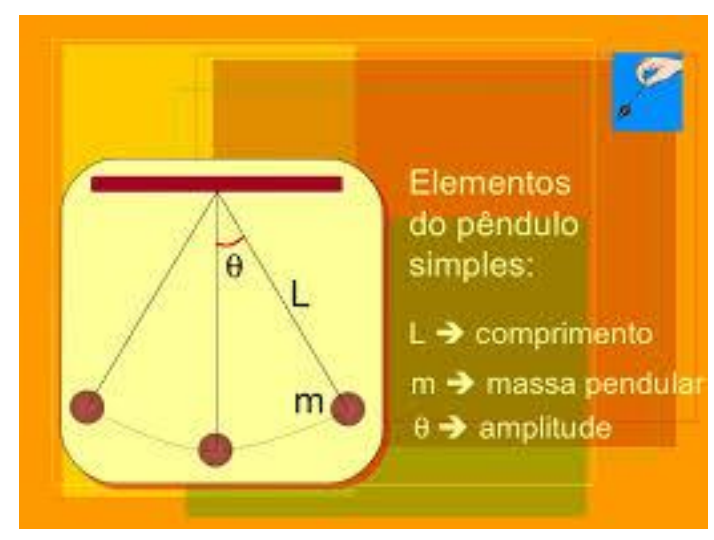

Fonte: https://www.google.com.br/search?q=pendulo+simples\&source =Inms\&tbm=isch\&sa=X\&ved=0ahUKEwiW4dnpplLgAhWjHbkGHdy9DkAQ_AUIDigB\&biw=1360\&bih=626 


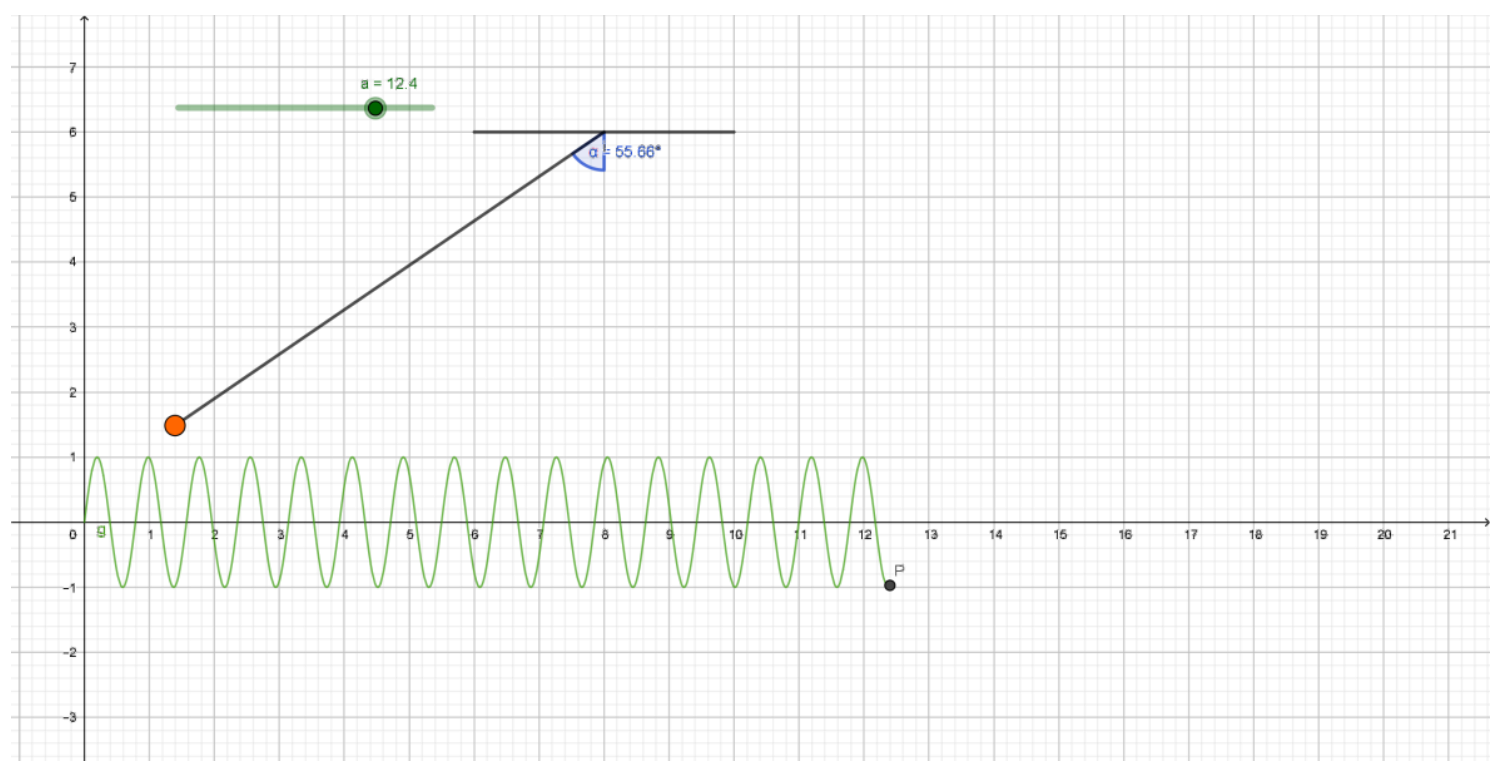

Fonte: Feito pelo autor - gráfico feito no programa Geogebra

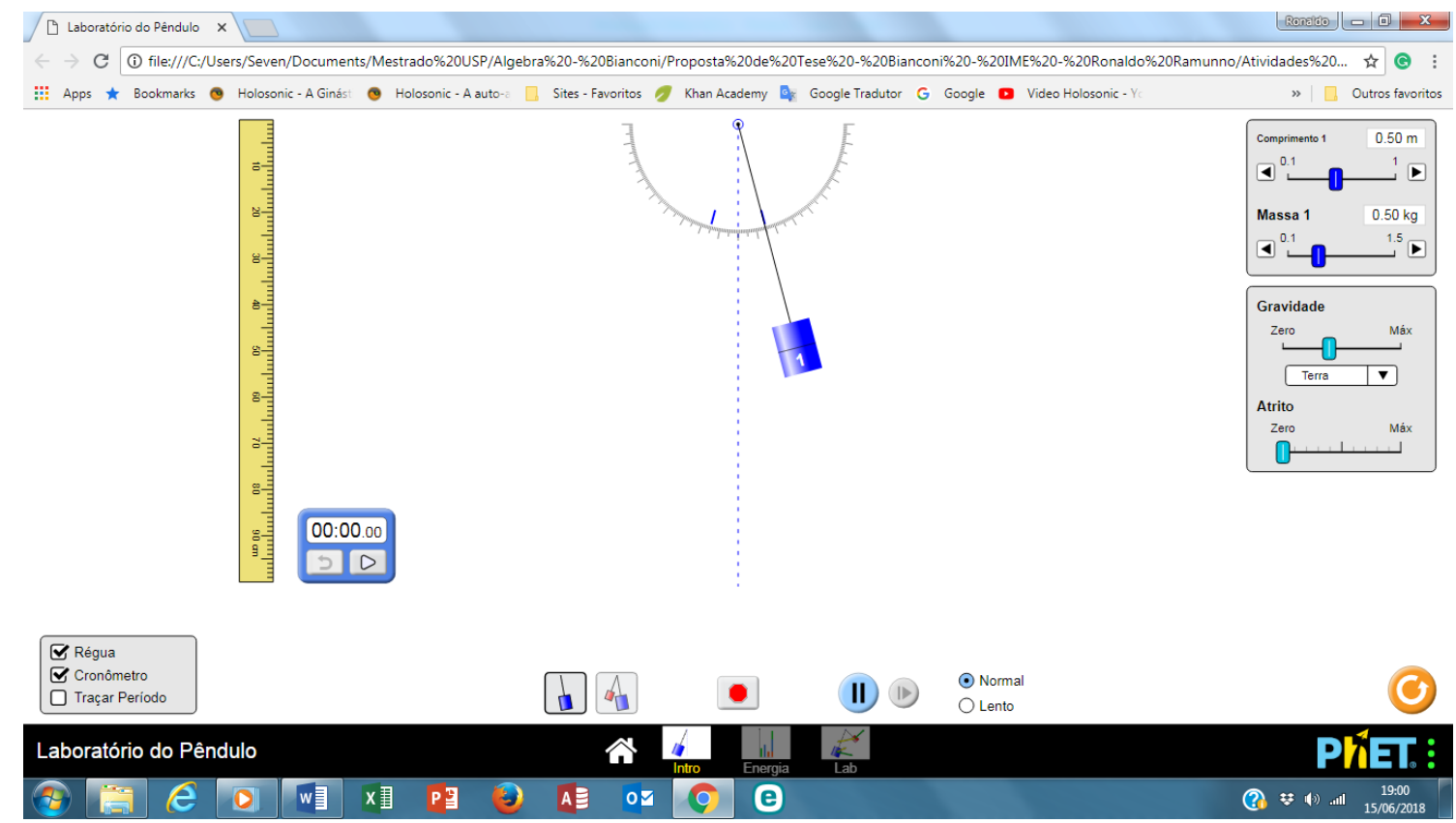

Fonte: Programa gratuito que funciona online por Phet Interactive Simulations University of Colorado 
Atividade 1: Comprimento $\mathbf{L}$ variável e ângulo de lançamento $\boldsymbol{\Theta}$ fixo $\left(\boldsymbol{\Theta}=5^{\circ}\right.$ ou $\boldsymbol{\Theta}=\mathbf{0 , 0 8 7 2 7}$ rad), calculando o período T através do aplicativo PHET Simulator. Amplitude: $\mathbf{A}=\mathbf{L} \times \mathbf{\theta}$ $\mathbf{V}_{\text {máx }}=\mathbf{A} \cdot \mathbf{w} \quad$ Quando $T=\pi / \mathbf{4}$ temos $\mathbf{V}_{\text {máx }}$

Fazer gráficos: $\mathbf{y}(\mathbf{t}) \mathbf{x} \mathbf{t}$ e $\mathbf{v}(\mathbf{t}) \mathbf{x} \mathbf{t}$

\begin{tabular}{|c|c|c|c|c|c|}
\hline $\begin{array}{c}\text { Comp. do } \\
\text { pêndulo (L) }\end{array}$ & $\begin{array}{c}\text { Período em } \\
\text { seg. (T) }\end{array}$ & $\begin{array}{c}\text { Frequência f } \\
\mathbf{( H z )}\end{array}$ & $\begin{array}{c}\text { Velocidade } \\
\text { angular } \\
(\mathbf{w}=\mathbf{2} \text {.л. f) }\end{array}$ & y (t)=A.cos.(2.л./T) & $\mathbf{V}_{\mathbf{m}}$ (t)= - A.w.sen.(2.л./T) \\
\hline 0,10 & 0,6347 & 1,5755 & 9,8991 & $-0,0077$ & $-0,0864$ \\
\hline 0,20 & 0,8976 & 1,1141 & 7,0000 & 0,0658 & $-0,1222$ \\
\hline 0,30 & 1,0993 & 0,9097 & 5,7158 & 0,0736 & $-0,0262$ \\
\hline 0,40 & 1,2694 & 0,7877 & 4,9493 & 0,0205 & $-0,1727$ \\
\hline 0,50 & 1,4192 & 0,7046 & 4,4271 & $-0,0246$ & $-0,1932$ \\
\hline 0,60 & 1,5546 & 0,6432 & 4,0413 & $-0,0543$ & $-0,2116$ \\
\hline $\mathbf{0 , 7 0}$ & 1,6792 & 0,5955 & $\mathbf{3 , 7 4 1 6}$ & $-0,0720$ & $\mathbf{- 0 , 2 2 8 5}$ \\
\hline 0,80 & 1,7951 & 0,5571 & 3,5004 & $-0,0817$ & $-0,2444$ \\
\hline 0,90 & 1,9040 & 0,5252 & 3,2999 & $-0,0862$ & $-0,2592$ \\
\hline 1,00 & 2,0070 & 0,4982 & 3,1303 & $-0,0873$ & $-0,2732$ \\
\hline
\end{tabular}

Fica claro tanto na tabela como nos gráficos que aumentando o comprimento $\mathbf{L}$, o período $\mathbf{T}$ aumenta, a frequência diminui e a velocidade angular diminui.

Sabemos da Física que a relação entre o período e o comprimento de um pêndulo é:

$$
T=2 . \pi \cdot \sqrt{\frac{L}{g}}
$$

$$
F=\frac{1}{T}
$$$$
W=2 . \pi . f
$$

Os alunos verificarão que os dados obtidos do período com o simulador de pêndulo são muito próximos dos cálculos gerados pela fórmula acima. Partindo do período $\mathbf{T}$, podemos calcular a frequência $\mathbf{f}$, pois $\mathbf{f}=\mathbf{1} / \mathbf{T}$ e tendo a frequência podemos calcular a velocidade angular $\mathbf{w}$ e como temos $\mathbf{L}$ e $\boldsymbol{\Theta}$ podemos calcular a amplitude $\mathbf{A}$, desse modo temos todos os dados para modelar as funções $\mathbf{y}(\mathbf{t}) \mathbf{e} \mathbf{v}(\mathbf{t})$. 


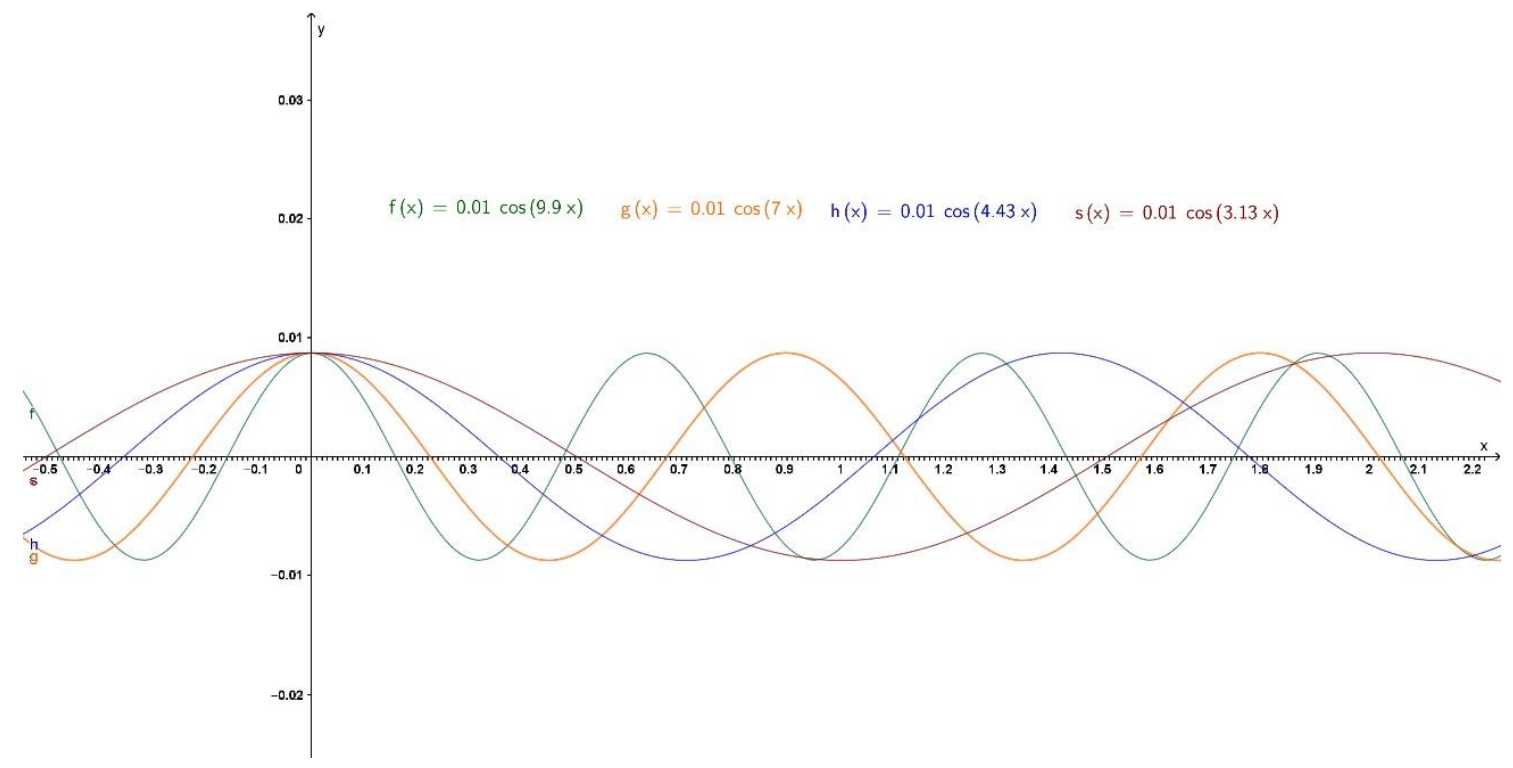

$y(t)=$ A.cos. $(2$.л. $/ T)$

Fonte: Feito pelo autor - gráfico feito no programa Geogebra 


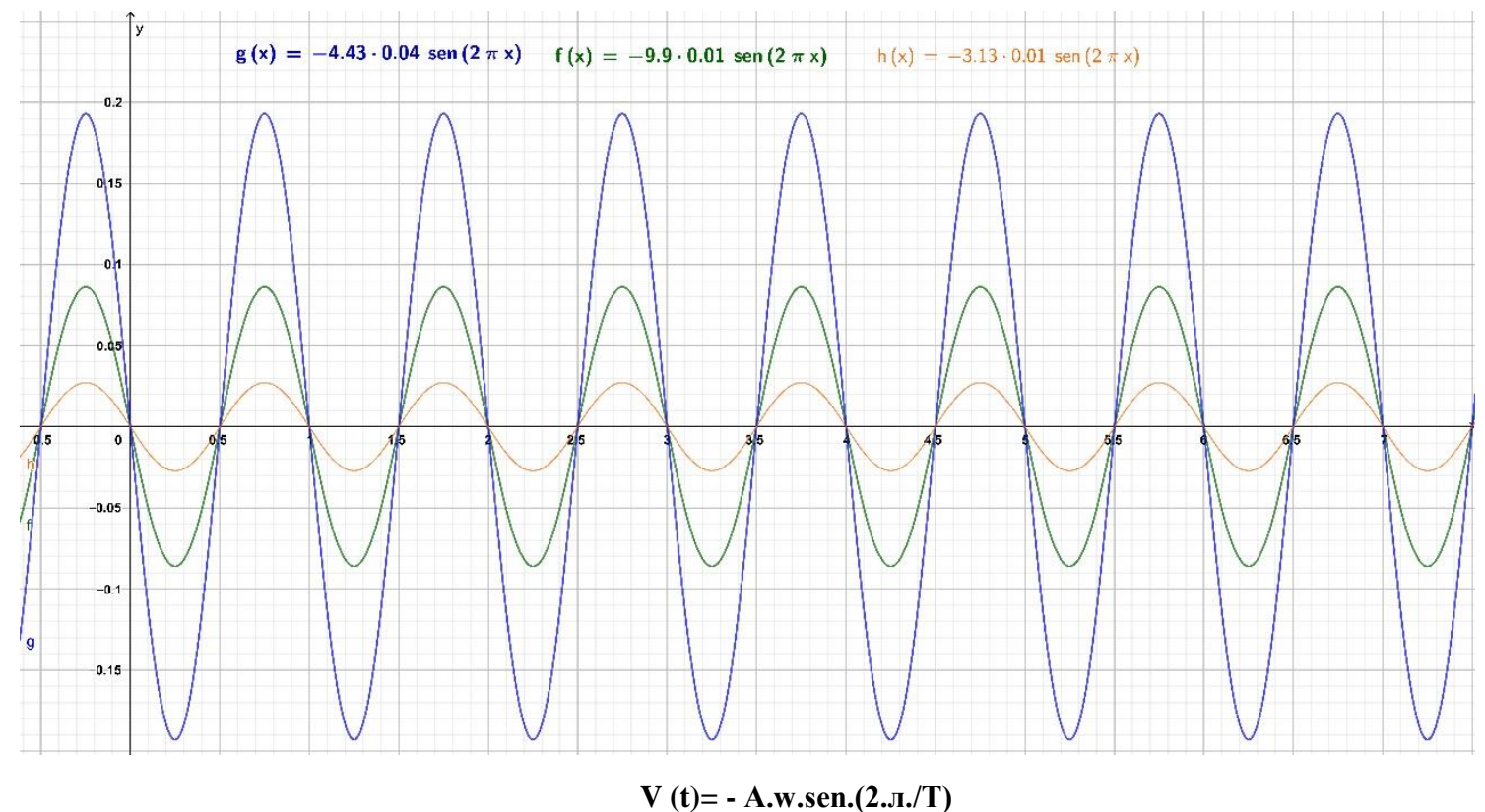

Fonte: Feito pelo autor - gráfico feito no programa Geogebra

Situação-problema 2: Partindo de um comprimento $\mathbf{L}$ fixado e variando o ângulo de lançamento do pêndulo. Determinar a relação entre o período e o ângulo de lançamento de um pêndulo simples e depois descrever um modelo matemático partindo de um ângulo de lançamento fixado, usando as $\mathbf{v}(\mathbf{t}) \mathbf{x} \mathbf{t}$ onde $\mathbf{t}$ é o período e $\mathbf{v}(\mathbf{t})$ a velocidade da massa do pêndulo.

Atividade 2: Comprimento $\mathbf{L}$ fixo ( $\mathrm{L}=0,70 \mathrm{~m})$ e ângulo de lançamento $\boldsymbol{\Theta}$ variável $\operatorname{com} \boldsymbol{\Theta}$ (rad), e calculando o período $\mathbf{T}$ através do aplicativo PHET Simulator. Amplitude: $\mathbf{A}=\mathbf{L} \mathbf{x} \boldsymbol{\theta} \mathbf{V}_{\text {máx }}=$ w.A. Fazer cálculo e gráfico da $\mathbf{v}(\mathbf{t}) \times \mathbf{t}$. Quando $T=\pi / 2$ temos: $V_{\text {máx }}$

\begin{tabular}{|c|c|c|c|c|c|}
\hline $\begin{array}{c}\text { Ângulo de } \\
\text { lançamento } \\
(\boldsymbol{\Theta}) \mathbf{r a d}\end{array}$ & $\begin{array}{c}\text { Amplitude } \\
\mathbf{A}=\mathbf{L} \mathbf{x} \boldsymbol{\Theta}\end{array}$ & $\begin{array}{c}\text { Período em } \\
\mathbf{s e g u n d o s} \\
\mathbf{( T )}\end{array}$ & $\begin{array}{c}\text { Frequência f } \\
\mathbf{( H z )}\end{array}$ & $\begin{array}{c}\text { Velocidade } \\
\text { angular } \\
(\mathbf{w}=\mathbf{2} \text {.л. f) }\end{array}$ & $\begin{array}{c}\mathbf{V}_{\text {máx }}(\mathbf{T})=\mathbf{-} \\
\text { A.w.sen.(2.J./T) }\end{array}$ \\
\hline $1^{\mathbf{0}}(0,01745)$ & 0,0122 & 1,6784 & 0,5959 & 3,7442 & $-0,0457$ \\
\hline $2^{\mathbf{o}}(0,03490)$ & 0,0244 & 1,6785 & 0,5958 & 3,7435 & $-0,0913$ \\
\hline $3^{\mathbf{o}}(0,05236)$ & 0,0366 & 1,6787 & 0,5957 & 3,7429 & $-0,1370$ \\
\hline $4^{\mathbf{o}}(0,06981)$ & 0,0489 & 1,6789 & 0,5956 & 3,7423 & $-0,1830$ \\
\hline $\mathbf{5}^{\mathbf{0}}(0,08727)$ & 0,0611 & 1,6792 & 0,5955 & $\mathbf{3 , 7 4 1 6}$ & $\mathbf{- 0 , 2 2 8 6}$ \\
\hline $6^{\mathbf{o}}(0,10472)$ & 0,0733 & 1,6795 & 0,5954 & 3,7410 & $-0,2742$ \\
\hline $7^{\mathbf{o}}(0,12217)$ & 0,0855 & 1,6800 & 0,5952 & 3,7397 & $-0,3197$ \\
\hline $8^{\mathbf{o}}(0,13962)$ & 0,0978 & 1,6804 & 0,5951 & 3,7391 & $-0,3657$ \\
\hline
\end{tabular}




\begin{tabular}{|c|c|c|c|c|c|}
\hline $9^{\circ}(0,15708)$ & 0,1099 & 1,6810 & 0,5949 & 3,7379 & $-0,4108$ \\
\hline $10^{\circ}(0,17453)$ & 0,1222 & 1,6816 & 0,5947 & 3,7366 & $-0,4566$ \\
\hline & & & & & \\
\hline
\end{tabular}

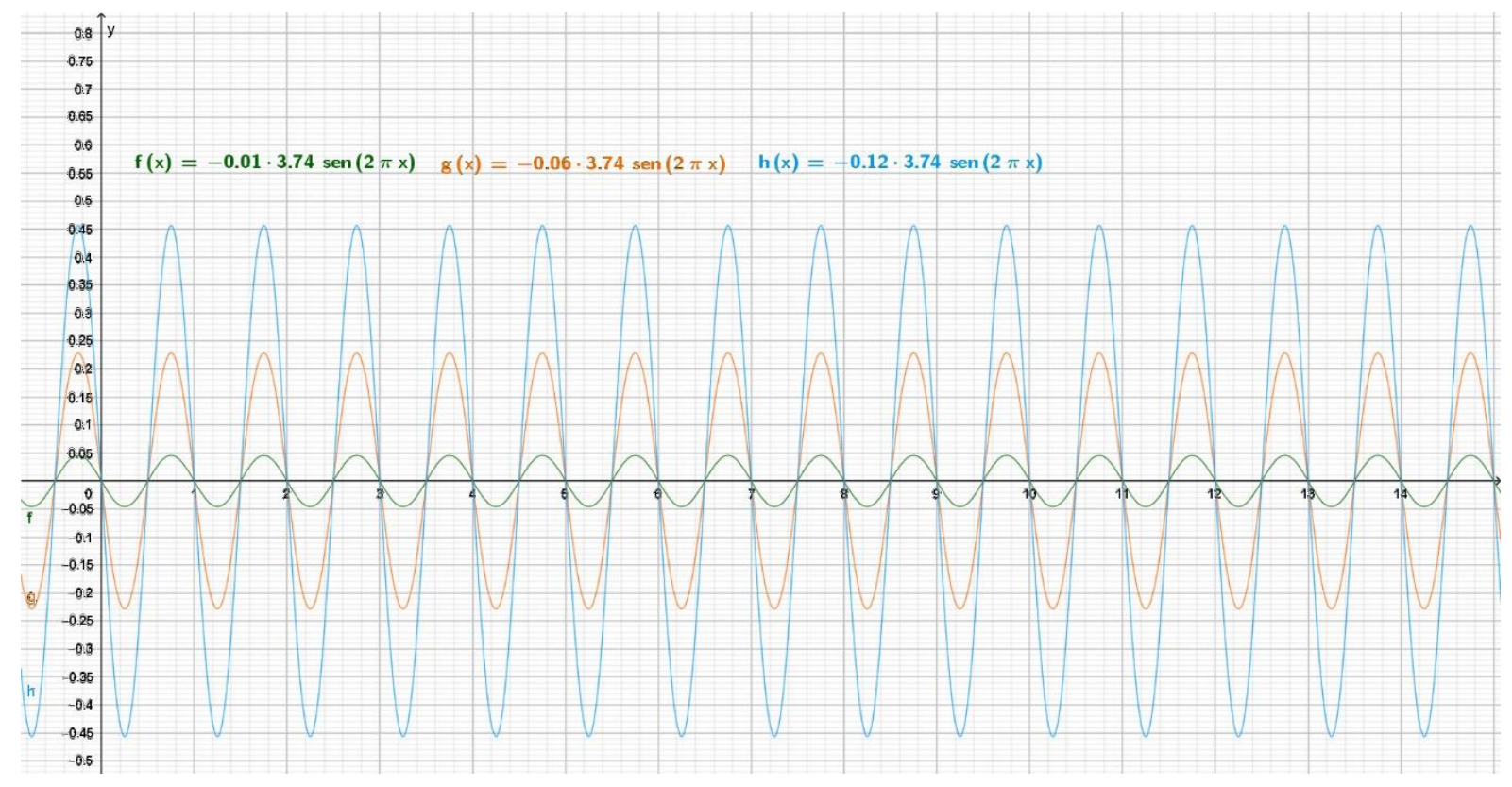

$\mathrm{V}(\mathrm{t})=$ - A.w.sen.(2.л. $/ \mathrm{T})$

Fonte: Feito pelo autor - gráfico feito no programa Geogebra

Fica claro tanto na tabela e no gráfico, que aumentando o ângulo de lançamento $\boldsymbol{\Theta}$, o período $\mathbf{T}$ aumenta, a frequência diminui e o módulo da velocidade linear $\mathbf{v}(\mathbf{t})$ aumenta, isso se deve pelo fato de que maior ângulo $\boldsymbol{\Theta}$ causa maior energia potencial do pêndulo, e também maior energia cinética, logo maior velocidade linear.

Sabemos da Física que: $\quad \mathbf{E}_{\mathbf{p}}=\mathbf{m} \cdot \mathbf{g} \cdot \mathbf{h} \quad \mathbf{E}_{\mathbf{c}}=\mathbf{m} \cdot \mathbf{v}^{2} / \mathbf{2}$

Como $\mathbf{h}=\mathbf{L} \cdot \operatorname{sen}(\boldsymbol{\Theta})$ (para ângulos menores que $10^{\circ}$ ), assim aumentando $\boldsymbol{\Theta}$, aumenta-se $\mathbf{h}$ e portanto aumenta a energia potencial e como a energia potencial é convertida em energia cinética à medida que o pêndulo oscila, a energia cinética também aumenta com o aumento do ângulo $\boldsymbol{\Theta}$. Maior energia cinética, com a massa $\mathbf{m}$ constante, temos maior velocidade linear.

Usando o geogebra para visualizar a relação da variação do ângulo $\boldsymbol{\Theta}$ com o período $\mathbf{T}$ 


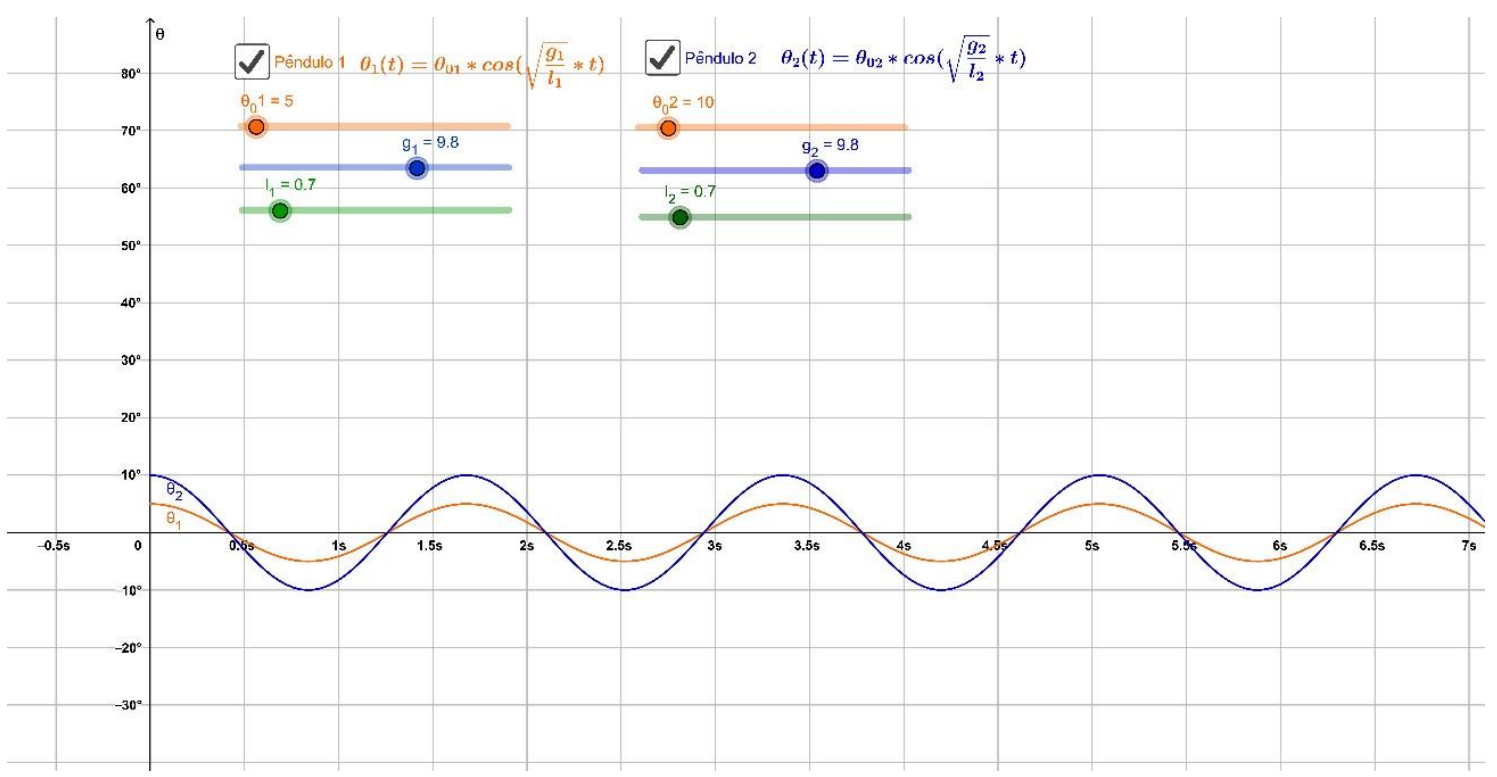

Fonte: Feito pelo autor - gráfico feito no programa Geogebra 